\title{
THE EFFECT OF QUASI-PRECONSOLIDATION ON COMPRESSION OF CLAY SOILS
}

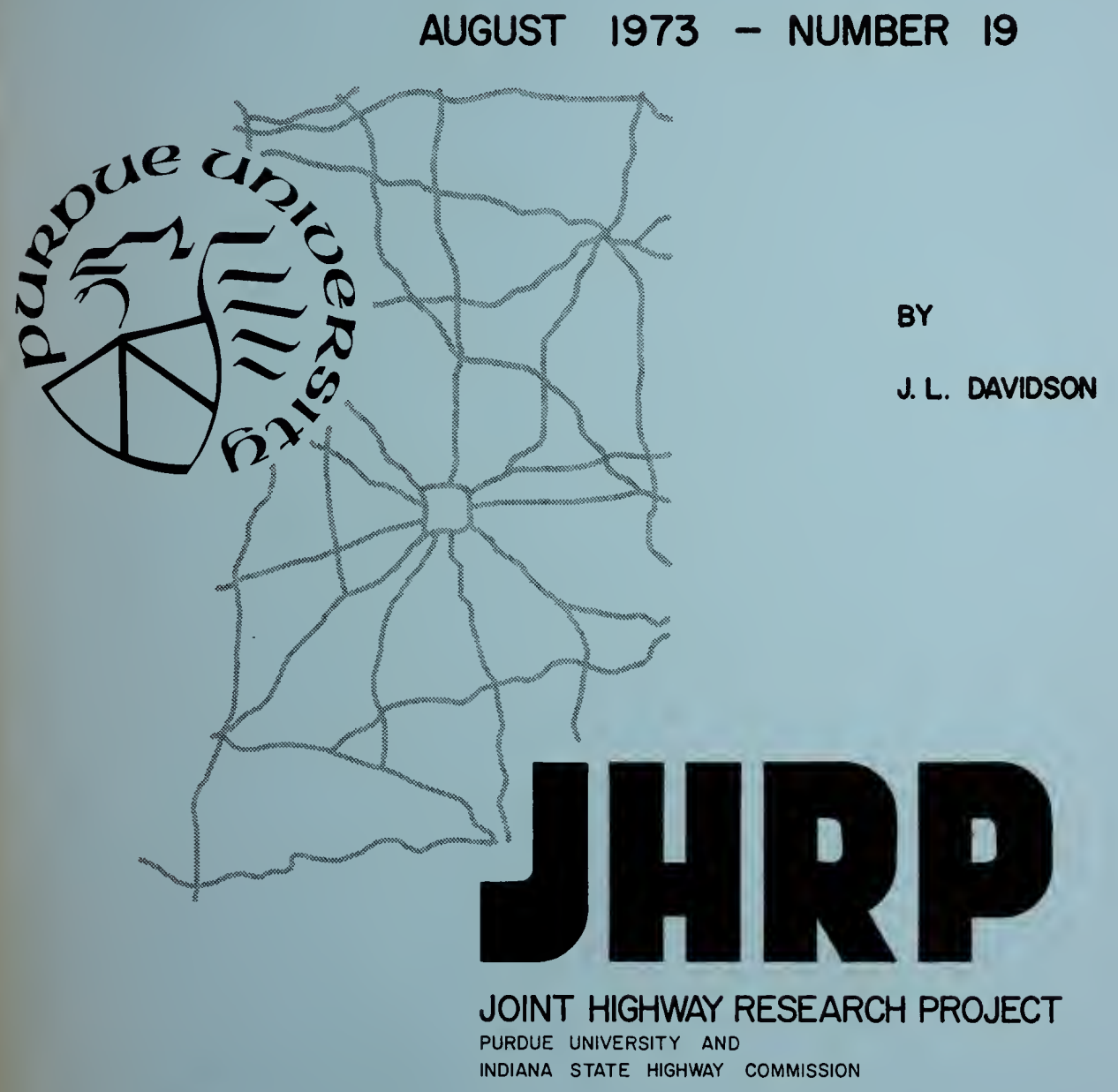



THE EFFECT OF QUASI-PRECONSOLIDATION ON

COMPRESSION OF CLAY SOILS

T0: J. F. McLaughlin, Director Joint Highway Research Project

FROM: H. L. Michael, Associate Director Joint Highway Research Project
August 29,1973

Project: $\quad C-36-5 F$

File: $6-6-6$

The attached Interim Report titled "The Effect of QuasiPreconsolidation on Compression of Clay Solls" is on the HPR Part II Research Study titled "Deformation of Compacted Cohesive Soll Embankments". It has been authored by Mr. John L. Davidson, Graduate Instructor in Research and directed by Professor W. L. Perloff.

The purpose of the portion of the study reported herein was to develop a model which would predict pore pressures and displacements during primary consolidation of a clay soll which exhibits a quasi-preconsolidation effect. A model representing this behavior was formulated and incorporated into a finite element program which yielded solutions to realistic boundary values problems.

The Report is submitted in partial fulfillment of the objectives of this Research Study and for review and comment of the sponsoring agencies, the Indiana state Highway Commission and the Federal Highway Administration.

$H L M: m s$

Respectfully submitted,

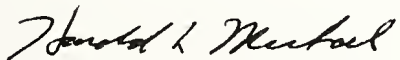

Harold L. Michael

Associate Director
CC: W. L. Dolch
R. L. Eskew
G. D. Gibson
W. H. Goetz
M. J. Gutzwiller
G. K. Hallock

R. H. Harrell

M. L. Hayes

C. W. Lovell

G. W. Marks

R. D. Miles

G. T. Satterly
C. F. Scholer

M. B. Scott

J. A. Spooner

N. W. Steinkamp

H. R. J. Walsh

E. J. Yoder 
Digitized by the Internet Archive in 2011 with funding from

LYRASIS members and Sloan Foundation; Indiana Department of Transportation 


\begin{tabular}{|c|c|}
\hline 2. Government Accession No. & 3. Recipient' Cotolog No. \\
\hline \multirow{2}{*}{$\begin{array}{l}\text { 4. Title and Subtille } \\
\text { THE EFFECT OF QUASI-PRECONSOLIDATION ON } \\
\text { COMPRESSION OF CLAY SOILS }\end{array}$} & $\begin{array}{l}\text { 5. Report Dote } \\
\text { August } 1973\end{array}$ \\
\hline & $\begin{array}{l}\text { 6. Porforming Orgonizotion Codo } \\
C-36-5 F\end{array}$ \\
\hline John L. Davidson & JHRP $-19-73$ \\
\hline $\begin{array}{l}\text { 9. Performino Orgonizotion Nome ond Addres: } \\
\text { Joint Highway Research Project } \\
\text { Civil Engineer }\end{array}$ & 10. Work Unit No. \\
\hline \multirow{2}{*}{$\begin{array}{l}\text { Civil Engineering Building } \\
\text { Purdue University } \\
\text { West Lafayette, Indiana } 47907\end{array}$} & $\begin{array}{l}\text { 11. Controct or Gront No. } \\
\text { HPR-I (II) Part I I }\end{array}$ \\
\hline & \multirow{2}{*}{$\begin{array}{l}\text { 13. Typo of Roport ond Poriod Covered } \\
\text { Interim Report } \\
\text { Prediction Model Phase }\end{array}$} \\
\hline \multirow{2}{*}{$\begin{array}{l}\text { 12. Sponsoring Agency Nome ond Addres: } \\
\text { Indiana State Highway Commission } \\
\text { loo North Senate Avenue } \\
\text { Indianapolis, Indiana } 46204\end{array}$} & \\
\hline & $\begin{array}{l}\text { 14. Sponsoring Agency Codo } \\
\text { CA } 375\end{array}$ \\
\hline
\end{tabular}

15. Supplementory Notes Conducted in cooperation with the U.S. Department of Transportation, Federal Highway Administration, Research Study titled "Deformation of Compacted Cohesive Soil Embankments"

16. Abatroct

The report introduces a procedure for predicting pore pressures and displacements during primary consolidation of a clay soll which exhibits a quasi-preconsolidation effect. A soil model representing this behavior was formulated from laboratory testing, and was incorporated into a finite element program to yield solutions to realistic boundary value problems. Results indicate the following soil behavior.

1. Prior to yielding settlements are small, pore pressures are small and dissipation rapid.

2. Upon yielding pore pressures increase due to the transfer of load from the soll skeleton to the pore water. Settlements are large and pore pressures dissipate slowly.

3. Such behavior is in agreement with recently published field instrumentation studies.

17. Koy Words 18. Distribution Statement

Clay, Compressibility, Quasipreconsolidation, Finite element

19. Security Clossif. (of this report) Unclassified
20. Security Closenif. (of this page)

Unclassified
22. Price

312 
THE EFFECT OF QUASI-PRECONSOLIDATION ON COMPRESSION OF CLAY SOILS

by

John L. Davidson

Graduate Instructor in Research

Joint Highway Research Project

Project No.: $\quad C-36-5 F$

File No.: 6-6-6

Prepared as Part of an Investigation

Conducted by

Joint Highway Research Project

Engineering Experiment Station

Purdue University

in cooperation with the

Indiana State Highway Commission

and the

U.S. Department of Transportation

Federal Highway Administration

The contents of this report reflect the views of the author who is responsible for the facts and the accuracy of the data presented herein. The contents do not necessarily reflect the official views or policies of the Federal Highway Administration. This report does not constitute a standard, specification, or regulation. 


\section{ACKNOWLEDGMENTS}

The author wishes to express deep appreciation to his advisor, Dr. W. H. Perloff, for his valuable guidance and constructive criticism.

The interest shown by the other members of the Graduate Committee, Professors G. A. Leonards, A. G. Altschaeffl, W. D. Kovacs and J. Genin is gratefully acknowledged.

To Mr. W. L. DeGroff and Mr. H. G. Landau the author extends special thanks for their invaluable assistance.

Thanks are also due to the Joint Highway Research Project for the financial support which made this research possible.

To his wife Annette, for her encouragement and patience, the author is deeply grateful. 
TABLE OF CONTENTS

Page

LIST OF TABLES . • • • • • • • • • • • • •

LIST OF FIGURES. • • • • • • • • • • • • • • • • • vii

LIST OF SYMBOLS. • • • • • • • • • • • • • xiv

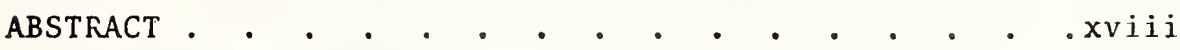

1. INTRODUCTION . . . • • • • • • • . . . . 1

2. REVIEW OF Literature. . . . . . . . . . . . 3

2.1 Introduction. . . . . . . . . . . . 3

2.2 Spatial Variation of Soil Parameters. . . . 6

2.3 The Linearity Assumption. . . . . . . . 7

2.4 The Quasi-preconsolidation Effect. . . . . 10

2.5 Field Observations of the Preconsolidation

2.6 Characteristics of the Quasi- ${ }^{\circ} \cdot{ }^{\circ} \cdot{ }^{\prime} \cdot$

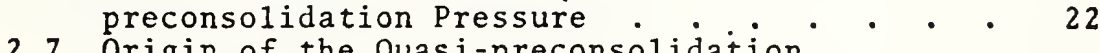

2.7 Origin of the Quasi-preconsolidation
Effect. . . . . . . . . 26

2.8 Objectives of study $\quad \cdot \quad \cdot \quad \cdot \quad \cdot \quad \cdot \quad \cdot \quad \cdot \quad \cdot \quad \cdot \quad 28$

3. EXPERIMENTAL PROCEDURE FOR LABORATORY TESTS . • . 30

3.1 Introduction. . • . . . . . . . . . 30

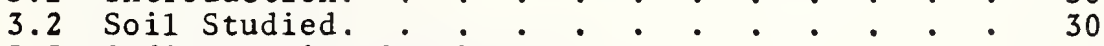

3.3 Sedimentation Samples. . . . . . . . . 31

3.4 Triaxial Samples . . . . . . . . . . 31

3.5 Definitions . . . . . . . . . . . . 36

3.6 Triaxial Testing . . . . . . . . . . 40

4. RESULTS AND DISCUSSION OF QUASI TESTS . . . . . 47

4.1 Introduction. . . . . . . . . . . . 47

4.2 The Triaxial Test Types . . . . . . . . 49

4.3 The q-Yield Surface . . . . . . . . . 49

4.4 Discussion . . . . . . . . . . . . 64 
Page

5. THE Finite SOLUTION PROCEDURE. . . . . . . . 69

5.1 Introduction. . . . . . . . . . . . 69

5.2 Finite-element Equations for a 70

5.3 The Consolidation Process : . . . . . . 77

5.4 The Finite-element Program. . . . . . . 80

5.5 Illustrative Problems. . . . . . . . . 84

5.5.1 Introduction . . . . . . . . . 84

5.5.2 One-Dimensional Consolidation Problem, No Quasi-Preconsolidation Effect. . . 88

5.5.3 One-Dimensional Consolidation Problem, with Quasi-Preconsolidation Effect. . 97

5.5.4 Two-Dimensional Consolidation Problem, No Quasi Preconsolidation Effect. . . 126

5.5.5 Two-Dimensional Consolidation Problem, with Quasi Preconsolidation Effect. . 133

5.6 Field Studies . • . . . . . . . . . 141

6. CONCLUSIONS AND RECOMMENDATIONS . . . . . . . 146

6.1 Conclusions . . . . . . . . . . . . . 146

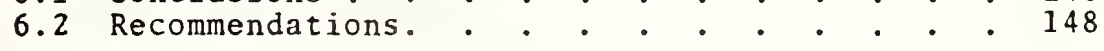

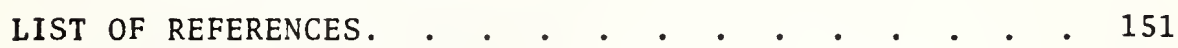

APPENDICES

Appendix A: Sample Preparation . . . . . . . 156

A.1 Sedimentation Apparatus : . . . . 156

A.2 Sedimentation Procedure . . . . . . 160

A.3 Triaxia1 Apparatus . . . . . . . . 167

A.3.1 The Triaxial Ce11 Set-up. . . . 167

A.3.2 The Triaxial Cel1s. . . . . 171

A.3.3 Testing Machine and Recorders. . 177

Appendix B: Laboratory Test Results . . . . . 182

B.1 Introduction. . . . . . . . . . 182

B.2 Triaxial Test Number $23 .{ }^{\circ} \cdot$. $^{\circ} \cdot{ }^{\circ} 182$

B.3 Triaxial Test Plots. . . . . . 193

Appendix C: The Triaxial Test Reduction Program: 230

C.1 Introduction.......... . . 230

C.2 Input Format for Triaxial Program. . . 232

C.3 Example Problem for Triaxial Test 233

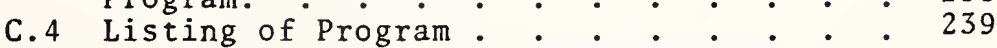

Appendix D: The Finite Element Consolidation 244

D.1 Input Format for Consolidation Program . 244

D.2 Listing of Program... . . . . 248 


\section{LIST OF TABLES}

Table

4.1 q-Consolidation Pressures and Times. . . . . 48

4.2 Test Types and Loading Rates . . . . . . . 50

4.3 q-Yield Stress Results . . . . . . . . . 52

4.4 Ellipse Constants for the q-Yield Curves . . . 57

4.5 Least-squares Parameters for B-lines. . . . . 57

Appendix

Tables

A.1 Glass Siphon Calibrations . . . . . . . 162

B.1 Volume Change during the q-consolidation Period - Test Number 23... . . . . . 187

C.1 Sandborn Data for Example Triaxial Test Reduction Program . . . . . . . . . . . 234

C.2 Input Data Cards for Example Triaxial Test Reduction Program . . . . . . . . . 235

C. 3 Output from Example Triaxial Test Reduction Program. 


\section{LIST OF FIGURES}

Figure

Page

2-1 Schematic Void Ratio-Logarithm Pressure Curve for Normally Consolidated Clay . . . . 11

2-2 The Quasi-Preconsolidation Effect . . . . . 14

2-3 Predicted Vs. Observed Final Settlements . . 15

2-4 Effect of Duration of Single Load Increment on "e-log P" Curves. . . . . . 16

2-5 Void Ratio-Logarithm Pressure Plot Showing Quasi-Preconsolidation Effect . . . . 18

2-6 Void Ratio-Logarithm Pressure Curves . . . 20

2-7 Effect of Quasi-Preconsolidation Pressure on Coefficient of Consolidation . . . . . . 23

2-8 Effect of Consolidation Pressure on Quasi-Preconsolidation Pressure . . . . . . 25

3-1 Classification Properties of Grundite . . . 32

3-2 Grain Size Distribution for Grundite . . . 33

3-3 Triaxial Specimen Preparation Equipment . . . 35

3-4 Stress State within a Triaxial Compression Test Specimen.. . . . . . . . . . 38

3-5 Triaxial Test Stress Paths. . . . . . . 41

3-6 Burette with Pressure Transducer Attachment. . 43

3-7 Incremental Loading Frame . . . . . . . . 44

4-1 The 16.7 psi q-Yield Curve. . . . . . . . 53

4-2 The 24 psi q-Yield Curve . . . . . . . . 54

4-3 The 30 psi q-Yield Curve . . . . . . . . 55 
4-4 Three q-Yield Curves and $\alpha$-Lines. . . . . 58

4-5 Schematic Drawing of q-Yield Curves, $\alpha$ and $\beta$ Lines. . . . . . . . . . . . 59

4-6 B-Lines for q-Yield Surface Interpolation. . . 60

4-7 Schematic Isometric View of q-Yield Surface. . 62

4-8 Schematic Development of the Shape of the Quasi Stress-Strain Curves.

5-1 Flow Chart for Consolidation Program . . . 83

5-2 One and Two Dimensional Consolidation Configurations.

5-3 Excess Pore Pressure Contours for Case of a Rough Base $(u=0)$. . . . . . . . .

5-4 Excess Pore Pressure Contours for Case of a Smooth Base $(t=0)$. . . . . . . .

5-5 One Dimensional Consolidation Problem -

Finite Element Grid • • • . • • • • • . 89

5-6 Analytical Consolidation Program. . . . . . 91

5-7 Pore Pressure Isochrones for Analytical and

Finite Element Solutions . . • . . • . . 92

5-8 Excess Pore Pressure Ratio - Log Time Factor Plot for Seventy-Five Element Grid - First Row No Yielding.

5-9 Excess Pore Pressure Ratio - Log Time Factor Plot for Seventy-Five Element Grid Second Row No Yielding

5-10 Excess Pore Pressure Ratio - Log Time Factor Plot for Seventy-Five Element Grid Third Row No Yielding . . . . . . . .

5-11 Relative Settlement - Log Time Factor Plot for Seventy-Five Element Grid - No Yielding • • . 96

5-12 Single Element Consolidation Grid • • • • 98 
Figure

5-13 Excess Pore Pressure Ratio - Log Time Factor Plot for One Element Grid - No Yielding .

5-14 Relative Settlement - Log Time Factor Plot for One Element Grid - No Yielding

5-15 Excess Pore Pressure Ratio - Log Time Factor Plot for One Element Grid - With Yielding.

5-16 Relative Settlement - Log Time Factor Plot for One Element Grid - With Yielding . . . . 103

5-17 Elements for Two Element Consolidation Program.

- 5-18 Excess Pore Pressure Ratio - Log Time Factor Plots for Two Element Grid - No Yielding

5-19 Relative Settlement - Log Time Factor Plots for Two Element Grid - No Yielding

5-20 Excess Pore Pressure Ratio - Log Time Factor Plot for Two Element Grid - Top Element with Yielding.

5-21 Excess Pore Pressure Ratio - Log Time Factor Plot for Two Element Grid - Bottom Element with Yielding.

5-22 Relative Settlement - Log Time Factor Plot for Two Element Grid - Top Element with Yielding

5-23 Relative Settlement - Log Time Factor Plot for Two Element Grid - Bottom Element with Yielding.

5-24 Tota1 Relative Settlement - Log Time Factor Plot for Two Element Grid with Yielding

5-25 Element Yield and No Yield Conditions . . . . 118

5-26 Time Factor and Pre-Yield Excess Pore Pressure Ratio when Element Yields

5-27 Excess Pore Pressure Ratio - Log Time Factor Plot for Seventy-Five Element Grid - First Row with Yielding.

5-28 Excess Pore Pressure Ratio - Log Time Factor Plot for Seventy-Five Element Grid - Second Row with Yielding. 
Figure

Page

5-29 Excess Pore Pressure Ratio - Log Time Factor

Plot for Seventy-Five Element Grid - Third

Row with Yielding. • . . . . . . . . . 125

5-30 Relative Settlement - Lot Time Factor P1ot

for Seventy-Five Element Grid - with Yielding . 127

5-31 Two Dimensional Consolidation Problem -

Finite Element Grid . . • • • . • • • . 128

5-32 Pore Contours and Relative Surface Settlements

for Two Dimensional Problem - No Yielding - I . 130

5-33 Pore Contours and Relative Surface Settlements

for Two Dimensional Problem - No Yielding - II . 131

5-34 Pore Contours and Relative Surface Settlements

for Two Dimensional Problem - No Yielding - III. 132

5-35 Pore Contours and Relative Surface Settlements

for Two Dimensional Problem - With Yielding - I. 134

5-36 Pore Contours and Relative Surface Settlements

for Two Dimensional Problem - With Yielding - II. 135

5-37 Pore Contours and Relative Surface Settlements

for Two Dimensional Problem - With Yielding-III. 137

5-38 Pore Contours and Relative Surface Settlements for Two Dimensional Problem - With Yielding - IV. 138

5-39 Pore Contours and Relative Surface Settlements for Two Dimensional Problem - With Yielding - V. 139

5-40 Relative Surface Settlements with and without Quasi-Preconsolidation Effect. • . . . . 140

5-41 Observed Excess Pore Pressures . . . . . . 143

5-42 Field Yield Curve. . . . . . . . . . . 144

Appendix

Figure

A-1 The Sedimentation Frame. . . . . . . . 157

A-2 Line Diagram of Sedimentation Frame. • • • 158

A-3 Lucite Tube and Piston. . . . . . . . 159

A-4 Glass Capil1ary Siphon . . . . . . . . 161 
Appendix

Figure

Page

A-5 Preparation Equipment for Sedimentation

Samples . . . . . . . . . . . . . 163

A-6 Sedimentation Samples before and after

Standing Period.. . . . . . . . 165

A-7 Typical Sedimentation Loading Curve. . . . 166

A-8 Grain Size Distribution for Sedimentation

Sample . . . . . . . . . . . 168

A-9 Triaxial Set-Up for q-Consolidation Period . . 169

A-10 Line Diagram of Triaxial Set-Up . . . . . . 170

A-11 The Geonor Triaxial Test . . . . . . 172

A-12 Geonor Ce11, Rotating Bushing Detail • . . . 172

A-13 Rotating Bushing Effect. . . . . . . . . 174

A-14 Rubber and Spring Tests for Rotating Bushing. . 175

A-15 Set-Up for Isotropic Loading Test . . . . . 176

A-16 The Wykeham-Farrance Ce11 . . . . . . . . 178

A-17 The Test Lab Cel1. . . . . . . . . 178

A-18 The Triaxial Testing Machine . . . . . . 179

A-19 The Sandborn 321 Recorder . . . . . . . 181

A-20 The Varian G-14A-1 Recorder . . . . . . . 181

B-1 Load-Time Plot for Sedimentation Samp1e ID . . 183

B-2 Void Ratio-Pressure Curve for Sample 1D . . . 185

B-3 Sample Summary Sheet. . . . . . . . . 186

B-4 Test Number 23 Octahedral Shear Stress-Axial

Strain Plot. . . . . . . . . . . . . 190

B-5 Test Number 23 Octahedra1 Shear StressDeviatoric Strain Plot.

B-6 Test Number 23 Octahedral Normal StressVolumetric Strain Plot. 
Appendix

Figure

Page

B-7 Test Number 1 Deviator Stress-Axial Strain P1ot. 195

B-8 Test Number 2 Deviator Stress-Axial Strain P1ot. 196

B-9 Test Number 3 Deviator Stress-Axial Strain P1ot. 197

B-10 Test Number 4 Ce11 Pressure-Vertical

Deformation P1ot . . . . . . . . . . . 198

B-11 Test Number 5 Deviator Stress-Axial Strain P1ot. 199

B-12 Test Number 6 Ce11 Pressure-Burette Reading

P1ot.............. . . 200

-B-13 Test Number 7 Cel1 Pressure-Vertical

Deformation Plot. . . . . . . . . . 201

B-14 Test Number 7 Cel1 Pressure-Volume Change Plot . 202

B-15 Test Number 8 Deviator Stress-Axial Strain P1ot. 203

B-16 Test Number 9 Deviator Stress-Axial Strain Plot. 204

B-17 Test Number 10 Deviator Stress-Axial Strain

Plot. . . . . . . . . . . . . 205

B-18 Test Number 11 Deviator Stress-Axial Strain

Plot.............. . . 206

B-19 Test Number 12 Cel1 Pressure-Volume Change Plot. 207

B-20 Test Number 13 Axial Stress-Axial Strain Plot . 208

B-21 Test Number 13 Octahedral Shear StressDeviatoric Strain Plot. . . . . . . . 209

B-22 Test Number 14 Axial Stress Increment-

Volume Change and Axial Deformation. . . . . 210

B-23 Test Number 15 Octahedral Shear Stress-

Volume Change and Axial Deformations Plots . . 211

B-24 Test Number 16 Octahedral Normal Stress-

Volume Change Plot . . . . . . . . . . 212

B-25 Test Number 17 Deviator Stress-Axia1 Strain

Plot. . . . . • . . . . . . . . . 213 
Appendix

Figure

Page

B-26 Test Number 18 Octahedral Shear StressVolume Change and Axial Deformation Plots. . . 214

B-27 Test Number 19 Octahedral Shear StressAxial Strain Plot. . . . . . . . . . . 215

B-28 Test Number 19 Octahedral Shear StressDeviatoric Strain Plot. . . . . . . . 216

B-29 Test Number 19 Octahedral Shear StressVolumetric Strain P1ot. . . . . . . . 217

B-30 Test Number 20 Octahedral Shear StressVolumetric Strain P1ot. . . . . . . . 218

B-31 Test Number 20 Volumetric StrainOctahedral Normal Stress Plot. . . . . . 219

B-32 Test Number 21 Octahedra1 Shear StressDeviatoric Strain P1ot. . . . . . . . 220

B-33 Test Number 21 Volumetric StrainOctahedral Normal Stress Plot.

B-34 Test Number 22 Ce11 PressureAxial Deformation Plot. . . . . . . 222

B-35 Test Number 23 Octahedral Shear StressAxial Strain Plot. . . . . . . . . . 223

B-36 Test No. 23 Octahedral Shear StressDeviatoric Strain Plot . . . . . . . . 224

B-37 Test Number 23 Volumetric StrainOctahedral Normal Stress Plot.

B-38 Test Number 24 Deviator StressAxial Strain Plot.

B-39 Test Number 25 Octahedral Shear StressAxial Strain Plot. . . . . . .

B-40 Test Number 26 0ctahedral Shear StressAxial Deformation Plot

B-41 Test Number 27 Octahedral Normal StressVolume Change and Axial Deformation Plots.

C-1 F1ow Chart for Triaxial Test Reduction Program. 


\section{LIST OF SYMBOLS}

$$
\begin{aligned}
& \text { Ap Piston area } \\
& \text { A Triaxial specimen cross section area } \\
& a_{v} \quad \text { Coefficient of compressibility } \\
& \text { \{b\} External body forces } \\
& \mathrm{C}_{\mathrm{c}} \text { Compression index } \\
& \mathrm{C}_{\mathbf{i}} \quad \mathbf{i}=1,2,3 \quad \text { Curve fitting constants } \\
& c_{v} \text { Coefficient of consolidation } \\
& \text { D Diameter, constraint modulus } \\
& \text { E Elastic or Young's modulus } \\
& E_{a} \text { Elastic modulus just after yielding } \\
& \mathrm{E}_{\mathrm{b}} \quad \text { Elastic modulus just before yielding } \\
& E_{\text {new }} \quad \text { Elastic modulus after yielding } \\
& \text { Eld Elastic modulus before yielding } \\
& \text { e Void ratio } \\
& \text { e Overburden void ratio } \\
& e_{\phi} \quad \text { Volumetric strain } \\
& \left\{F_{C}\right\} \quad \text { External nodal forces } \\
& \text { G Shear modulus } \\
& \text { H Stratum thickness } \\
& \text { h Length of drainage path } \\
& \text { [K] Stiffness matrix } \\
& \mathrm{K}_{\mathrm{b}} \quad \text { Bulk modulus }
\end{aligned}
$$




$$
\begin{aligned}
& k, k_{x x}, k_{y y} \quad \text { Permeability } \\
& \text { L Length } \\
& M, m \text { Terzaghi equation constants } \\
& m_{v} \quad \text { Coefficient of volume change } \\
& \text { P Axial load } \\
& \text { \{P\} Nodal forces } \\
& \text { \{p\} External surface pressures } \\
& \text { p Effective pressure } \\
& \mathrm{p}_{\mathrm{c}} \quad \text { Maximum past effective pressure } \\
& \mathbf{p}_{\text {cq }} \text { Quasi-preconsolidation pressure } \\
& \mathrm{p}_{\mathrm{o}} \quad \text { Effective overburden pressure } \\
& \text { q- Related to the quasi-preconsolidation } \\
& \text { triaxial tests } \\
& q_{c} \quad \text { Consolidation pressure } \\
& \mathrm{q}_{\mathrm{c}_{i}} \quad \text { Octahedral normal stress prior to shearing } \\
& r \text { Diameter - length ratio } \\
& \text { \{S\} Excess pore pressure } \\
& \text { (T) Element volume change } \\
& \mathrm{T} \text { Dimensionless time factor } \\
& \text { t Time } \\
& t_{f} \text { Time to failure } \\
& \overline{\mathrm{U}}_{\mathrm{f}} \quad \text { Average degree of dissipation at failure } \\
& \mathbf{U}_{\mathbf{i}} \quad \text { Work done by internal stresses } \\
& \text { u Excess pore water pressure } \\
& \mathbf{u}_{\mathrm{a}} \text { Excess pore pressure just after yielding } \\
& u_{b} \quad \text { Excess pore pressure just before yielding }
\end{aligned}
$$




$$
\begin{aligned}
& u_{0} \quad \text { Initial excess pore pressure } \\
& \text { \{u\} Displacements at a typical point } \\
& \left\{u_{n}\right\} \quad \text { Displacements at the node points } \\
& \text { V Volume } \\
& \text { W Virtual work } \\
& x \quad q \text {-octahedral normal stress incremnet } \\
& \text { y q-octahedral shear stress increment } \\
& x_{\alpha}, y_{\alpha} \quad \text { coordinates of } \alpha \text {-line, } q \text {-yield curve inter- } \\
& \text { cept } \\
& z \text { depth } \\
& \alpha-, \beta-1 \text { ines Interpolation curve construction } 1 \text { ines } \\
& \text { w Unit weight of water } \\
& \text { Change } \\
& t \text { Time increment } \\
& \left.\begin{array}{l}
\Delta \bar{\sigma}_{\text {oct }} \\
\Delta \tau_{\text {oct }}
\end{array}\right\} \begin{array}{l}
\text { Octahedral effective normal and shear } \\
\text { stresses at the } q-y i e l d \text { stress point }
\end{array} \\
& \delta_{0} \quad \text { Observed settlement } \\
& \delta_{\mathrm{p}} \quad \text { Predicted settlement } \\
& \delta \varepsilon \quad \text { Deviatoric strain increment } \\
& \delta \mathrm{v} \quad \text { Volumetric strain increment } \\
& \varepsilon_{\mathbf{i}} \quad \mathbf{i}=1,2,3 \quad \text { Principal strains } \\
& \text { Erate Strain or loading rate } \\
& \varepsilon_{x}, \varepsilon_{y} \quad \text { Strain in } x-, y \text {-direction } \\
& \varepsilon_{v} \quad \text { Vertical strain } \\
& \xi \quad \text { Triaxial specimen drainage factor } \\
& n \text { Octahedral shear-normal stress ratio }
\end{aligned}
$$




$$
\begin{array}{cl}
\rho_{i} & \text { Settlement in } i^{\text {th }} \text { element } \\
\rho_{u 1 t} & \text { Ultimate settlement } \\
\sigma & \text { Total stress } \\
\sigma_{a} & \text { Total stress just after yielding } \\
\bar{\sigma}_{a} & \text { Effective stress just after yielding } \\
\sigma_{b} & \text { Total stress just before yielding } \\
\bar{\sigma}_{b} & \text { Effective stress just before yielding } \\
\bar{\sigma}_{c} & \text { Cell confining pressure } \\
\sigma_{i}=1,2,3 & \text { Principal stresses } \\
\sigma_{\text {oct }} & \text { Octahedral normal stress } \\
\sigma_{v} & \text { Vertical stress } \\
\text { oct } & \text { Octahedral shear stress } \\
\bar{v} & \text { Poisson's ratio of the soil skeleton }
\end{array}
$$




\section{ABSTRACT}

Davidson, John Leitch. Ph.D., Purdue University, August 1973. The Effect of Quasi-Preconsolidation on Compression of Clay Solls. Major Professor: Dr. William II. Perloff.

The research was initiated to predict pore pressures and displacements during primary consolidation of a clay soil which cxhibits a quasi-preconsolidation effect. A soil model representing this behavior was formulated from laboratory testing, and was incorporated into a finite element program to yield solutions to realistic boundary values problems.

In the 1aboratory study, drained triaxial tests were performed on soil specimens in which a quasi-preconsolidation effect had been induced by maintaining them under a constant hydrostatic stress for a period of time. Resulting stress-strain plots showed an essentially bi-linear behavior, with an initially high and subsequently lower stress-strain modulus. The break point represents yielding of the bonds formed during the period of constant loading, and is equivalent to the phenomenon observed by Leonards and Ramiah during consolidation testing and designated by them as the quasipreconsolidation pressure point. From different stress path tests on specimens consolidated under different 
hydrostatic pressures, a three-dimensional yield surface was formulated in terms of the hydrostatic stress and the test effective octahedral stress increments.

The finite element solution to the consolidation problem, based on the Biot theory for an elastic soil, calculated stresses, pore pressures and displacements within the soil after each increment of pore pressure dissipation. A bilinear model with associated yield surface, derived from laboratory test results, was introduced into the finite element program and solutions were obtained for one-dimensional and two-dimensional plane strain consolidation problems.

Solutions were obtained using the Purdue University Control Data Corporation 6500 Computer System and employing a Fortran IV source deck.

Results from the finite element programs incorporating the yield model indicate the following soil behavior.

1. Prior to yielding settlements are sma11, pore pressures are small and dissipation rapid.

2. Upon yielding pore pressures increase due to the transfer of load from the soil skeleton to the pore water. Settlements are large and pore pressures dissipate slowly.

3. Such behavior is in agreement with recently published field instrumentation studies. 


\section{INTRODUCTION}

In order to satisfactorily predict stresses and deformations in a soil mass which will act as a foundation for construction, a number of interrelated phases must be considered. A subsurface investigation of the site yields both samples and a delineation of the insitu soil conditions. Laboratory and field tests are then performed on representative samples in order that soil parameters may be defined, and these and their variations are used in the formation of a descriptive model or material constitutive law. A solution procedure incorporating the model is employed to calculate deformations and stresses for the specific boundary value problem. Finally, measurements from field instrumentation during construction are compared with predicted values and, if necessary, lead to alteration of design or construction procedures.

Much research in recent years has been directed towards better formulation of the descriptive model and towards development of better and more versatile solution procedures for such models. Traditionally, earth masses have been modelled as homogeneous isotropic materials, rigid and perfectly plastic for stability analyses, and linear elastic for stress distribution and settlement analyses.

In current research, soils are being more realistically modelled as inhomogeneous anisotropic materials, characterized 
by non-linear elasticity, viscoelasticity, strain hardening and softening plasticity and combinations thereof.

A major problem exists, however, in relating models derived in the laboratory on samples deformed under simple stress conditions to more complex field problems. Exact solution procedures are often capable of considering only highly idealized soil constitutive behavior and simple boundary conditions.

In the past decade, advances in the field of computer sciences and the ready availability of large digital computers have transformed much of the emphasis on solution procedures from exact to numerical methods. With the aid of the computer, procedures such as the finite difference and the more recent and versatile finite element method become efficient and accurate methods of solving field problems with complicated boundary conditions and more realistic soil behavior.

However, models are still by necessity simplifications of reality, and must be chosen to reflect those characteristics deemed most significant for the problem at hand. This research represents a study of one such behavior, namely the quasipreconsolidation effect. Based on laboratory results, a stress-deformation model considering this behavior is formulated. Incorporation of the model into a finite element program allows realistic boundary value problems to be solved. 


\section{REVIEW OF LITERATURE}

\subsection{Introduction}

Karl Terzaghi's formulation of the one-dimensional consolidation theory is generally considered the beginning of modern soil mechanics. And yet, the problem of predicting the magnitude and rate of deformation of soft fine grained soils has remained one of the main concerns and areas of research, both theoretical and practical, in geotechnical fields. This is especially so now, when "unsatisfactory" subsurface conditions often play a minor role in determining the location and size of engineering structures such as large buildings and highway embankments. Foundation engineers, more so now than ever, are required to use the material available at the site available.

The process of consolidation can be viewed as a transfer of load from pore water of low compressibility to a more compressible soil structure. Loads applied at the soil boundaries create pressures in the pore fluid in excess of hydrostatic, and gradients in this excess pressure induce flow towards drainage zones. This physical process whereby pore water is slowly squeezed out of the clay stratum due to external loads has long been recognized. In 1809 Telford in Scotland preloaded a thick soft clay layer for nine months 
before constructing a canal lock. In the United States, papers by W. S. Smith in 1892 and E. C. Shankland in 1896 described building settlements in Chicago due to consolidation. However a theoretical explanation and reliable methods for estimating consolidation settlement and time rate did not exist until Terzaghi first introduced the principle of effective stress in 1921 and his classical theory of consolidation two years later (Terzaghi, 1923). The one-dimensional equation derived by Terzaghi, governing the dissipation of excess pore pressure with depth and time is

$$
c_{v} \frac{\partial^{2} u}{\partial z^{2}}=\frac{\partial u}{\partial t}
$$

a linear partial differential equation of parabolic form where

$$
\begin{aligned}
& u(z, t) \text { - excess (above hydrostatic) pore water pressure } \\
& \mathbf{t} \text { - time } \\
& z \text { - depth } \\
& c_{v}=\frac{k}{\gamma_{w} m_{v}} \text { - coefficient of consolidation } \\
& \mathbf{k} \text { - permeability } \\
& r_{w} \text { - unit weight of water } \\
& m_{v} \text { - coefficient of volume compressibility }
\end{aligned}
$$

This equation is of the same form as that for the nonstationary one-dimensional flow of heat through isotropic bodies and consequently a complete methodology and a large number of solutions became immediately available. Carslaw 
(1921) in his book "Introduction to the Mathematical Theory of the Conduction of Heat in Solids" outlines solutions to the heat flow equation for many different boundary and initial conditions. A closed form solution based on Fourier mathematics is given by Terzaghi (1941) for boundary and initial conditions corresponding to the laboratory consolidation test.

In order to reduce the complex consolidation problem to the above simple equation it was necessary for Terzaghi to make a number of linearizing assumptions. These greatly limit the generality of the problems which can be solved and researchers have modified them in deriving solutions to problems with particular soils and boundary conditions which depart significantly from those assumed by Terzaghi.

There are three basic assumptions inherent in the derivation of the Terzaghi consolidation equation. First is the premise that the consolidation settlements are related to and dependent solely on the dissipation of the excess pore water pressure developed by the loading; that is, a hydrodynamic process. Secondly, it is assumed that the soil deposit is both isotropic and homogeneous. No spatial variation of material parameters is possible, and both deformation and drainage are assumed to be one-dimensional. Final$1 y$, in order to achieve the simple resulting differential equation it was necessary for Terzaghi to assume a constant coefficient of permeability and a linear stress-strain, or void ratio-pressure relationship. 
The first assumption regarding the hydrodynamic effect has been generally accepted by subsequent researchers and efforts have been concentrated on relaxing the homogereity and linearity assumptions. A brief review of such research is given in the following two sections.

\subsection{Spatial Variation of Soil Parameters}

A number of solution procedures has been introduced to take into account the non homogeneous nature of virtually all soil deposits. Parameter variation with depth can often be approximated by a number of essentially homogeneous horizontal strata: the n-layer problem. This has been solved in closed form (Gray, 1945), by averaging coefficients (Terzaghi, 1940), and by a transformation method (Glick, 1945). The finite difference solution procedure (Forsythe and Wasow, 1960) has been adapted for the one-dimensional consolidation problem and used by several researchers including Abbott (1960), Raymond (1966), and Davis and Lee (1969) .

Other authors have published solutions to problems in which particular soil parameters were permitted to vary in some manner with depth. Edelmann (1953) obtained an analytical solution to the problem in which the modulus of elasticity increased with depth. Schiffman and Gibson (1964) considered the case in which the permeability and the coefficient of compressibility varied with depth, while Martins (1965) and Schiffman (1958) permitted only the permeability to vary. 
Two- and three-dimensional consolidation theories have been formulated, based on the work of Biot (1941), and solutions derived. These have however, by necessity, been solutions to problems with simple boundary configurations, simple loading conditions and ideal constitutive laws. No solution procedure existed which could take into account such complex conditions until the Finite Element Method was introduced, (Turner et al., 1956; Clough, 1960; Wilson, 1965). Using this versatile numerical tool, many solutions to specific soil engineering problems have since been published. A review of many of these papers is given by Radhakrishnan and Reese (1970), and illustrates the versatility of the Finite Element Method in areas of non-linear constitutive behavior, random spatial variation of soil parameters, and complex boundary and loading conditions.

\subsection{The Linearity Assumption}

Formulation of the consolidation equation by considering flow into and out of a soil domain results in the following equation

$$
\frac{k\left(1+e_{0}\right)}{\gamma_{w}} \frac{\partial^{2} u}{\partial z^{2}}=\frac{\partial e}{\partial t}
$$

where

$$
\begin{aligned}
& \text { e - void ratio } \\
& \text { e - initial void ratio }
\end{aligned}
$$

and other terms are as defined for equation (2.1). 
In order to solve for the excess pore pressure, $u(z, t)$, it is necessary to assume relationships between permeability and void ratio, or permeability and effective stress, and between void ratio and excess pore pressure or void ratio and effective stress.

Terzaghi in his fundamental derivation assumed a constant coefficient of permeability and the linear void ratio-pressure relationship,

$$
\frac{\Delta e}{\Delta \bar{\sigma}}=-a_{v}
$$

Schiffman (1965) assumed a linear void ratio-pressure relationship but permitted the permeability to decrease either step by step with time, or as an exponential function of the excess pore pressure.

Davis and Raymond (1965) assumed a linear void ratiologarithm of pressure relationship and varied the permeability such that the coefficient of consolidation $c_{v}$ remained constant.

Barden and Berry (1965), Raymond (1969), and Poskitt (1969) all assumed linear void ratio-logarithm of pressure and linear void ratio-logarithm of permeability relationships. Gibson et al., (1967) formulated a consolidation equation in which both the permeability and the effective stress were general functions of the void ratio. This reduced to a form similar to Terzaghi's equation but with a more complex coefficient $c_{F}$. Solutions were obtained assuming $c_{F}$ constant and linearly related to the void ratio. 
Results from the above theories have been compared with the simple linear Terzaghi formulation, and in certain cases do show some variation. However, it was noted by Barden and Berry (1965) that at the field scale the simple linear Terzaghi theory may generally be applied to the majority of clays exhibiting no unusual properties such as partial saturation or high compressibility.

Raymond (1966) performed consolidation tests on two different soils in an apparatus consisting of either two or four oedometer cells with their drainage lines connected in series. He observed an apparent overconsolidation behavior during consolidation after a load was applied. He formulated a one-dimensional finite difference program capable of describing the consolidation process during a pressure increment in which the preconsolidation pressure was exceeded. Assumptions were made of a bilinear void ratio-pressure relationship with the break at the preconsolidation pressure, and of constant but different coefficients of permeability above and below this pressure. The consolidation process then consisted of an internal boundary moving through the initially overconsolidated soil. As this boundary passed the soil behavior changed from overconsolidated to normally consolidated. Theoretical results showed that consideration of even-slightly overconsolidated behavior resulted in significant differences from the Terzaghi solution, indicating a rapid dissipation of pore-water pressure until a critical point was reached after which dissipation was much slower. 
Many clays which from their geologic history would be classified as normally consolidated do not behave in the expected simple lincar void ratio-logarithmic pressure manner when initially loaded, but rather show an apparent overconsolidation behavior of the type observed by Raymond. In fact it appears that most clay soils if permitted to remain under a constant stress state for even a short period of time will, in some manner, develop interparticle bonding which can support some additional loading with very little deformation. If however, the applied pressure exceeds some critical value the comparatively rigid bonds are susceptible to sudden breakdown. This behavior results in a sharp slope increase on the e-log $\mathrm{p}$ curve at a pressure which, by analogy with the effect of precompression, has been termed the "quasi-preconsolidation pressure, $\mathrm{p}_{c q}$ " by Leonards and his co-workers at Purdue University. This phenomenon is discussed in detail in the following section.

\subsection{The Quasi-preconsolidation Effect}

A normally consolidated soil deposit is defined as one in which the existing effective overburden pressure $p_{0}$ is equal to the maximum effective pressure that the soil has ever experienced $p_{c}$. Figure 2.1 shows a schematic void ratio-vertical pressure plot of normally consolidated clay behavior. Line $A B$ represents the geologic sedimentation of the soil and BC the projected behavior, should further loading be applied. Point $B$ denotes the present insitu 


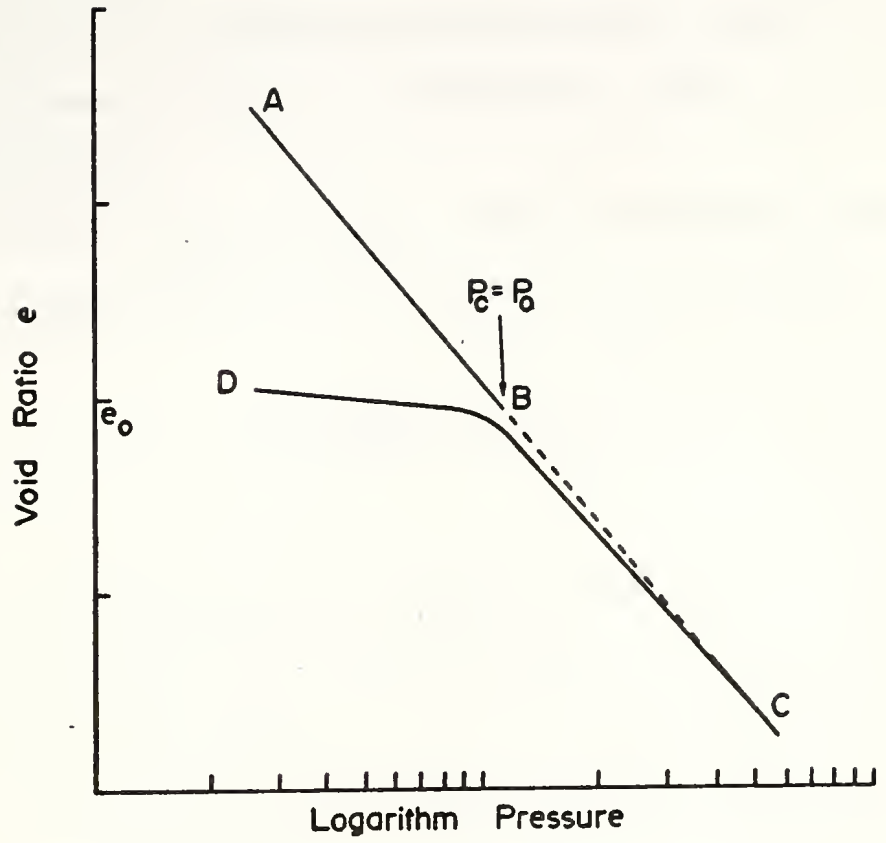

FIGURE 2-1 SCHEMATIC VOID RATIO-LOGARITHM PRESSURE CURVE FOR N.C. CLAY. 
state, with void ratio $e_{0}$ and vertical pressure equal to the overburden pressure $p_{0}$. Curve DC represents the results of a consolidation test on an "undisturbed" sample of the clay and consists of a recompression curve which bends into the virgin compression curve at a pressure $\mathrm{p}_{c}$ equal to the overburden pressure.

Since BC is approximately linear on the semi-logarithmic plot settlement calculations are made using the equation

$$
\delta=\sum_{z}^{0} \frac{c_{c}}{1+e_{0}} \log \frac{p_{0}+\Delta p}{p_{0}} \Delta z
$$

where

$p_{0}$ is the effective overburden pressure

$\Delta \mathrm{p}$ is the vertical load increment

$\Delta z$ is the thickness of an individual clay layer

$\mathrm{C}_{\mathrm{c}}$ is the compression index (slope of the virgin compression curve)

Bjerrum (1964) published a report in which he compared observed settlements of structures and embankments on soft clay with computations made using the above equation. The results showed that for heavy structures with large settlements good agreement was obtained, but for light structures the calculations greatly overpredicted the actual field settlements. The explanation of this discrepancy lies in the failure of the analysis to take into account the quasipreconsolidation effect which exists in most clay soils. 
This effect manifests itself on the void ratio-log pressure plot (Figure 2.2) as an almost horizontal, low compressibility line from $p_{0}$ to $p_{c q}$ when the effect is destroyed. The curve then reverts to the approximately linear virgin compression line. It is this latter fact which accounts for the large structure settlement agreement reported by Bjerrum, since loading was of sufficient magnitude to destroy and exceed any $p_{c q}$ effect. However, for a small load increment failure to consider the initial stiffness results in large errors. These two loading cases are shown schematically in Figure 2.3.

Extensive research on the quasi-preconsolidation phenomenon has been carried out by Leonards and others at Purdue University. A program of one-dimensional consolidation tests on two remolded soils, a limestone residual clay and a silty clay of glacial origin, was performed and reported by Leonards and Ramiah (1960). During testing, a single pressure increment was maintained for periods of time up to 100 days. In some tests secondary compression during this period was permitted, while in other tests after a 24 hour period of primary consolidation further volume change was prevented. In all cases, whether secondary compression was permitted or not, continued loading after the rest period, using small pressure increments, produced a quasipreconsolidation effect considerably larger than the maximum previous consolidation pressure. Figure 2.4 from Ramiah 


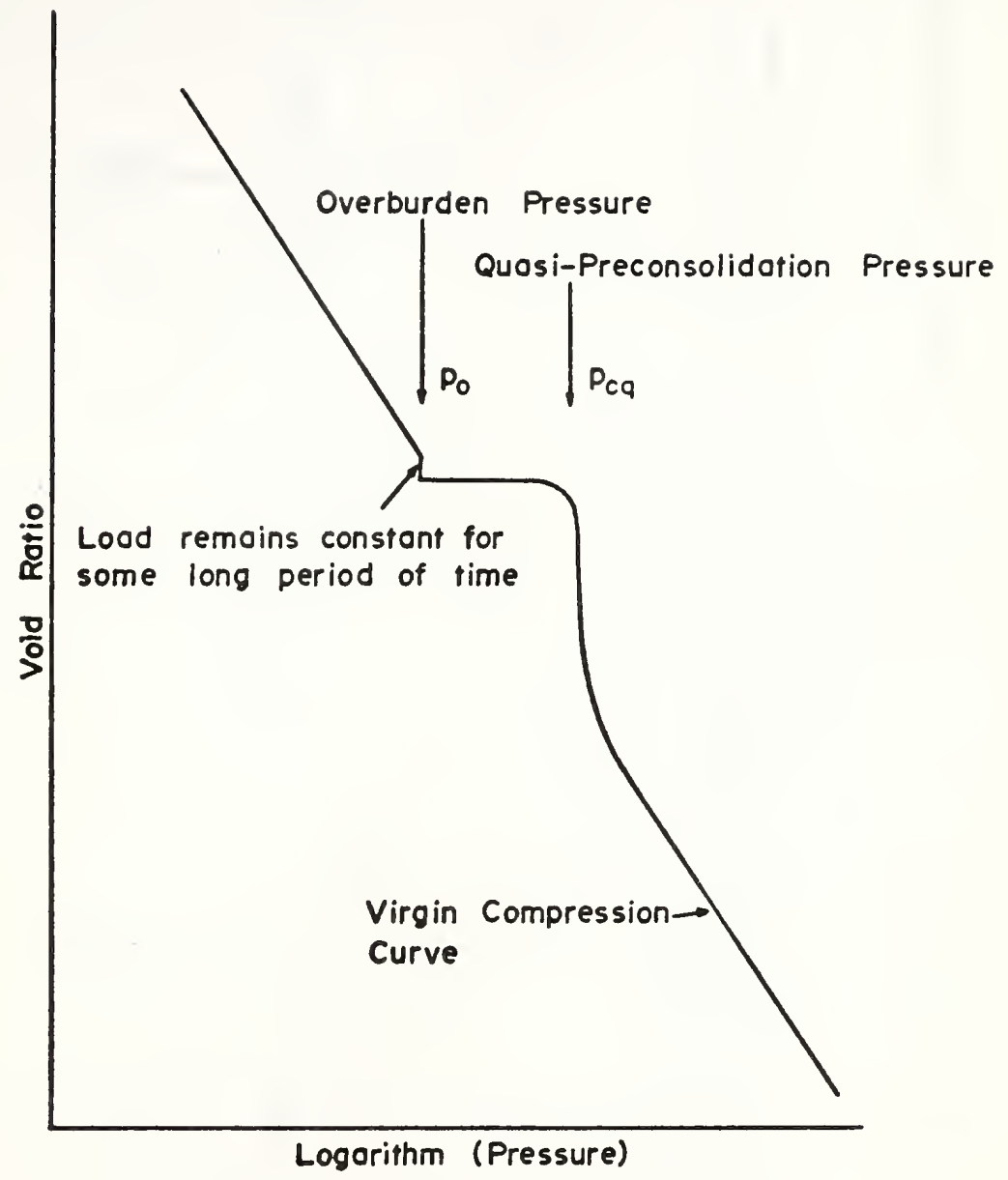

FIGURE 2-2 THE QUASI-PRECONSOLIDATION EFFECT 


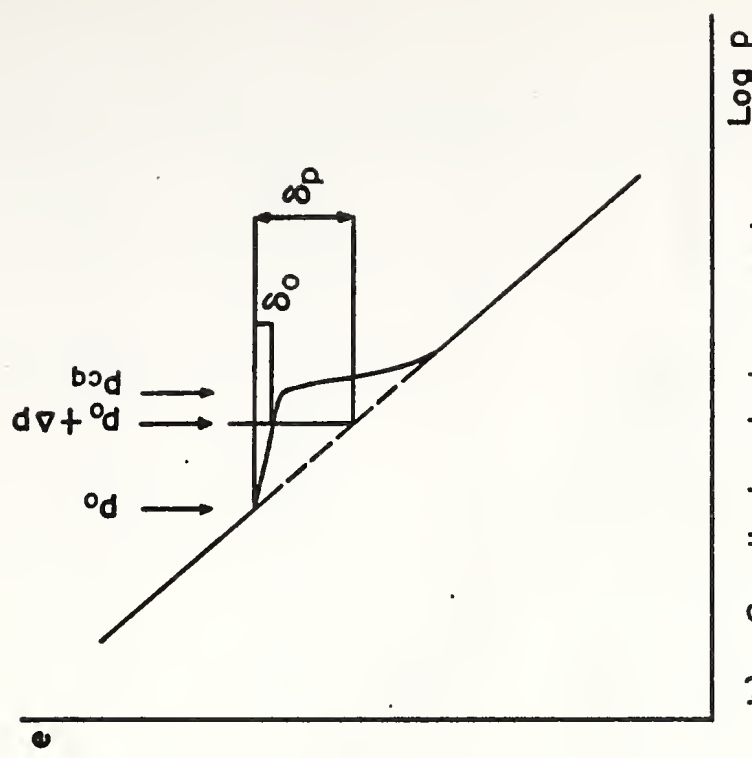

ㅇ

임

है

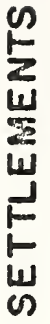

$\stackrel{\overline{0}}{\frac{1}{n}} \quad \frac{1}{4}$

20

0
$u$
0
$\omega$
0
0

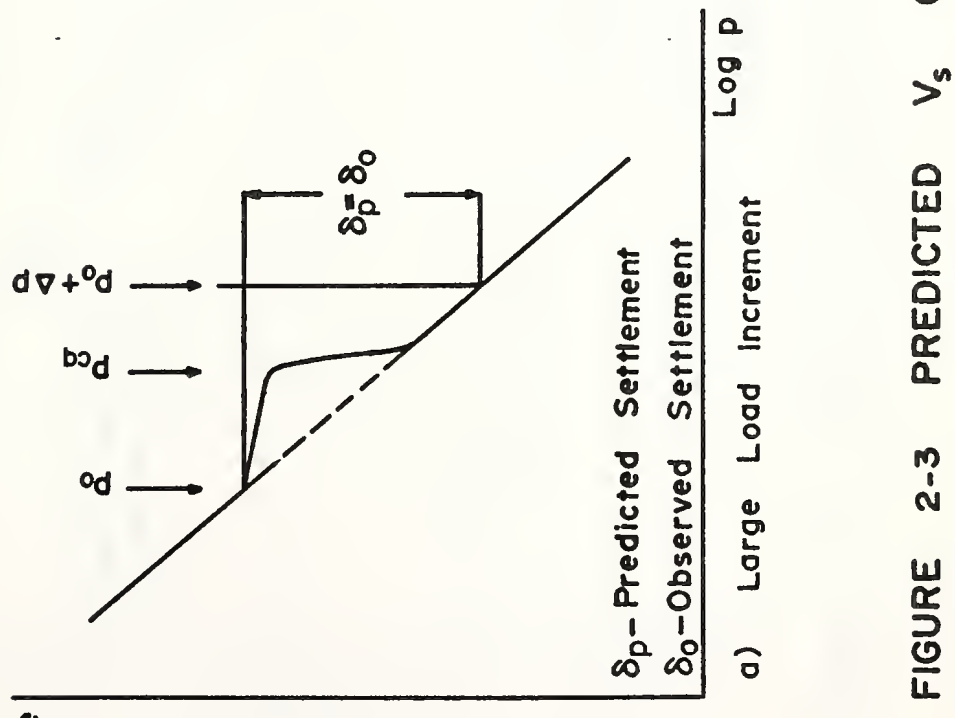




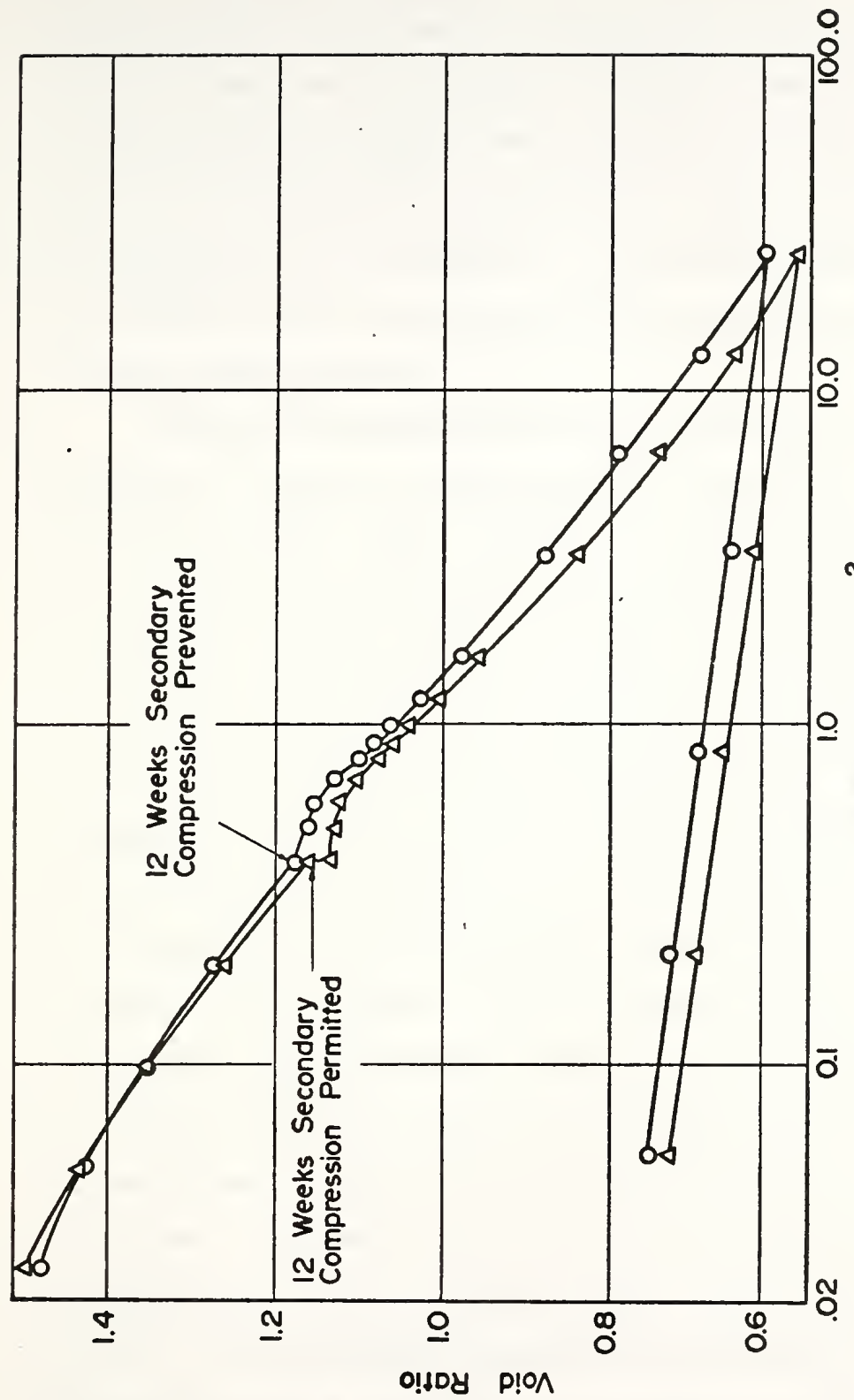

2

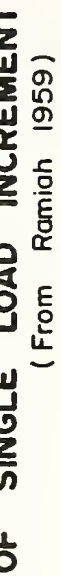

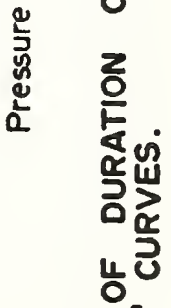
늘 $\hat{N}$ $\frac{11}{5}$ 
(1959) illustrates this phenomenon which was observed in all tests on both clays and at varying moulding water contents. Further tests were carried out in which samples were prepared as before except that after the rest period the specimens were unloaded and "sampled" by rapid penetration of a floating ring consolidometer with sharpened edge. Consolidation tests were then performed and the quasi-preconsolidation effect again observed.

Further experimentation was performed on artificially sedimented samples of the limestone residual clay (Leonards and Altschaeff1, 1964). Samples were prepared and loaded in lucite tubes at rates approaching those encountered in the formation of river deltas. Different combinations and rates of loading, unloading, reloading and rest periods were easily accomplished in the especially designed sedimentation apparatus (Altschaeff1, 1960). Figure 2.5 shows the void ratio-log pressure plot for one test which was loaded to $0.512 \mathrm{~kg} / \mathrm{cm}^{2}$ and then allowed to remain under this constant pressure for 100 days. The specimen was then unloaded, permitted another 100 day rest period and finally loaded to a pressure well in excess of the maximum past pressure experienced. A distinct quasi-preconsolidation pressure was obtained. Besides insitu tests as described above, consolidometer tests were run on specimens sampled from the lucite tube. Good agreement was obtained provided specimens were obtained using a good piston-type sampler and the elapsed 


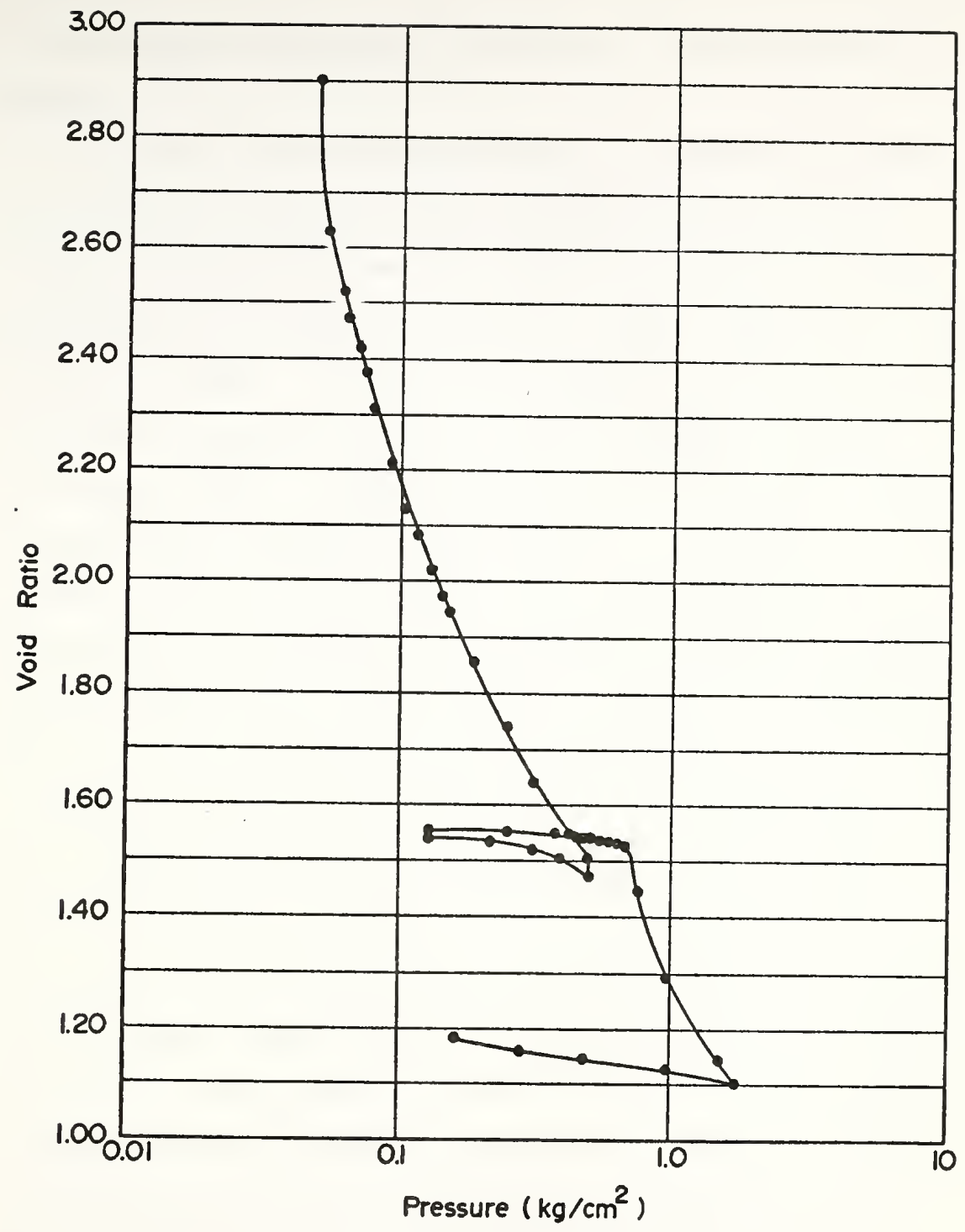

FIGURE 2.5 VOID RATIO-LOGARITHM PRESSURE PLOT SHOWING QUASI-PRECONSOLIDATION EFFECT.

(From Altschaeffl 1960) 
time between unloading and reloading in the oedometer was short.

In the seventh Rankine Lecture of the British Geotechnical Society, Bjerrum (1967) introduced his concept of delayed consolidation and his unique relationship between void ratio, overburden pressure and time. Figure 2.6, taken from that paper, illustrates his theory. Line $A B$ represents the field sedimentation curve while BC shows the change in void ratio under a constant effective stress due to delayed consolidation (secondary compression). If the soil is now loaded, curve $C D$ with a distinct $\mathrm{p}_{\mathrm{cq}}$-effect break will be obtained and represents the "instant" (primary consolidation only) compression. The dotted line depicts the magnitude of the "total" (instant + delayed) compression after a period of time, in this case thirty years. This represents a somewhat different behavior from that reported by Leonards and his co-workers. In the Bjerrum theory the magnitude of the quasi-preconsolidation pressure is dependent on the amount of secondary compression, while Leonards and Ramiah (1960) observed a quasi-preconsolidation effect even when secondary compression was prevented (Figure 2.4). Also, in the void ratio-logarithm pressure plot shown in Figure 2.5 (from Altschaeffl, 1960) it is seen that a much larger quasipreconsolidation pressure was observed than could be predicted using Bjerrum type curves. 


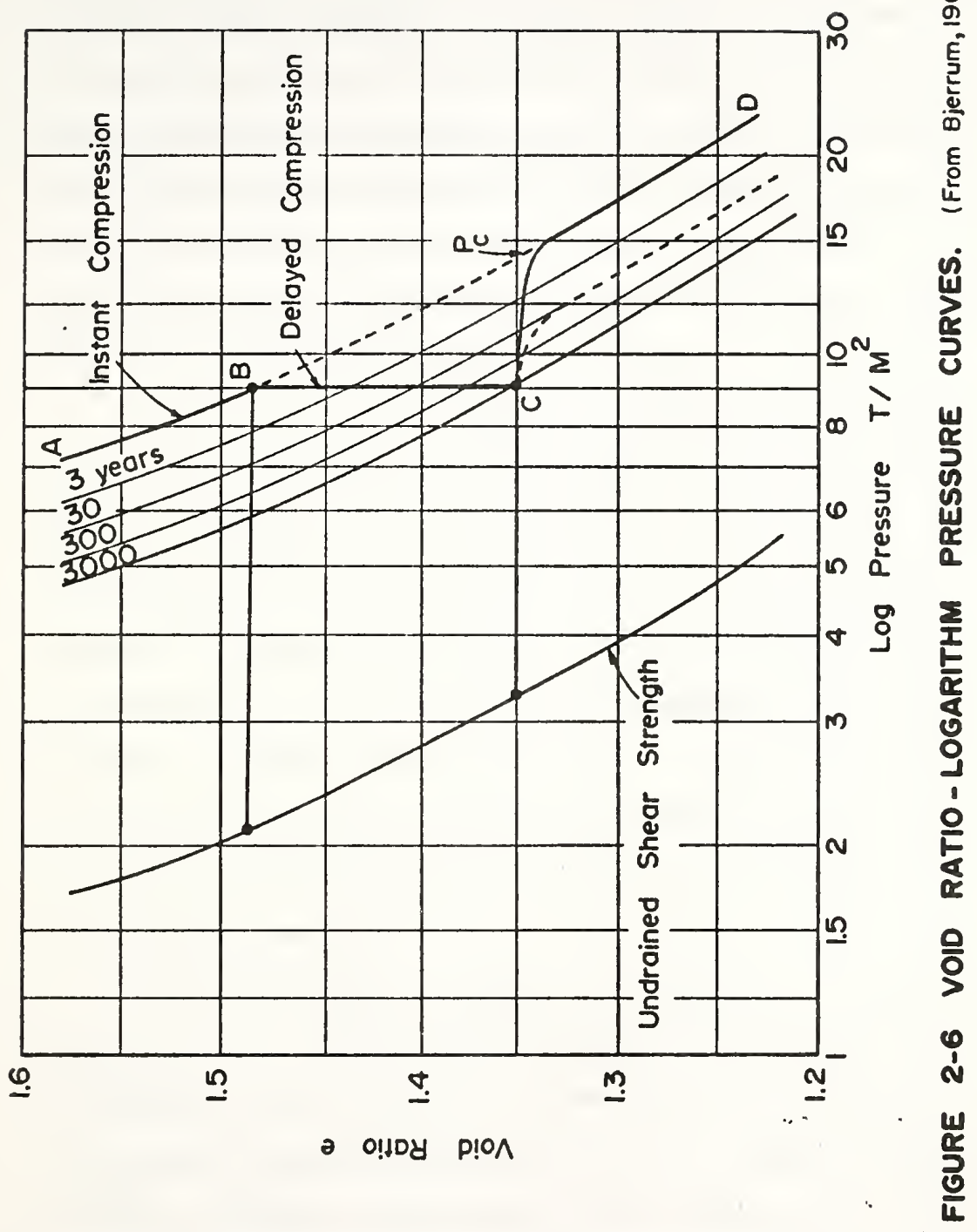


2.5 Field Observations of the Preconsolidation Effect

In recent years several test embankments have been instrumented and the effects of the preconsolidation pressure in soft clays observed. In some cases it has been possible to take advantage of this effect within the design procedure. The clay particle bonding results in small deflections and small excess pore pressures which dissipate rapidly when the applied pressure is less than some critical value. When this pressure is exceeded deformations are large, pore pressures are large and dissipation slow.

Such effects were reported by Höeg et al. (1969) when two field load tests were performed on a soft quick Norwegian clay. Piezometers in the foundation soil showed a gradual build-up for low embankment loads until a critical stress level was attained, after which a much higher rate of increase was observed. Vertical settlements for low loads increased linearly and were largely recoverable. Beyond the critical stress the load displacement curves started to bend over and the time dependent settlements accumulated at a much higher rate.

Bjerrum (1972) as leader for Session I - Embankments on soft clays at the Purdue Conference on the Performance of Earth-Supported Structures, summarized the conference papers on preconsolidation pressure effects. Papers by Moh et al., (1972) and Holtz and Lindshog (1972) demonstrate respectively, behavior when pressures are less than $p_{c q}$ with pore pressures 
small and dissipation rapid, and greater than $\mathrm{p}_{\mathrm{cq}}$ when pore pressures are large and dissipate slowly. These effects are also evident in plots of pore pressure measurements under low and high embankments reported by Elias and Storch (1970). The quasi-preconsolidation effect may also explain results such as those obtained by Rico et al. (1969), in which settlements observed under three meter high embankments were much smaller than predicted. In such a case the applied loading probably did not exceed the critical pressure.

\subsection{Characteristics of the Quasi-preconsolidation Pressure}

Compressibility: As has already been noted and illustrated in Figures 2.4 and 2.5 , the existence of the quasi-preconsolidation effect greatly affects the compressibility of a clay after it has experienced a period of time under constant effective stress. The soil is capable of carrying some additional load with minimal deformation. Further increase in loading will exceed the critical pressure rupturing the interparticle bonding and deformations will revert to the virgin compression line.

Coefficient of Consolidation: When a pressure increment is applied to a soil exhibiting a quasi-preconsolidation effect such that $p_{c q}$ is just exceeded, an extremely large reduction in the coefficient of consolidation $c_{v}$ is observed. Figure 2.7 from Altschaeffl (1960) demonstrates this phenomenon for 


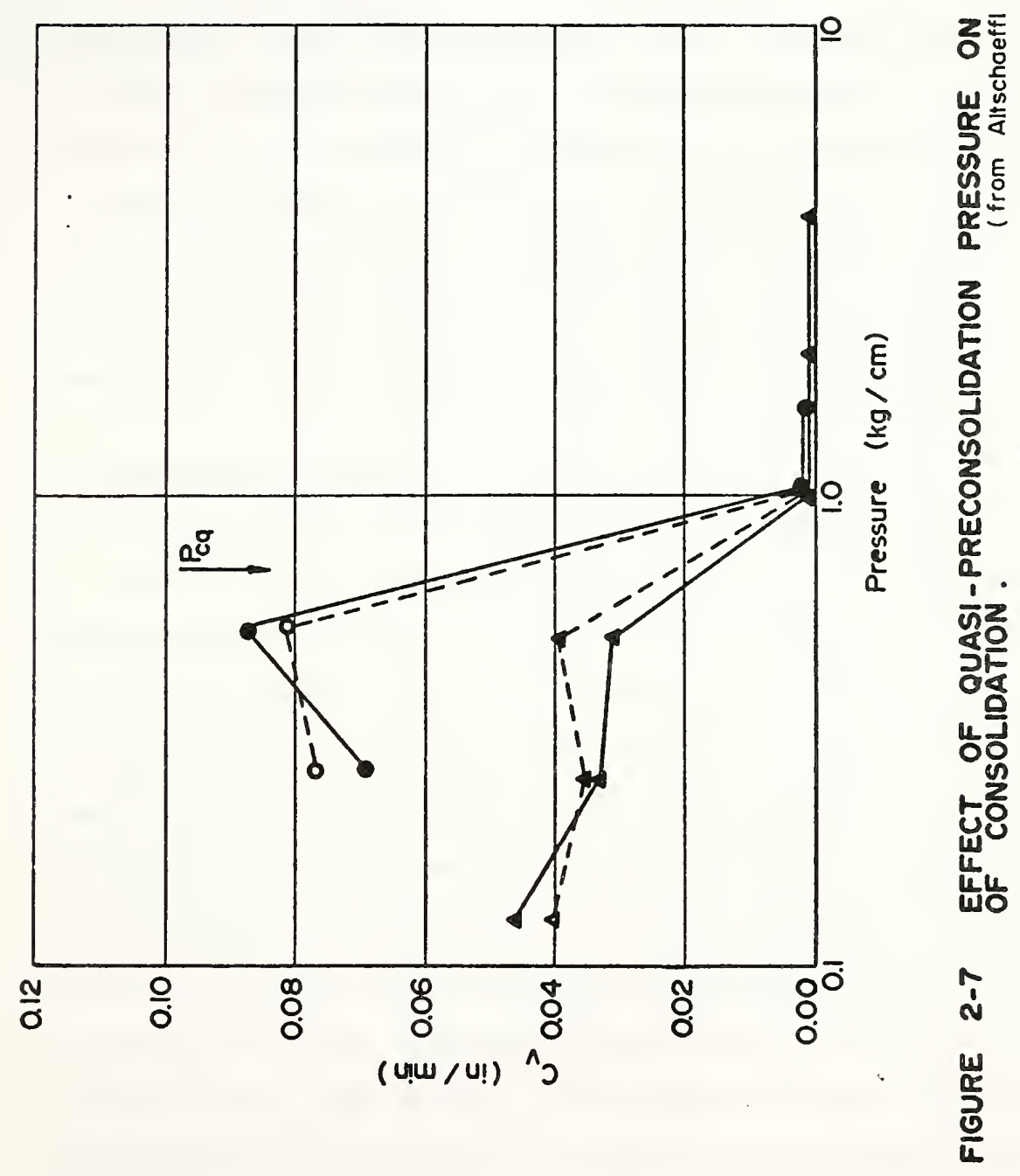


two tests on a sedimented soil. Similar effects were observed in the laboratory by Leonards and Ramiah (1960) and by Höeg, et al. (1969) in the field, where rates of pore pressure dissipation were rapid when pressures were less than $\mathrm{p}_{c q}$, and slow when $\mathrm{p}_{c q}$ was exceeded.

Duration of Load: Narain et al. (1969) performed tests on a highly plastic organic clay. They consolidated several samples to a pressure of 4 tons/sq.ft. and allowed the load to remain constant for different periods of time up to 80 days. Continuing the loading using a load increment ratio of $1 / 16$ they found the quasi-preconsolidation pressure to be directly proportional to the duration of the loading.

Consolidation Pressure: Leonards and Altschaeffl (1964) related the magnitude of the quasi-preconsolidation bonding to the initial interparticle spacing and hence to the effective overburden pressure. A compilation of available data on the magnitude of the quasi-preconsolidation pressure effect is shown in Figure 2.8 and shows a remarkable agreement between many very different soil deposits. The conclusion which can be drawn from this essentially linear plot is that for many soil deposits a pressure increment of approximately 40 percent of the effective overburden pressure can be applied without expecting compression to occur along the virgin curve. Moh et al. (1972) report a higher preconsolidation-overburden ratio of 1.8 for the soft Bangkok clay, 


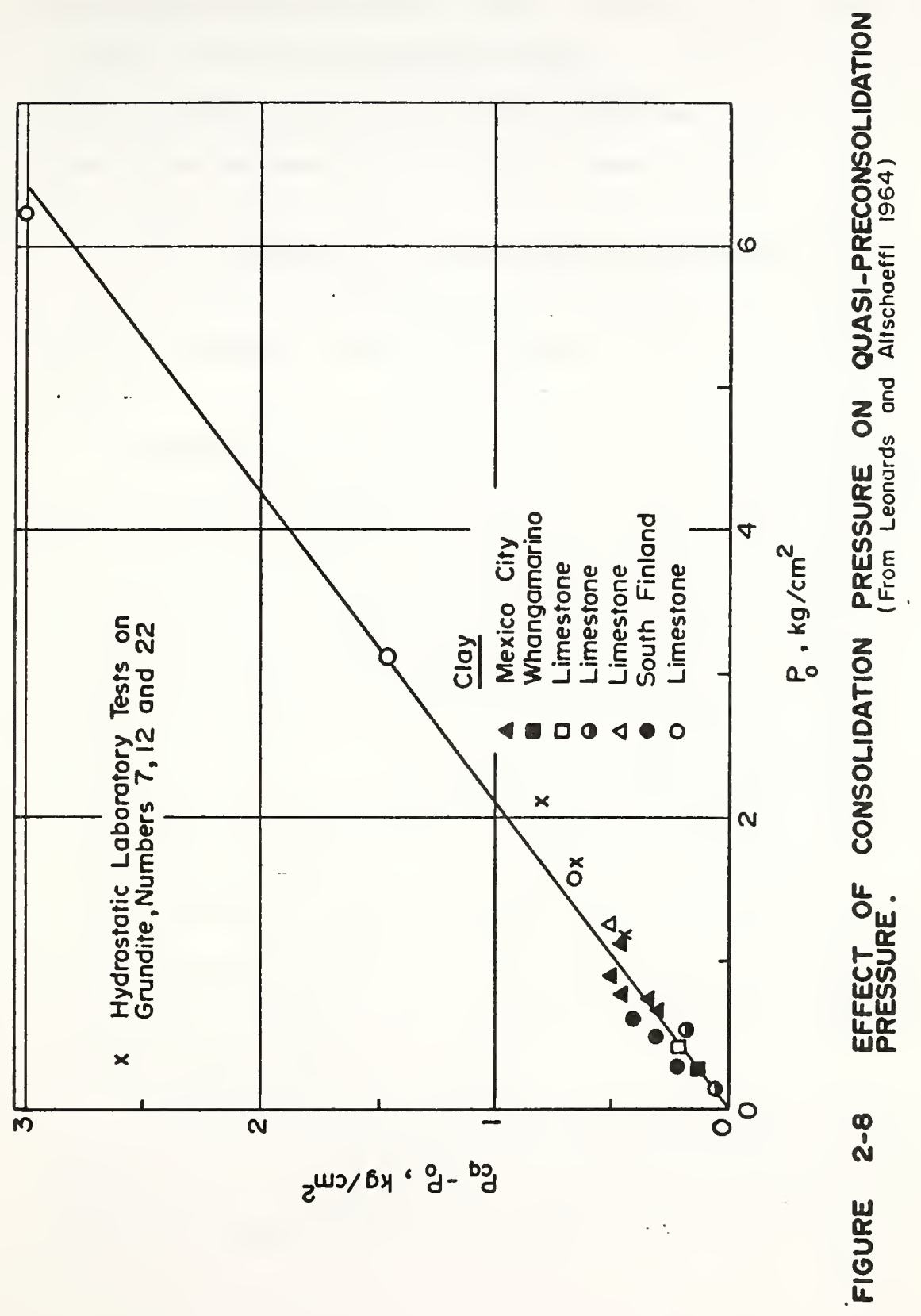


while Bjerrum (1972) cites a lower value of 1.2-1.3 for the very soft clays at Vasby, Sweden. Narain et al. (1969) also found a linear relationship between the quasi-preconsolidation pressure and the effective overburden pressure in which the slope depended on the load increment ratio.

2.7 Origin of the Quasi-preconsolidation Effect

A variety of factors has been proposed to explain the physio-chemical bases for the quasi-preconsolidation pressure.

Leonards and Altschaeff1 (1964) formulated a mechanism for the compression of a clay soil and for the formation of the quasi-preconsolidation pressure effect. During a period of time when a clay is subjected to constant applied stresses, water molecules become orientated in the vicinity of the edge-to-face contact points. Particles slowly displace or creep into "the most efficient arrangement possible from the standpoint of bond strength." The magnitude of this strength depends on the initial interparticle spacing which is related to the effective overburden pressure. The mineral skeleton can now sustain pressure increments with very little deformation until sliding of the particles is again initiated at the quasi-preconsolidation pressure.

Terzaghi in 1941 postulated the quasi-preconsolidation effect to be a consequence of loading rates and variation of viscosity of pore water with distance from the particle. 
Lambe (1960) indicates that particle cementation can result from chemical weathering when ferric oxides which are active comenting agents are present.

Moum and Rosenqvist (1957) suggest another type of chemical weathering which causes a change in the minerology of the upper clay layers, usually the formation of increased amounts of montmorillonites. Root holes and fissures allow oxygen rich pore water into the clay where oxidation of mica to montmorillonite occurs. Increased plasticity leads to increased shear strengths.

Bjerrum and wu (1960), during investigation of fundamental shear-strength properties on a Swedish marine plastic clay, observed a preconsolidation effect and concluded that rigid cementation bonds existed between the particles in the undisturbed clay. They believed the bonds to be the result of chemical changes over a geological time, and possibly associated with a period when the clay was submerged at great depth below sea level.

Results from tests performed by Kenny on a quick clay from Labrador indicated strong cementation bonding by iron compounds, (Bjerrum, 1967). Samples which were permeated with a chemical which dissolved cementing agents such as carbonates, gypsum and iron compounds, showed preconsolidation pressures only 40 percent of the magnitude of those from untreated specimens. 
In marine clays, the exchangeable ions attached to the surface of the clay mineral particle are predominantly sodium cations $\mathrm{Na}^{+}$. Substitution of Calcium $\mathrm{Ca}^{++}$, Magnesium $\mathrm{Mg}^{++}$, Aluminum $\mathrm{Al}^{+++}$, Ferrous $\mathrm{Fe}^{++}$, Ferric $\mathrm{Fe}^{+++}$, or Potassium $\mathrm{K}^{+}$ ions for the sodium ion leads to an increased plasticity index and shear strength. The exchange cations result from chemical weathering of felspar, mica or chlorite by an acidic pore water.

Thus, it seems apparent that several different factors may be capable of producing the observed quasi-preconsolidation pressure and it would be speculative to assign a single cause for the formation of the effect.

\subsection{Objectives of Study}

From the revicw presented, two important conclusions may be drawn. First, the quasi-preconsolidation effect is a real phenomenon which has been observed both in the laboratory and in the field. It has a significant effect on the time-rate and magnitude of primary consolidation, causing normally consolidated deposits to behave as though overconsolidated. Second, it is noted that the analyses and controlled experiments conducted in the past pertain to onedimensional conditions exclusively. In many instances in the field conditions are clearly not one-dimensional. This suggests a need to investigate the quasi-preconsolidation phenomenon and its effects in a more generalized frame of reference. 
The objectives of this study are, therefore:

1. To formulate an experimentally derived model of the quasi-preconsolidation effect under. generalized two-dimensional conditions.

2. To incorporate the quasi-preconsolidation effect into the prediction of deformations and stresses during primary consolidation, for complex two-dimensional boundary and loading conditions. The finite element method is employed as the analytical solution procedure. 
3. EXPERIMENTAL PROCEDURE FOR LABORATORY TESTS

\subsection{Introduction}

In order to formulate a two-dimensional description of the quasi-preconsolidation effect a laboratory study was performed consisting of a series of triaxial compression tests on clay soils in which a quasi-preconsolidation pressure $\left(\mathrm{p}_{c q}\right)$ had already been established. Triaxial test samples were cut from a block of artificially sedimented soil and a quasi-preconsolidation pressure allowed to develop by confining the samples under a constant effective stress for approximately twenty-three days. This pressure, under which the quasi-preconsolidation pressure is allowed to develop, is denoted herein the $q$-consolidation pressure. The time during which it acts is denoted the q-consolidation time. Drained compression tests along a variety of different stress paths were then performed. Descriptions of the apparatus, preparation and testing procedures are given in the following sections and in Appendix A.

\subsection{Soil Studied}

A commercially available soil, Grundite, processed by the Illinois Clay Products Company was used for the laboratory study. Its clay fraction is primarily illite (01sen 
and Langfelder 1965). Classification properties are given in Figure 3.1 and the results of hydrometer tests in Figure 3.2. The advantage of using such a commercial clay is that large quantities with minimal variation of the material properties can be obtained.

\subsection{Sedimentation Samples}

The clay samples to be ultimately tested under triaxial conditions were initially prepared by a one-dimensional sedimentation process in $31 / 2$ inch diameter lucite tubes. The loading frame, in which very slow rates of sedimentation can be achieved, and the sedimentation equipment are described in Appendix A.1. All samples were prepared in an identical manner, using the same proportions of grundite, water, dispersant and flocculant. Mixing and deairing periods were also constant. Sedimentation samples were initially loaded in the frame at a very slow rate which was then increased such that a final pressure of 11.45 psi was reached in approximately three weeks. Tests on the homogeneity of the samples were made and are described along with a detailed description of the preparation procedure in Appendix A.2.

\subsection{Triaxial Samples}

Triaxial test specimens of standard dimensions were cut from the sedimented soil described in the previous section. Details of the procedure are given below. It was then 


\title{
GRUNDITE SOIL
}

\author{
Illinois Clay Products Compony \\ $L L=56$ \\ $P L=32$ \\ $P I=24$
}

$\%$ Clay $=68 \quad$ Primarily Illite

$S G=2.79$

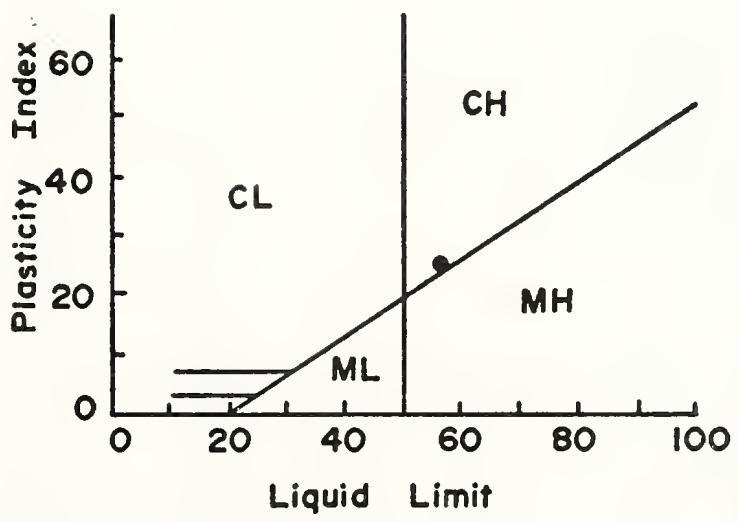

FIGURE 3.1 CLASSIFICATION PROPERTIES OF GRUNDITE . 


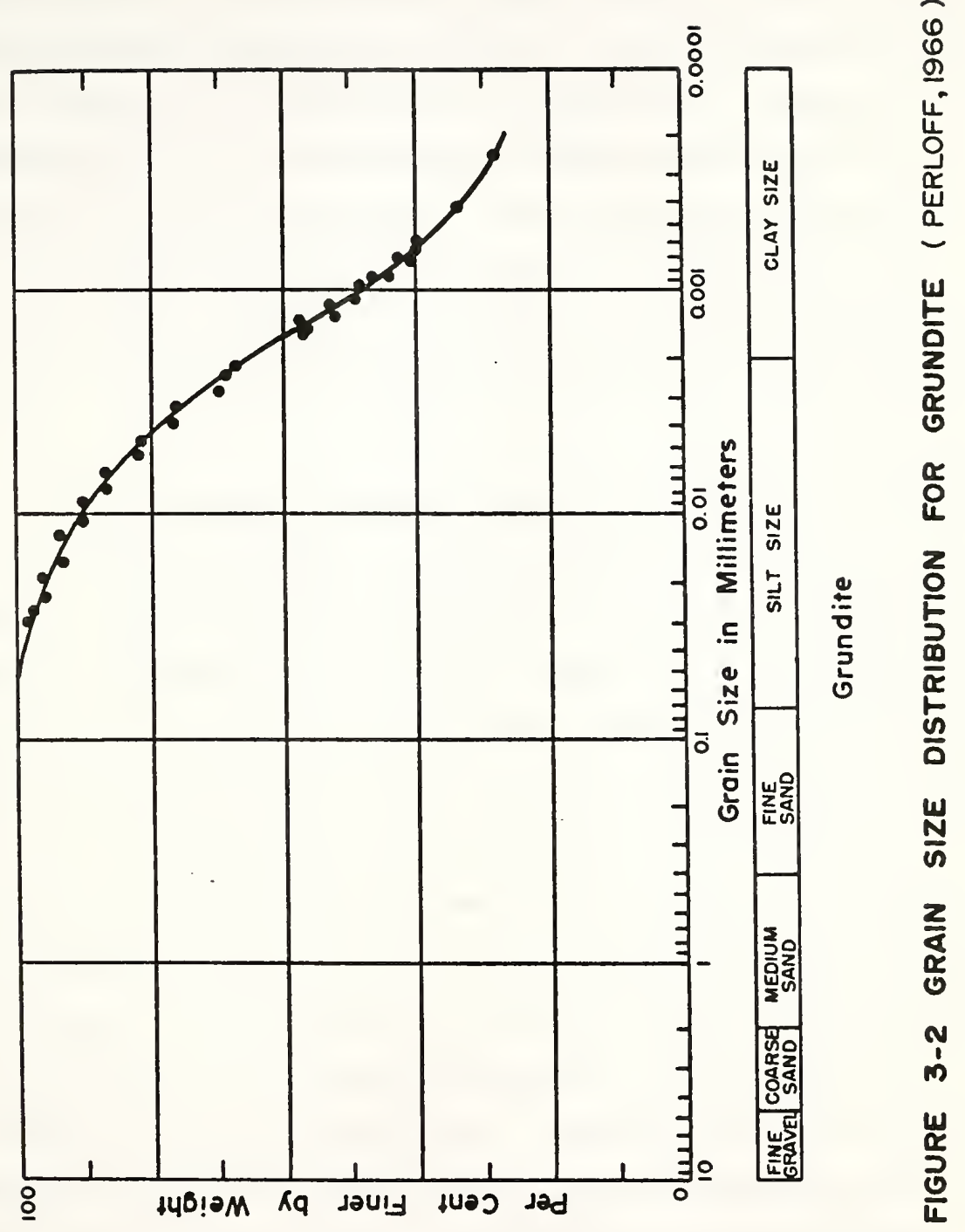


desired to isotropically load the sample and maintain a constant cell confining pressure for a period of approximately three weeks. $\Lambda$ set-up whereby eight triaxial cells could be simultaneously loaded was designed. The confining pressure was supplicd via a laboratory air source with a back up nitrogen tank for use should the primary source fail to maintain the desired pressure. This triaxial cell set-up is described in detail in Appendix A.3.1. Details of the triaxial cells, the constant strain rate testing machine and the recorders used are given in Appendices A.3.2 and A. 3.3.

The laboratory sedimented sample was extruded from the lucite tubc by removing the base and porous stone and pushing the sample out with the piston. The sample was approximately 4 inches high, with a unit weight of 112 pcf and a void ratio of 1.57 . The sample was trimmed using the soil lathe shown in Figure 3-3 to a right circular cylinder, 1.4 inches in diameter, and 2.9 inches high. Slotted filter paper was placed around the sample to facilitate drainage, and deaired saturated porous stones were placed on each end. The sample with top platen was mounted on the cell pedestal and enclosed with two rubber membranes, held in place by 0-Rings or strips of Dental Dam. Drainage lines were all carefully filled with water taken from the sedimentation tube with the same chemical composition as the sample pore fluid. The triaxial cell was screwed into place and filled 


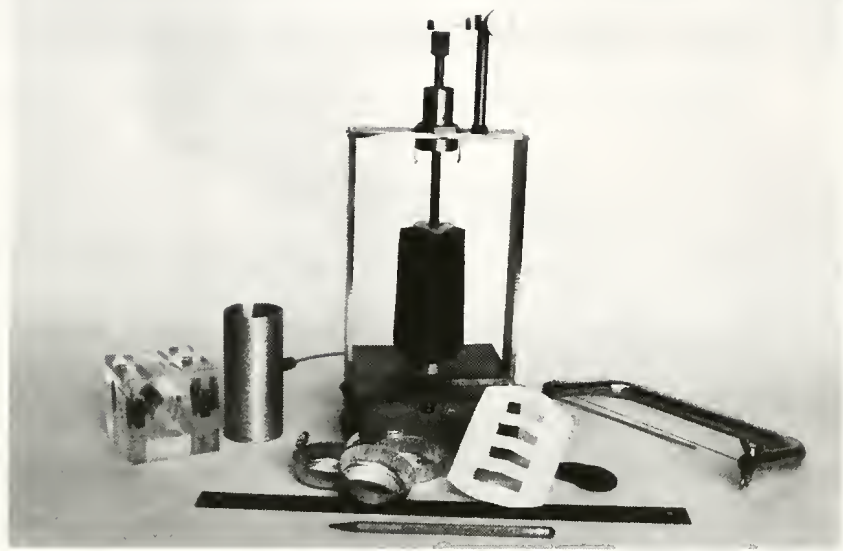

FIGURE 3-3 TRIAXIAL SPECIMEN PREPARATION EQUIPMENT. 
with distilled water. A $1 / 2$ inch layer of S.A.E. 40 oil was placed at the top of the cell to insure piston lubrication during the long loading period.

The triaxial cell was then connected into the system and a burette attached to the drainage lines. The confining pressure was increased over a period of two days to the desired value and the sample allowed to remain under this constant pressure for approximately twenty three days. Burette levels were read and recorded regularly.

\subsection{Definitions}

Prior research on the quasi-preconsolidation effect in clay soils has been carried out under conditions of one dimensional loading and drainage. In such a test only one stress parameter, the vertical pressure $p$, and one strain parameter, the vertical strain $\varepsilon_{v}$ or the void ratio e, are required for complete recording of the test behavior, usually in the form of an e - $\log \mathrm{p}$ plot. (Leonards and A1tschaeff1 1964).

In this work the effect has been studied using the more versatile triaxial test apparatus, in which both the vertical and radial stresses can be varied. It is assumed that these are respectively equal to the major and minor principle stresses and that the tangential stress is always the intermediate principle stress and is equal in magnitude to the radial stress (Perloff and Pombo 1969). The axial stress is equal to the total vertical load divided by the sample 
area while the radial stress is equal to the confining fluid pressuro. A diagram illustrating the triaxial test stress state is given in Figure 3.4 .

Stress parameters used for the representation of the triaxial test results were based on those recommended by Roscoe and Burland (1968) and are derived below.

A stress increment is defined as the difference between the final and the initial stress levels

$$
\begin{aligned}
& \text { i.e. } \Delta \sigma_{j}=\sigma_{j_{\text {final }}}-\sigma_{j_{\text {initial }}} j=1,2,3 \\
& \text { or } \Delta \sigma_{j}=\sigma_{j_{f}}-\sigma_{j_{i}}
\end{aligned}
$$

Octahedral Normal Effective Stress $\bar{\sigma}_{\text {oct }}$

$$
\begin{aligned}
\bar{\sigma}_{\text {oct }} & =\left(\bar{\sigma}_{1}+\bar{\sigma}_{2}+\bar{\sigma}_{3}\right) / 3 \\
\Delta \bar{\sigma}_{\text {oct }} & =\bar{\sigma}_{\text {oct }}{ }_{f i n a l}-\bar{\sigma}_{\text {oct }} \text { initial } \\
& =\left(\bar{\sigma}_{1_{f}}+\bar{\sigma}_{2_{f}}+\bar{\sigma}_{3_{f}}\right) / 3-\left(\bar{\sigma}_{1_{i}}+\bar{\sigma}_{{ }_{i}}+\bar{\sigma}_{3_{i}}\right) / 3 \\
& =\left(\Delta \bar{\sigma}_{1}+\Delta \bar{\sigma}_{2}+\Delta \bar{\sigma}_{3}\right) / 3
\end{aligned}
$$

For triaxial test results this reduces to

$$
\Delta \bar{\sigma}_{\text {oct }}=\left(\Delta \bar{\sigma}_{1}+2 \Delta \bar{\sigma}_{3}\right) / 3
$$




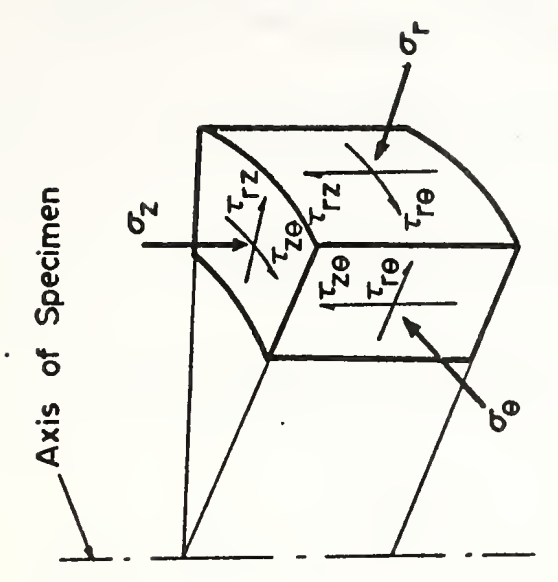

$\frac{5}{5}$

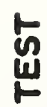

동

$\frac{2}{\frac{2}{2}}$

ธ
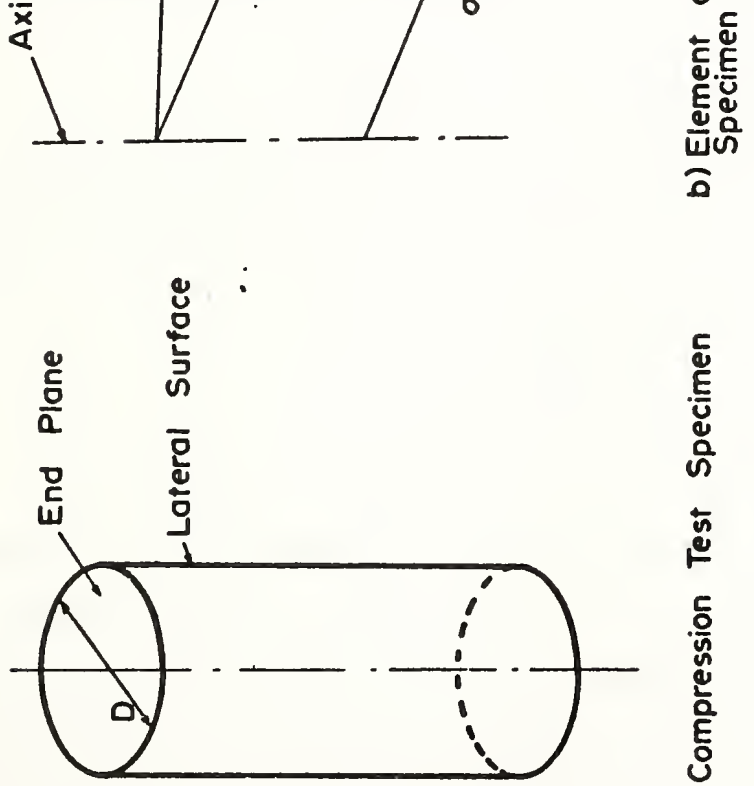

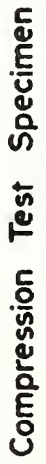

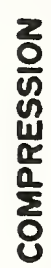

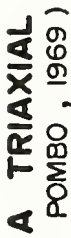

$2 \frac{0}{2}$

I

튼

$\vec{x}$

(1)

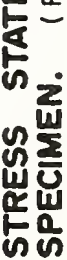

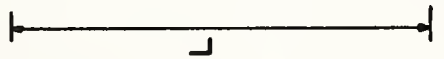

$\frac{0}{x}$
$\frac{0}{0}$
$\frac{0}{0}$

n

$\frac{w}{\frac{w}{0}}=\cdots$ 
Octahedral Shear Stress

$$
\begin{aligned}
\tau_{\text {oct }} & =\sqrt{\left(\bar{\sigma}_{1}-\bar{\sigma}_{2}\right)^{2}+\left(\bar{\sigma}_{2}-\bar{\sigma}_{3}\right)^{2}+\left(\bar{\sigma}_{3}-\bar{\sigma}_{1}\right)^{2}} \\
& =\tau_{\text {oct }} t_{f i n a l}-\tau_{\text {oct }} \text { initial } \\
& =\sqrt{\left(\bar{\sigma}_{1 f}-\bar{\sigma}_{2 f}\right)^{2}+\left(\bar{\sigma}_{2 f}-\bar{\sigma}_{3 f}\right)^{2}+\left(\bar{\sigma}_{3 f}-\bar{\sigma}_{1 f}\right)^{2}} \\
& -\sqrt{\left(\bar{\sigma}_{1 i}-\bar{\sigma}_{2 i}\right)^{2}+\left(\bar{\sigma}_{2}-\bar{\sigma}_{3 i}\right)^{2}+\left(\bar{\sigma}_{3 i}-\bar{\sigma}_{1 i}\right)^{2}}
\end{aligned}
$$

For triaxial test results this reduces to

$$
\Delta \tau_{\text {oct }}=\frac{\sqrt{2}}{3}\left(\Delta \bar{\sigma}_{2}-\Delta \bar{\sigma}_{3}\right)
$$

A useful parameter for designating certain stress paths is the octahedral effective stress ratio.

$$
\eta=\frac{\Delta \tau_{\text {oct }}}{\Delta \bar{\sigma}_{\text {oct }}}
$$

As with the stress state, three principle natural

strains can be defined. In compression tests the axial and radial strains are respectively the major and the minor principle strains, with the assumption that $\varepsilon_{1}>\varepsilon_{2}=\varepsilon_{3}$. The two strain increment parameters chosen were the compressive volumetric strain increment $\delta \mathrm{v}$ and the deviatoric (shear distortional) strain increment $\delta \varepsilon$, where

$$
\begin{aligned}
& \delta v=-\frac{\Delta V}{V}=-\frac{\Delta e}{1+e}=\delta \varepsilon_{1}+\delta \varepsilon_{2}+\delta \varepsilon_{3} \\
& \delta \varepsilon=\delta \varepsilon_{1}-\delta v / 3
\end{aligned}
$$


where $\Delta V$ and $\Delta e$ are the changes in volume and void ratio. For the triaxial test these reduce to

$$
\begin{aligned}
& \delta \mathrm{v}=\delta \varepsilon_{1}+2 \delta \varepsilon_{3} \\
& \delta \varepsilon=\frac{2}{3}\left(\delta \varepsilon_{1}-\delta \varepsilon_{3}\right)
\end{aligned}
$$

and

\subsection{Triaxial Testing}

Triaxial tests along four different types of stress path were carried out. These paths are illustrated in Figure 3.5 and are designated as follows

Type 1 Constant chamber pressure tests

Type 2 Isotropic loading tests

Type 3 Constant $\bar{\sigma}_{\text {oct }}$ tests

Type 4 Constant $n$ tests

The constant chamber pressure tests, Type 1, were run in the Engineering Laboratory Equipment (E.L.E.) frame described in Appendix A.3.3. In the special case where the test chamber pressure was equal to $q_{c}$, the confining pressure under which the quasi-preconsolidation effect was allowed to develop, an extension piece of tubing was inserted between the cell and the triaxial set-up and the cell placed in the E.L.E. frame. When the test confining pressure was different from $q_{c}$, the cell was connected independently to one of the air sources and the chamber pressure changed slowly in increments over a period of several hours or days, to the desired test pressure. The load-cell was carefully calibrated 
41

Type 1

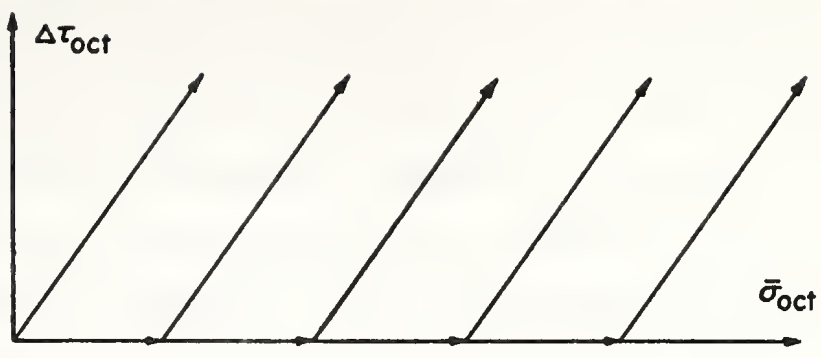

Type 2

$\Delta \tau_{\text {oct }}$
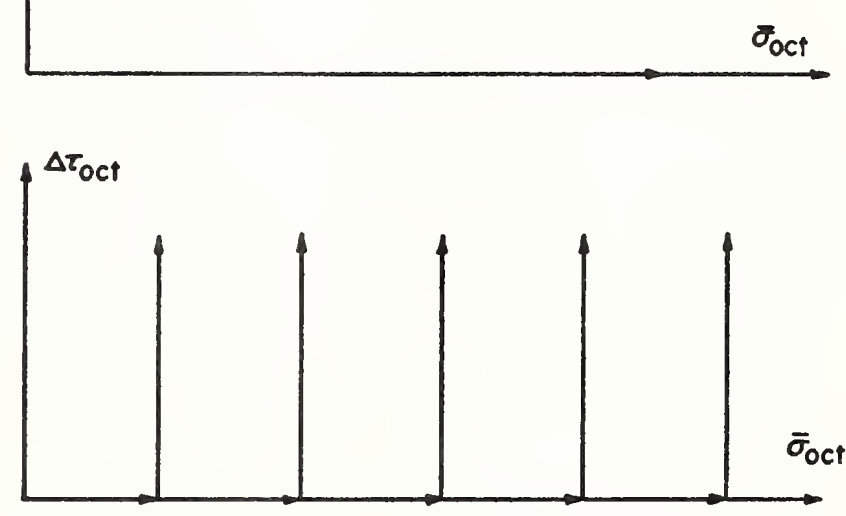

Type 4

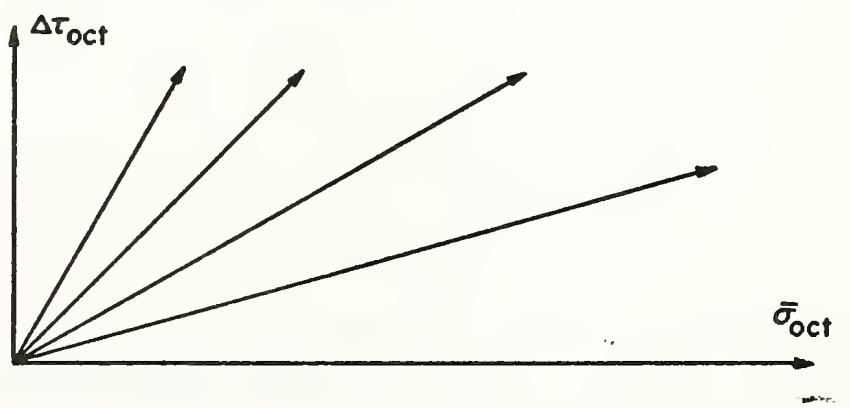

FIGURE 3-5 TRIAXIAL TEST STRESS PATHS. 
using dead weight and the sample volume change burette also calibrated. This simple apparatus shown in Figure 3.6 consisted of a 2 cc burette connected to the sample drainage lines. A pressure transducer measured the weight of the column of water and the output was recorded on the same chart as the load cell readings. Most of the tests were run at a constant rate of $4.0 \times 10^{-5}$ inches per minute, which is approximately one percent strain in twelve hours. At the end of a test water contents at six different levels within the sample were obtained.

A computer program was written to reduce the triaxial test data, and is described in detail in Appendix $\mathrm{C}$ where input format, flow chart, program listing and an example problem are given.

The Isotropic loading tests (Type 2) were carried out in the adapted Geonor cell described in Appendix A.3.2 and illustrated in Figure A.15. After the $q_{c}$ confinement period the Geonor cell was independently connected to one of the sources and the confining pressure increased incrementally at regular intervals. Burette levels were noted at the end of each loading period and output from the LVDT was continuously recorded on the Varian machine.

The constant $\bar{\sigma}_{\text {oct }}$ and constant $n$ tests (Types 3 and 4) were run using standard Geonor cells in a special incremental loading frame. The set-up is shown in Figure 3.7 . The cell confining pressure was supplied, as in all the 


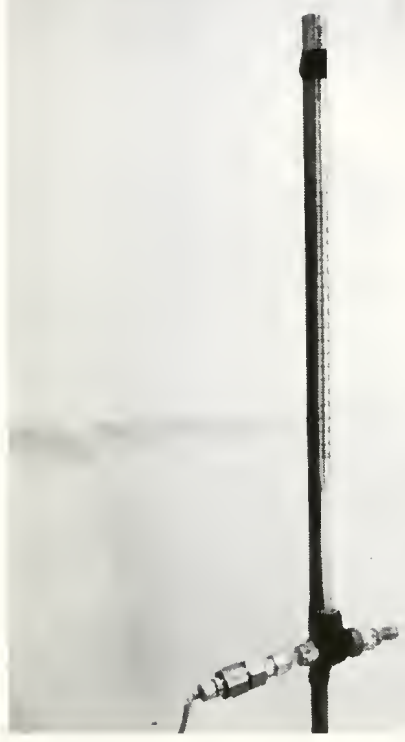

FIGURE 3-6 BURETTE WITH PRESSURE TRANSDUCER ATTACHMENT. 


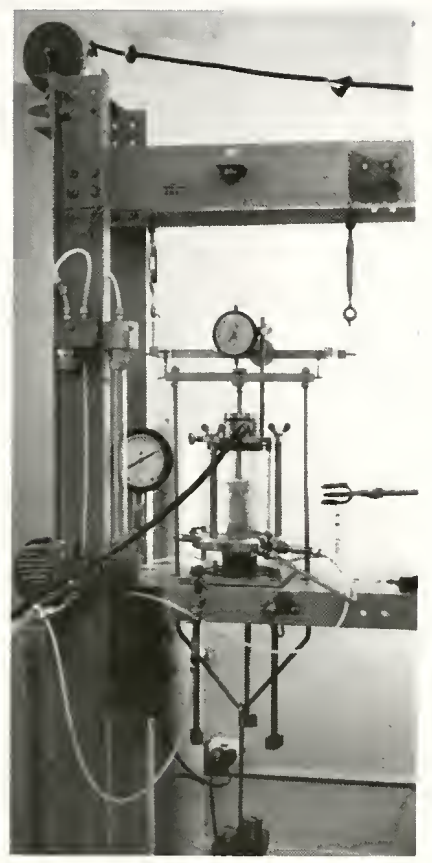

FIGURE 3-7 INCREMENTAL LOADING FRAME. 
tests, by compressed air, and controlled by means of a regulator with attached dial gauge. The axial stress was applied incrementally by adding weights to an initially balanced hanger bearing on the cell piston. For the constant $\bar{\sigma}_{\text {oct }}$ stress path it is necessary that

$$
\Delta \bar{\sigma}_{\text {oct }}=\frac{\Delta \bar{\sigma}_{2}+2 \Delta \bar{\sigma}_{3}}{3}=0
$$

or

$$
\Delta \bar{\sigma}_{3}=-\Delta \bar{\sigma}_{1} / 2
$$

This test was conducted by increasing the axial stress by some increment and decreasing the confining pressure by half as much. In Type 4 tests similar computations were carried out for each $n$ value. For example

$$
\begin{aligned}
\eta=1 & =\frac{\Delta \tau \text { oct }}{\Delta \bar{\sigma}_{\text {oct }}} \\
\therefore \quad \frac{\sqrt{2}}{3}\left(\Delta \bar{\sigma}_{1}-\Delta \bar{\sigma}_{3}\right) & =\frac{1}{3}\left(\Delta \bar{\sigma}_{1}+2 \Delta \bar{\sigma}_{3}\right) \\
& \text { or } \quad \Delta \bar{\sigma}_{3}=0.121 \Delta \bar{\sigma}_{1}
\end{aligned}
$$

In this case the confining pressure was increased by an amount equal to 0.121 times the axial stress increment. A Type 3 test is, in fact, a special case of Type 4 with $\eta=\infty$. Since pistons of smaller cross sectional area than the sample were used the load $L$ required to give a desired vertical stress $\bar{\sigma}_{v}$ is given by 


$$
L=\bar{\sigma}_{v} A_{s}-\bar{\sigma}_{c}\left(A_{s}-A_{p}\right)
$$

where $\bar{\sigma}_{c}$ is the cell confining pressure

$A_{s}$ is the sample area

$A_{p}$ is the piston area. 


\section{RESULTS AND DISCUSSION OF QUASI TESTS}

\subsection{Introduction}

Twenty-seven triaxial test specimens were prepared and allowed to consolidate under constant confining pressures $q_{c}$ as described in Section 3.4. Ten samples were confined under a constant pressure of 16.7 psi, eight under 24.0 psi and the remaining nine under 30.0 psi. This period of isotropic consolidation, called the q-consolidation time, ranged from 20 to 27 days in all cases except test Number 21 , which was allowed to remain 44 days prior to testing.

All the grundite sedimentation samples were prepared in the same manner and all but Test Number 1 loaded to $50 \mathrm{~kg}$, in the sedimentation frame. The resulting specimens had a void ratio range of 1.52 to 1.62 . In the case of Test 1 the sedimentation sample was loaded to $30 \mathrm{~kg}$., with a resulting higher void ratio of 1.88 .

Three types of triaxial cells were used and are described in Section A.3.2. Twenty-two tests were performed in Geonor cells, four in the Wykeham-Farrance and one in the Testlab cell. Five tests were carried out with single drainage from the base of the sample, while the remaining twenty-two had both top and bottom drainage facilities. Test details are given in Table 4.1 . 
TABLE 4.1

q-Consolidation Pressures and Times

\begin{tabular}{|c|c|c|c|c|c|}
\hline Test & $\mathrm{Ce} 11$ & $\begin{array}{c}\text { Double } \\
\text { or } \\
\text { Single } \\
\text { Drainage }\end{array}$ & $\begin{array}{l}\text { Void } \\
\text { Ratio }\end{array}$ & ${ }^{q_{c}}$ & $\begin{array}{r}\mathrm{q}_{\mathrm{c}} \text { Time } \\
\text { (days) }\end{array}$ \\
\hline 1 & Testlab & Single & 1.88 & 16.7 & 21 \\
\hline 2 & Wykeham & Double & 1.53 & 16.7 & 21 \\
\hline 3 & Geonor & Double & 1.55 & 16.7 & 24 \\
\hline 4 & Geonor & Double & 1.54 & 16.7 & 27 \\
\hline 5 & Geonor & Double & 1.61 & 16.7 & 25 \\
\hline 6 & Geonor & Double & 1.60 & 16.7 & 26 \\
\hline 7 & Geonor & Double & 1.62 & 16.7 & 20 \\
\hline 8 & Geonor & Single & 1.52 & 16.7 & 22 \\
\hline 9 & Geonor & Double & 1.61 & 16.7 & 22 \\
\hline 10 & Geonor & Double & 1.57 & 16.7 & 20 \\
\hline 11 & Geonor & Double & 1.53 & 24.0 & 25 \\
\hline 12 & Geonor & Double & 1.57 & 24.0 & 25 \\
\hline 13 & Wykeham & Double & 1.53 & 24.0 & 24 \\
\hline 14 & Geonor & Double & 1.55 & 24.0 & 21 \\
\hline 15 & Geonor & Single & 1.56 & 24.0 & 22 \\
\hline 16 & Geonor & Doub le & 1.55 & 24.0 & 26 \\
\hline 17 & Geonor & Double & 1.56 & 24.0 & 22 \\
\hline 18 & Geonor & Double & 1.61 & 24.0 & 25 \\
\hline 19 & Geonor & Double & 1.54 & 30.0 & 21 \\
\hline 20 & Geonor & Double & 1.54 & 30.0 & 27 \\
\hline 21 & Geonor & Single & 1.61 & 30.0 & 44 \\
\hline 22 & Geonor & Double & 1.60 & 30.0 & 21 \\
\hline 23 & Wykeham & Double & 1.57 & 30.0 & 22 \\
\hline 24 & Geonor & Double & 1.55 & 30.0 & 25 \\
\hline 25 & Wykeham & Single & 1.60 & 30.0 & 24 \\
\hline 26 & Geonor & Double & 1.62 & 30.0 & 22 \\
\hline 27 & Geonor & Double & 1.56 & 30.0 & 21 \\
\hline
\end{tabular}


The test results are summarized and interpreted in the following sections.

\subsection{The Triaxial Test Types}

Four different types of triaxial tests described in Section 3.6 were performed.

In summary, Type 1 were constant strain rate tests with constant confining pressures. Type 2 were isotropic tests using the adapted geonor cell with LVDT attachment in which the confining pressure was increased incrementally. Type 3 were incremental loading tests in which the confining pressure was decreased and the axial pressure increased so that a constant octahedral normal stress was maintained. Type 4 were also incremental loading tests in which the axial and confining stresses were altered so as to maintain a constant octahedral shear stress, normal stress ratio $n$.

Table 4-2 1ists the test numbers, types of tests performed, rates of loading, and $\mathrm{q}_{\mathrm{c}_{i}}$, the octahedral normal stress prior to increasing the shear stress.

\subsection{The q-Yield Surface}

The one-dimensional consolidation testing in which quasi-preconsolidation effects were observed has been discussed in Chapter 2 and typical e-log p plots of the behavior are shown in Figures 2.4 and 2.5 . The salient feature of the testing was the apparent formation of interparticle bonding during a rest or confinement period at constant effective stress, which enabled the soil to carry an additional loading 
TABLE 4.2

Test Types and Loading Rates

Test Type $q_{c}$

$q_{c_{i}}$

Loading Rate$$
1
$$

2

$$
3
$$$$
4
$$ \\ 4}

5

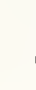

\section{7}

1116.7

21

16.7

16.7

16.7

16.7

$5.0 \times 10^{-4}$ inches/minute

31

16.7

$1.5 \times 10^{-4}$ inches/minute

42

16.7

16.7

16.7

$4.0 \times 10^{-5}$ inches/minute

$0.5 \mathrm{psi} / 2$ hours

51

16.7

$1.5 \times 10^{-4}$ inches/minute

$0.5 \mathrm{psi} / 3$ hours

$1.0 \mathrm{psi} / \mathrm{hour}$

$\begin{array}{lll}8 & 1 & 16.7\end{array}$

16.7

$1.5 \times 10^{-4}$ inches/minute

$\begin{array}{lll}9 & 1 & 16.7\end{array}$

101

16.7

$\begin{array}{ll}11 & 1 \\ 12 & 2\end{array}$

24.0

24.0

$13 \quad 1$

24.0

143

24.0

$\begin{array}{lll}16 & 4 & 24.0\end{array}$

$17 \quad 1$

24.0

$\begin{array}{lll}18 & 3 & 24.0\end{array}$

$19 \quad 1 \quad 30.0$

201

30.0

$21 \quad 1$

30.0

$22 \quad 2$

30.0

231

30.0

$24 \quad 1$

30.0

$25 \quad 1$

30.0

$26 \quad 4 ; 3$

30.0

30.0

18.2

19.7

30.0

24.0

24.0

25.5

24.0

25.0

30.0

30.0

35.0

30.0

$4.0 \times 10^{-4}$ inches/minute

$1.5 \times 10^{-5}$ inches/minute

$4.0 \times 10^{-5}$ inches/minute

$1.0 \mathrm{psi} / 12$ hours

$4.0 \times 10^{-5}$ inches/minute increase $\Delta \bar{\sigma}_{1} 1 \mathrm{psi} / 24$ hours increase $\Delta \bar{\sigma}_{1} 1 \mathrm{psi} / 24$ hours increase $\Delta \bar{\sigma}_{1} 1 \mathrm{psi} / 24$ hours $4.0 \times 10^{-5}$ inches/minute increase $\Delta \bar{\sigma}_{1} 1 \mathrm{psi} / 24$ hours $4.0 \times 10^{-5}$ inches/minute $4.0 \times 10^{-5}$ inches/minute $4.0 \times 10^{-5}$ inches/minute $1.0 \mathrm{psi} / 12$ hours $30.04 .0 \times 10^{-5}$ inches/minute $40.0 \quad 4.0 \times 10^{-5}$ inches $/$ minute 26.0 $4.0 \times 10^{-5}$ inches/minute 30.0 30.0 decrease $\Delta \bar{\sigma}_{3} 5 \mathrm{psi} / 24$ hours increase $\Delta \bar{\sigma}_{1} 4 \mathrm{psi} / 24$ hours 
with only small deformation. If this loading were increased beyond some critical pressure, the quasi-preconsolidation pressure, the bonds were ruptured and the e-log p plot reverted to the virgin curve. This was shown schematically in Figure 2.2. On Figure 2.8 are plotted the results of the three isotropic loading tests for different q-confining pressures. Although not directly comparable because of the isotropic q-confinement pressure the results do compare well with this field data.

Figures B.4 to B.41 for the triaxial tests performed in this study indicate a similar type of behavior. The origin in each plot represents the octahedral normal stress $q_{c_{i}}$ in the triaxial cell prior to increasing the shear stress. The axes denote stress increments from this "initial" state. For all the tests performed stress-strain curves are initially steep, i.e., the soil exhibits low compressibility, then change fairly abruptly to a more shallow (more compressible) slope. Al1 plots have the appearance of two straight lines with a transition curve, until large strains when failure ensues.

For each test the intersection of the two straight line portions was defined as the q-yield stress point. The vertical and lateral stresses at this point are known and from these the octahedral normal $\left(\Delta \bar{\sigma}_{\text {oct }}\right)$ and shear $\left(\Delta \tau_{\text {oct }}\right)$ stresses can be calculated. These are 1 isted in Table 4.3 , and are plotted along with Test Numbers and Stress-paths in Figures 4.1, 4.2, or 4.3, each figure corresponding to a specific q-consolidation pressure. Each plot depicts a curve which will be called the 
TABLE 4.3

q-Yield Stress Results

Test

Number

1

2

3

4

5

6

7

8

9

10

11

12

13

14

15

16

17

18

19

20

21

22

23

24

25

26

27
$\Delta \sigma_{\text {oct }}$

2.75

2.80

2.50

6.10

2.90

6.50

6.30

2.73

4.03

5.20

8.20

9.00

3.75

0.00

1.50

$-4.80$

4.47

6.00

5.23

8.89

4.66

11.50

5.10

11.50

0.81

2.88

11.30
$\Delta \tau_{\text {oct }}$

3.89

3.96

3.54

0.00

4.10

0.00

0.00

3.86

3.58

3.11

3.11

0.00

5.30

5.15

5.40

1. 20

4.90

4.60

7.40

5.50

6.59

0.00

7.20

2.12

6.80

7.20

$2.83=$ 


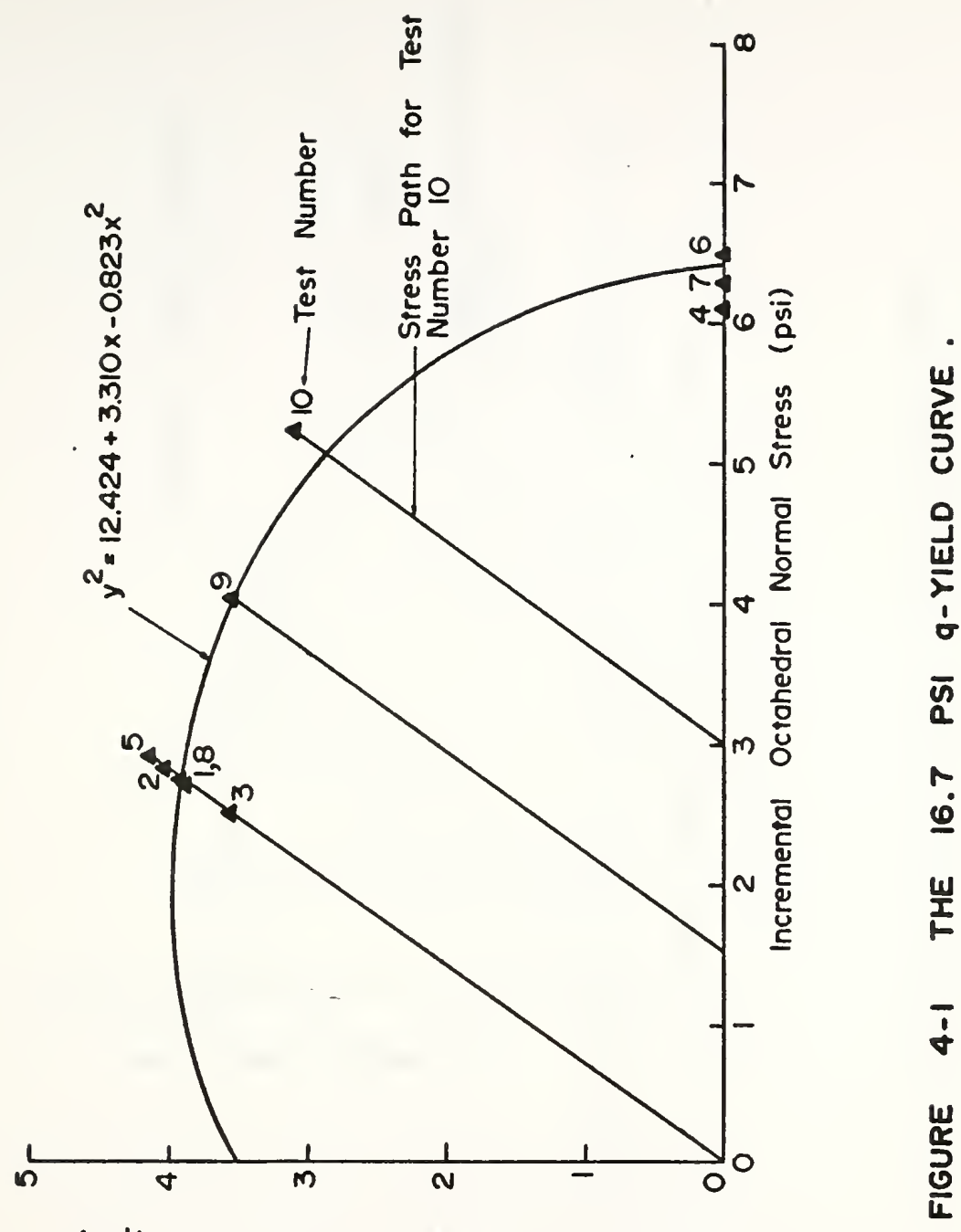

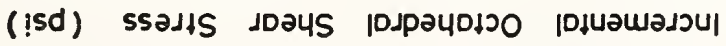




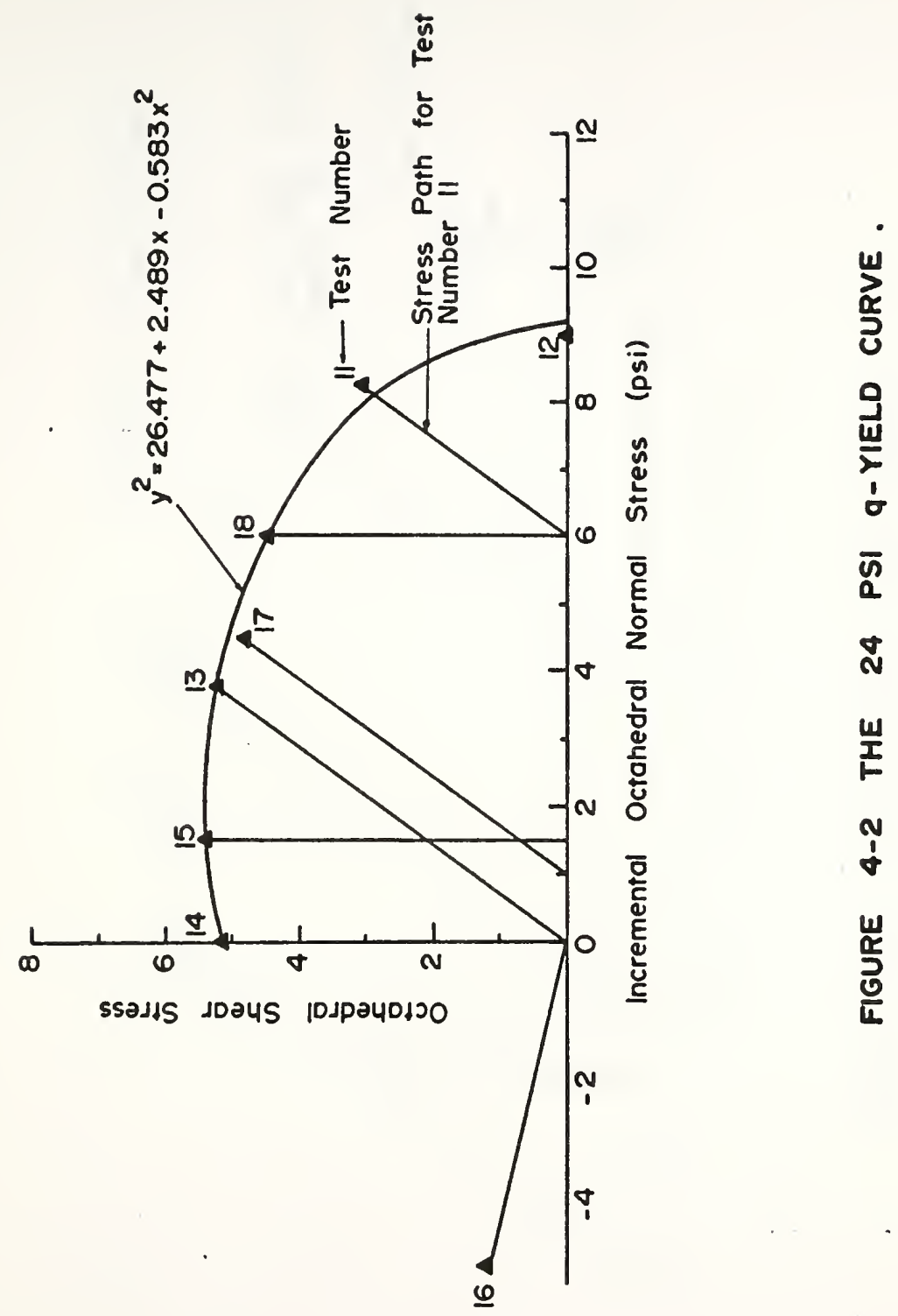




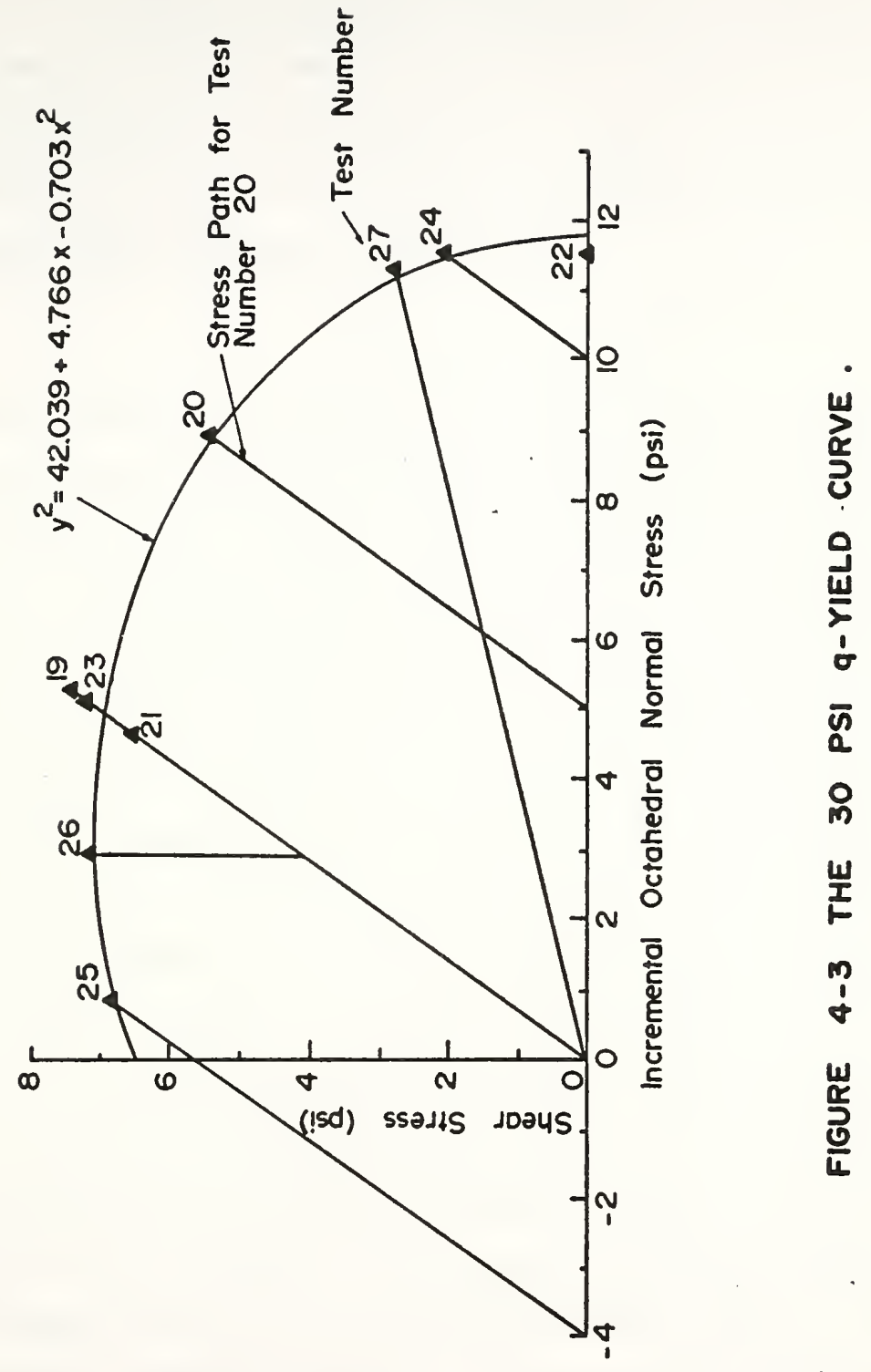


q-yield curve for that particular q-consolidation pressure.

A Stepwise Regression Program BMD2R, Purdue University Computer Science Center, was used to calculate the best-fit polynomials for the three sets of quasi data points. The resulting curves were ellipses displaced along the abscissa and having equations of the form

$$
y^{2}=C_{1}+C_{2} x+C_{3} x^{2}
$$

The values of the constants are given in Table 4.4. The "Best-fit" curves have been plotted with the data points in Figures $4.1,4.2$ and 4.3 , and are drawn together in Figure 4.4. It was then desired to formulate a single equation which would represent the q-yield curve for any q-consolidation pressure. The method is illustrated schematically in Figure 4.5. In Figure 4.4 straight lines radiating from the origin at angles $\alpha\left(0,5,10,20,30,40,54.7\right.$ and $\left.90^{\circ}\right)$ were constructed. The ordinates $\left(y_{\alpha}\right)$ of the points of intersection of these $\alpha$-lines and the three $q$-yield curves were noted. For the $\alpha=0$ line where the intercept ordinates are zero the abscissae values $\left(x_{\alpha}\right)$ were recorded and used instead. In Figure 4.6 these intercept values were plotted on their respective q-consolidation pressure lines, $16.7,24.0$ and 30.0 psi. Straight lines known as $\beta-1$ ines were then drawn through the points representing a particular $\alpha$. A least squares analysis was used to determine the best straight lines, and their slopes and intercept values with a 20 psi consolidation pressure line are given in Table 4.5. Since 
TABLE 4.4

Ellipse Constants for the q-Yield Curves

q-Consolidation
Pressure psi

$\begin{array}{ll}16.7 & 12.424 \\ 24.0 & 26.477 \\ 30.0 & 42.039\end{array}$

$\mathrm{C}_{1}$

$\mathrm{C}_{2}$

3.310

2.489

4.746
$\mathrm{C}_{3}$

$-0.823$

$-0.583$

$-0.703$

TABLE 4.5

Least-squares Parameters for $\beta-1$ ines

$\alpha-1$ ine angle

$$
0^{\circ}
$$

$5^{\circ}$

$10^{\circ}$

$20^{\circ}$

$30^{\circ}$

$40^{\circ}$

$55^{\circ}$

$90^{\circ}$
Slope of B-line

0.3885

0.0338

0.0661

0.1214

0.1620

0.1892

0.2280

0.2149
Intercept with

20 psi line

7.769

0.676

1.322

2.428

3.240

3.783

4.560

4.297 


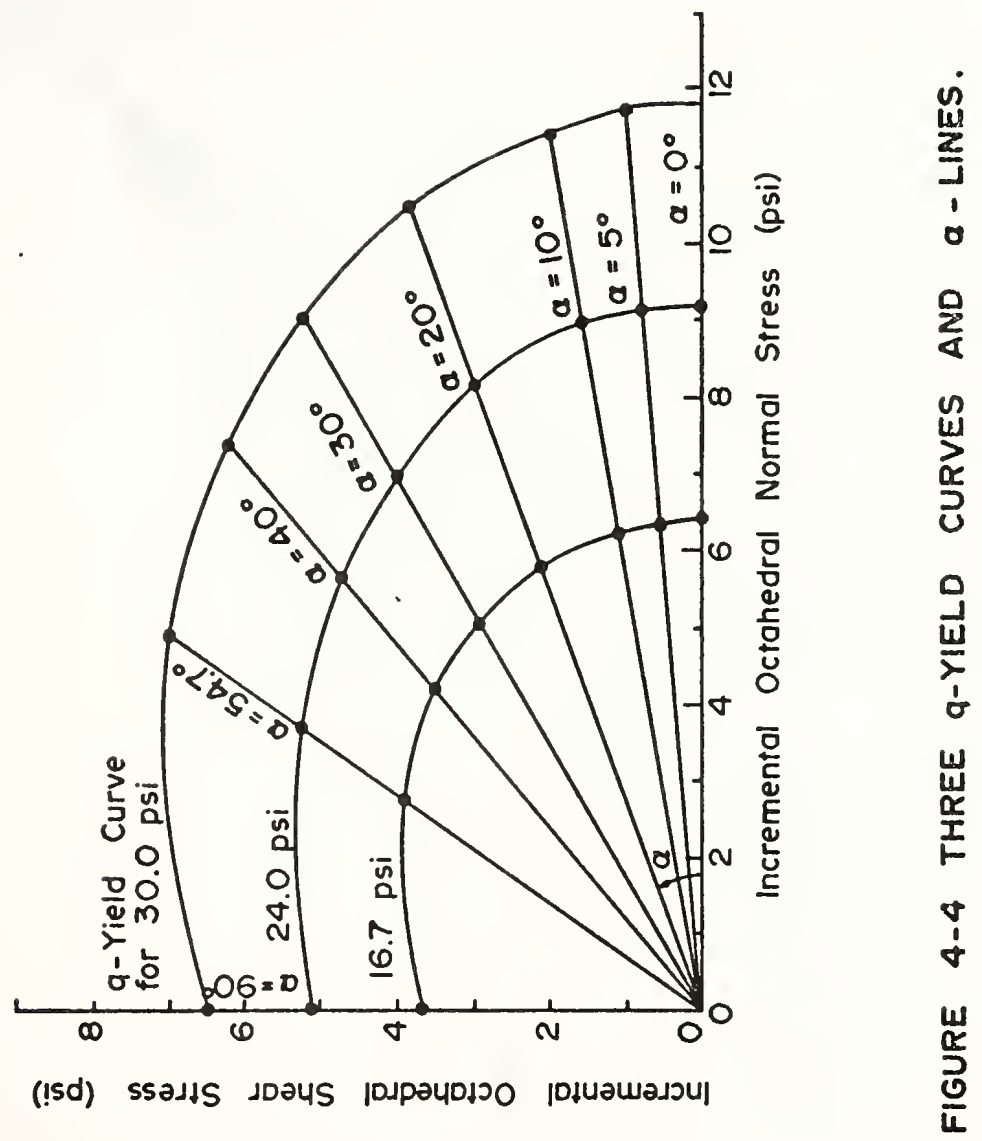




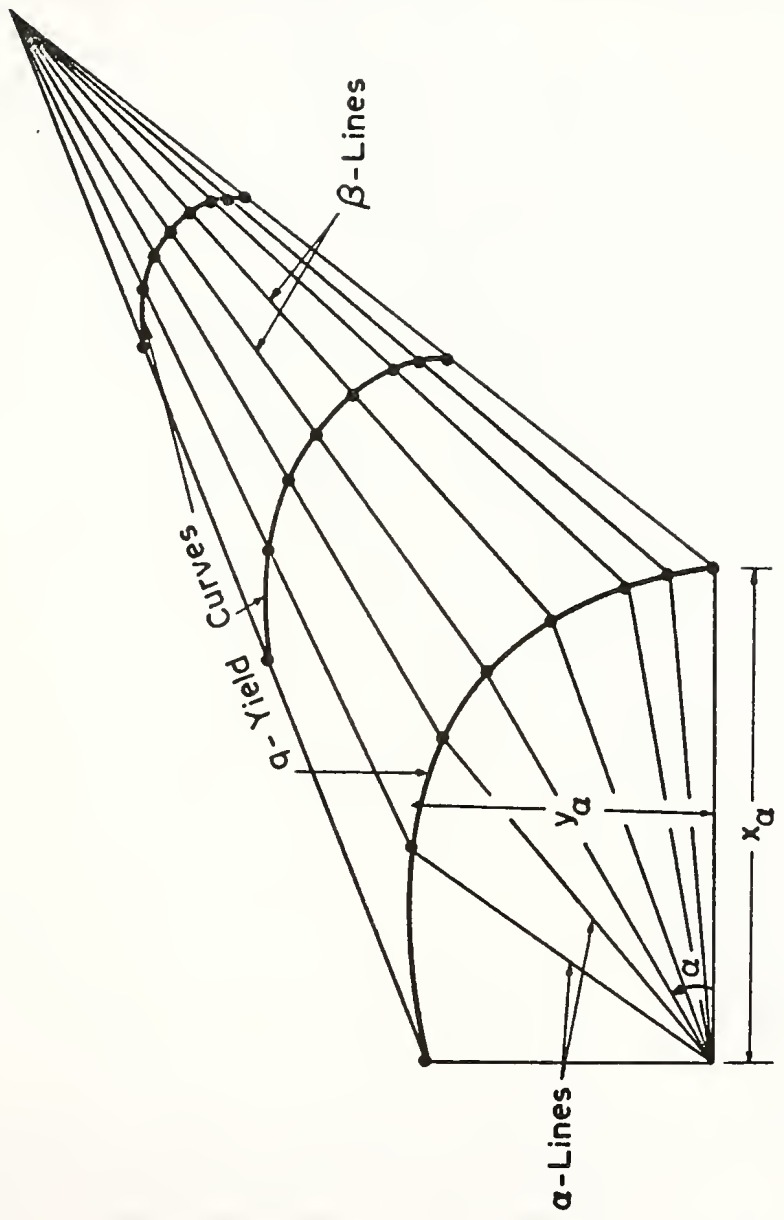

曾

$\infty$

$\frac{9}{8}$

.

高

芳

แ

旁

$\frac{U}{E}$

'

$\frac{w}{0}$ 


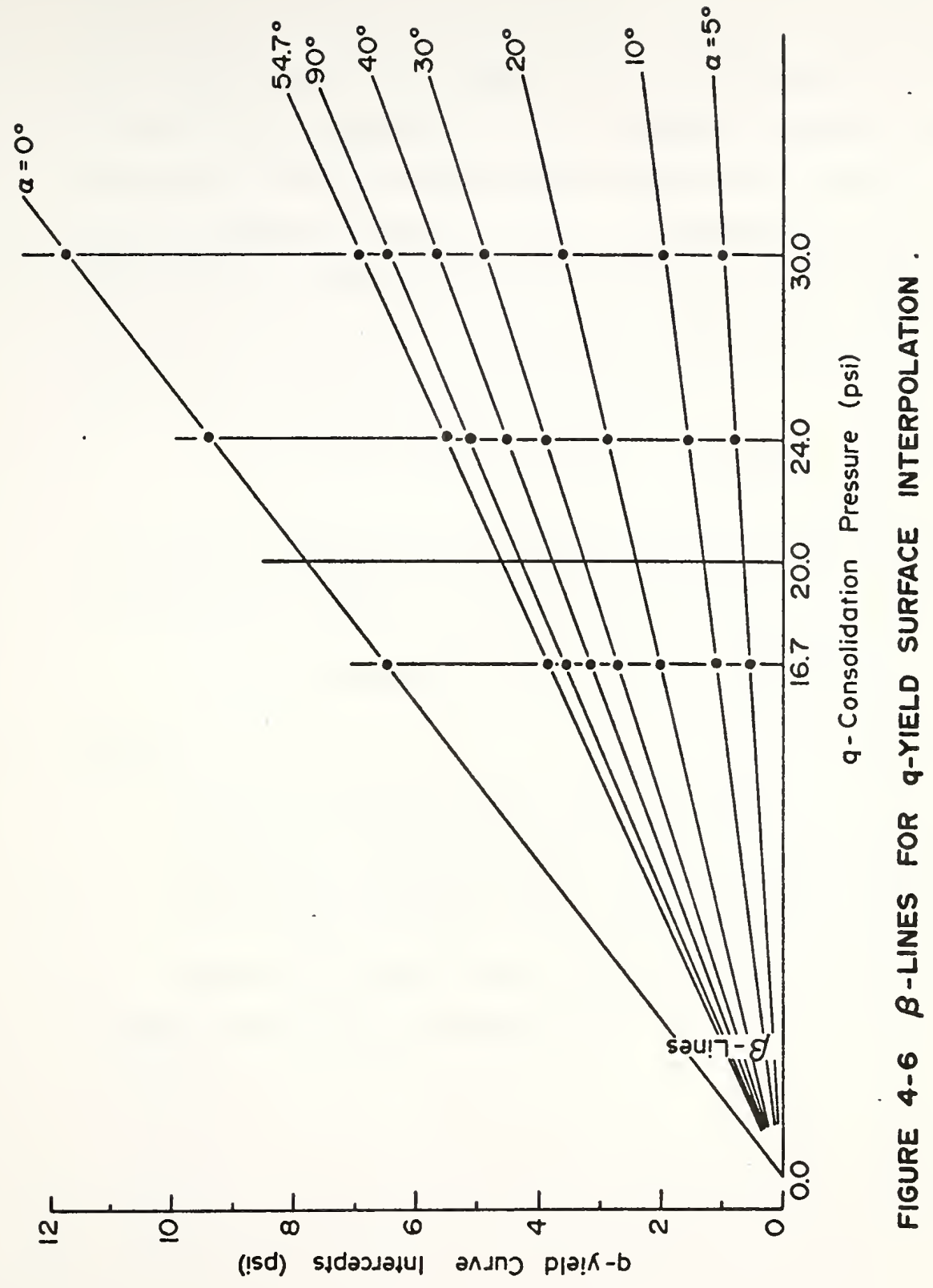


these $B$-lines all intersect at a zero consolidation pressure point the q-yield curves represent sections of an elliptic cone, shown sketched in Figure 4.7, and called the q-yield surface. The q-yield curve for a grundite specimen prepared under any q-consolidation pressure can now be found by interpolation from the known curves. The intercepts of the $\beta-1$ ines and a 20 psi consolidation line were observed in Figure 4.6 and noted in Table 4.5. These points were used to calculate the 20 psi interpolation q-yield curve

$$
y^{2}=18.903+1.617 x-0.526 x^{2}
$$

A study of the form of this equation with relation to an elliptic cone leads to the general equation

$$
y^{2}=0.032818 q^{2}+0.067384 q x-0.52570 x^{2}
$$

where

$\mathrm{q}$ is the $\mathrm{q}$-consolidation pressure (psi)

$x$ is the q-octahedral normal stress increment (psi)

$y$ is the q-octahedral shear stress increment (psi)

Use will be made of this equation later in the Finite Element formulation in Chapter 5 . 


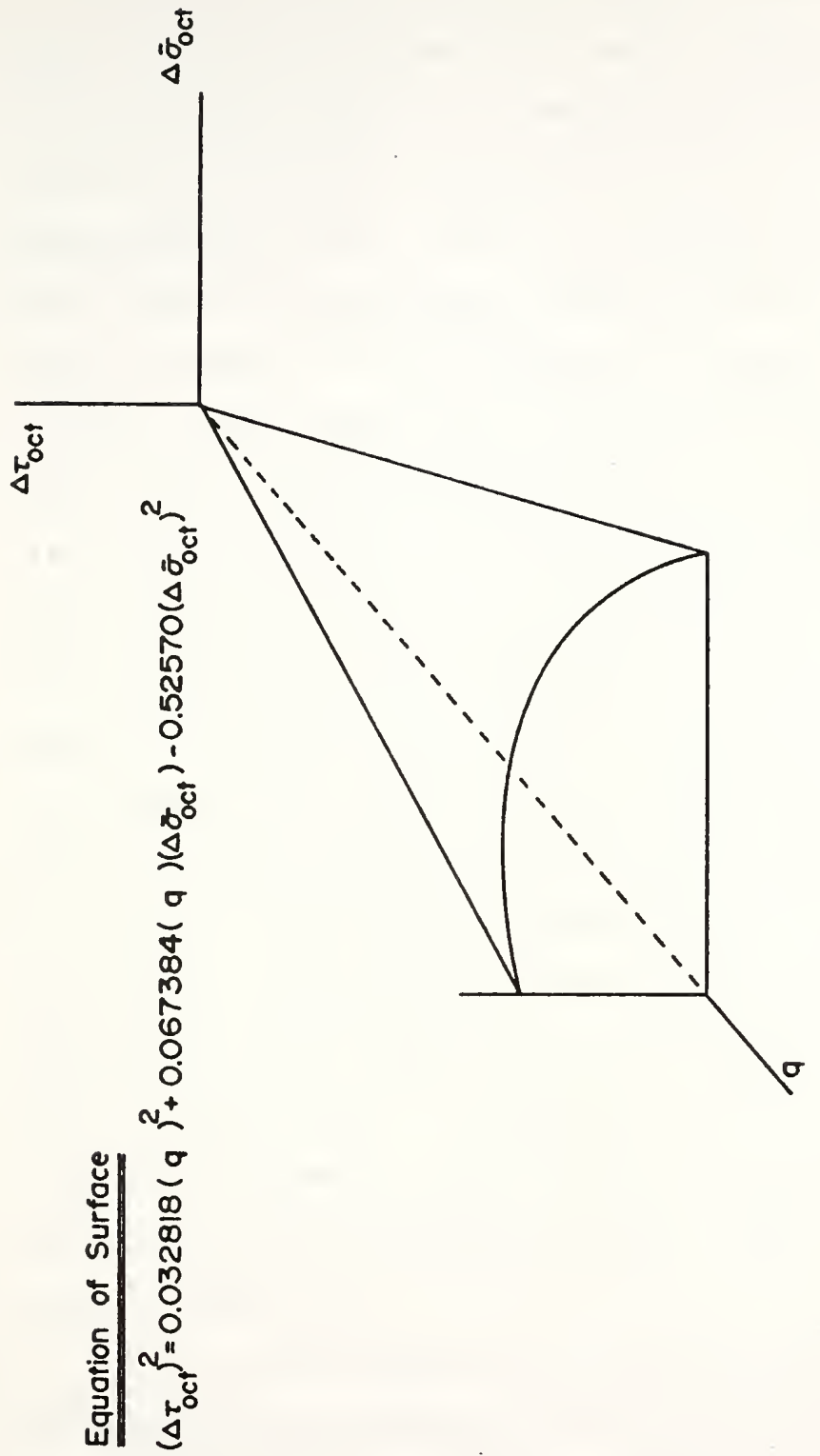

$\frac{1}{0}$

3

$\frac{0}{10}$

嵌

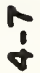

$\frac{5}{6}$ 


\subsection{Discussion}

The aim of the laboratory experimentation was to formulate a simple soil model which would take into account, in a more general manner, the quasi-preconsolidation effect observed by Leonards and Ramiah (1960) for one-dimensional consolidation tests. This was accomplished by running triaxial tests on clay samples which had been prepared in a manner conducive to the formation of quasi-preconsolidation bonding. The samples were prepared and the tests run as described in Chapter 3 and Appendix A. The resulting stressstrain curves showed an initially steep slope followed by a fairly sharp transition to an essentially linear curve of much lower slope. The intersection of the two straight line portions of the curve was termed the q-stress point, and represents the stress at which the temporary bonding which had developed during the consolidation period was assumed to rupture. Bond breaking probably occurred over some range of stresses, explaining the transition curve. Conlon (1966) observed similar shaped curves for cemented Canadian marine and estuarine clays. He explained the shape as the sum of two effects, namely, the normal soil shearing resistance and the interparticle bonding strength. This is shown schematica11y in Figure 4.8 .

The q-stress points for different tests and different q-consolidation pressures were plotted to form q-yield curves and the q-yield surface as described in Section 4.3. Of the twenty-seven tests there were 19 different stress paths; the 


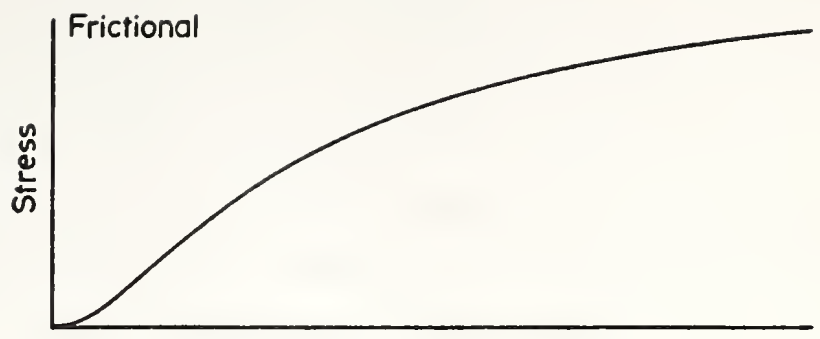

Stroin
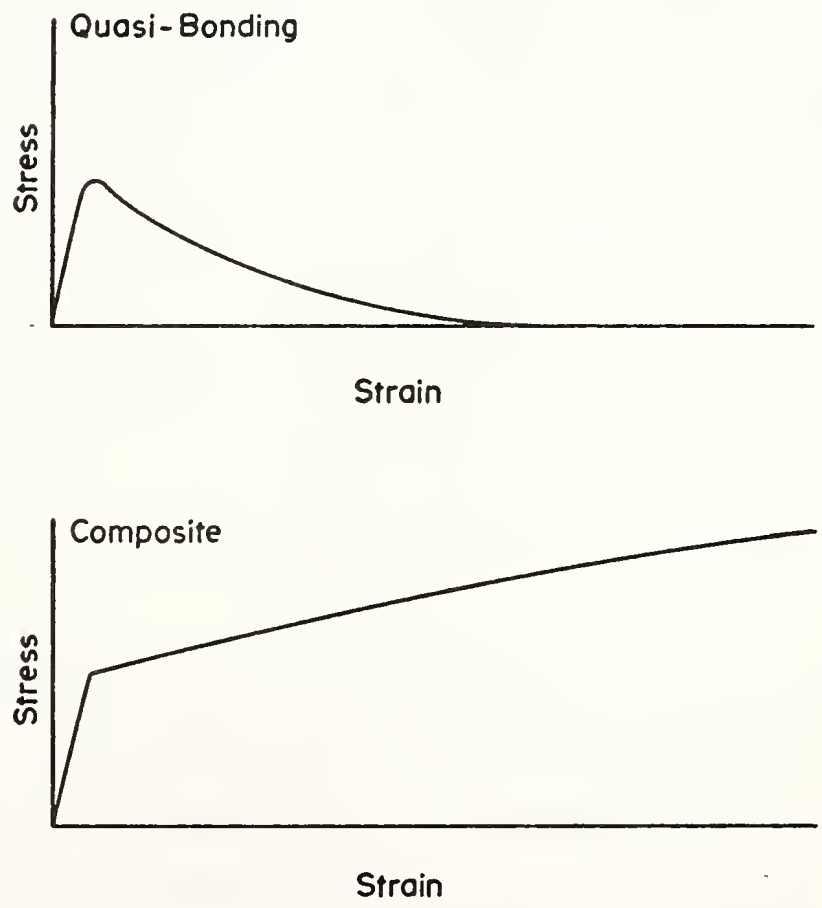

FIGURE 4-8 SCHEMATIC DEVELOPMENT OF THE SHAPE OF THE QUASI STRESS-STRAIN CURVES 
remaining 8 tests being duplicate tests mostly of Type 1 with confining pressures equal to their q-consolidation pressure. With such a limited number of points spread over an extensive three-dimensional surface it is possible only to state that there appears to be a unique surface, independent of stress path, which divides this stress space into two regions, A and B. Space B within the surface and A outside the surface represent soil behavior Before and After rupture of the quasi-preconsolidation bonds. Since the stress-strain plots showed essentially bilinear behavior a simple soil model may be defined giving the soil a large Modulus value $E_{B}$ if its stress path lies within Region B. When a stress path crosses the surface the bonds are assumed to rupture and a lower Modulus $\mathrm{E}_{\mathrm{A}}$ would be appropriate. The model proposed is entirely elastic and no consideration is made of ultimate yield. The inherent assumption is therefore made that loads do not exceed the elastic limit and no plastic behavior is permissible. The effects of the q-yield surface and the bilinear constitutive law during the consolidation process will be demonstrated in Chapter 5 .

During the sample preparation and testing little attempt was made to consider the effects of all the parameters which might change the magnitudes of the q-stress points. In fact every effort was made to standardize the complete testing procedure. This was not always possible especially for the q-consolidation time since actual testing took varying amounts of time and the equipment was not always vacant for a particular sample at a particular time. Table 4.1 shows 
that the consolidation periods varied from 20 to 27 days. In order to ascertain if this time might be a critical parameter one test, Number 21 , was permitted to remain under a consolidation pressure of 30 psi for 44 days, a period almost twice as long as the average value of 23.9 days. It might have been expected that since more time was available for inter particle movement and bonding, a higher q-stress point would result, as was observed by Narain et al. (1969) for the one-dimensional case. This was not so; in fact test Number 21 had the lowest q-stress point of the three samples tested along that particular stress path. Since this test did not show any increase in q-stress, let alone the almost 2 to 1 increase obtained by Narain in one-dimensional testing, it may be assumed that the effects of the length of q-consolidation with a maximum of 4 days variation from the mean may be neglected.

Triaxial Test Number 1 was loaded in the sedimentation tube to a final pressure 40 percent less than all other tests and consequently had a higher initial void ratio. However during the q-consolidation period it should attain the same void ratio as the other samples assuming a unique e-log $p$ relationship for the grundite, and this was apparently borne out since the quasi stress for Test 1 was approximately the mean of the five similar tests.

Table 4.1 shows that while most of the triaxial specimens had drainage from both top and bottom, six tests had bottom or pedestal drainage only. Table 4.3 shows that most 
of the tests performed in the Testing Apparatus were run at a rate of $4.0 \times 10^{-5}$ inches/minute while a few were run at $1.5 \times 10^{-4}$ and one at $5.0 \times 10^{-4}$ inches/minute. These two factors can be lumped together as a measure of the ease with which pore water may flow out of the sample so as to maintain a zero or low excess pore pressure and a pure effective stress system. Triaxial Test Number 3 had double drainage and a loading rate of $4.0 \times 10^{-5}$ inches/minute while Test Number 8 had single drainage and the faster loading rate of $1.5 \times 10^{-4}$ inches/minute. Other factors were essentially similar. Test 8 resulted in a q-octahedral shear stress about 8 percent higher than in Test 3 . This increase is in the direction reported by Crawford (1964, 1965) during studies on the effect of loading rate on the preconsolidation pressure. A recommended rate of loading can be calculated by a method formulated by Gibson and Henkel (1954). They found that the average degree of dissipation at failure $\bar{U}_{f}$ may be expressed in the form

$$
\bar{U}_{f}=1-\frac{h^{2}}{\xi c_{v}{ }^{t} f}
$$

where $h=$ half the height of the sample

$$
\begin{aligned}
& c_{v}=\text { coefficient of consolidation } \\
& t_{f}=\text { time to failure }
\end{aligned}
$$

and $\quad \xi=$ a factor depending on drainage conditions.

For a degree of dissipation of $95 \%$, the time to failure is given by 


$$
t_{f}=\frac{20 h^{2}}{\xi c_{v}}
$$

For a test with drainage from both ends and filter-paper drains Bishop and Henkel (1962) recommend a value of $\xi=40.4$. The value of $c_{v}$ was obtained from a consolidation test performed on Grundite. From a dial reading - time plot for a load increment beyond the quasi preconsolidation yield point, $t_{50}$ was found

$$
\begin{aligned}
c_{v} & =\frac{0.197 \mathrm{H}^{2}}{t_{50}} \\
& =6.94 \times 10^{-4} \mathrm{in}_{0}^{2} / \mathrm{min} .
\end{aligned}
$$

The time to failure

$$
t_{f}=\frac{20 \times 1.4^{2}}{40.4\left(6.94 \times 10^{-4}\right)}=1398 \mathrm{~min}
$$

If failure occurs at 15 percent strain then the strain or loading rate is given by

$$
\begin{aligned}
\varepsilon_{\text {rate }} & =\frac{0.028 \times 15}{1398} \\
& =3.00 \times 10^{-4} \mathrm{in} . / \mathrm{min} .
\end{aligned}
$$

With the exception of Test Number 1 this recommended rate is faster than the two loading rates $\left(1.5 \times 10^{-4}\right.$ and $4.0 \times 10^{-5}$ in./min.) used for the triaxial testing. 


\section{THE FINITE ELEMENT SOLUTION PROCEDURE}

\subsection{Introduction}

The finite element program into which the quasi-preconsolidation soil model has been introduced is an adaptation of a consolidation program CONSOL written at the Massachusetts Institute of Technology, (Christian and Boehmer, 1970; Christian et a1., 1972), and based on programs developed originally by wilson (1963).

Single phase finite element programs have been widely reported in the Soil Mechanics literature and formulation of the equations is readily available (Perloff, 1969). However, since the consolidation process is a two phase problem (soil skeleton and pore water), a short description of the theory and equation derivation is given in the following two sections. Section 5.4 briefly describes the original CONSOL program setup, changes incorporated, and the introduction of the quasi-preconsolidation model formulated from the laboratory experiments. In Section 5.5 results from example programs illustrate the effects of the model on pore pressures, displacements and stresses during the primary consolidation process. In the final section qualitative comparison is made between analytical results and recently published field studies. 


\subsection{Finite-element Equations for a Two-phase Material}

The principle of virtual displacements states that for a conservative system under equilibrium the virtual work $d w$, due to any virtual displacement from a compatible state is equal to the virtual strain energy $\mathrm{dU}_{i}$.

$$
\mathrm{dW}=\mathrm{dU}_{\mathbf{i}}
$$

where $d W$ is the first order work done by the external forces $\mathrm{dU}_{\mathbf{i}}$ is the first order work done by the internal stresses.

The internal work is equal to

$$
d U_{i}=\int_{V} \delta\{\varepsilon\}^{T}\{\sigma\} d(\text { volume })
$$

where the strain vector, is

$$
\{\varepsilon\}^{T}=\left[\begin{array}{lll}
\delta \varepsilon_{x} & \delta \varepsilon_{y} & \delta \gamma_{x y}
\end{array}\right]
$$

and the stress vector

$$
[\sigma]=\left\{\begin{array}{c}
\sigma_{x} \\
\sigma_{y} \\
\sigma_{x y}
\end{array}\right\}
$$

The external work is equal to

$\delta W=\int_{v} \delta\{u\}^{T}\{b\} d v+\int_{s} \delta\{u\}^{T}\{p\} d s+\delta\left\{u_{n}\right\}^{e, T}\{F\}_{c}^{e} \quad(5-5)$

Equating the external work and the internal strain energy and substituting in the effective stress principle 


$$
\{\sigma\}=\{\bar{\sigma}\}+\{S\}
$$

gives

$$
\begin{aligned}
\int_{v} \delta\{\varepsilon\}^{T}\{\bar{\sigma}\} \mathrm{dv} & +\int_{v} \delta\{\varepsilon\}^{T}\{S\} d v=\int_{v} \delta\{u\}^{T}\{b\} d v \\
& +\int_{s} \delta\{u\}^{T}\{p\} d s+\delta\left\{u_{n}\right\}^{e, T}\{F\}_{c}^{e}
\end{aligned}
$$

where

$\{\bar{\sigma}\}$ the effective stress associated with the soil skeleton

\{S\} the excess pore pressure associated with the pore fluid phase

(b\} the external body forces

\{p\} the external surfaces pressures

$\left\{F_{C}\right\}$ any external force applied at the node

(u\} displacements at a typical point

$\left\{u_{n}\right\}$ displacements at the node points

In the finite element method, the continuum is divided by imaginary lines or boundaries into a finite number of small elements. These "finite-elements" are assumed to be interconnected at a discrete number of boundary points, called nodes. The displacements of the node points are interpreted as the actual displacements of the corresponding points of the soil and are the basic unknowns of the problem. In the single phase procedure assumptions are made relating the displacements within an element to the nodal displacements, 
then with the soil constitutive 1 aw, substituted into the equilibrium equation reducing it to the matrix form

$$
\{P\}^{e}=[K]\left\{u_{n}\right\}^{e}
$$

where

$\{P\}^{e}$ is the vector of known nodal forces

$\left\{u_{n}\right\}^{e}$ is the vector of unknown nodal displacements

[K] is the stiffness matrix relating the above.

The superscript (c) indicates one particular element.

This is not however possible in the two-phase problem since in the equilibrium equation (5-7) the first term on the right hand side contains $\{S\}$ the unknown pore pressure which cannot be expressed in terms of $\left\{u_{n}\right\}$. Equation (5-7) can be reduced to matrix form in the same manner as for the single phase but the resulting equation has an extra term.

$$
\{P\}^{e}=[K]\left\{u_{n}\right\}^{e}+\left[K^{\prime}\right](H)^{e}
$$

where

$$
(\mathrm{H})^{e}=\mathrm{S} / \mathrm{K}_{\mathrm{b}}
$$

$S$ is the unknown pore pressure assumed constant throughout the element

$\mathrm{K}_{\mathrm{b}}$ is the soil bulk modulus

Another equation is now required in order to solve for the additional unknown resulting from the introduction of the second phase. This equation equates the volumetric strain $\left(e_{\phi}\right)$ and fluid outflow $\frac{\Delta V}{V}$ during consolidation. 


$$
\frac{\Delta V}{V}=\left(e_{\phi}\right)
$$

from which we obtain

$$
\{T\}^{e}=\left[K^{\prime}\right]^{T}\left\{u_{n}\right\}^{e}
$$

where

$$
\{\mathrm{T}\}^{\mathrm{e}}=\left(\frac{\Delta V}{V}\right) K_{\mathrm{b}} \text { Area }
$$

and

$$
\left[K^{\prime}\right]^{T}\left\{u_{n}\right\}=\left(e_{\phi}\right) K_{b} \text { Area }
$$

Equations (5-9) and (5-11) can be combined to form

$$
\left\{\begin{array}{l}
P \\
T
\end{array}\right\}=\left[\begin{array}{ll}
K & K^{\prime} \\
K, T & 0
\end{array}\right]\left\{\begin{array}{l}
u_{n} \\
H
\end{array}\right\}
$$

where $\left\{\begin{array}{l}\mathrm{P} \\ \mathrm{T}\end{array}\right\}$ is the vector of known loads and volumetric strains and $\left\{\begin{array}{l}u_{n} \\ H\end{array}\right\}$ is the vector of unknown nodal displacements and pore pressures. The equation formulation is demonstrated below. The displacement function chosen for constant strain triangular elements is

$$
\begin{aligned}
& u=\alpha_{1}+\alpha_{2} x+\alpha_{3} y \\
& v=\alpha_{4}+\alpha_{5} x+\alpha_{6} y
\end{aligned}
$$

or

$$
\{u\}=\left\{\begin{array}{c}
u \\
v
\end{array}\right\}=[M]\{\alpha\}
$$


The strains are defined as

$$
\{\varepsilon\}=\left\{\begin{array}{c}
\varepsilon_{x} \\
\varepsilon_{y} \\
\gamma_{x y}
\end{array}\right\}=\left\{\begin{array}{c}
\frac{\delta u}{\delta x} \\
\frac{\delta v}{\delta y} \\
\frac{\delta u}{\delta y}+\frac{\delta v}{\delta x}
\end{array}\right\}=\left[\begin{array}{llllll}
0 & 1 & 0 & 0 & 0 & 0 \\
0 & 0 & 0 & 0 & 0 & 1 \\
0 & 0 & 1 & 0 & 1 & 0
\end{array}\right]\left\{\begin{array}{c}
\alpha_{1} \\
\alpha_{2} \\
\alpha_{3} \\
\alpha_{4} \\
\alpha_{5} \\
\alpha_{6}
\end{array}\right\}
$$

or

$$
\{\varepsilon\}=[L]\{\alpha\}
$$

The volumetric strain is

$$
\left(e_{\phi}\right)=\left(\varepsilon_{x}+\varepsilon_{y}\right)=\left(\frac{\delta u}{\delta x}+\frac{\delta v}{\delta y}\right)=[010001]\{\alpha\}=[g]\{\alpha\}
$$

Substituting the known node point coordinates into equation (5-15) gives the relationship between node point displacements and the $\{\alpha\}$ 's.

$$
\left\{\begin{array}{c}
u_{i} \\
v_{i} \\
u_{j} \\
v_{j} \\
u_{k} \\
u_{k}
\end{array}\right\}=\left[\begin{array}{cccccc}
1 & x_{i} & y_{i} & 0 & 0 & 0 \\
0 & 0 & 0 & 1 & x_{i} & y_{i} \\
1 & x_{j} & y_{j} & 0 & 0 & 0 \\
0 & 0 & 0 & 1 & x_{j} & y_{j} \\
1 & x_{k} & y_{k} & 0 & 0 & 0 \\
0 & 0 & 0 & 1 & x_{k} & y_{k}
\end{array}\right]\left\{\begin{array}{l}
\alpha_{1} \\
\alpha_{2} \\
\alpha_{3} \\
\alpha_{4} \\
\alpha_{5} \\
\alpha_{6}
\end{array}\right\}
$$

or

$$
\left\{u_{n}\right\}=[A]\{\alpha\}
$$


Inverting equation (5-21)

$$
\{\alpha\}=[A]^{-1}\left\{u_{n}\right\}
$$

Substituting equation $(5-22)$ into $(5-16),(5-18)$ and $(5-19)$ gives

$$
\begin{aligned}
\{u\} & =[M][A]^{-1}\left\{u_{n}\right\}=[N]\left\{u_{n}\right\} \\
\{\varepsilon\} & =[L][A]^{-1}\left\{u_{n}\right\}=[B]\left\{u_{n}\right\} \\
\left(e_{\phi}\right) & =[g][A]^{-1}\left\{u_{n}\right\}=[G]\left\{u_{n}\right\}
\end{aligned}
$$

The elastic stress-strain relationship is

$$
\{\bar{\sigma}\}=[D]\{\varepsilon\}
$$

Substituting equations $(5-23),(5-24),(5-25)$ and $(5-26)$ into the two equilibrium equations (5-7) and (5-10) we obtain

$$
\begin{aligned}
& \int_{v}[B]^{T}[D][B] d v\left\{u_{n}\right\}^{e}+\int_{v}[G]^{T} \bar{K}_{b} d v(H)^{e} \\
& \quad=\int_{v}[B]^{T}[D]\left[\varepsilon_{0}\right] d v+\int_{v}\{b\}^{T}[N] d v \\
& +\int_{S}\{p\}^{T}[N] d s+\{F\}_{C}^{e}
\end{aligned}
$$

and

$$
\frac{\Delta V}{V}=[G]\left\{u_{n}\right\}^{e}
$$


These can be combined as before to give

$$
\left\{\begin{array}{c}
P \\
T
\end{array}\right\}^{e}=\left[\begin{array}{cc}
K & K^{\prime} \\
K^{\prime} T & 0
\end{array}\right]\left\{\begin{array}{c}
u_{n} \\
H
\end{array}\right\}^{e}
$$

where

$$
\begin{aligned}
& \{P\}^{e}=\{F\}_{C}^{e}+\int_{v}[B]^{T}[D]\left\{\varepsilon_{o}\right\} d v+\int_{v}\{b\}^{T}[N] d v \\
& \quad+\int_{S}\{p\}^{T}[N] d s \\
& \{T\}^{e}=\left(\frac{\Delta V}{V}\right)\left(\bar{K}_{b} \text { Area }\right) \\
& {[K]=\int_{V}[B]^{T}[D][B] d v} \\
& {\left[K^{\prime}\right]=\int_{v}[G]^{T} d v \bar{K}_{b}} \\
& {\left[K^{\prime T}\right]=\int_{v}[G] d v \bar{K}_{b}}
\end{aligned}
$$

$\left\{u_{n}\right\}^{e}=$ the unknown modal displacement

$(\mathrm{H})=$ the unknown pore pressure.

$[B],[D],[G],[N]$ and thus $[K]$ and $\left[K^{\prime}\right]$ are functions of location.

$\{b\},\{p\},\left\{F_{c}\right\},\left\{\varepsilon_{o}\right\}$ and $\{T\}$ are loads which are to be specified. $\left\{u_{n}\right\}^{e}$ and $(H)^{e}$ can hence be solved. 


\subsection{The Consolidation Process}

The solution to the transient flow, or consolidation problem, follows directly from the two phase formulation by specifying values for the volume changes in the load vector.

As sume

$$
\frac{1}{\Delta t} \frac{\Delta V}{V}=-\left(\frac{\delta v_{x}}{\delta x}+\frac{\delta v_{y}}{\delta y}\right)
$$

and

$$
\text { Darcy's 1 aw } \quad \begin{aligned}
v_{x} & =-k_{x x} \frac{\delta h}{\delta x} \\
v_{y} & =-k_{y y} \frac{\delta h}{\delta y}
\end{aligned}
$$

Substituting equations $(5-36)$, and $h=S / \gamma_{W}$ into equation $(5-35)$ gives

$$
\frac{1}{\Delta t}\left(\frac{\Delta V}{V}\right)=\frac{k_{x x}}{r_{w}} \frac{\delta^{2} S}{\delta x^{2}}+\frac{k_{y y}}{r_{w}} \frac{\delta^{2} S}{\delta y^{2}}
$$

or

$$
\frac{1}{\Delta t}\{T\}=\frac{\bar{K}_{b} \cdot \text { Area }}{\gamma_{w}}\left[k_{x x} \frac{\delta^{2} S}{\delta x^{2}}+k_{y y} \frac{\delta^{2} S}{\delta y^{2}}\right]
$$

The pore pressure $S$ has been defined as constant throughout each element. If quadrilateral elements are used in the finite element program then a quadrilateral and its four adjacent quadrilaterals allow the $\beta^{\prime} s$ in the following polynomial to be defined

$$
S=\beta_{1}+\beta_{2} x+\beta_{3} y+\beta_{4} x^{2}+\beta_{5} y^{2}
$$




$$
\left\{S_{n}\right\}=\left\{\begin{array}{c}
S_{i} \\
S_{j} \\
S_{k} \\
S_{l} \\
S_{m}
\end{array}\right\}=[E]\left\{\begin{array}{c}
\beta_{1} \\
\beta_{2} \\
\beta_{3} \\
\beta_{4} \\
\beta_{5}
\end{array}\right\}
$$

$$
\therefore\{B\}=[E]^{-1}\left\{S_{n}\right\}
$$

From equation $(5-39)$

$$
\frac{\delta^{2} S}{\delta x^{2}}=2 \beta_{4}, \quad \frac{\delta^{2} S}{\delta y^{2}}=2 \beta_{5}
$$

From the relevant portion of equation (5-41)

$$
\left\{\begin{array}{l}
\beta_{4} \\
\beta_{5}
\end{array}\right\}=\left[\begin{array}{lllll}
E_{41} & \bar{E}_{42} & \bar{E}_{43} & \bar{E}_{44} & \bar{E}_{45} \\
\bar{E}_{51} & \bar{E}_{52} & E_{53} & E_{54} & \bar{E}_{55}
\end{array}\right]\left\{\begin{array}{c}
S_{i} \\
S_{j} \\
S_{k} \\
S_{l} \\
S_{m}
\end{array}\right\}
$$

Substituting equations $(5-42)$ and $(5-43)$ into $(5-38)$

$$
\begin{array}{r}
\{T\}=\Delta t \cdot \frac{\bar{K}_{b} \text { Area }}{\gamma_{w}}\left[k _ { x x } \left(E_{41} S_{i}+E_{42} S_{j}+E_{43} S_{k}\right.\right. \\
+E_{44} S_{\ell} \\
\left.+E_{45} S_{m}\right) \\
\left.+k_{y y}\left(\bar{E}_{51} S_{i}+\bar{E}_{52} S_{j}+\bar{E}_{53} S_{k}+\bar{E}_{54} S_{\ell}+\bar{E}_{55} S_{m}\right)\right]
\end{array}
$$


where

\{T\} is the volume change for each element

$\Delta t$ is the spccified time increment

$\overline{\mathrm{K}}_{\mathrm{b}}$ is the soil Bulk modulus

Area is the element area

$k_{x x}, k_{y y}$ the principle permeabilities.

The solution procedure for the consolidation problem consists of alternately solving equations (5-14) and (5-44)

$$
\begin{aligned}
& \left\{\begin{array}{c}
P \\
T
\end{array}\right\}=\left[\begin{array}{cc}
K & K^{\prime} \\
K^{\prime} T & 0
\end{array}\right]\left\{\begin{array}{c}
u_{n} \\
H
\end{array}\right\} \\
& \{T\}=\Delta t \frac{K_{b} \text { Area }}{\gamma_{W}}[E]\left\{S_{n}\right\}
\end{aligned}
$$

First, the initial undrained displacements and pore pressures are found by assuming $\{T\}$, the volume changes, to be zero in equation (5-14). These pore pressures are then substituted into equation (5-44) and new volume changes calculated after dissipation for some time increment $\Delta t$. The $\{T\}$ 's are now used as known volume changes in the load vector in (5-14) to determine new displacements and pore pressures. This cycle is repeated until the pore pressures have dissipated to some specified level. 


\subsection{The Finite-element Program}

The original finite element program CONSOL consisted of a MAIN program and ten major subroutines. Four supplementary subroutines can be employed for plotting, special consolidation output, rigid loads and time dependent loading. A further subroutine QUASI has been added to take into account the special soil constitutive behavior and will be described later in detail. The major program divisions are listed below with a brief description of their function. Input formats and a program listing are given in Appendix D.

MAIN - routes the finite element procedure through the necessary subroutines for a solution to the input problem.

MLDATA - reads in material properties and calculates all necessary soil parameters.

DATA1 - reads in node point, element, pore pressure and boundary loading data. Sets up location arrays and determines the band width.

DATA2 - reads in boundary drainage conditions, determines element incidences and terms for the flow calculations. SOLSTF - formulates the load-volumetric strain vector and the overall stiffness matrix.

MODIFY - takes into account specified displacements and pore pressures.

QUAD - assembles the stiffness matrix for the quadrilatera1 element by subdividing it into four triangles and then superimposing results. 
BANSOL - triangularizes the stiffness matrix by Gaussian Elimination and solves for the unknown displacements and pore pressures by backsubstitution.

FLOWCA - calculates the volumetric strains due to each increment of fluid flow during consolidation. TMCRIT - calculates the time increments. STRESS - from the determined displacements calculates

strains and stresses and prints out results in tabular form.

QUASI - checks if the stress path has crossed the quasisurface and if so changes the element soil properties.

Two major changes were made to the MIT CONSOL program and are described below. In the original program input data were read in the three DATA subroutines, the stiffness matrix formulated in SOLSTF and the initial undrained results calculated in BANSOL and output in STRESS. For the consolidation phase the program then entered a loop consisting of BANSOL (back-substitution only), FLOWCA and, whenever output was desired, STRESS. Each cycle through this loop represents one time increment of excess pore pressure dissipation.

A major revision of the existing program was necessary to satisfy the requirements of the present research. For the soil model being considered a check of the effective stress state against the q-yield surface is required after each dissipation increment. The program was therefore altered such that subroutine STRESS was called during every cycle 
but that the write-out section within STRESS was again only utilized at specified times.

The second major change made to the original program was the addition of the soil model subroutine, QUASI. This is called from STRESS, for each grid element, after the displacements, strains and stresses have been calculated at a particular time. The insitu effective stresses are determined in QUASI assuming a simple geostatic state with water table at the soil surface and with assumed values of soil unit weight and coefficient of earth pressure at rest. These insitu stresses prior to loading are required both in the calculation of the octahedral shear stress increment, $\Delta \tau_{\text {oct }}$, and as a representation of the field q-consolidation pressure. For this pressure a corresponding q-yield curve is determined and a comparison made with the element effective octahedral stress increments due to the loading. If the incremental stress state represents a point outside the elliptic yield curve then the post yield elastic parameters are assigned to that soil element and are used in the next cycle determination. This change in element soil parameters necessitates leaving the dissipation loop described above and calling SOLSTF in order to calculate a new stiffness matrix. Triangularization is then required within BANSOL. These reroutings have been inserted into the program and a simplified flow chart is shown in Figure 5.1. 


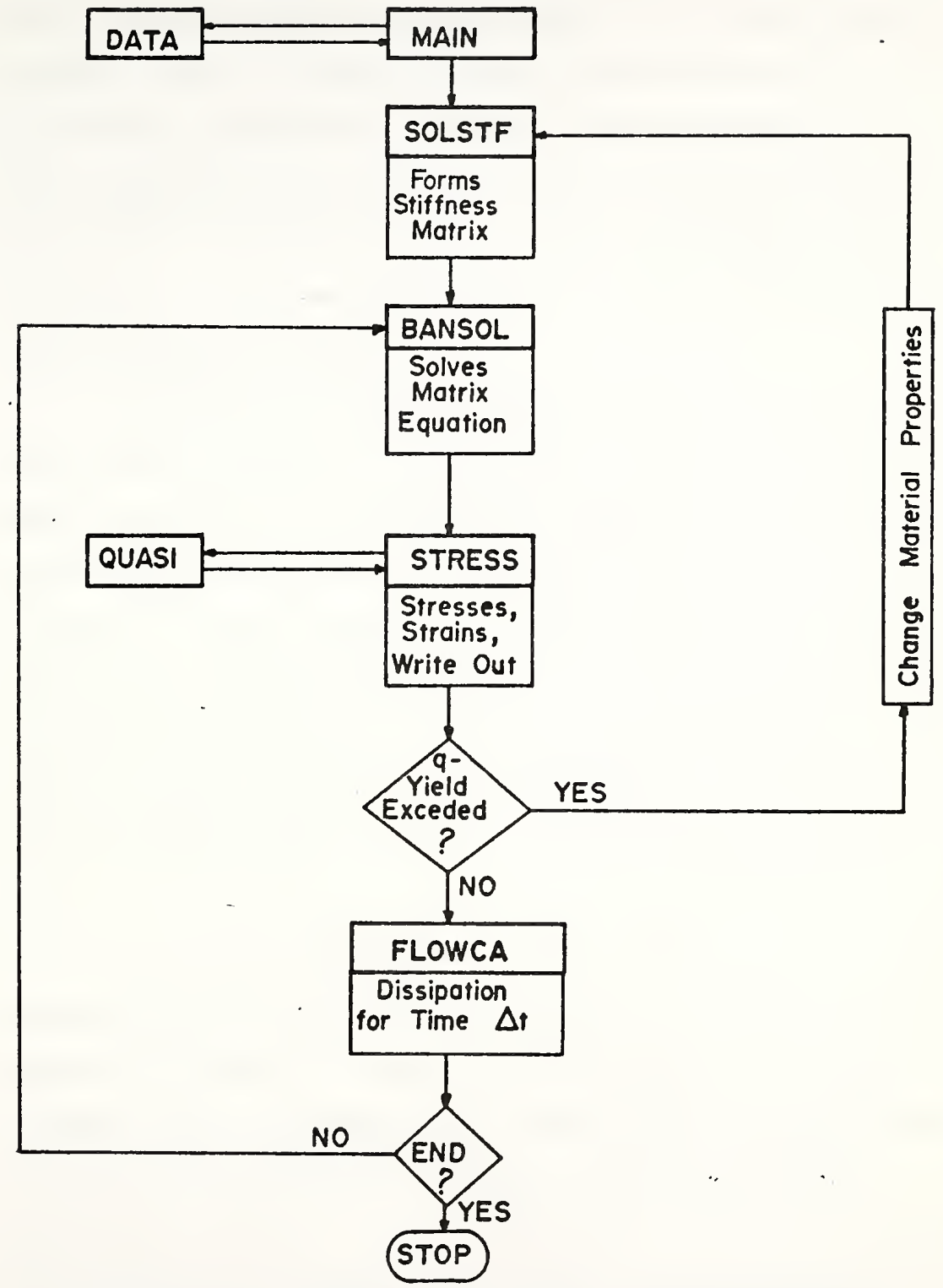

FIGURE 5-I FLOW CHART FOR CONSOLIDATION PROGRAM. 


\subsection{Illustrative Problems}

5.5.1 Introduction. In order to determine the effect of the quasi-preconsolidation model on the consolidation process, finite clement solutions were obtained for four different consolidation problems. These represented the one- and two-dimensional cases shown in Figure 5.2, with and without consideration of the quasi-preconsolidation behavior. Plots and discussion of these results are given in subsequent sections.

In the finite element method the degree of freedom of each node point must be specified. A choice exists as to this freedom for the bottom row of node points, representing the soil-rock interface. Each node may be fixed, or may be permitted to move only in the $x$-direction. These cases represent, respectively, the $u=0$ (rough) and $\tau=0$ (smooth) boundary conditions of analytical stress distribution theory. Finite element programs for the two cases were run, and initial excess pore pressures calculated using the equation

$$
\Delta \mathrm{u}=\Delta \sigma_{\text {oct }}+(0.2) \Delta \tau_{\text {oct }}
$$

Contours of excess initial pore pressure are plotted in Figures 5.3 and 5.4. When the lower nodes are allowed a single degree of freedom, the fixed right hand grid boundary is the only component preventing lateral deformation. Horizontal stresses do not dissipate to zero with increasing distance from the load, as reflected in the pore pressure 


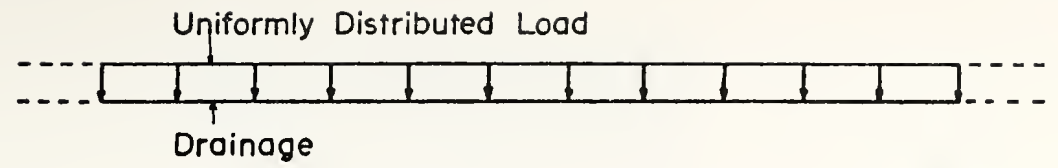

Cloy

No Drainage

Rock

a)- One-Dimensional Consolidation Configuration.

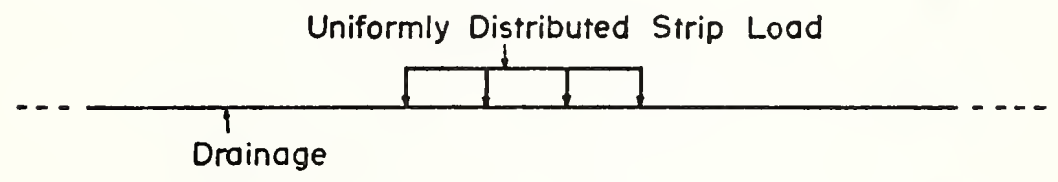

Cloy

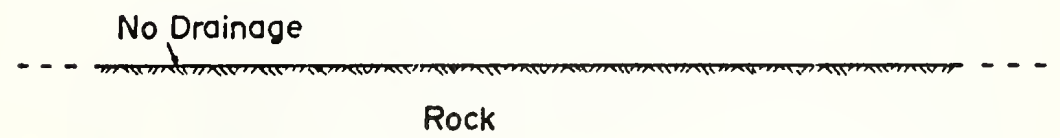

b)- Two-Dimensional Consolidation Configuration. CONFIGURATIONS. 


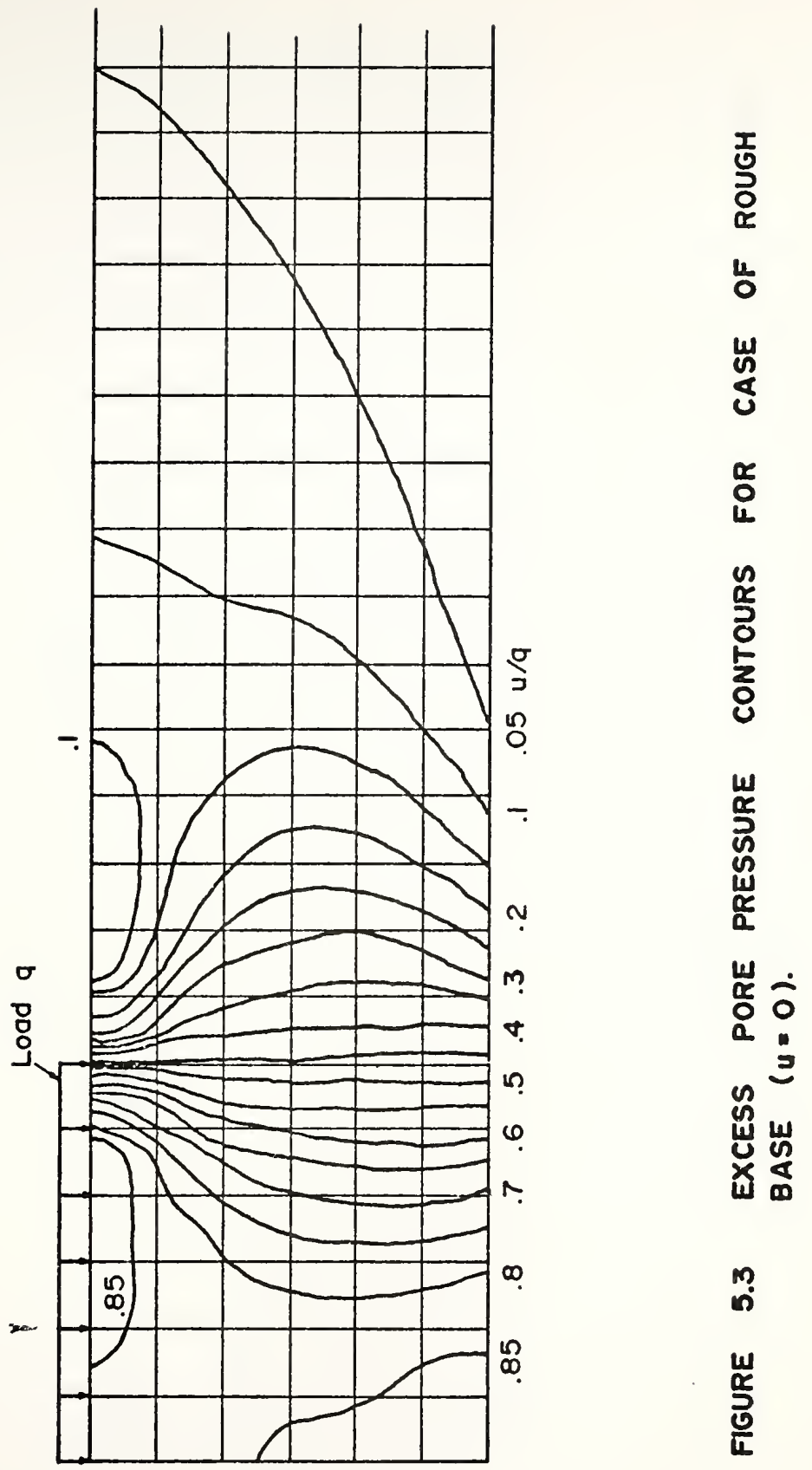




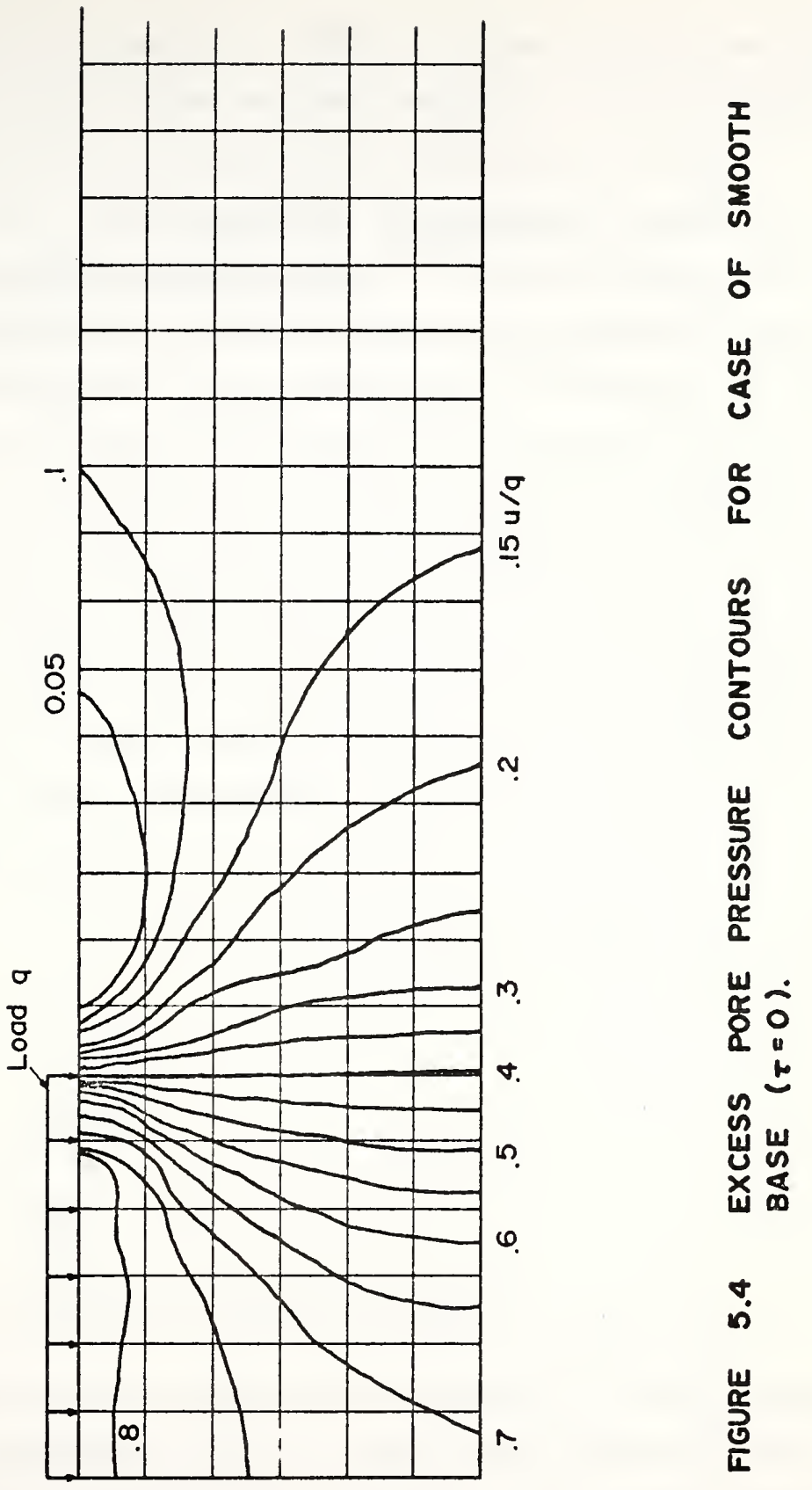


contours of Figure 5.4. Thus, it appears that fixed lower boundary node points are more realistic. It was therefore decided to fix the bottom node points in all cases.

5.5.2. One-Dimensional Consolidation Problem, No Quasi-Preconsolidation Effect. A finite element grid, consisting of seventy-five elements and shown in Figure 5.5, was employed for the one-dimensional no yielding solution. In order to obtain one-dimensional deformation and drainage behavior, a uniformly distributed load was assigned over the upper surface, with drainage permitted only from the same boundary. This problem allows a comparison between the finite element solution and the analytical Terzaghi onedimensional consolidation theory. For the case where the initial excess pore pressure $u=u_{0}$ is constant, the Terzaghi solution may be written

$$
u=u_{0} \sum_{m=0}^{\infty} \frac{2}{M} \sin \frac{M Z}{H} \exp -M^{2} T
$$

where

$$
\begin{aligned}
& M=\frac{(2 m+1) \pi}{2} \quad m=0,1,2,3 \ldots . \\
& T=\frac{c_{v} t}{H^{2}}
\end{aligned}
$$

and $H=$ thickness of the clay layer.

A simple computer program was developed to solve this equation, calculating $u / u_{o}$ for input values of depth factor $Z / H$ and time factor $T$. The program, in which a summation of $\mathrm{m}$ 


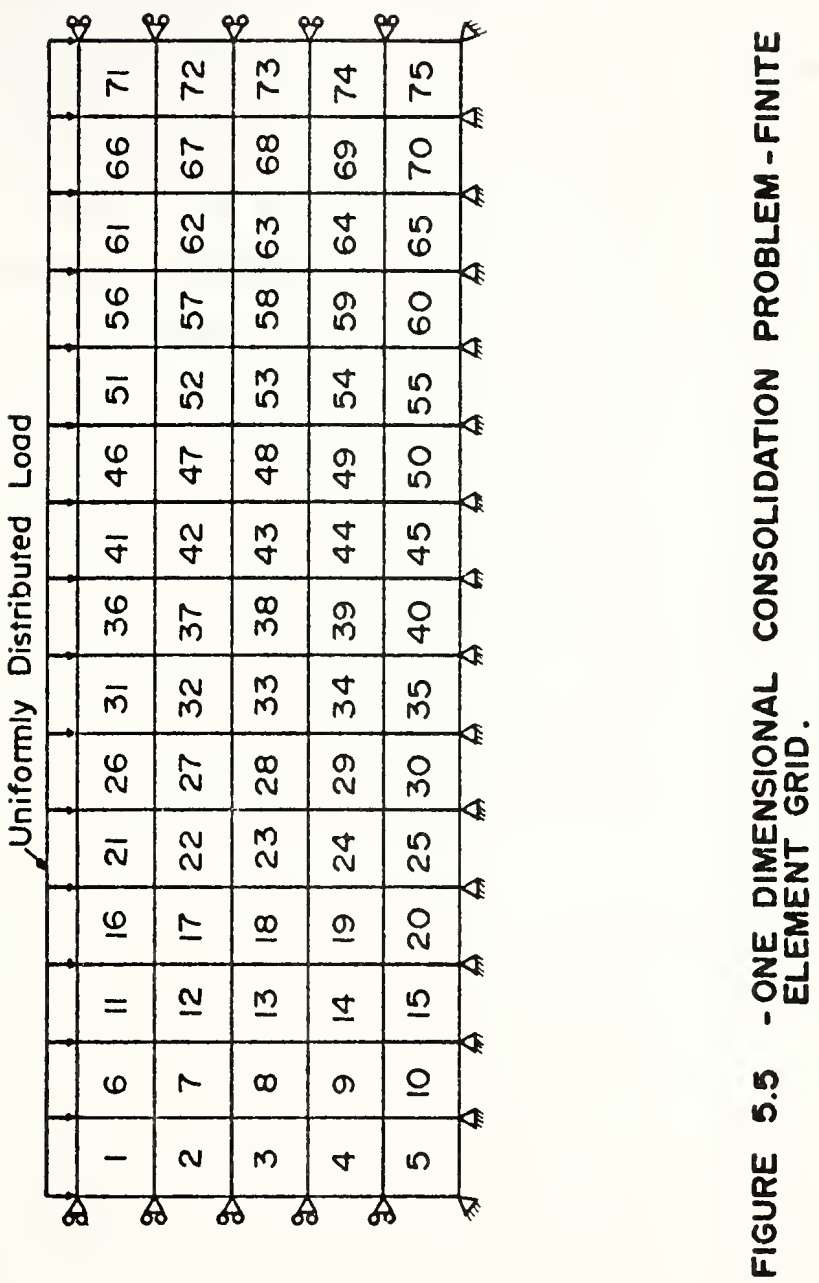


from 0 to 50 was employed, is listed in Figure 5.6. In Figure 5.7 are plotted isochrones for different values of the time factor. The Terzaghi solution is given in the upper portion of the figure, and that for the five row finite element program in the lower part. Agreement even for this coarse grid is quite good, except near the drainage boundary where pore pressures in the finite element method dissipate more rapidly than in the Terzaghi solution. Christian and Boehmer (1970), compared solutions from the original CONSOL program for various numbers and shapes of grid elements, with Terzaghi's solution, finite difference solutions, and an analog computer solution. For a ten row finite element solution plots were indistinguishable from Terzaghi's solution. For a five row program they also found some deviation from the correct solution but that the isochrones throughout most of the depth were close to the correct values.

In Figures 5.8, 5.9 and 5.10 are plotted excess pore pressure ratio values versus logarithm of the time factor for elements in the top, second and third rows of the finite element grid. The Terzaghi solutions are also plotted and illustrate the close agreement except in the first row of elements adjacent to the drainage boundary. Surface settlements are plotted in dimensionless form in Figure 5.11. These relative settlements are the actual settlements $\rho$ divided by the ultimate consolidation settlement $\rho_{u l t}$. 
DIMENSION $Z(6), T(10)$

$\mathrm{PI}=3.14159265$

$\operatorname{READ}(5,1) \quad(\mathrm{T}(\mathrm{K}), \mathrm{K}=1,10)$

1 FORMAT (8F10.0)

DO $4 \mathrm{~J}=1,5$

$\mathrm{AJ}=\mathrm{J}$

$Z(J)=(2.0 * \mathrm{AJ}-1.0) / 10.0$

DO $4 \mathrm{~K}=1,10$

SUM $=0.0$

DO $2 \quad I=1,51$

$M=I-1$

$\mathrm{AM}=\mathrm{M}$

$\mathrm{BIGM}=(2.0 * \mathrm{AM}+1.0) * \mathrm{PI} / 2.0$

$\mathrm{F} 1=\mathrm{BIGM} * \mathrm{Z}(\mathrm{J})$

$\mathrm{S}=\operatorname{SIN}(\mathrm{F} 1)$

$\mathrm{F} 2=-\mathrm{BIGM} * \mathrm{BIGM} * \mathrm{~T}(\mathrm{~K})$

$E=\operatorname{EXP}(F 2)$

$\mathrm{F} 3=(2.0 / \mathrm{BIGM}) * \mathrm{~S} * \mathrm{E}$

$2 \mathrm{SUM}=\mathrm{SUM}+\mathrm{F} 3$

WRITE $(6,3) \quad Z(J), T(K)$, SUM

3 FORMAT $(/ 7 \mathrm{HDEPTH}=, \mathrm{F} 8.5,5 \mathrm{X}, 3 \mathrm{HT}=, \mathrm{F} 9.5,5 \mathrm{X}, 3 \mathrm{HU}=, \mathrm{F} 6.3 /$ )

4 CONTINUE

END 


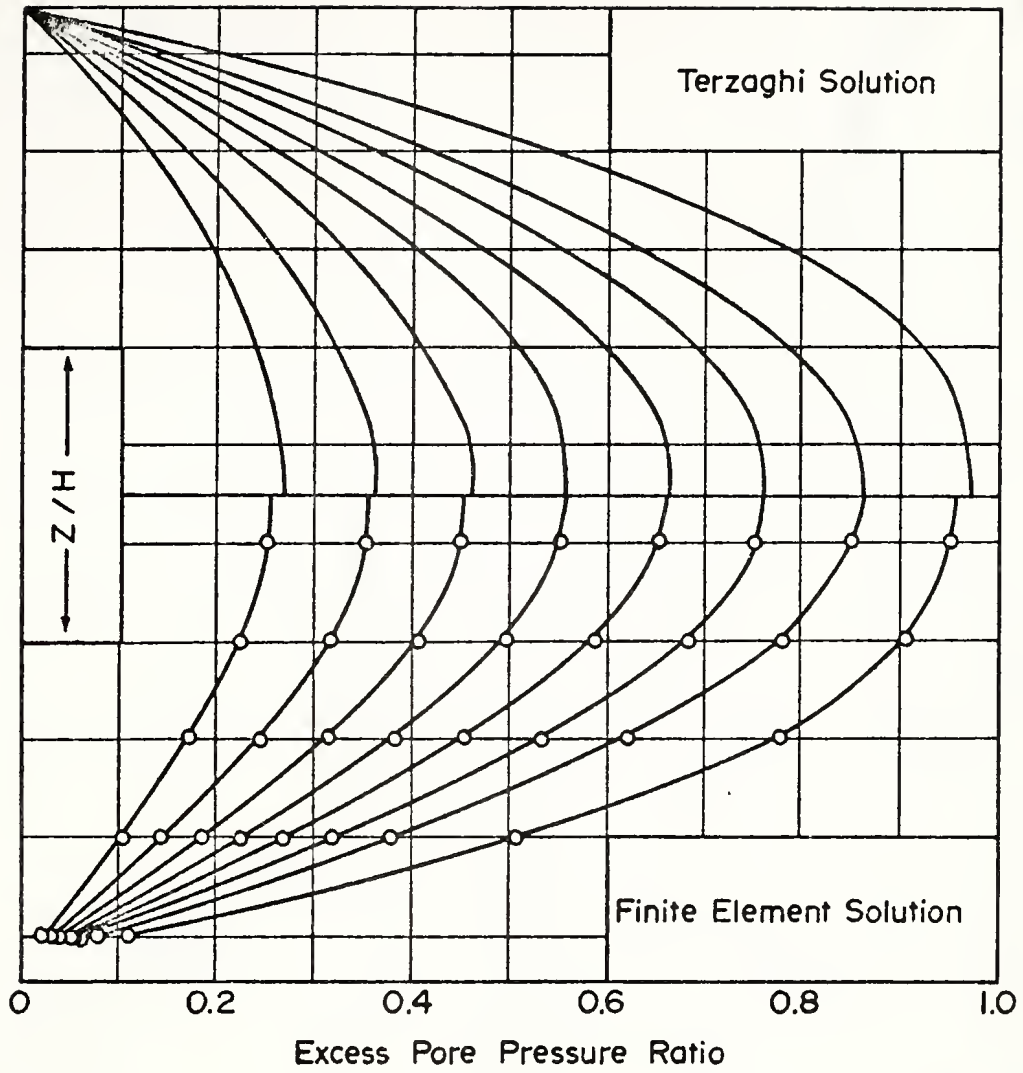

FIGURE 5.7 - PORE PRESSURE ISOCHRONES FOR ANALYTICAL AND FINITE ELEMENT SOLUTIONS. 


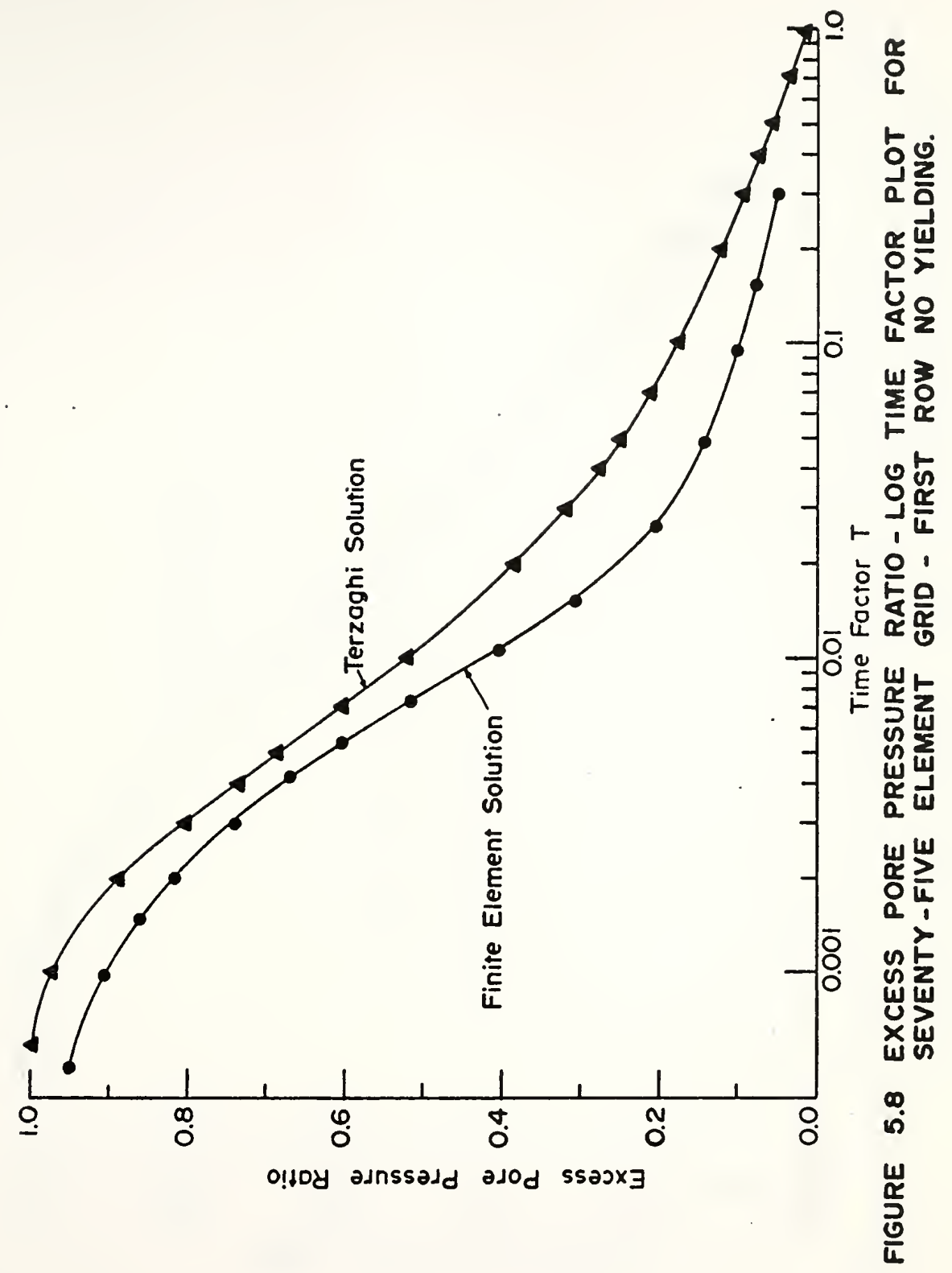




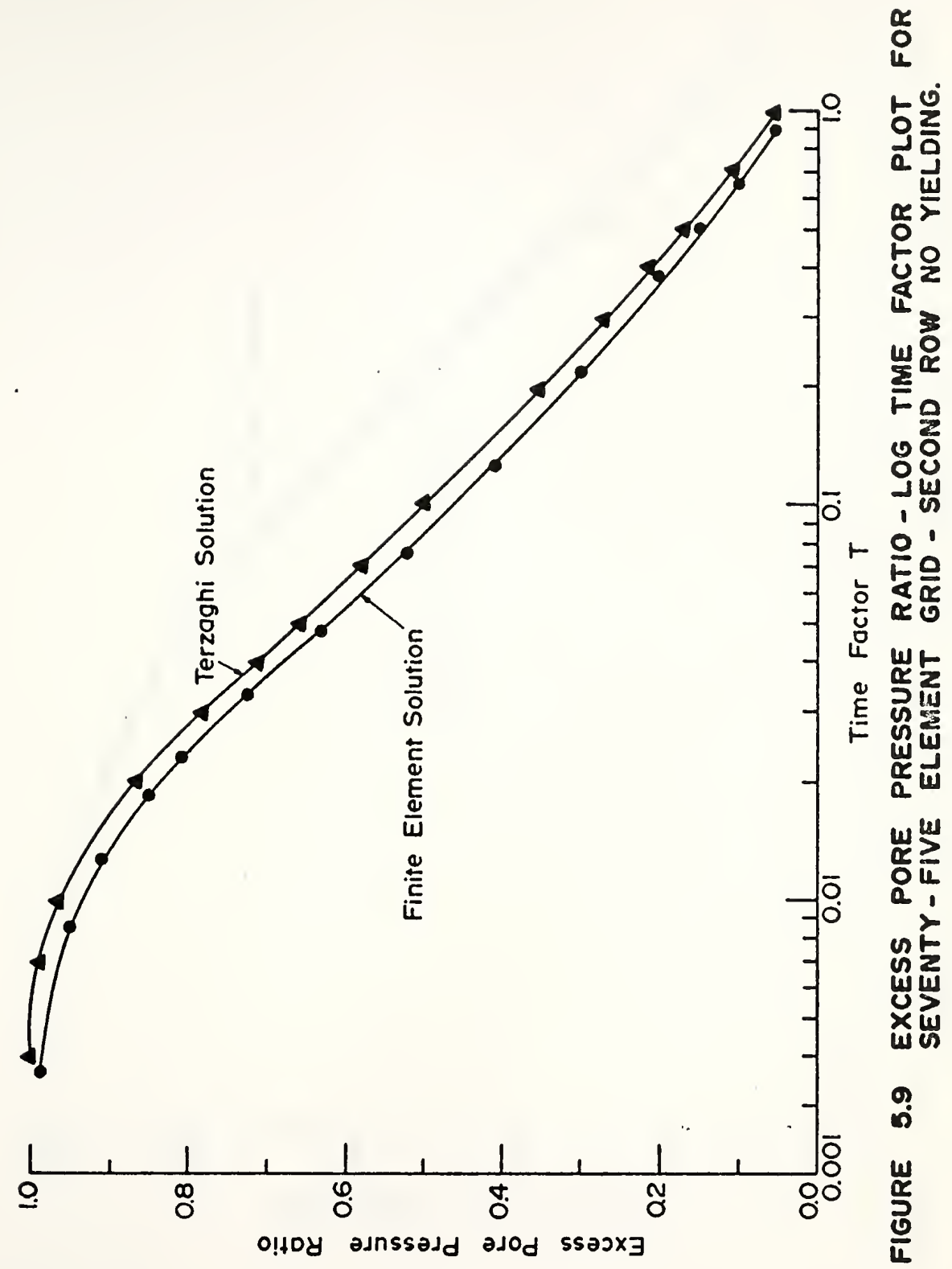




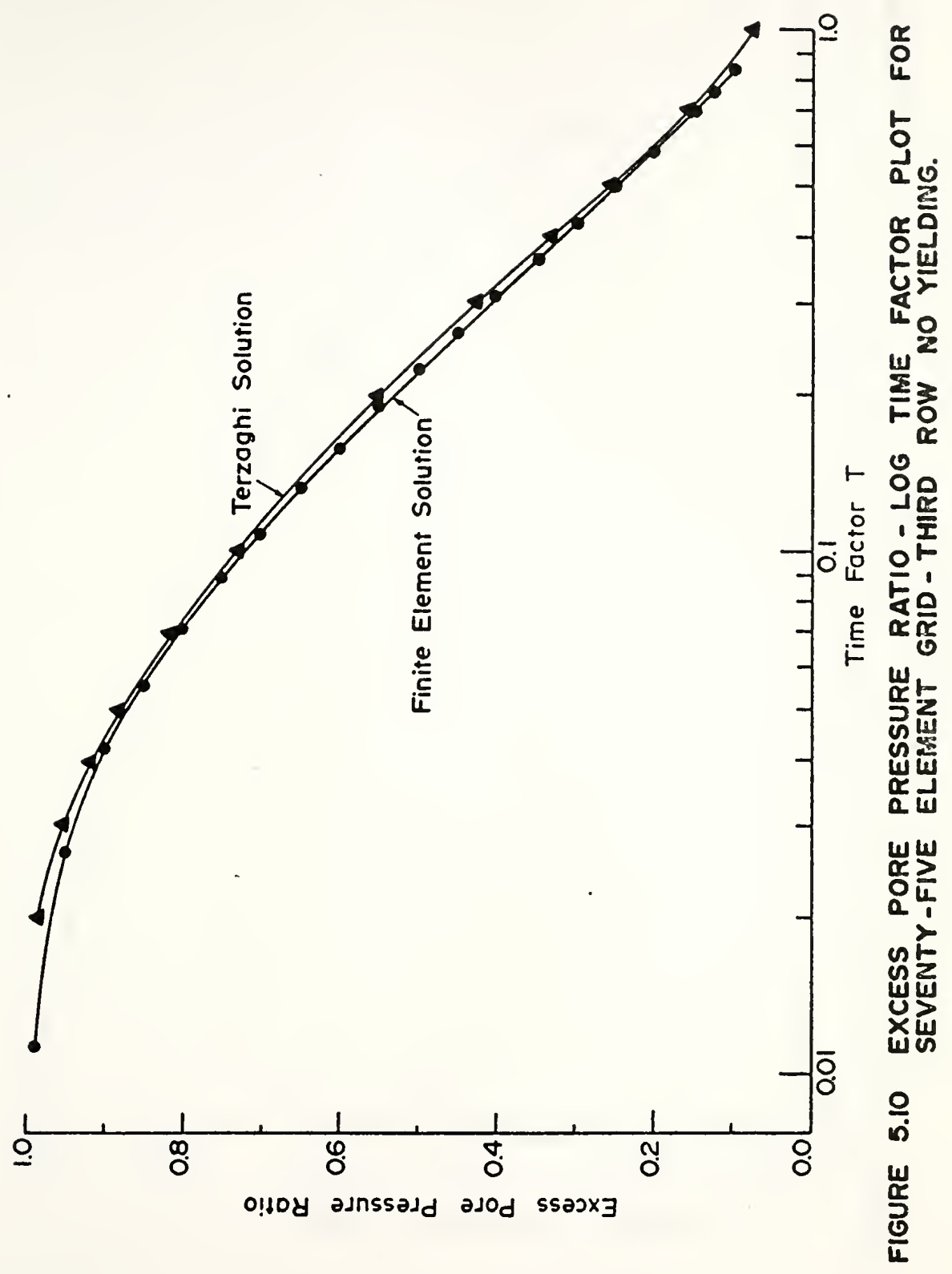




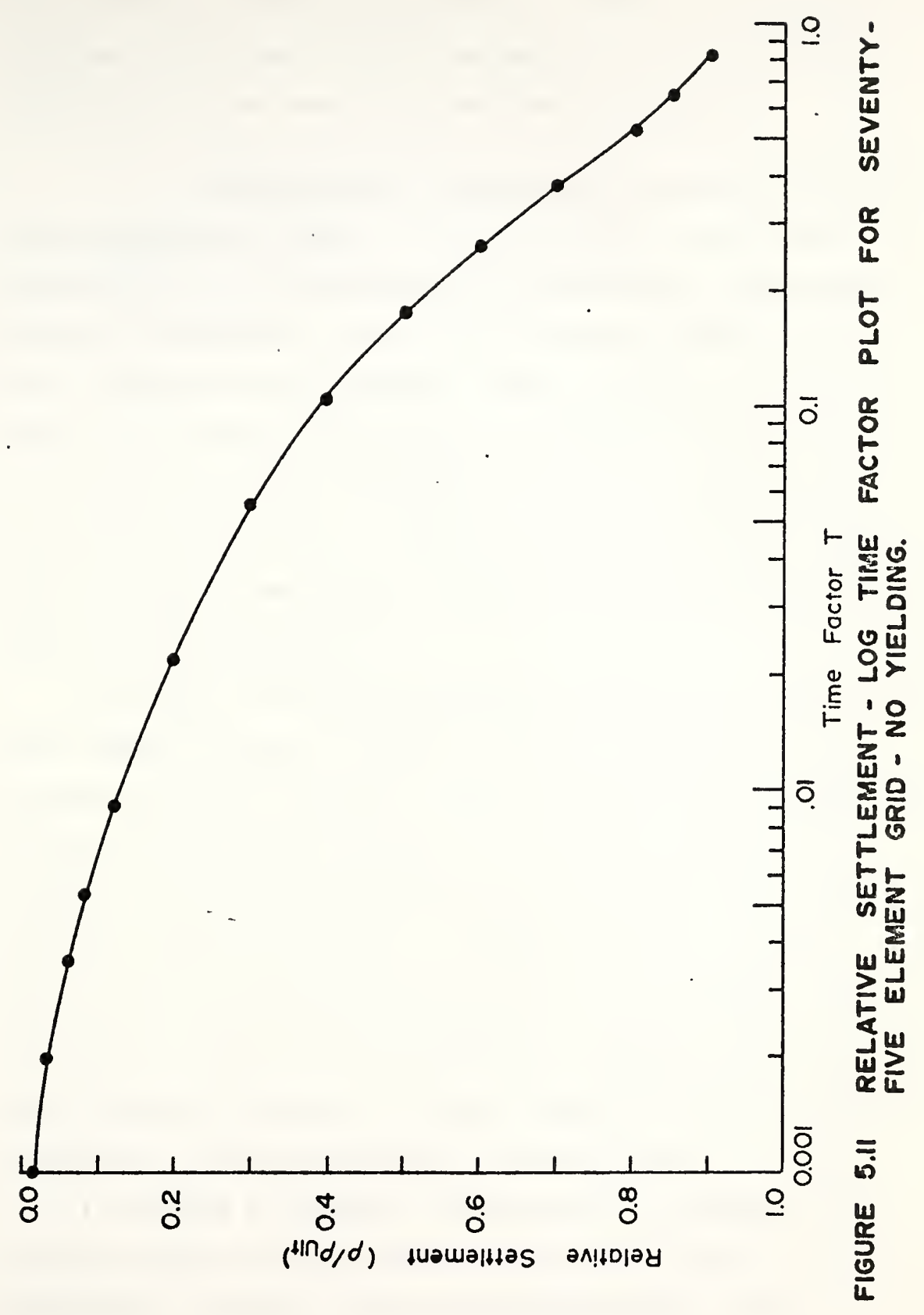


In Section 5.5.3 these plots will be compared with results obtained for a similar grid configuration, but with consideration of the quasi-preconsolidation behavior.

5.5.3 One-Dimensional Consolidation Problem with QuasiPreconsolidation Effect. A finite element solution was obtained to the corresponding one-dimensional consolidation problem in which the quasi-preconsolidation effects previously discussed were included. This solution was generated using the seventy-five element mesh shown in Figure 5.5. In addition, in order to observe in detail changes within an element when it, or a neighboring element yiclds, two further meshes consisting of one and two elements were used. These are discussed below.

The single element representation illustrates the effect which sudden change in elastic modulus, corresponding to yielding, has on excess pore pressures and volume strain at the point where yield occurs. The single element was a square, undrained on three sides and subjected to a uniform vertical surface pressure. As shown in Figure 5.12 the nodes were constrained to permit only one-dimensional displacements of the element boundaries. Figures 5.13 and 5.14 show, respectively, plots of pore pressure ratio and relative settlement versus logarithm of the time factor.

The effect of yielding was obtained by reducing the elastic modulus E by a factor of four after five time increments of excess pore pressure dissipation. This 


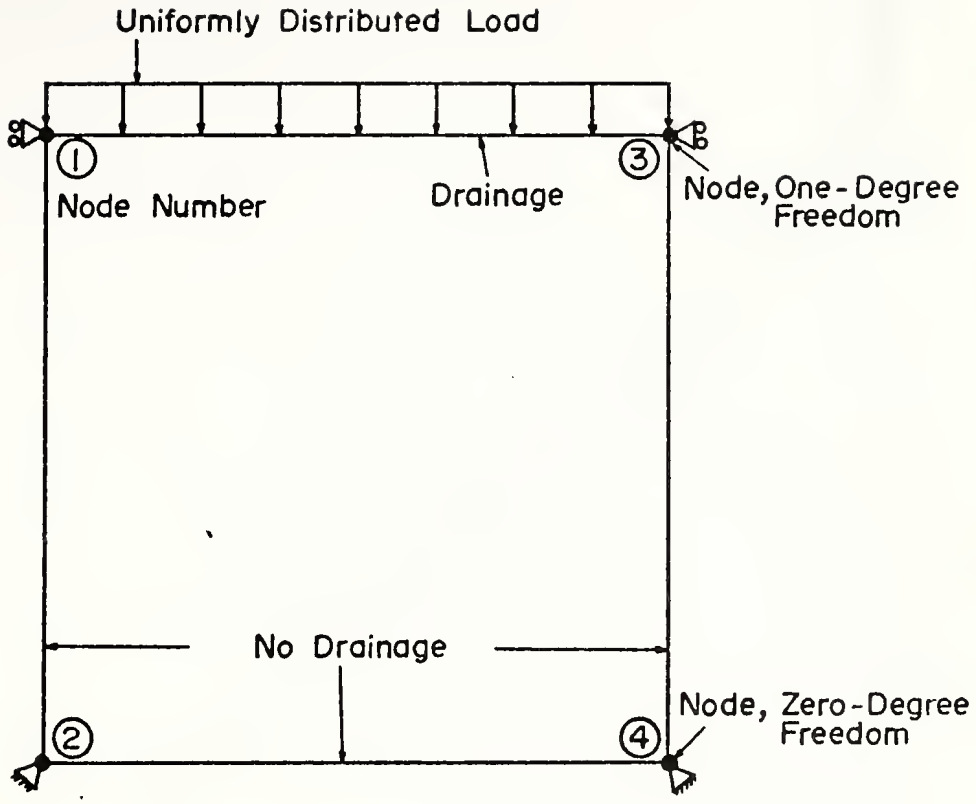

FIGURE 5.12 SINGLE ELEMENT CONSOLIDATION GRID. 


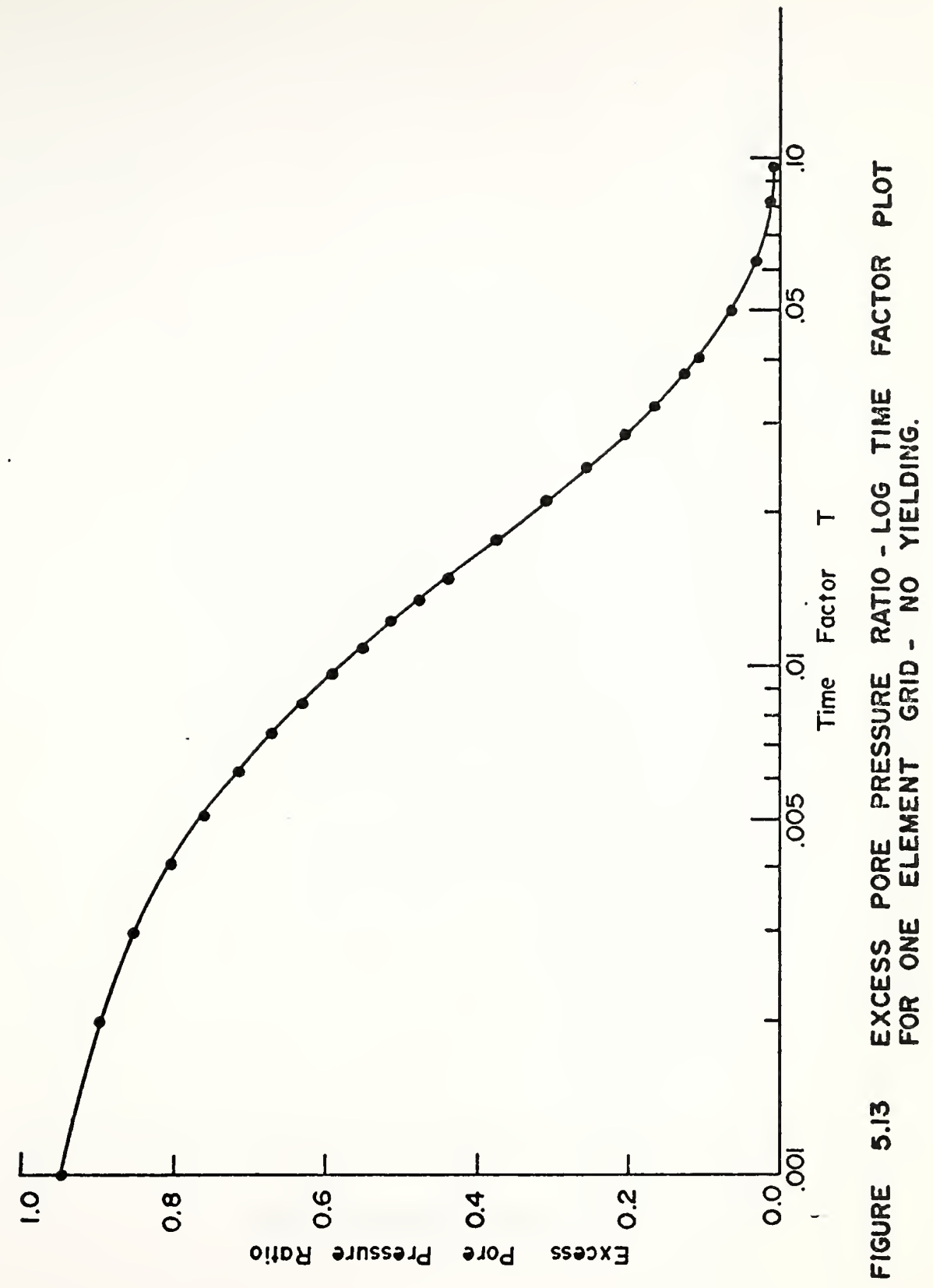




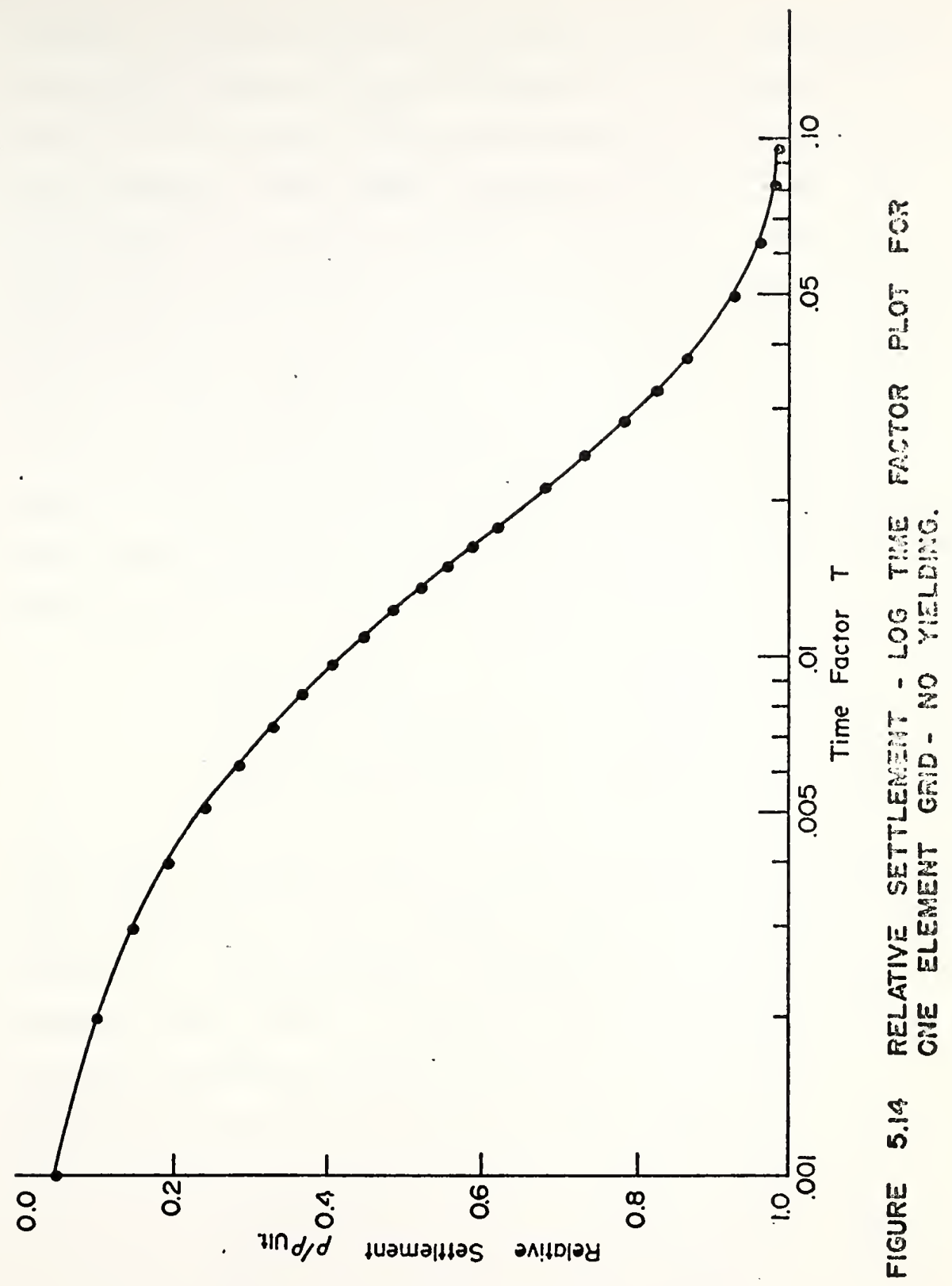


induced yielding resulted in the pore pressure and relative settlement response depicted respectively in Figures 5.15 and 5.16. The curves for the non yielding case are plotted for comparison. The sudden yielding and increase in compressibility of the soil skeleton results in a transfer of load to the pore fluid, and the consequent increase in excess pore pressure ratio from 0.76 to 0.94 (Figure 5.15). For the single element representation, these values can be verified directly: For the one-dimensional consolidation process, applied boundary loads are supported initially by the pore water and not by the soil skeleton. The initial stresses, normalized with respect to the applied load, are

$$
\begin{array}{ll}
\text { Total stress } & \sigma=1.00 \\
\text { Excess pore pressure } & u=1.00 \\
\text { Effective stress } & \bar{\sigma}=0.00
\end{array}
$$

With timc, as water drains from the clay soil the excess pore pressure at a point decreases and the effective stress increases. The one element representation indicates a pore pressure ratio value of 0.76 just prior to yielding. Since in the one-dimensional case the total stress remains constant the normalized stresses at this time are

$$
\begin{array}{ll}
\text { Tota1 stress } & \sigma_{b}=1.00 \\
\text { Excess pore pressure } & u_{b}=0.76 \\
\text { Effective stress } & \bar{\sigma}_{b}=0.24
\end{array}
$$




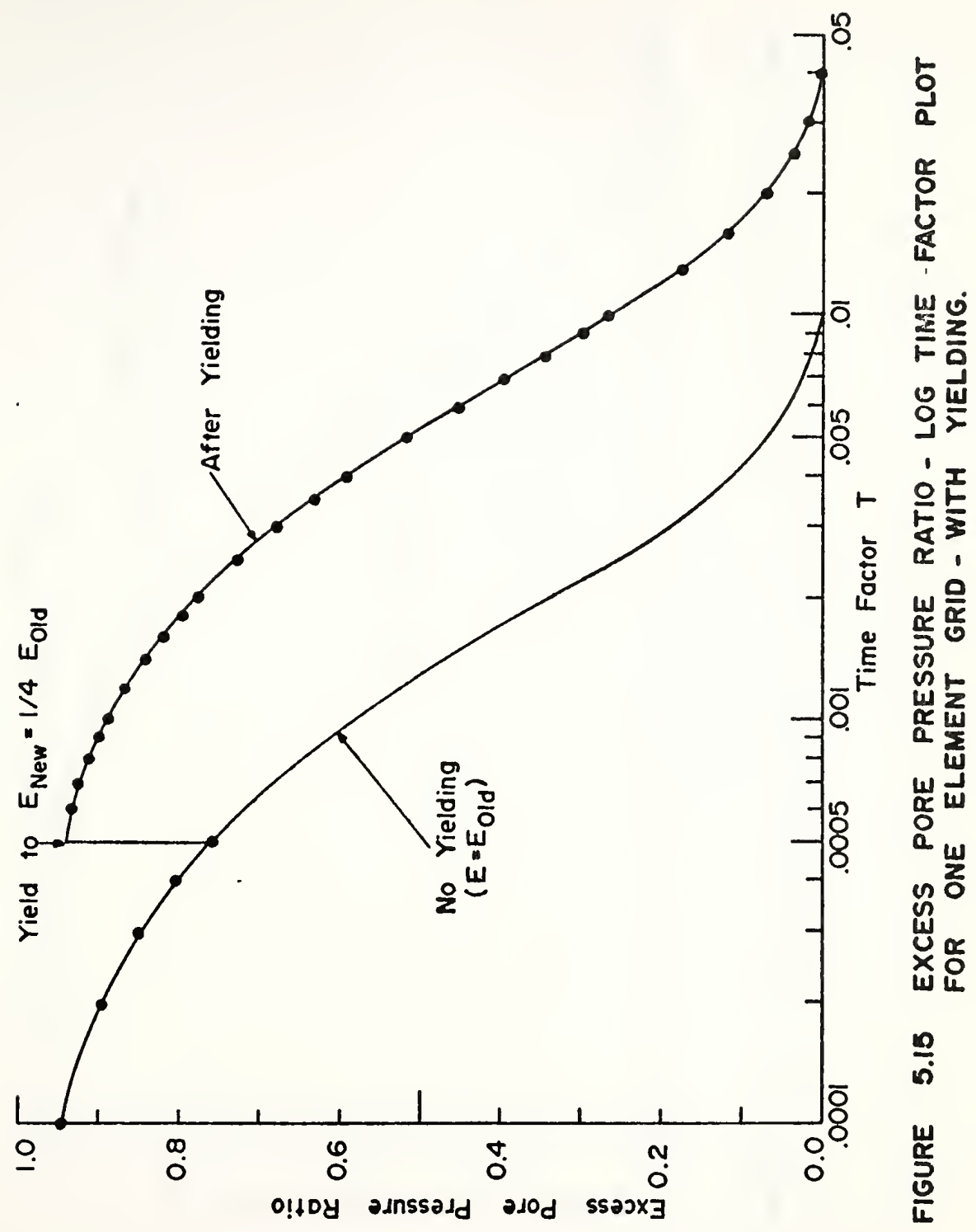




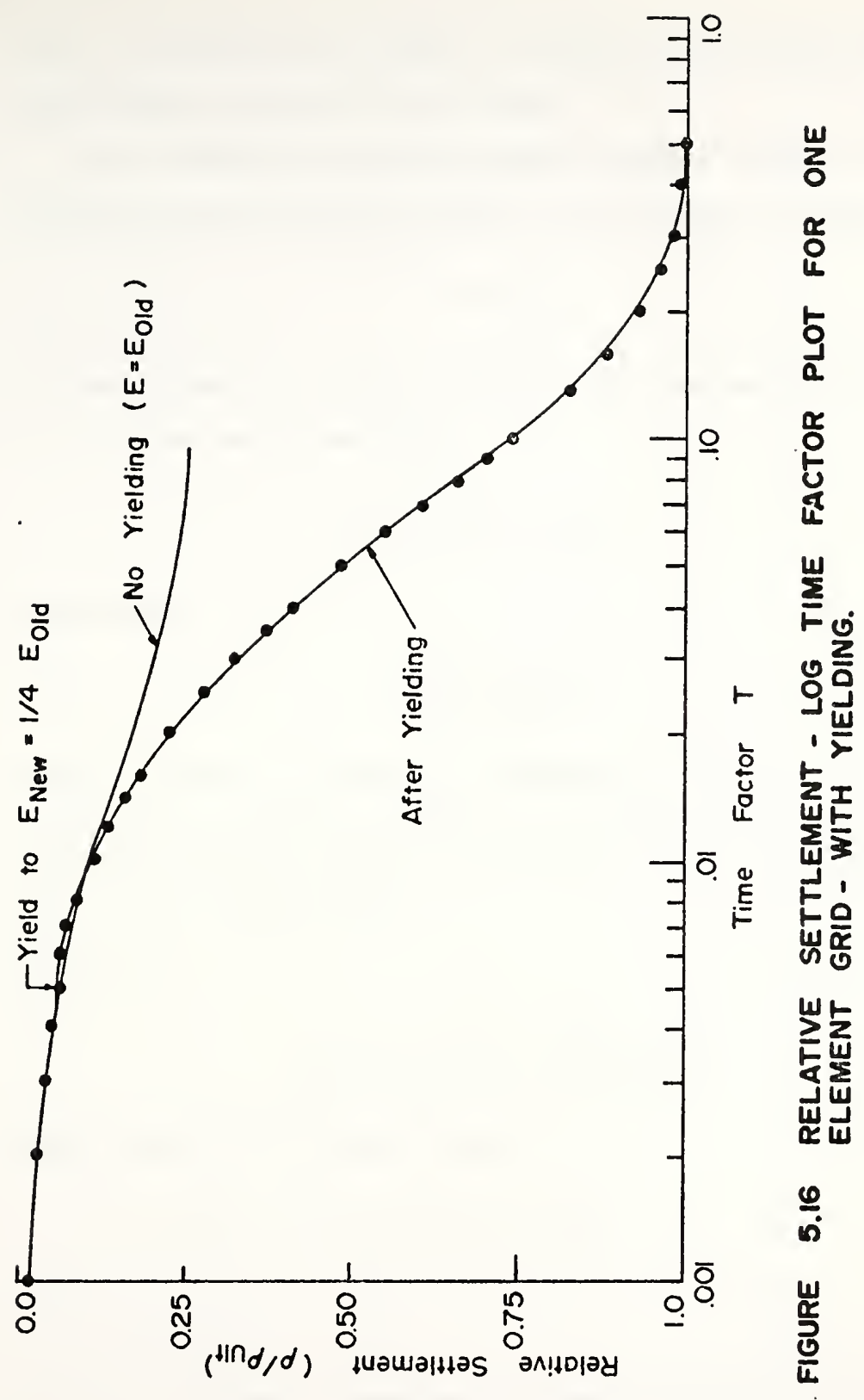


where the subscripts $b$ and a, respectively denote behavior just before and just after yield.

For a model assuming elastic skeleton behavior the effective stress and the strain are related by Hookes Law

$$
E=\frac{\bar{\sigma}}{\mathrm{e}}
$$

and the effective stress principle for the state just prior to yielding may be written

$$
\sigma_{b}=u_{b}+E_{b} \cdot \varepsilon
$$

from which

$$
\varepsilon=\frac{\sigma_{b}-u_{b}}{E_{b}}
$$

Just after the instantaneous yielding the strain has the same value as just before, since no flow of water out of the soil has taken place.

Therefore

$$
u_{a}=\sigma_{a}-E_{a} \cdot\left(\frac{\sigma_{b}-u_{b}}{E_{b}}\right)
$$

Substituting in the known value

$$
\begin{aligned}
u_{a} & =1.00-0.25(1.00-0.76) \\
& =0.94
\end{aligned}
$$

$=$ the pore pressure calculated in the program 
In Figure 5.16 relative settlements are plotted with time for the no-yielding and with yielding conditions. The decrease in elastic modulus upon yielding reduces the coefficient of consolidation $c_{v}$, and consequently the rate of pore pressure dissipation. Larger settlements also result from the reduced $E$.

The results for the two element grid shown in Figure 5.17, illustrate the effects which yielding in one element has on a neighboring element. Using this grid configuration, two features can be observed clearly: the effect of yielding of the upper element on the lower element and, that of the subsequent yielding of the lower element on the already yielded upper element. When no yield occurs, pore pressure dissipation and relative settlement for each element are as shown in Figures 5.18 and 5.19 respectively. The pore pressure in Element 1 initially dissipates more rapidy than in Element 2 because the only drainage surface is the top boundary. At later times however, its drainage is delayed as water from the lower element drains through it. Thus, the pore pressure approaches zero in both elements at the same time. In Figure 5.19 are plotted relative settlements of the elements. These are obtained by dividing the vertical displacements of Node Point 1 which represent the total surface settlement, the vertical displacements of Node Point 2 which represent the settlement within Element 2 , and the difference which represents the settlement within 


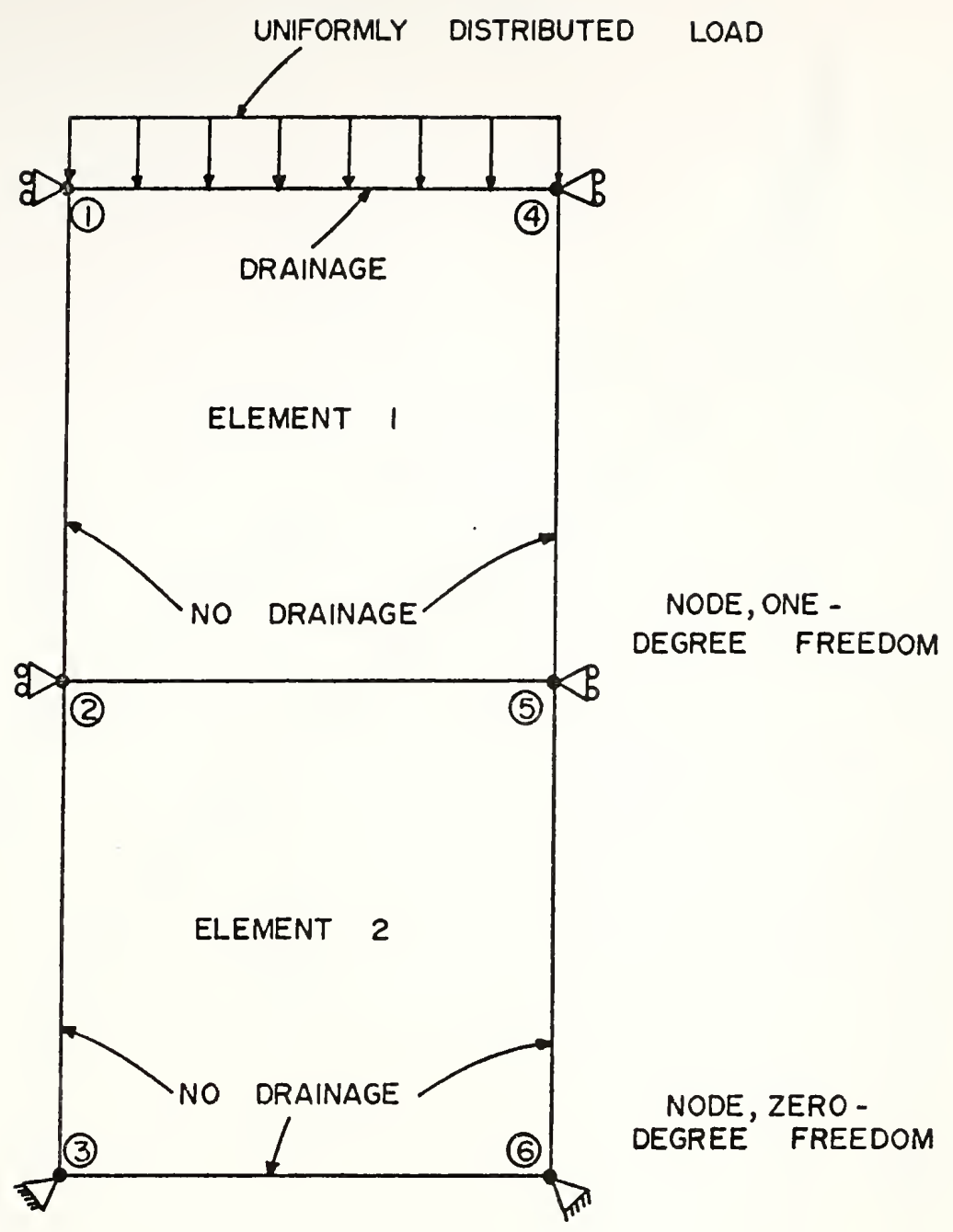

\section{FIGURE 5.17 ELEMENTS FOR TWO ELEMENT} CONSOLIDATION PROGRAM. 


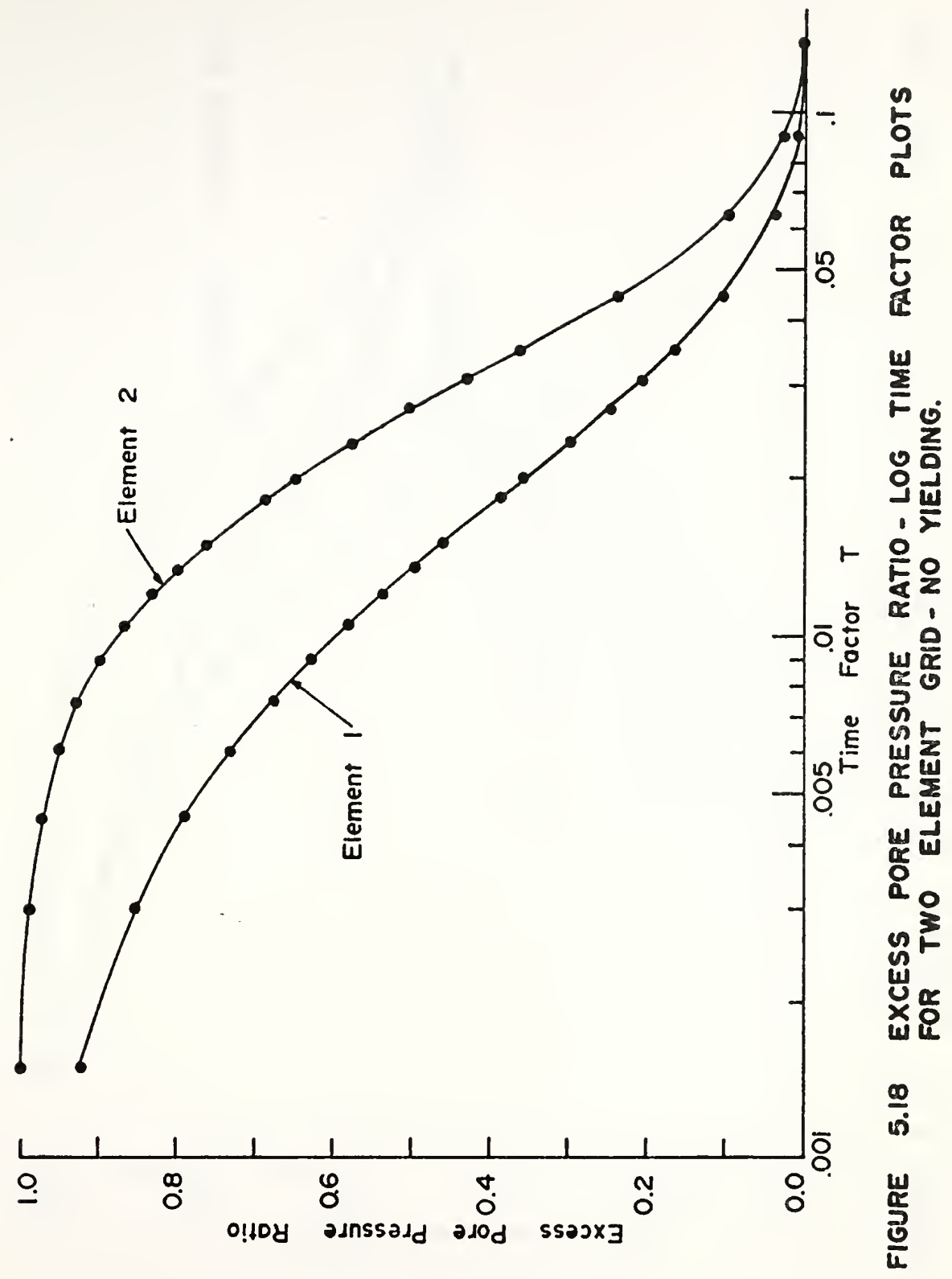




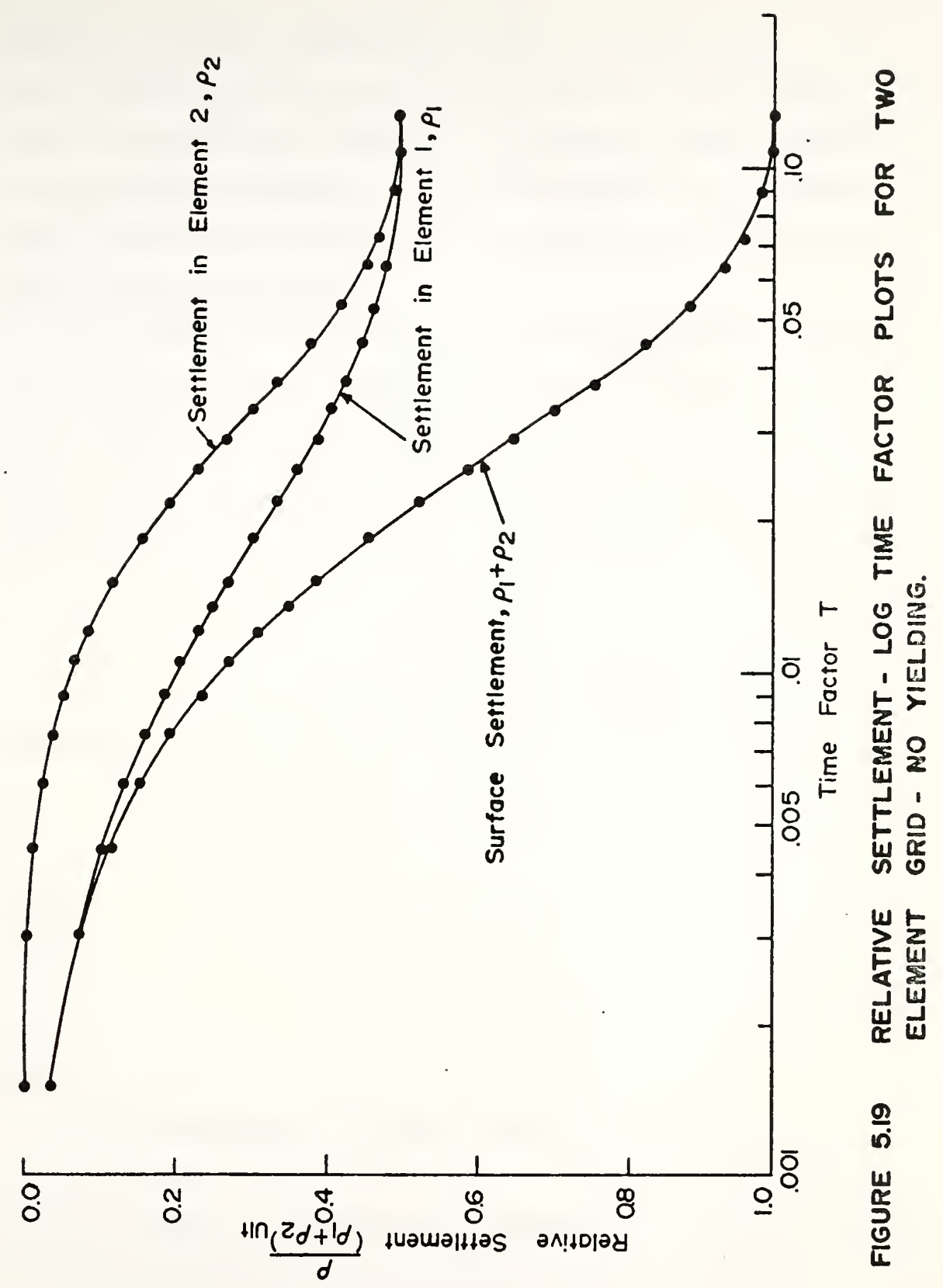


Element 1 , by the ultimate settlement of Node Point 1 . As in the case of the pore pressure dissipation, settlement occurs initially more rapidly in the upper element adjacent to the drainage boundary. Since the elements are identical final settlements within each are equal and one half of the total surface settlement.

The effect of yielding was observed by reducing instantaneously the elastic modulus by a factor of four in the upper clement after five dissipation cycles (at $\mathrm{T}=0.0075$ ) and in the lower element after fifteen cycles (at $T=0.0186$ ). The dimensionless time factor $T$ is defined by

$$
T=\frac{C_{v}}{H^{2}} \cdot t
$$

in which $c_{v}$ refers to the now yielded coefficient of consolidation. For an elastic analysis

$$
c_{v}=\frac{k}{\gamma_{w}} \cdot D
$$

where

$$
\begin{aligned}
& D=2 G \frac{1-\bar{v}}{1-2 \bar{v}} \\
& G=\frac{E}{2} \cdot(1+2 \bar{v})
\end{aligned}
$$

and

$$
\begin{aligned}
c_{v} & =\text { coefficient of consolidation } \\
t & =\text { real time } \\
H & =\text { maximum drainage path length } \\
k & =\text { coefficient of permeability } \\
r_{W} & =\text { unit weight of water }
\end{aligned}
$$




$$
\begin{aligned}
& D=\text { constraint modulus } \\
& G=\text { shear modulus } \\
& \bar{v}=\text { Poisson's ratio of the soil skeleton } \\
& E=\text { Young's modulus }
\end{aligned}
$$

The excess pore pressure ratio versus logarithm of the time factor for Element 1 is given in Figure 5.20, along with the no yield curve. When yielding occurred in Element 1 there was again, as in the one element program, an instantaneous increase in excess pore pressure due to the increased compressibility of the skeleton and the transfer of the load to the pore water. When Element 2 yielded at time factor 0.0186 , the effect of its pore pressure increase on Element 1 was small. The pressure gradient due to the drainage boundary dominated bchavior in Element 1 , and the effect of the increased gradient and increased flow of water from Element 2 upon its yielding was insignificant. The effect of the yielding of an element on another element which has already yielded, but which does not bound a drainage zone, will be observed in the results for the seventy-five element mesh discussed below.

Pore pressure behavior for the lower element, Number 2, is plotted in Figure 5.21, along with its no yield curve. When the upper element yielded at $\mathrm{T}=0.0075$ its pore pressure increased instantaneously, reducing the gradient and flow out of Element 2 . The rate of dissipation is markedly decreased, and the plot is displaced to the right 


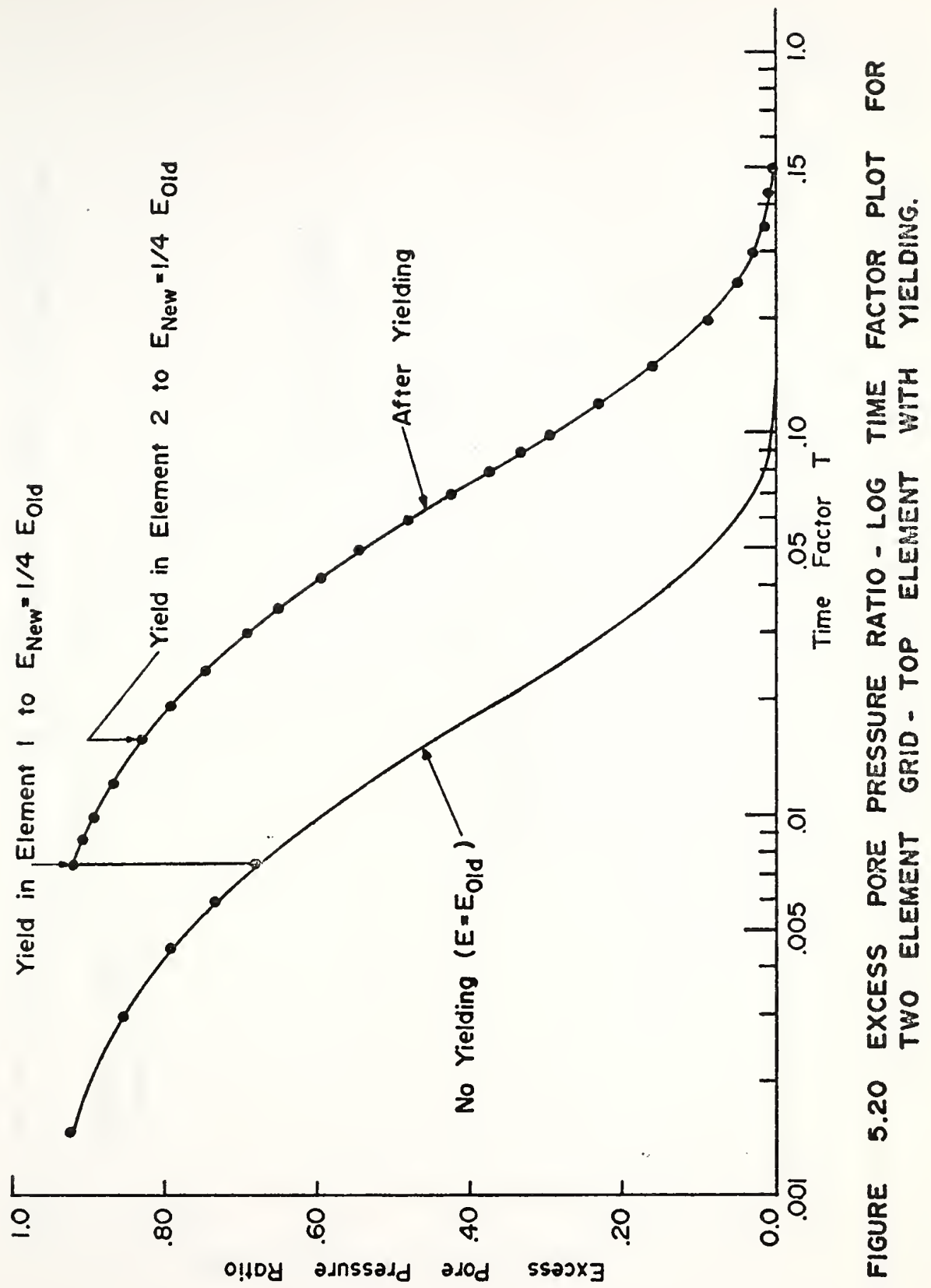




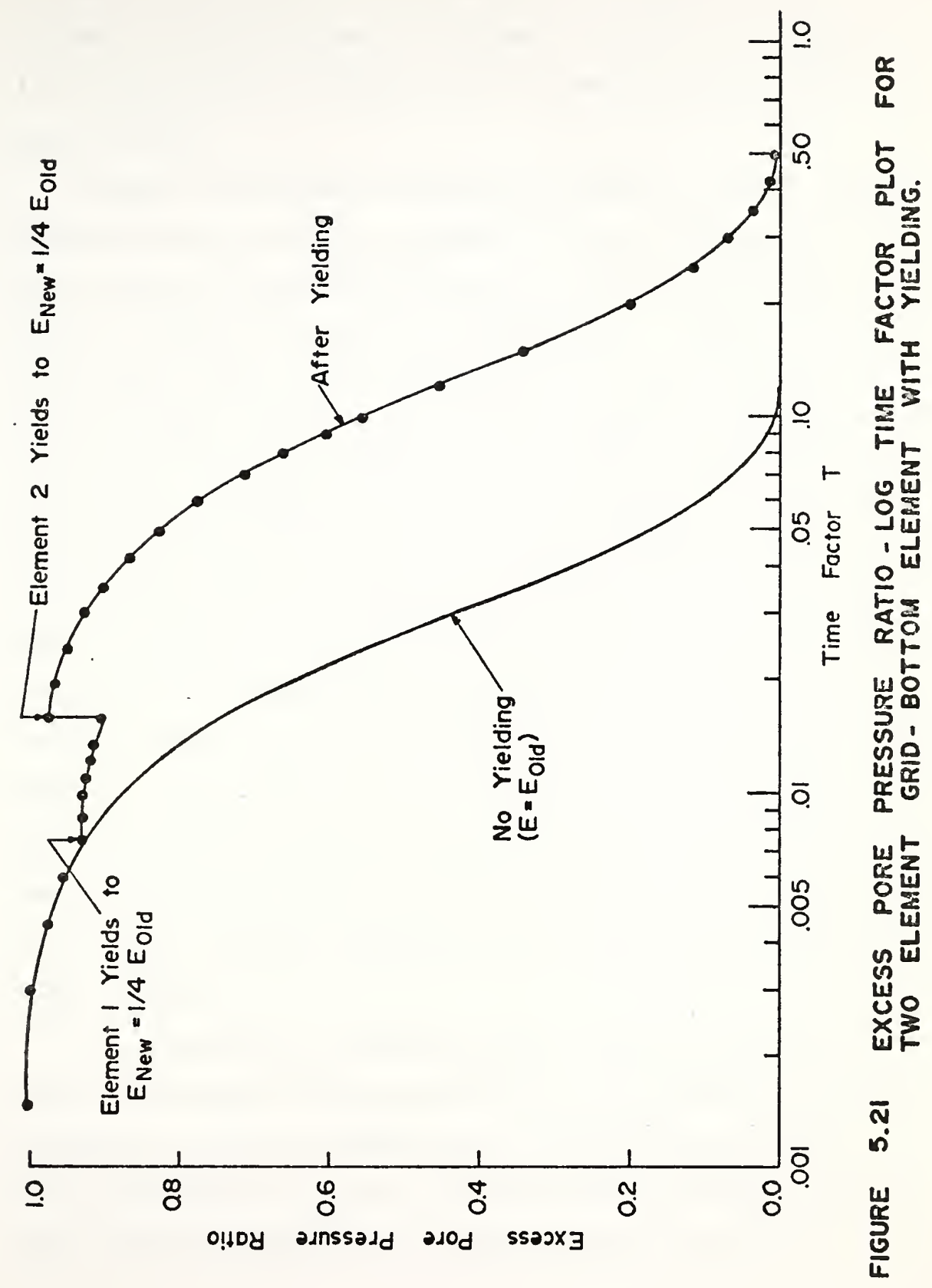


of the no yield curve. At time factor 0.0186 when it yielded, the pore pressure in Element 2 increased from 88 to 97 percent of its initial value, then dissipated with tíme to zero.

Relative settlements within the upper and lower elements and the total relative settlement for the yielding case, along with the corresponding no yield curves, are given in Figures $5.22,5.23$ and 5.24 , respectively. Settlement due to Element 1, Figure 5.22, is similar in form to that found for the single element mesh. After yielding, the rate of settlement is decreased and the final magnitude increased. No effect is observed on this plot when Element 2 yields. In the lower element, Figure 5.23, settlements initially are equal to the no yield values. After Element 1 yields, displacements are small until Element 2 itself yields at time factor 0.0186 . Settlements then occur in greater magnitude than for the no yield behavior. In Figure 5.24 is given the total relative surface settlement representing the sum of the previous two plots, and showing the increase in settlement due to the increased compressibility of the soil skeleton upon yielding.

The seventy-five element mesh was used with the laboratory derived model incorporated into the program to determine solutions to the one-dimensional consolidation problem for a soil which exhibits a quasi-preconsolidation effect. Rather than inducing yielding at a specific time, as in the 


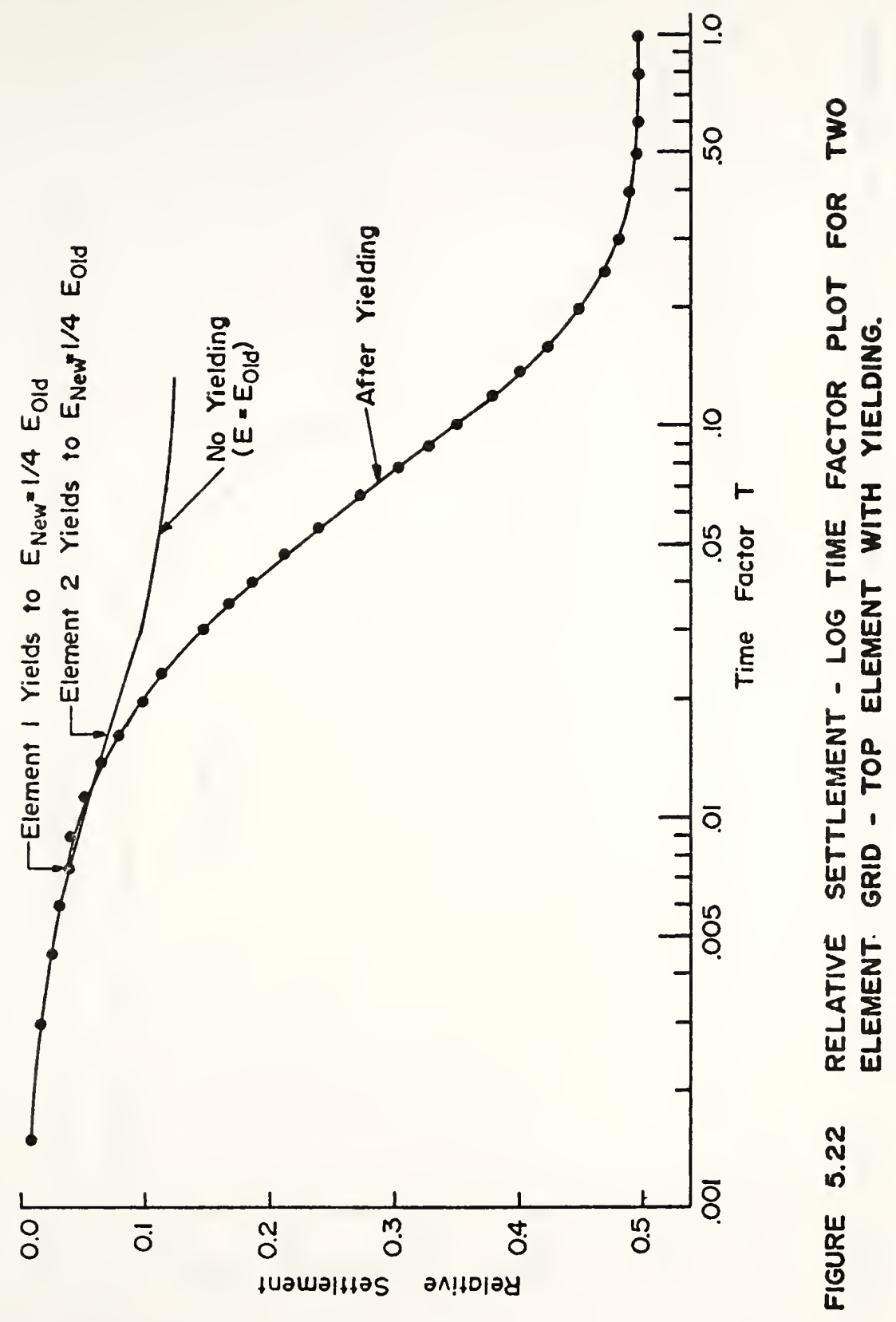




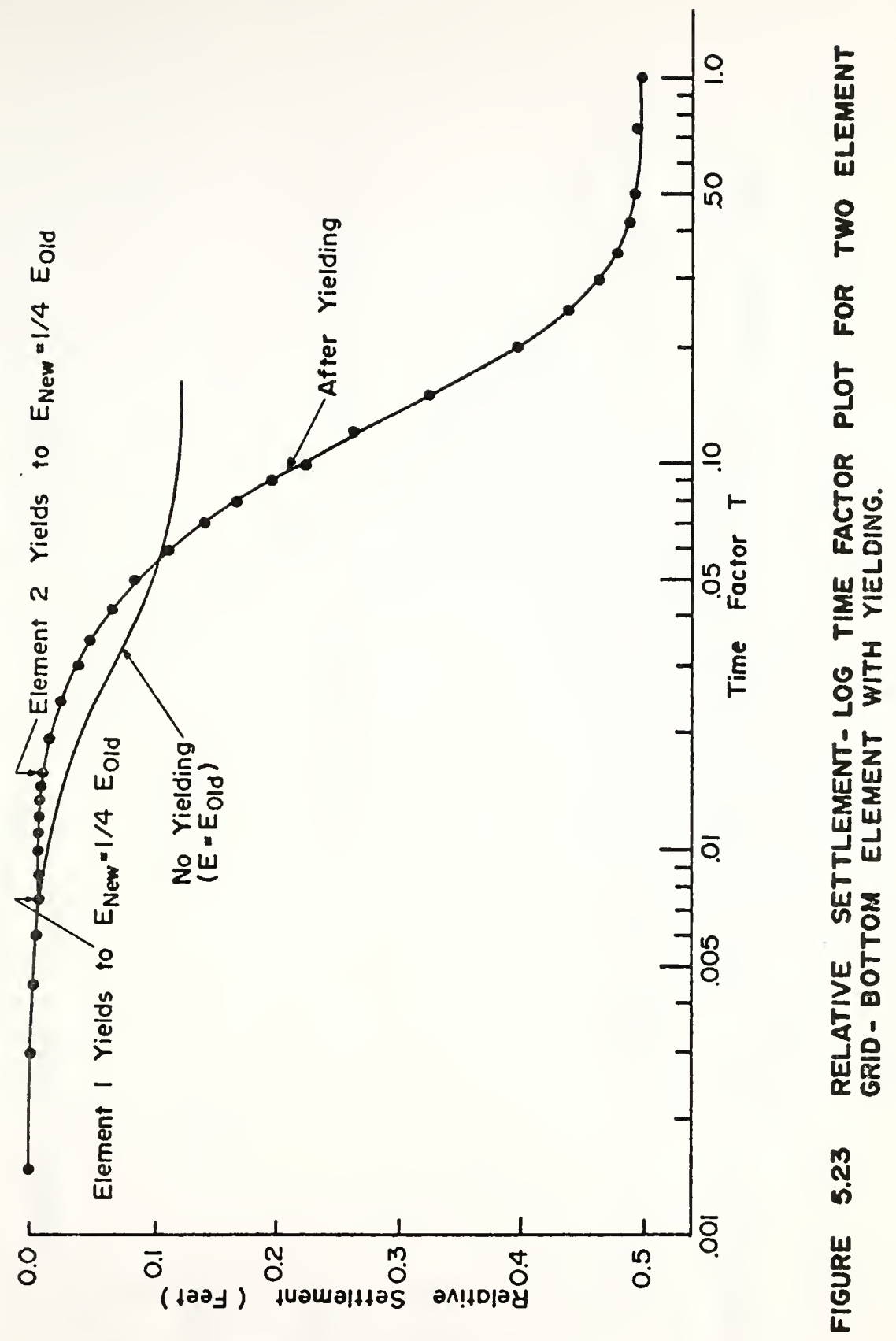




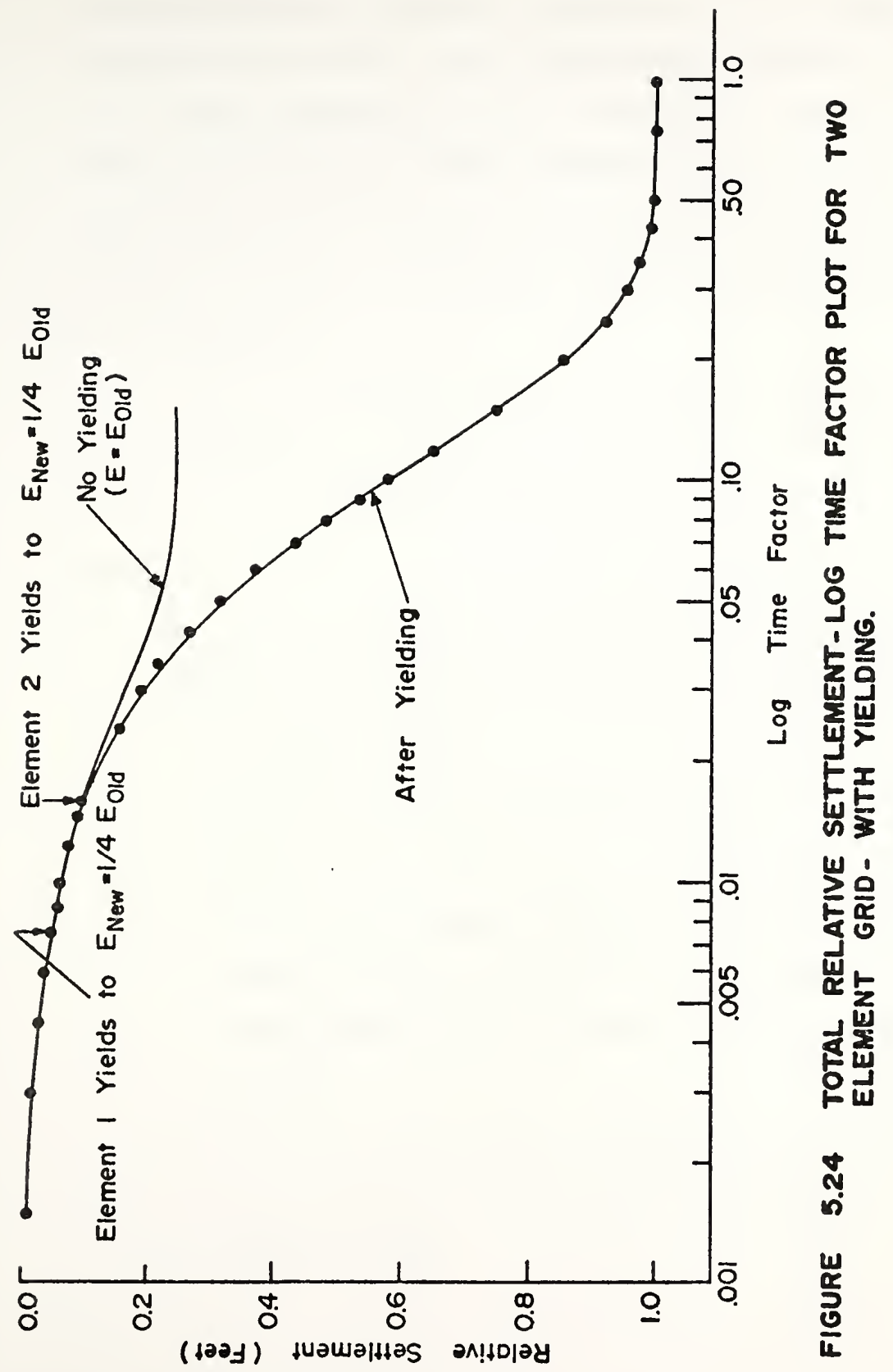


illustrative one and two element representations, yielding occurred when the effective stress state in an element exceeded the elliptic cone yield surface defined in Section 4.3. After each cycle of pore pressure dissipation the effective octahedral stress increments $\Delta \bar{\sigma}_{\text {oct }}$ and $\Delta \sigma_{\text {oct }}$, for each element, were checked to determine whether they lay within or outside the effective stress yield surface defined by the equation

$$
\begin{aligned}
\left(\Delta \tau_{\text {oct }}\right)^{2} & =0.032818\left(\bar{\sigma}_{q}\right)^{2}+0.067384\left(\bar{\sigma}_{q}\right)\left(\Delta \bar{\sigma}_{o c t_{q}}\right) \\
& -0.52570\left(\Delta \bar{\sigma}_{\text {oct }}\right)^{2}
\end{aligned}
$$

where

$\Delta \tau_{\text {oct }}$ is the octahedral shear stress increment at yield $\Delta \bar{\sigma}_{\text {oct }}{ }_{\mathrm{q}}$ is the octahedral effective normal stress increment at yicld

$\bar{\sigma}_{q}$ is the $q$-consolidation pressure

This was accomplished in the following steps:

1. For the particular element the effective octahedral normal stress at its center was calculated. This represented the $q$-confinement pressure for that element.

2. For this q-confinement pressure the yield curve on the $\Delta \tau$ oct $-\Delta \bar{\sigma}_{\text {oct }}$ plane was determined (Figure 5.25). 


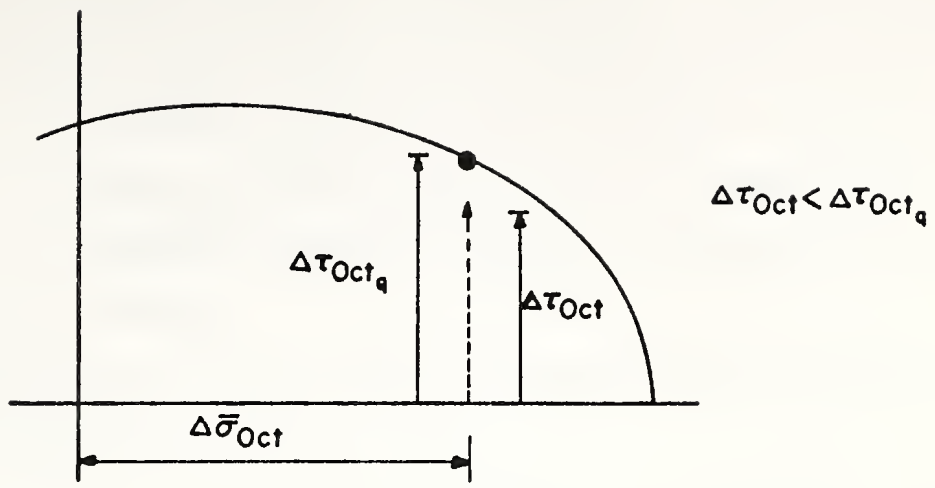

Element Not Yielded

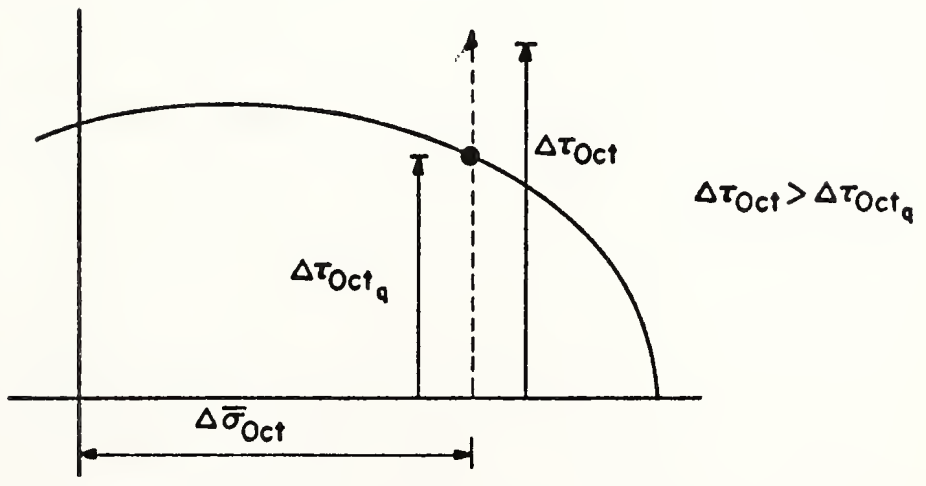

Element Yielded

FIGURE 5.25 ELEMENT YIELD AND NO YIELD CONDITIONS. 
3. For the element $\Delta \bar{\sigma}_{\text {oct }}$ the $\Delta \tau$ oct was compared with the ordinate of the curve intersection $\Delta \tau$ oct $q$.

4. If $\Delta \tau_{\text {oct }}$ was greater than $\Delta \tau_{\text {oct }}$ the element had yielded, and soil properties were reassigned. If $\Delta \tau_{\text {oct }}$ was less than $\Delta \tau_{\text {oct }}$ the element had not yielded, and soil properties remained at pre-yield values.

Sketches of no yield and yield conditions are shown in Figure 5.25 .

The state of the soil relative to yielding at each depth for the seventy-five element representation is shown schematically in Figure 5.26. At time zero when the surface load is applied, the excess pore pressure ratios are equal to unity in all elements for the one-dimensional case, and none of the elements have yielded. This is illustrated in the left hand diagram in Figure 5.26 by the unshaded squares. Due to the hydraulic gradient across the drainage boundary, water flow out of the soil, and the excess pore pressures dissipate with time. Since both loading and drainage are one-dimensional, behavior is identical, within the accuracy of the numerical method, in all elements in any row of the finite element grid. Pore water drainage occurs most rapidly in the top row of elements adjacent to the drainage boundary, and at time factor 0.00046 the excess pore pressure ratio has dissipated to 0.9569 . The effective stresses have changed such that at this time the effective octahedral 


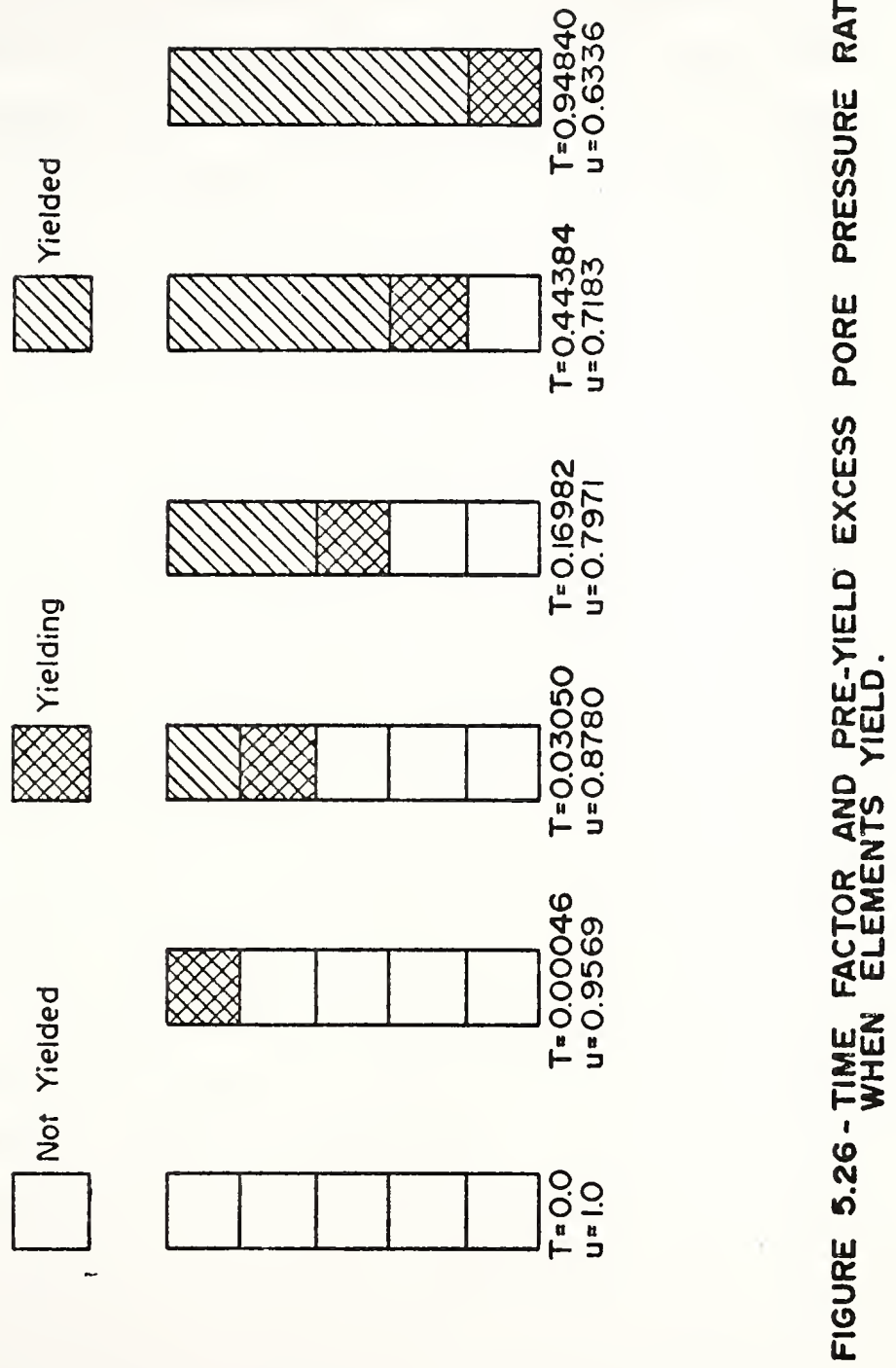


stress state lies outside the yield surface, Figure 5.26. This result is indicated schematically in the second diagram in Figure 5.26. Thus the elastic modulus was reduced in all top row elements to the post yield value. At $\mathrm{T}=0.03050$, when the excess pore pressure ratio in the second row of elements has dissipated to 0.8780 , the second row yields. The block diagrams in Figure 5.26 illustrate the time factor at which this and lower rows yield, and the excess pore pressure ratios within the yielding elements.

In Figure 5.27 is shown the excess pore pressure ratio versus logarithm of the time factor for a top row element for the seventy-five element one-dimensional consolidation representation, with the quasi-preconsolidation model incorporated. Also plotted for comparison is the no yield curve from Figure 5.8. As in the simple one and two element cases, excess pore pressures increase suddenly when the element yields. And, as in the two element model, there is no significant effect on these pore pressures when lower elements subsequently yield.

A similar plot for a second row element in Figure 5.28 shows four distinct effects due to yielding of the top, second, third and fourth rows. The top row of elements yielded at time factor 0.00046 , off the scale of this plot. The effect of this was, as described before, to reduce both the gradient and flow into this upper region. The excess pore pressure ratio plot is therefore displaced to the right 


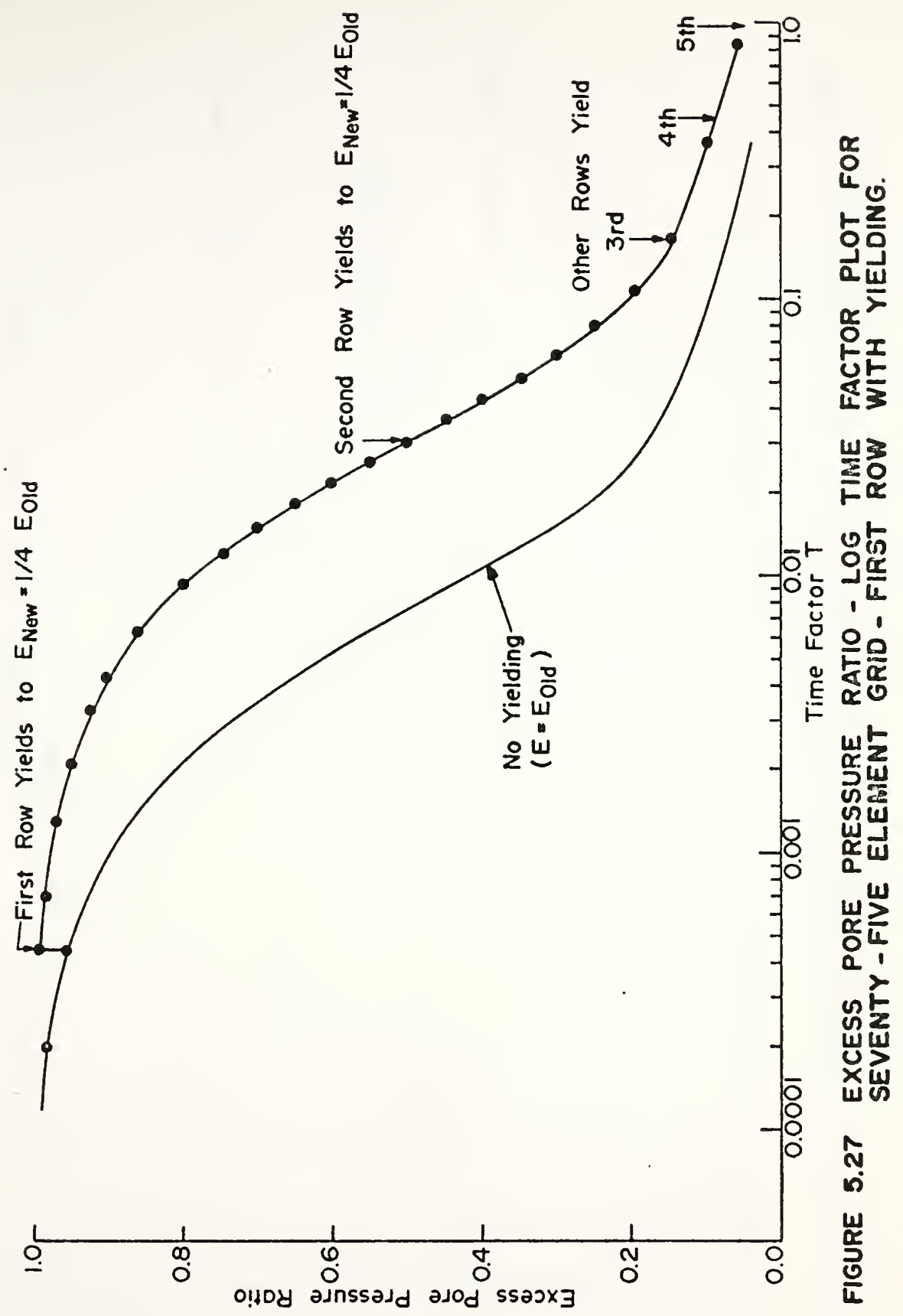




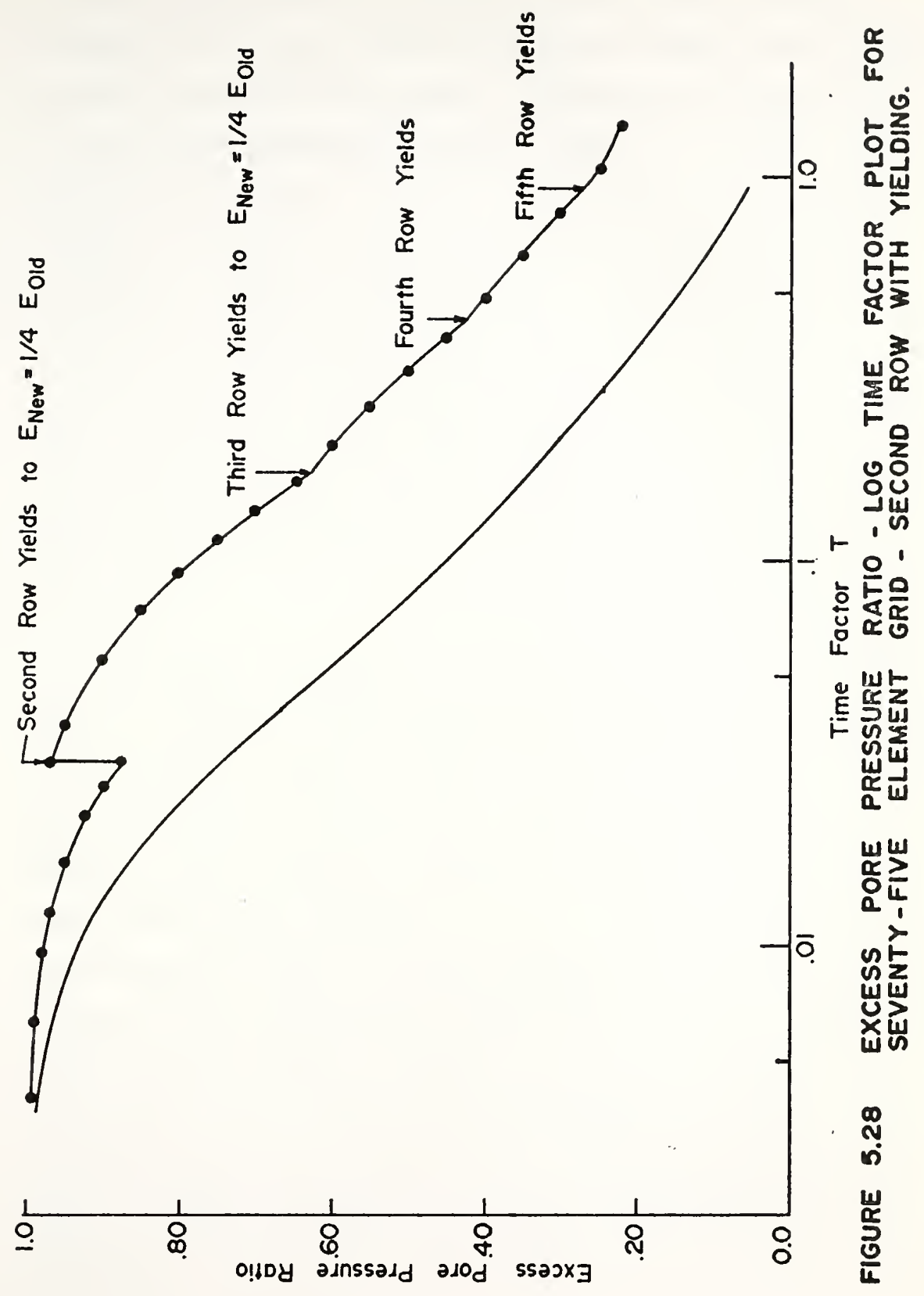


of the no yield curve. At time factor 0.03050 row two yields and the load transfer caused the excess pore pressure increase previously described. Dissipation of pore water pressure then progresses smoothly until $\mathrm{T}=0.16982$, when the third row yields. In this case, unlike the top row of elements, the excess pore pressures are effected by the yielding of elements directly below. The effect of the increased flow of water into the element is significant resulting in a further slowing of the consolidation process. This is observed on the plot as another displacement of the excess pore pressure curve to the right. A smaller effect can be noted at time factor 0.44384 when the fourth row yields.

In Figure 5.29 the plots for a third row element are given. The top row has already yielded by time factor 0.10 , and the curve is offset from the no yield behavior. At time factor 0.03050 row two yields, resulting in a curvature change at this time and a further retarding of the rate of pore pressure dissipation. At $T=0.16982$ the elenent under consideration yields with the associated sudden pore pressure increase. The fourth row yields at time factor 0.44384 and the fifth row yields at time factor 0.94840 . In each case, the effect of the increased compressibility of lower rows is to reduce the rate at which the excess pore pressure dissipates. Similar results were obtained for lower rows of elements. 


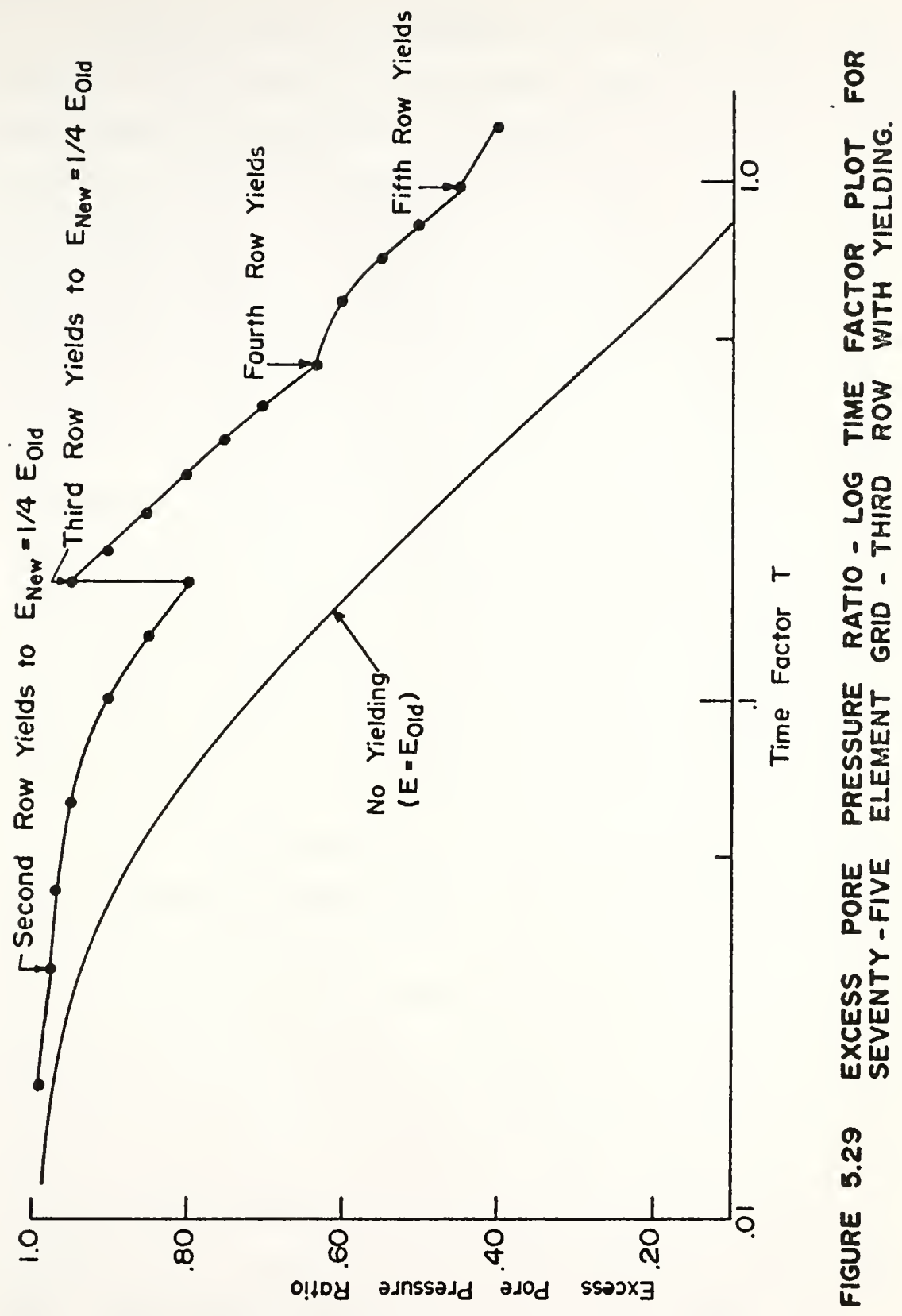


Relative surface settlements are plotted versus logarithm of the time factor in Figure 5.30, with the no yield case shown for comparison. Yielding of the top row of elements has already occurred by time factor .001 and the settlement curve lies to the left of that for no yield behavior. Changes in curvature resulting in increased settlements can be observed as each subsequent row of elements yields, at time factors $0.03050,0.16982$ and 0.94840 . In order to better illustrate these curvature changes in the settlement plot, four programs were run in which pore pressures corresponding to states just prior to yielding were input. Pore pressure dissipation was then continued but yielding was not permitted. These results are shown in Figure 5.30 as dotted curves, and illustrate the deviation in the settlement curve due to yielding

\subsubsection{Two-Dimensional Consolidation Problem, No}

Quasi-Preconsolidation Effect. The two-dimensional problem was introduced in Section 5.5.1 and illustrated in Figure 5.2. It consists of a stratum of clay soil underlain by a rigid impervious boundary, and loaded by a uniformly distributed surface strip load. This plane strain configuration is represented by the finite element grid consisting of 100 square elements and 126 nodal points, shown in Figure 5.31. Output from the two-dimensional finite element consolidation program consists of horizontal and vertical nodal displacements and excess pore pressure 


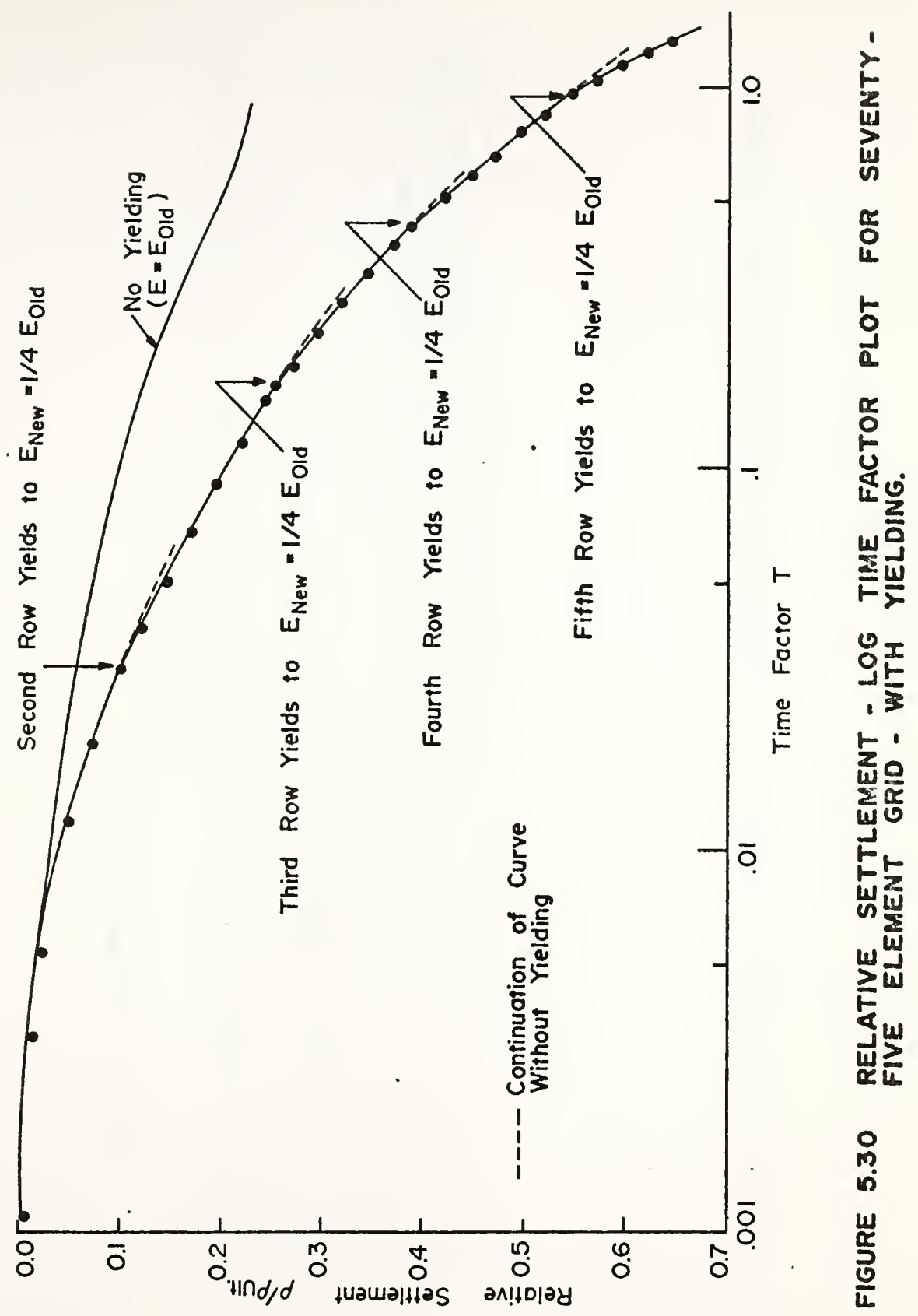




\begin{tabular}{|c|c|c|c|c|c|c|}
\hline 28 & & & & & & \\
\hline ต & $\hat{\sigma}$ & $\stackrel{\infty}{\sigma}$ & ब & 응 & & 5 \\
\hline $\bar{\sigma}$ & $\stackrel{N}{\sigma}$ & m & बั & $\stackrel{n}{\infty}$ & & $\sum_{\text {Wu }}^{\mathbf{W}}$ \\
\hline$\stackrel{\infty}{\infty}$ & $\hat{\infty}$ & $\underset{\infty}{\infty}$ & $\underset{\infty}{\mathscr{\infty}}$ & 요 & 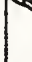 & $\vec{u}$ \\
\hline $\bar{\infty}$ & $\underset{\infty}{N}$ & $\underset{\infty}{M}$ & $\underset{\infty}{+}$ & $\stackrel{\mathscr{\infty}}{\mathscr{\infty}}$ & 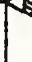 & 트 \\
\hline $\mathscr{N}$ & $\hat{\boldsymbol{N}}$ & $\stackrel{\infty}{\sim}$ & $R$ & $\stackrel{\infty}{\circ}$ & 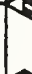 & $\frac{\vec{u}}{1}$ \\
\hline $\bar{N}$ & $\mathbb{N}$ & $\stackrel{M}{R}$ & R & $\stackrel{n}{R}$ & & u \\
\hline $\mathscr{\varphi}$ & $\hat{\sigma}$ & $\underset{0}{\mathscr{0}}$ & $\stackrel{\sigma}{6}$ & 웅 & 6 & 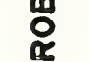 \\
\hline$\overline{0}$ & $\widetilde{\sigma}$ & m & ष & $\ddot{\varphi}$ & & \\
\hline $\mathscr{\varphi}$ & in & $\begin{array}{l}\infty \\
0 \\
0\end{array}$ & ( & 웁 & 6 & \\
\hline $\bar{n}$ & $\widetilde{N}$ & m & ப் & $n$ & 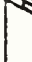 & $\frac{1}{0}$ \\
\hline $\mathscr{\sigma}$ & $\hat{\sigma}$ & $\mathscr{q}$ & \& & 응 & & ? \\
\hline $\bar{\sigma}$ & $\mathscr{q}$ & $\stackrel{m}{q}$ & 8 & $\mathscr{q}$ & & \\
\hline$\ddot{m}$ & $\hat{m}$ & $\begin{array}{l}\infty \\
m\end{array}$ & m & 암 & F & \\
\hline $\bar{m}$ & $\stackrel{N}{m}$ & $\stackrel{M}{M}$ & $\dot{m}$ & $\stackrel{n}{m}$ & & $\sum_{\text {iu }}$ \\
\hline$\stackrel{\varphi}{N}$ & $\bar{N}$ & $\stackrel{\infty}{\sim}$ & $\stackrel{D}{N}$ & 음 & 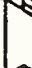 & $\frac{5}{0}$ \\
\hline $\bar{N}$ & $\stackrel{N}{N}$ & M & $\stackrel{d}{N}$ & $\stackrel{n}{N}$ & & 울음 \\
\hline$\varphi$ & $\simeq$ & $\underline{\underline{Q}}$ & $\underline{\sigma}$ & 오 & & $\bar{n}$ \\
\hline$=$ & $\underline{N}$ & $\underline{m}$ & \pm & $\underline{\underline{n}}$ & & $\dot{0}$ \\
\hline$\varphi$ & $\wedge$ & $\infty$ & $\sigma$ & 으 & & $\underset{\alpha}{\underline{\alpha}}$ \\
\hline- & $N$ & $m$ & $\sigma$ & $n$ & & $\frac{U}{u}$ \\
\hline
\end{tabular}


ratios at different values of the time factor. The time factor $T$ is defined as in Equation (5-53) with $H$ equal to the thickness of the clay stratum. The excess pore pressure ratio is the actual pore pressure at the center of an clement, divided by the magnitude of the distributed load. Contours of the initial distribution of excess pore pressure are given in the upper diagram of Figure 5.32. Values are greatest directly under the center of the load, and decrease with depth and with horizontal distance from the loaded area. The lower diagram of Figure 5.32, and the upper diagram of Figure 5.33, show the rapid dissipation of pore pressures in the top row of elements adjacent to the only drainage boundary. With further time pore pressures dissipate in all elements, and the contour lines move down through the soil 1ayer. By time factor 0.59671 the pore pressure ratios in all elements are less than 0.1. Figures 5.32, 5.33 and 5.34 illustrate with contour diagrams the progression of pore pressure dissipation.

Plotted below each pore pressure contour diagram is the corresponding surface settlement. Initially, at time factor equal to zero, there is settlement under the load and heave outside the loaded area. Had the finite element grid extended further laterally, this heave would have decreased to zero at some distance from the load. The area enclosed by the settlement portion of this plot is equal to the heave area, indicating that the initial settlement was due 


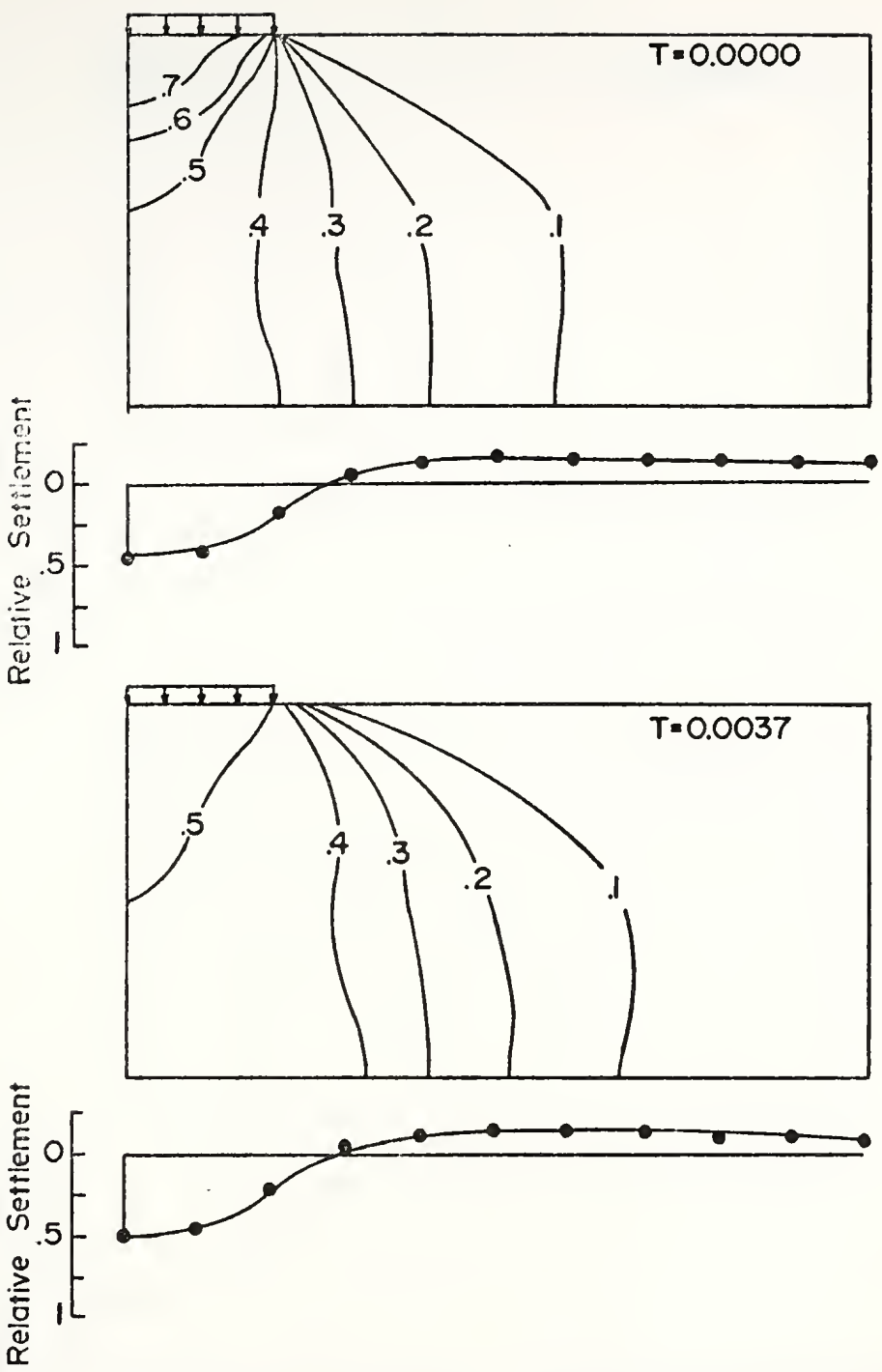

FIGURE 5.32-PORE PRESSURE CONTOURS AND RELATIVE SETTLEMENTS FOR TWO DIMENSIONAL PROBLEM - NO YIELDING I. 

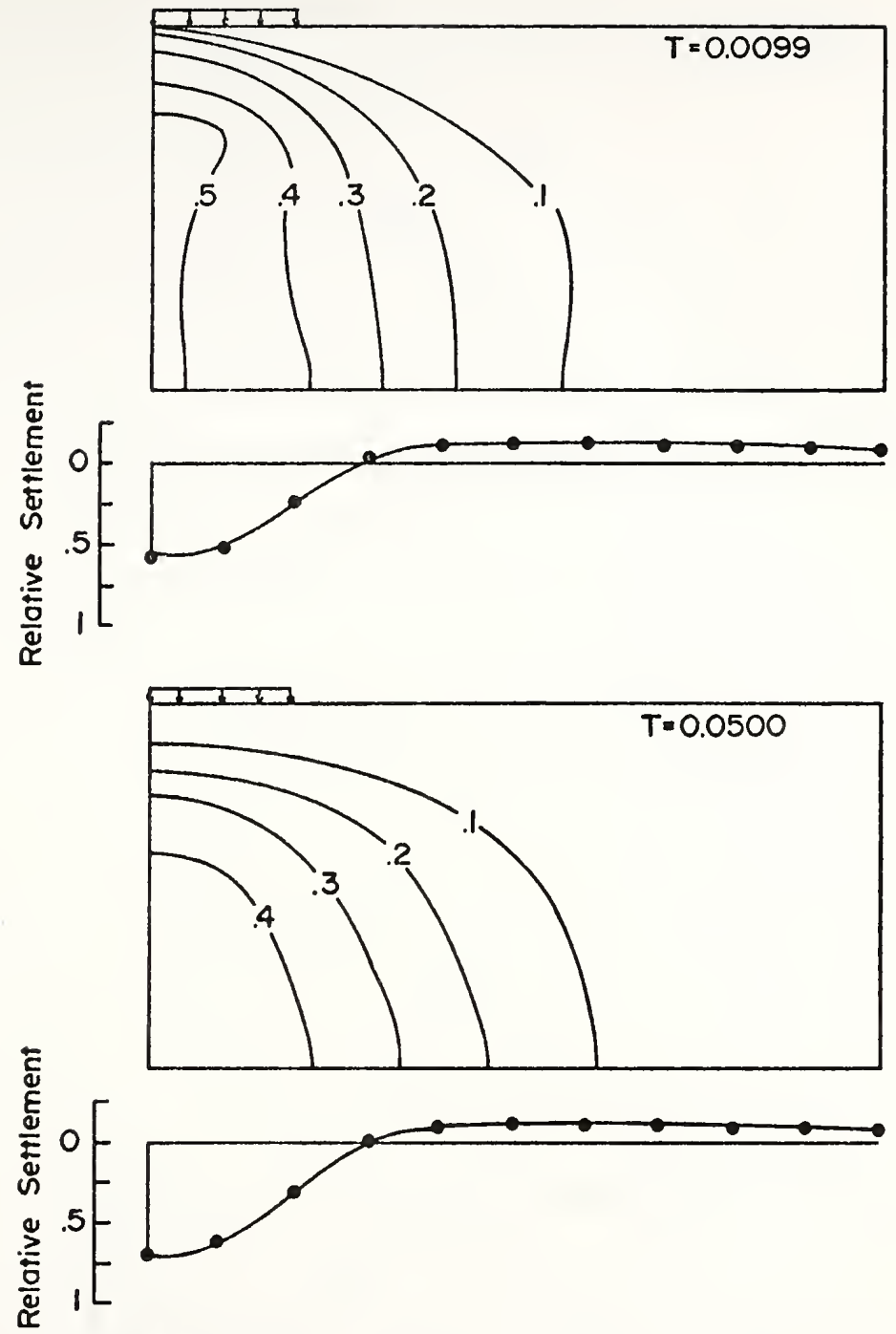

FIGURE 5.33-PORE PRESSURE CONTOURS AND RELATIVE SETTLEAENTS FOR TWO DIMENSIONAL PROBLEM - NO YIELDING II. 

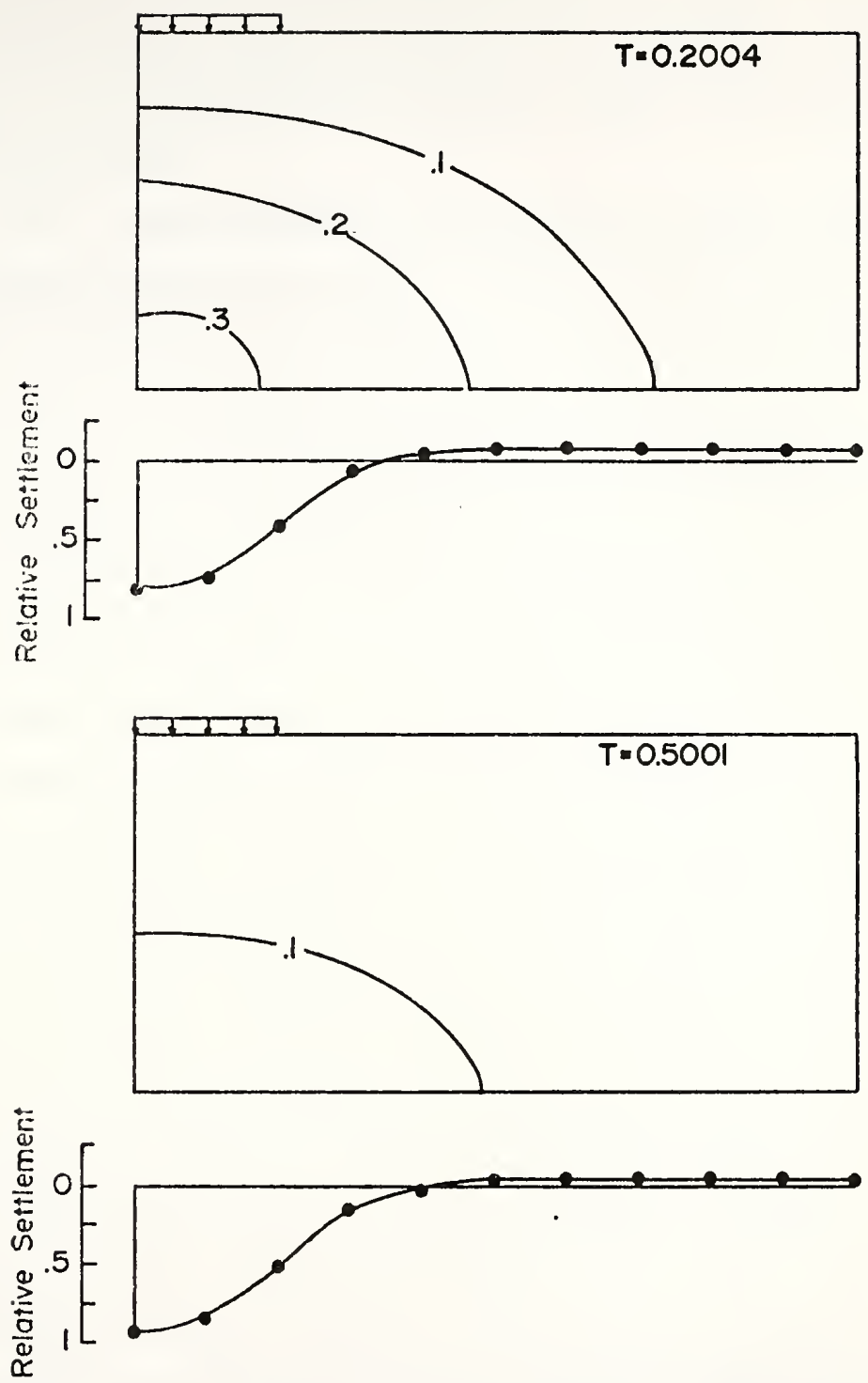

FIGURE 5.34-PORE PRESSURE CONTOURS AND RELATIVE SETTLEMENTS FOR TWO DIMENSIONAL PROBLEM - NO YIELDING III. 
to distortion of the soil with no volume change. Consolidation settlements occur with time, and settlement under the center of the loaded area increases, while the peripheral heave decreases.

\subsubsection{Two-Dimensional Consolidation Problem, with}

Quasi-Preconsolidation Effect. The two-dimensional consolidation solution for the case in which the quasi-preconsolidation effect is present was obtained using the grid illustrated in Figure 5.31 and employing the laboratory derived soil model as described for the seventy-five element one-dimensional program in Section 5.5.3. Results are presented in the form of excess pore pressure ratio contour diagrams and corresponding surface scttlements at different time factors.

When the load is applied at time zero the excess pore pressure distribution, given in the top diagram of Figure 5.35 , is identical to the no yield case of Figure 5.32. However several elements in the two rows under the load yield immedjately and pore pressures increase to the values shown in the lower diagram of Figure 5.35. The elastic modulus for a yielding element is reduced by a factor of four, from $E_{\text {new }}$ to $E_{o l d}$. Typical increases in excess pore pressure in this region were from 0.762 to 0.839 , from 0.568 to 0.771 ; from 0.591 to 0.688 and from 0.445 to 0.614 . Dissipation then proceeds with time as a result of water flow out of the top drainage boundary, Figure 5.36, until time factor 0.24632. At this time elements 48 and 53, adjacent to the grid center line in the third row, yield, 

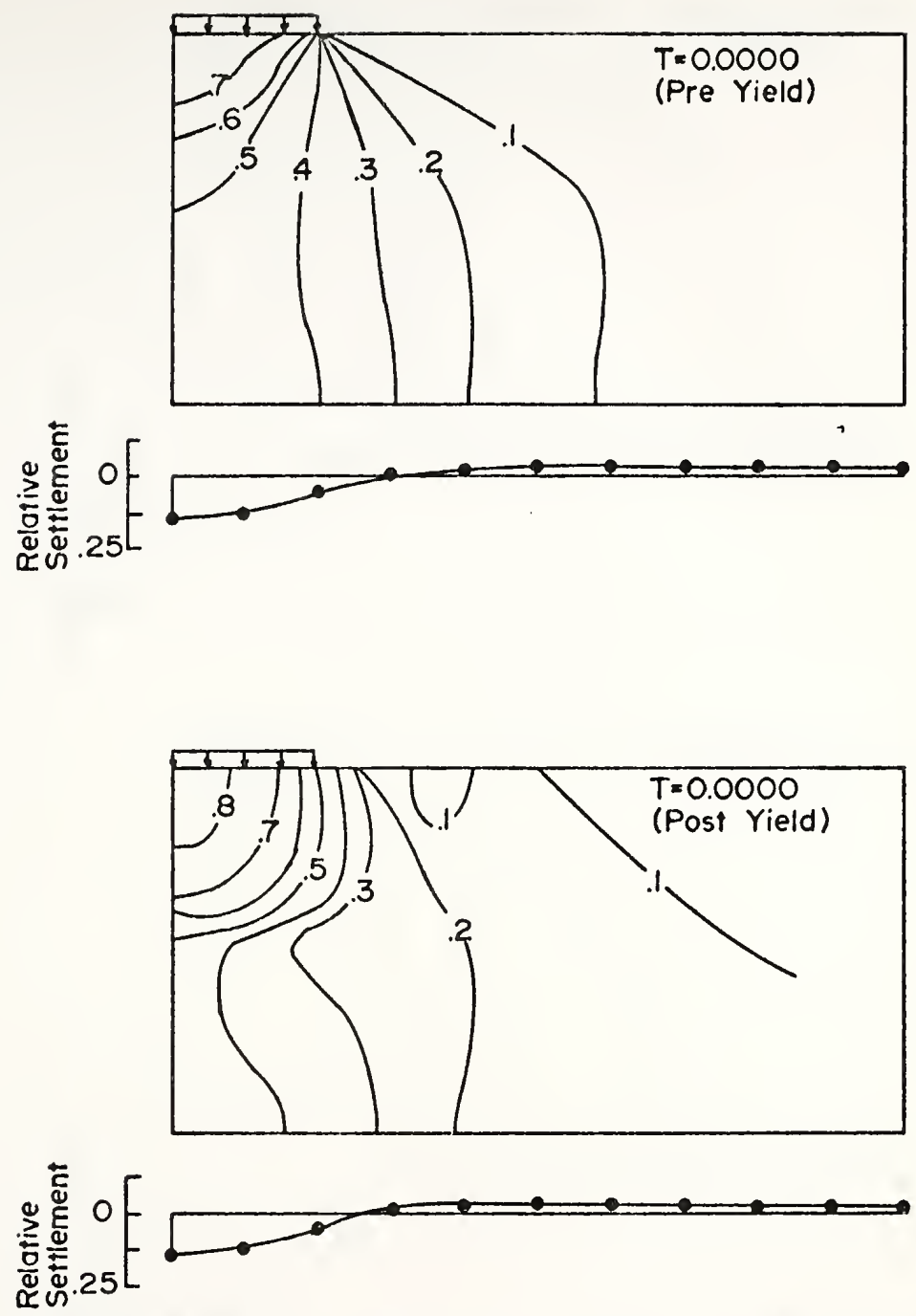

FIGURE 5.35-PORE PRESSURE CONTOURS AND RELATIVE SETTLEMENTS FOR TWO DIMENSIONAL PROBLEM - WITH YIELDING I. 

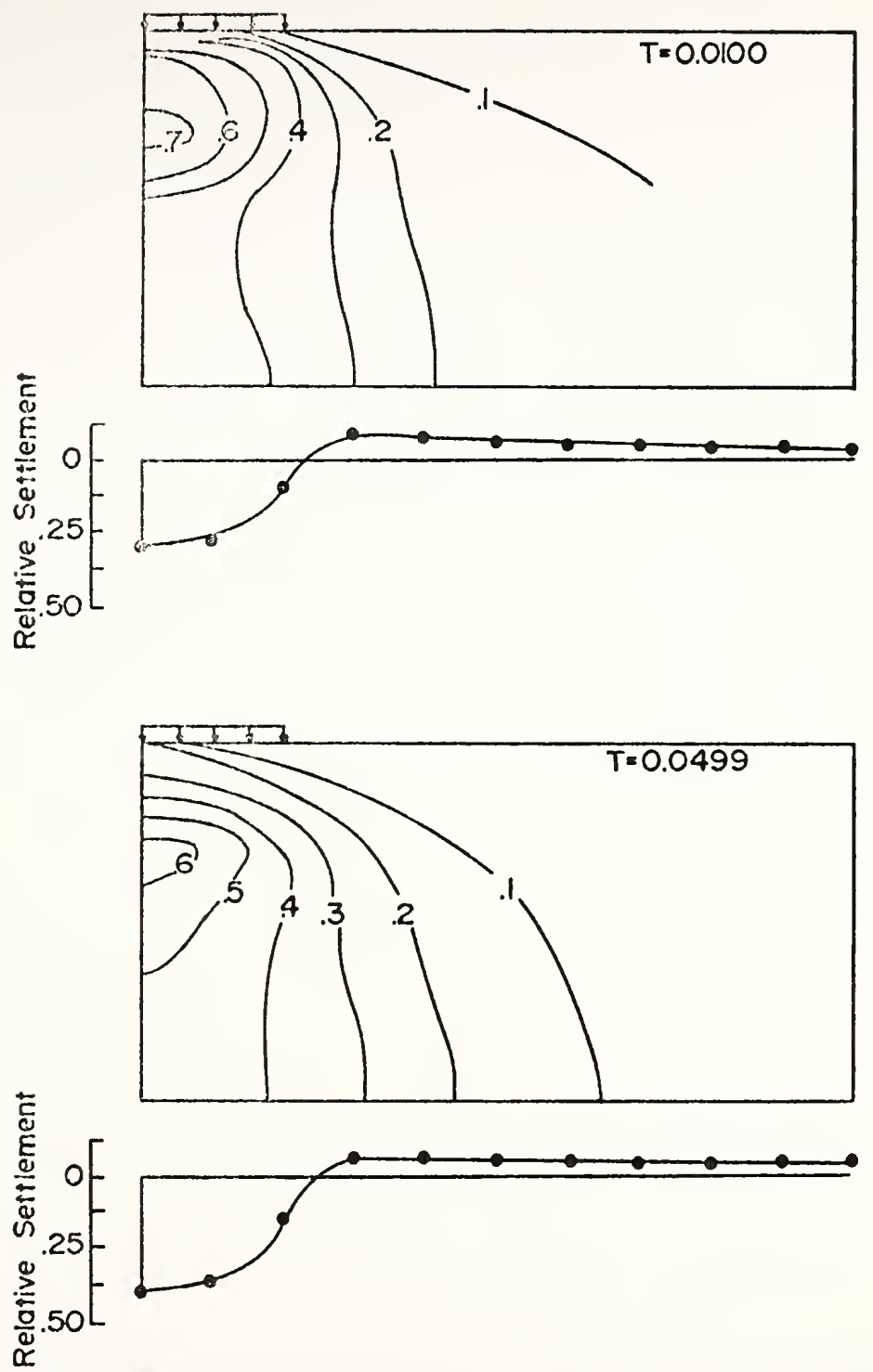

FIGURE 5.36-PORE PRESSURE CONTOURS AND RELATIVE SETTLEMENTS FOR TWO DIMENSIONAL PROBLEM - WITH YIELDING II. 
The pre- and post-yield pore pressure distributions are given in Figure 5.37. The top diagram shows that in the time between the initial yielding and just prior to this new yielding the pore pressure distribution had stabilized. That is, all localized areas of high pore pressure had disappeared and the distribution shows the smooth contour lines of the no yield behavior. In the lower diagram the yielded element, number 53, exhibits the characteristic pore pressure increase, up from 0.3362 to 0.5736 . Dissipation continues until $\mathrm{T}=0.26919$, Figure 5.38, when a small effect of the previous yielding still remained and when elements 43 and 58 of the third row yielded. Two more elcments of row three yielded at time factor 0.36629 again demonstrating the localized pore pressure increase due to the yielding of a particular element (Figure 5.39).

Initially, the surface settlements are equivalent to those obtained from the no yield program. These displacements shown in Figure 5.35 are due to distortion within the clay soil and are not accompanied by any volume change. Subsequent settlements are of larger magnitude than for the no yield case, a consequence of the increased compressibility of the yielded elements. This is shown in Figure 5.40 where surface settlements at three points are plotted versus time factor. Values are normalized by dividing actual settlements by the ultimate center-line settlement for the yield case. For the case of no yielding heave occurs initially outside the loaded area and then decreases with time. For the yield case heave increases from the initial value due to the yielding of elements under the load then decreases with time. 

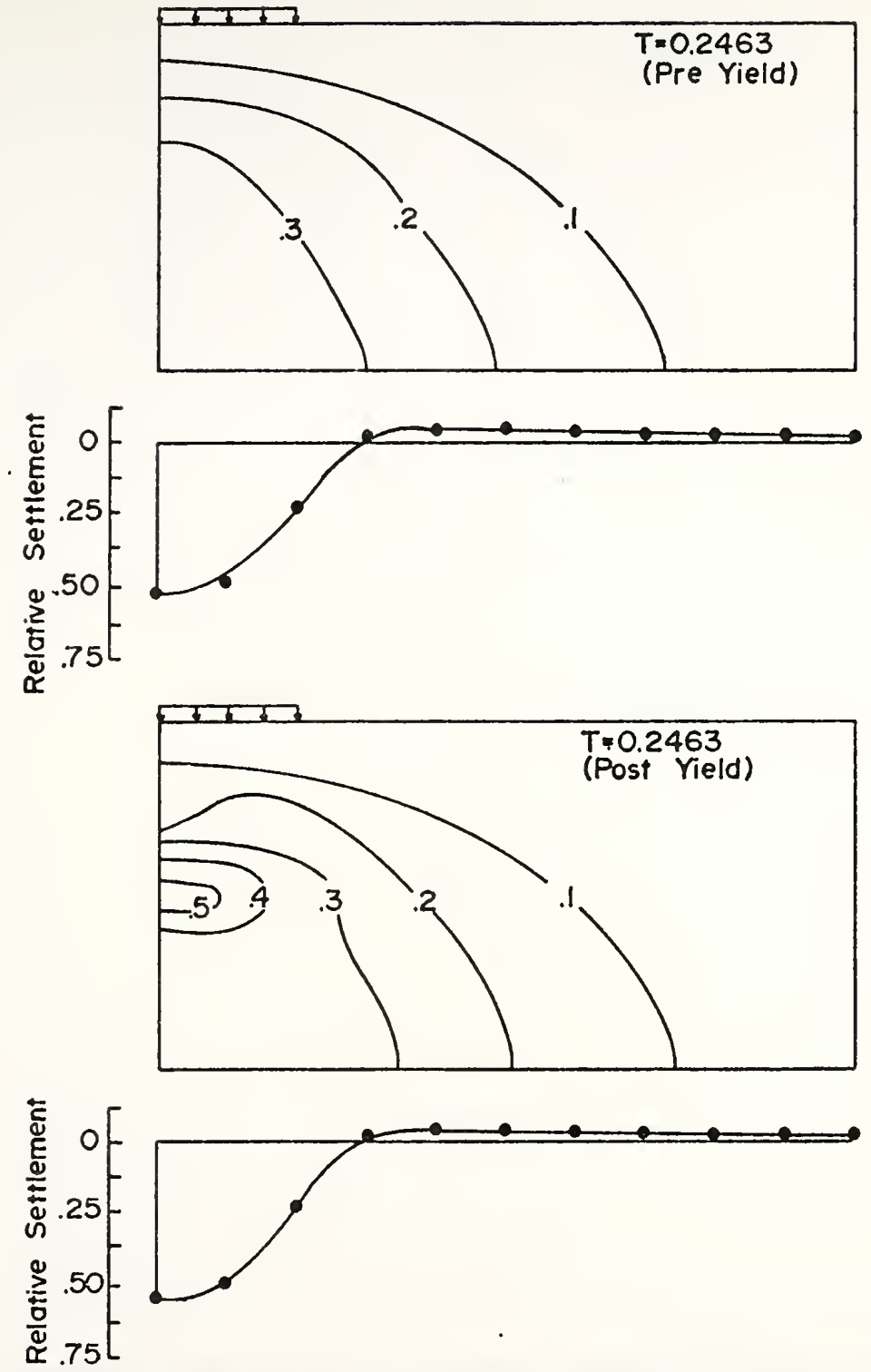

FIGURE 5.37-PORE PRESSURE CONTOURS AND RELATIVE SETTLEMENTS FOR TWO DIMENSIONAL PROBLEM - WITH YIELDING III. 

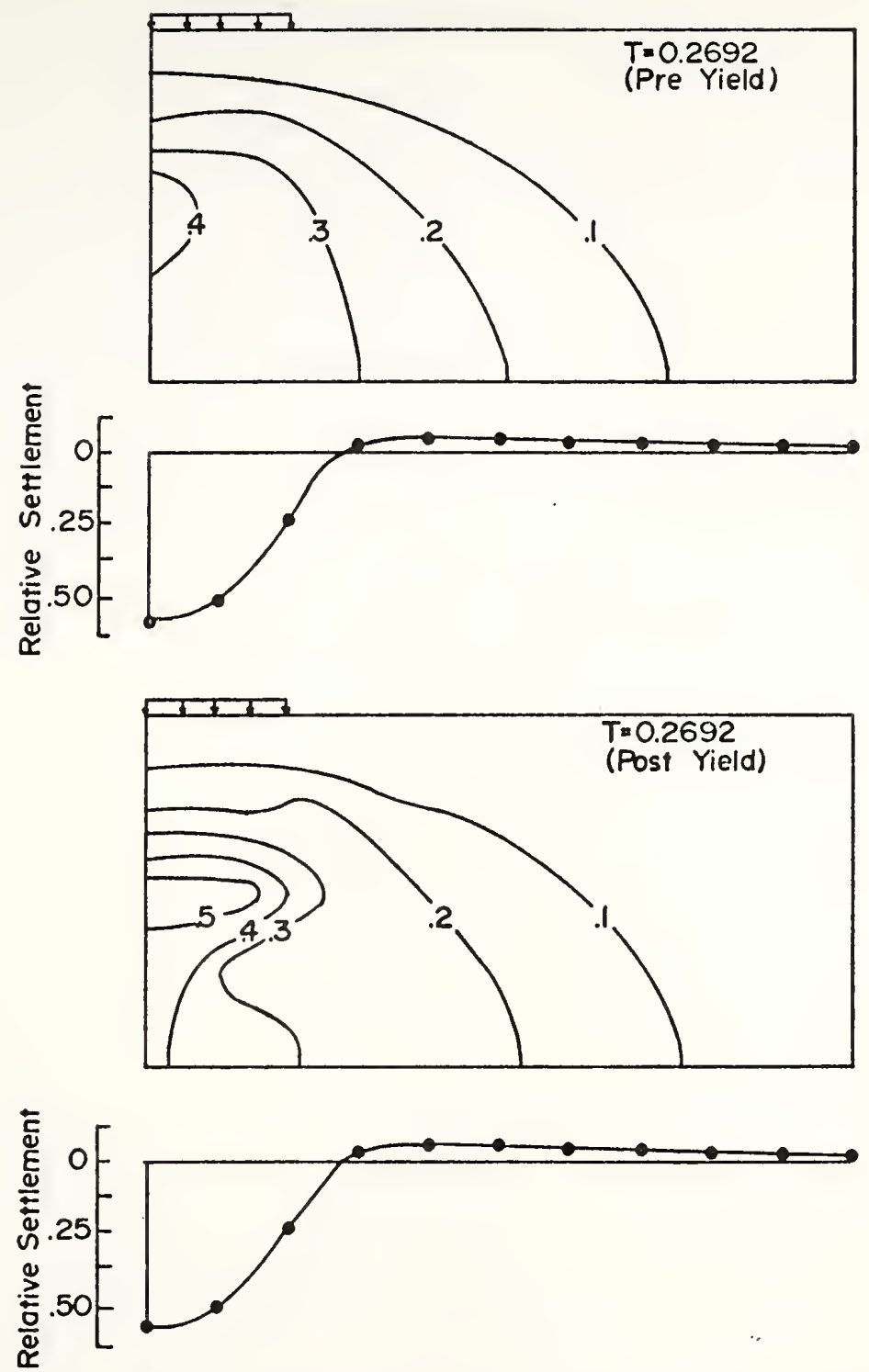

FIGURE 5.38-PORE PRESSURE CONTOURS AND RELATIVE SETTLEMENTS FOR TWO DIMENSIONAL PROBLEM - WITH YIELDING II. 


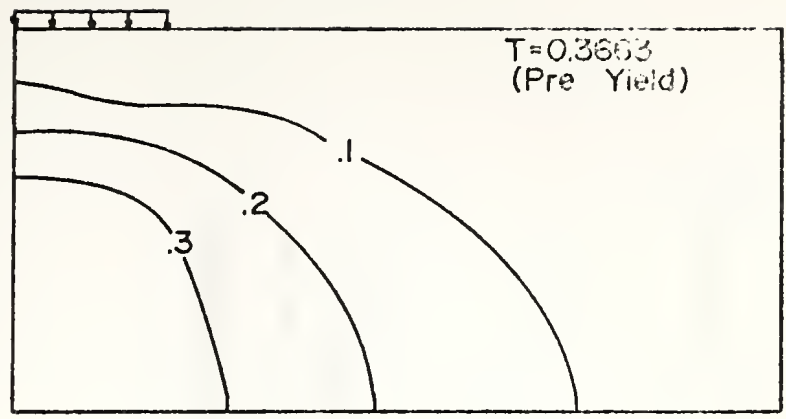

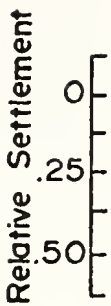
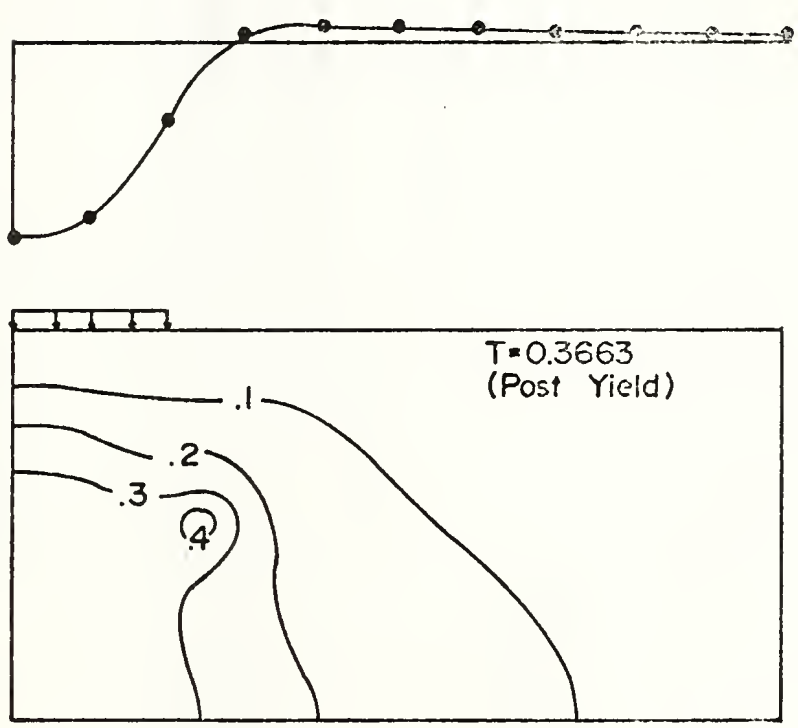

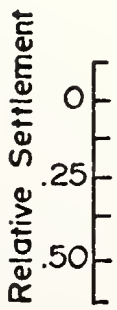

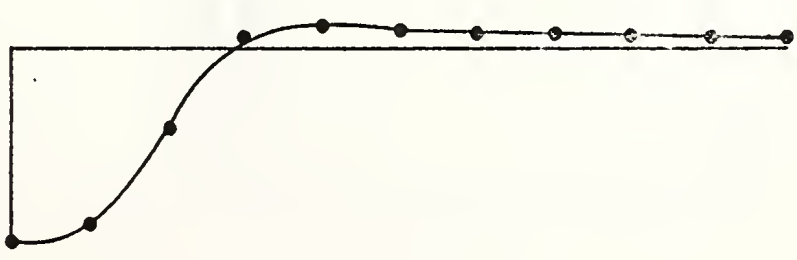

FIGURE 5.39-PORE PRESSURE CONTOURS AND RELATIVE SETTLERENTS FOR TVO DIRIENSIONAL PROBLEM - WITH YIELDING $\Psi$. 


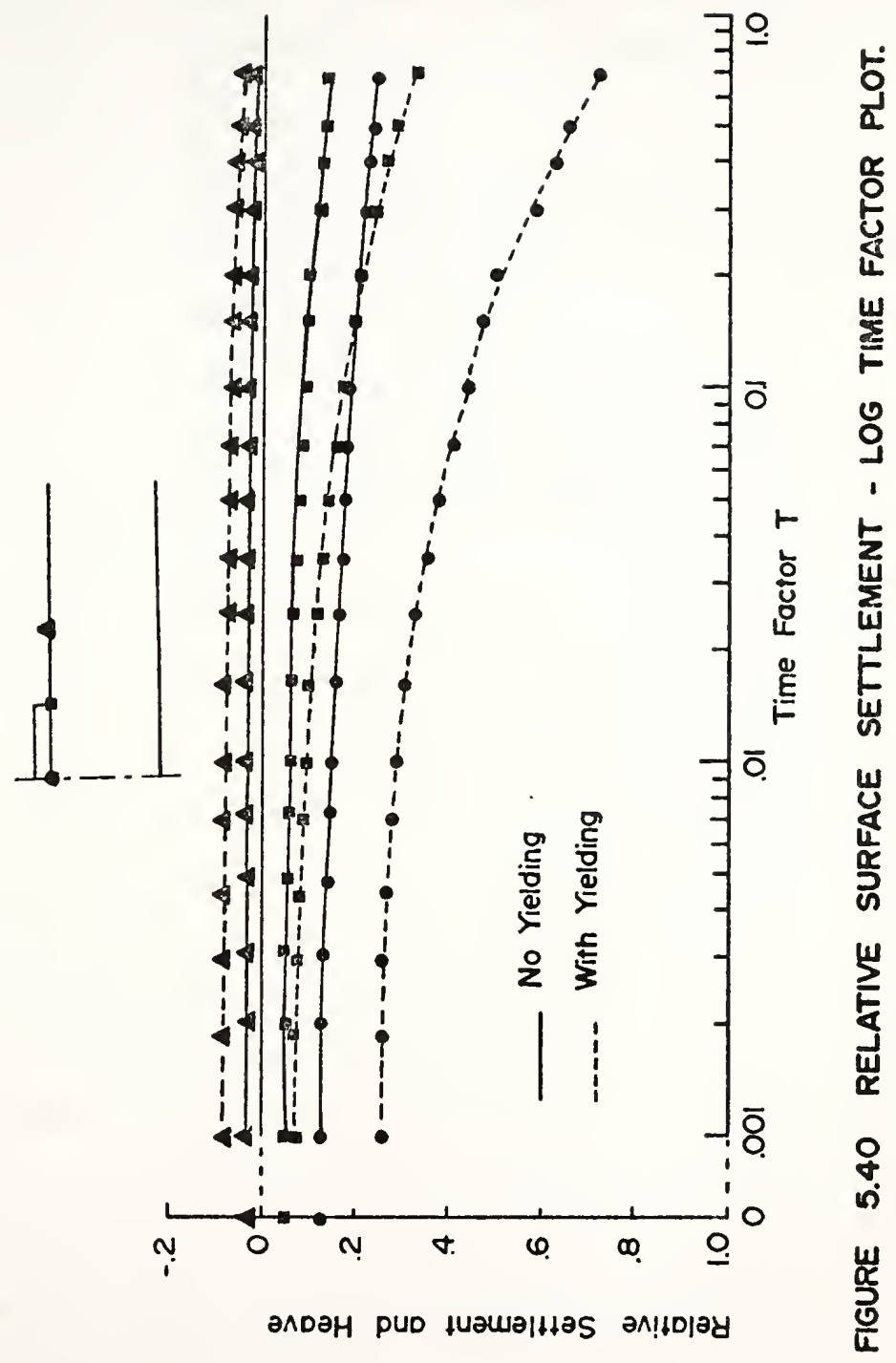




\subsection{Field Studies}

In recont years several instrumented embankments have becil constructed on soft clay soils and described in the soil mechanics 1itcrature. Bjerrum (1972) summarized much of this work with regard to the preconsolidation effect. His observations wore:

1. Almost all clay soils exhibit such an effect

2. For small loads within the range of the effect

a. settlements are small

b. excess pore pressures are small

c. excess pore pressures dissipate rapidly.

3. For larger loads which exceed the range of the effect

a. settlements are large

b. excess pore pressures are large

c. excess porc pressures dissipate slowly.

As suggested above, and in most reported case studies, the naturc of the response of a clay foundation to a superimposcd fill is related to the weight of the fill. Figure 5.41 is reproduced from a paper by Höeg et al. (1969) and illustrates the variations in undrained excess pore pressure at different locations with surface pressure. The slope change in each plot indicates yielding of the soil adjacent to that piezometer. The current research, however, treats the quasi-preconsolidation phenomenon more fundamentally in terms of effective stresses, and illustrates that yielding may occur in response to changes in both isotropic effective stresses and shear stresses independently of drainage 
conditions. When a load is applied to the surface of the two-dimensional problem part of the applied total stress is carried by the pore water and part by the soil skeleton as an effective stress. If the applied load is small, the effective stress and shear stress increments will be small and nowhere will the effective stress state exceed the yield surface. If however, the initial load is larger, or if additional shear stresses are applied the stress state may lie outside the yield surface. This yielding would be expected first either directly under the load and subsequently at greater depths and distances from the load, or at a point near the edge of the fill wherc shear stresses are high. In the case reported by Höeg et al. point $\Lambda$ on the fill center line yielded first, followed at greater loads by points $B$ and $C$. Yielding under an initial load was illustrated in the finite element two-dimensional study in Figure 5.35 .

An insitu yield curve may be back figured for the particular depth of the piezometers in Figure 5.41. From the known surface loading, total stresses and consequently effective stresses can be calculated at the piezometer locations.

Total stress increments were calculated assuming a uniform circular load on a homogeneous elastic half space. Tabulated stress functions were obtained from Ahlvin and Ulery (1962). In Figure 5.42 stress paths for the four locations are plotted in terms of the effective octahedral 


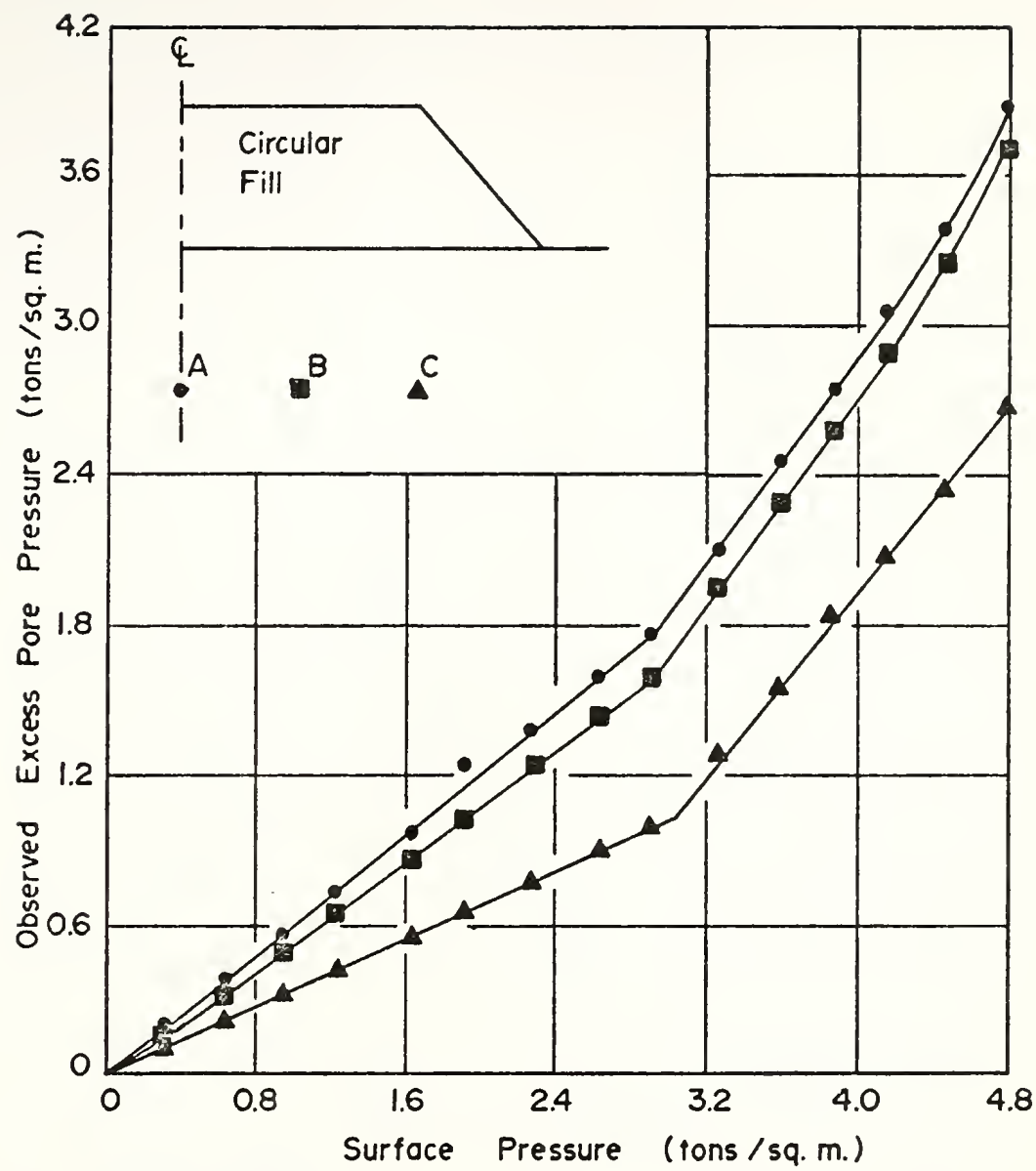

FIGURE 5.41 OBSERVED. EXCESS PORE PRESSURES (FROM HÖEG ET. AL. 1969) 


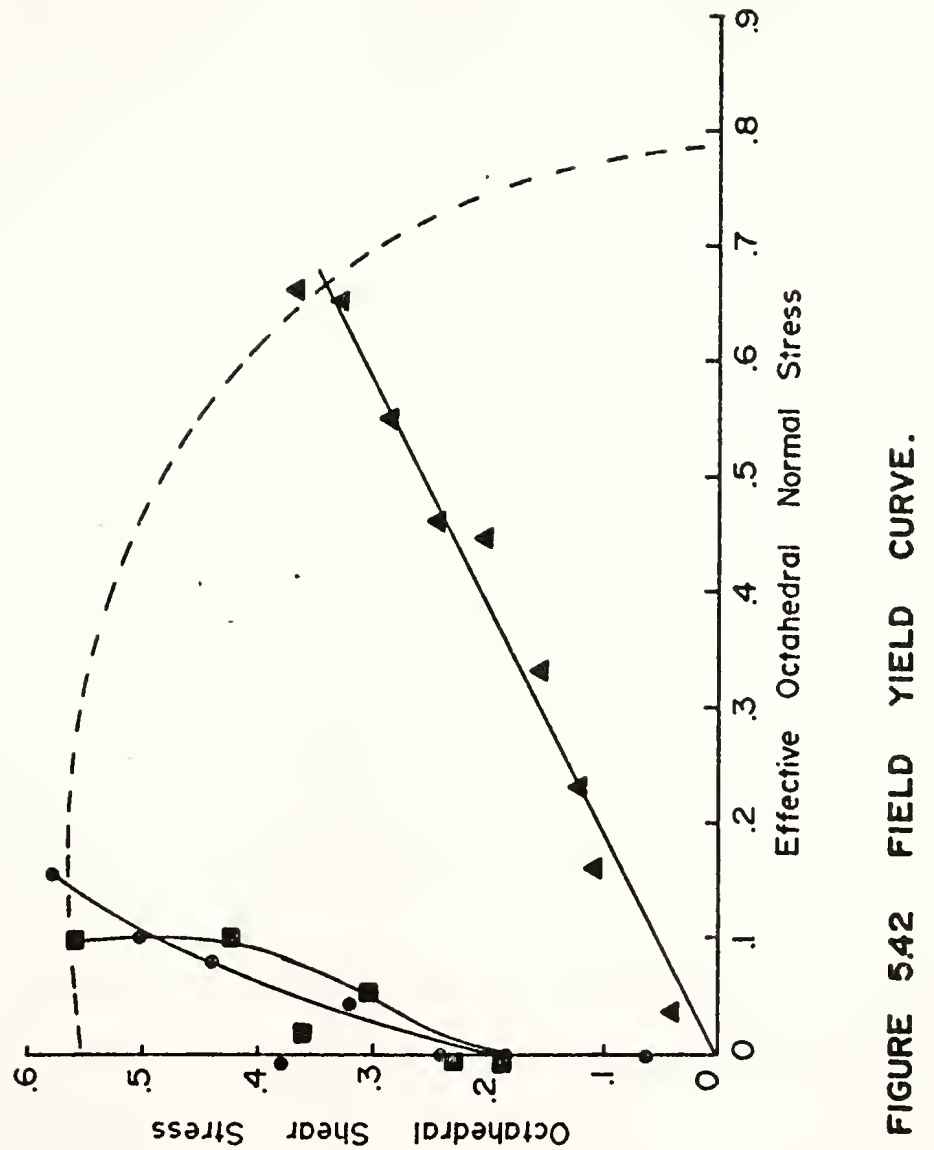


stress increments. The yield points define a yield curve sjmilar in shape to that found in the laboratory.

Yiclding may also occur during consolidation. As excess pore pressures decrease duc to flow of water out of the clay stratum, cffective stresses increase and may at a point exceed the yicld surface. This effect was observed in the one-, two-, seventy five-, and one hundred-eloment studies. These solutions also illustrate that the foundation yielding is progressive rather than occurring at one particular load. Zones of the soil may yield due to initial or subsequent loadings, while other zones may yield progressively during consolidation.

Results from the finite element study may be summarized as follows. If the incremental effective stress state for an applied load plots within the yield surface, then the settlements are small, pore pressures are small and dissipate rapidly. Should the effective stress state cross the yield surface, due to additional loading or consolidation, then settlements become large, pore pressure increases due to load transfer from skeleton to pore water, and dissipation is slow.

The overall soil behavior as predicted by the finite element study is in general agreement with reported field observations. 


\section{CONCLUSIONS AND RECOMMENDATIONS}

\subsection{Conclusions}

In this dissertation laboratory and analytical procedures were combined to study the effects of quasi preconsolidation on the compressibility of clay soils. A soil bchavior model was formulated from the results of triaxial tests performed on clay specimens in which a quasi preconsolidation effect had been induced. The model was then introduced into the finite element procedure such that boundary value consolidation problems could be solved. From the study performed the following conclusions may be drawn.

1. A quasi preconsolidation effect can be induced in a clay specimen by consolidating it in a triaxial cell, under a hydrostatic confining pressure. Loading periods of approximately 21 days were employed. This procedure eliminates the disturbance due to stress release and sample preparation experienced when samples are trimmed from blocks prepared in a consolidometer type apparatus.

2. Drained triaxial tests performed on such specimens along different stress paths, show essentially similar stress-strain behavior. In every case the plot is initially steep, followed by a fairly sharp transition curve to an approximately straight line with shallow slope At this 
transition, the compressibility increases abruptly.

3. From the triaxial test results a soil model may be formulated with the following features.

a. The stress-strain behavior can be represented by two straight lines intersecting at a point, termed the g-yield point.

b. For all tests performed on specimens prepared under the same confinement pressure, the q-yield points define a curve which can be closely approximated by an ellipse.

c. The yicld point ellipses for different confinement pressures are found to form cross sections of an elliptic cone with apex at the zero confinement origin.

This three-djmensional yield surface can be defined by a single cquation.

4. The soil model derived from laboratory test results, for a clay soil which exhibits a quasi preconsolidation effect, can be introduced into the finite element procedure. Due to the fundamental versatility of the finite element procedure, consolidation solutions can be obtained for a great variety of plane strain configurations.

5. Solutions were obtained for one- and two-dimensional problems with and without consideration of the quasi preconsolidation behavior for a number of finite element mesh sizes. Results illustrate 
a. fundamental behavior at a point within a clay soil prior to, at, and after the quasi preconsolidation pressure is; excceded. When yielding occurs the compressibility of the soil skeleton increases and a portion of the stress carried by it as an effective stress is transferred to the pore water. Subsequent settlements are increased and the rate of pore pressure dissipation decreased relative to no yiclding behavior.

and b. the overall effects of construction on a clay stratum which exhibits the quasi preconsolidation effect. Effective stresses from construction londs which do not exceed the insitu effective stress yicld surface result in small settlements and rapid dissipation of excess pore pressures. If yiclding does occur then the corresponding settlements are large and excess pore pressure dissipation slow. These are in agreement with field observations reported in the literature.

\subsection{Recommendations}

In the current research the laboratory study was performed to establish a utilitarian soil model that might be incorporated into the finite element procedure. For a more definitive investigation of the quasi preconsolidation effect under a three dimensional stress state the following recommendations are made. 
1. Further experiment using commercial soils, such as grundite, should be conducted:

a. to investigate the effects of length of q-confinement time

b. to establish the uniqueness of the yield curve and its shape for negative $\Delta \bar{\sigma}_{\text {oct }}$.

c. to verify the linear cone relationship by considering a greater range in confinement pressures, especially at low values.

2. The model for the quasi-preconsolidation effect should be verified for specimens consolidated under $K_{0}$ conditions. Comparison should be made with tests performed on specimens trimmed from clay consolidated in an oedometer type apparatus. Effects of anisotropy should be considered.

3. The applicability of the model to clays consolidated in the field should be studied using high quality undisturbed samples.

The model established for the clay soil in this research was that of a bi-linear elastic material, with the intersection point defined by a three-dimensional effective stress surface. The finite element procedure is of such versatility that more complicated behavior corresponding more closely to real response, can be accommodated. The soil behavior might be more accurately modeled using incremental stress-strain curves, by considering anisotropic conditions and by including an ultimate failure criterion. 
The actual finite element procedure used, proved to be extremely costly in computer time, due to the exceedingly short tine increments which must be employed. Programs consisting of 100 elements achieved approximately 200 cycles of dissipation in 1,000 seconds of CDC computer time. When determining stresses and deformations for field situations using the finite element method, 600 to 1000 elements are typically cmployed. Such a grid for the consolidation prob$1 \mathrm{~cm}$ would result in exorbitant computer running times. A nced exists, therefore for a more economical finite element procedure. More efficient storage to reduce memory requirements and the possibility of an implicit rather than explicit solution procedure might be considered.

Prediction-observation studies of field structures are strong1y recommended. Solutions from computer programs including models based on laboratory testing of field samples need to be compared with field instrumentation measurements.

Finally, the question arises as to the influence of the quasi-preconsolidation pressure on strength and how strength parameters should be determined in the laboratory. The implications of this question to stability analyses should be investigated. 


\section{LIST OF REFERENCES}




\section{LIST OF REFERENCES}

Abbott, M. B. (1960), "One Dimensional Consolidation of Multi-Layered Soils," Geotechnique, Vol. 10, No. 4, pp. 151-165.

Ahlvin, R. G., and Ulery, H. H. (1962), "Tabulated Values for Determining the Complete Pattern of Stresses, Strains, and Deflections beneath a Uniform Circular Load on a Homogeneous Half Space," High Research Board, Bulletin 342, pp. 1-13.

Altschaeffl, A. G. (1960), "Compressibility of Artificially Sedimented Clays," Ph.D. Thesis, Purdue University, Lafayet te, Indiana.

Andresen, A., and Simons, N. E. (1960), "Norwegian Triaxial Equipment and Technique," Proceedings, ASCE Conference on Shear Strength of Cohesive Soj.1s, University of Colorado, Boulder, Colorado, pp. 695-709.

Barden, L., and Berry, P. L. (1965), "Consoljdation of Normally Consolidated Clay," Proceedings, ASCE, Vol. 91, No. SM5, pp. 15-35.

Biot, M. A. (1941), "General Theory of Three-Dimensional Consolidation," Journal of Applied Physics, Vol. 12, pp. 155-164.

Bjerrum, L. (1964), "Re1asjon Mellom Målte og Beregnede Setninger av Byggverk pá Leire og Sand," NGF - Foredraget 1964. Oslo, Norwegian Geotechnical Institute, pp. 92 .

Bjerrum, L. (1967), "Engineering Geology of Norwegian Normally-Consolidated Marine Clays as Related to Settlements of Buildings," Geotechnique, Vo1. 17, No. 2, pp. 81-118.

Bjerrum, L. (1972), "Embankments on Soft Ground," Proceedings, ASCE Conference on Performance of Earth and Earth-Supported Structures, Purdue University, Lafayette, Indiana, Vol. II, pp. 1-54.

Bjerrum, L., and Wu, T. H. (1960), "Fundamental ShearStrength Properties of the Lilla Edet Clay," Geotechnique, Vol. 10, No. 3, pp. 101-109.

Carslaw, H. S. (1921), "Introduction to the Mathematical Theory of the Conduction of Heat in Solids," Macmillan and Co. Limited, London, England. 
Christian, J. T., and Boehmer, J. W. (1970), "Plane Strain Consolidation by Finite Elements," Proceedings, ASCE, Vo1. 96, No. SM4, pp. 1435-1457.

Christian, J. T., Boehmer, J. W., and Martin, P. P. (1972), "Consolidation of a Layer under a Strip Road," Proceedings, ASCE, Vol. 98, No. SM7, pp. 693-707.

Clough, R. W. (1960), "The Finite Element Method in Plane Stress Analysis," Proceedings, Second ASCE Conference on Electronic Computation, Pittsburgh, Pennsylvania, pp. $345-378$.

Conlon, R. J. (1966), "Landslide on the Toulnustouc River, Quebec," Canadian Geotechnical Journal, Vol. 3, pp. $113-132$.

Davis, E. H. and Lee, I. K. (1969), "One-Dimensional Consolidation of Layered Soils," Proceedings, Seventh International Conference on Soil Mechanics and Foundation Engincering, Mexico, Vol. 2, pp. 65-72.

Davis, E. H., and Raymond, P. (1965), "A Non Linear Theory of Consolidation," Geotechnique, Vol. 15, No. 2, pp. $161-173$.

Edelmann, T. (1953), "The Consolidation of a Layer, Modulus of Elasticity is Proportional to the Depth," Proceedings, Third International Conference on Soil Mechanics and Foundations Engineering, Zurich, Vol. 1, pp. 358.

Elias, V., and Storch, H. (1970), "Control and Performance during Construction of a Highway Embankment on Weak Soils," Highway Research Record, No. 323, pp. 60-70.

Forsythe, G. E. and Wasow, W. R. (1960), "Finite-Difference Methods for Partial Differential Equations," Wiley, New York.

Gibson, R. E., England, G. L., and Hussey, M. J. L. (1967), "The Theory of One-Dimensional Consolidation of Saturated Clays - Finite Non Linear Consolidation of Thin Homogeneous Layers," Geotechnique, Vo1. 17, No. 3, pp. 261-273.

Glick, G. W.. (1945), Discussion of "Simultaneous Consolidation of Contiguous Layers of Unlike Compressive Soils," by H. Gray, ASCE, Transactions, Vol. 110, pp. 1341-1342. 
Gray, H. (1945), "Simultaneous Consolidation of Contiguous Laycrs of Unlike Compressible Soils," ASCE, Transactions, Vol. 110, pp. 1327-1356.

Höeg, K., Andersland, O. B., and Rolfsen, E. N. (1969), "Undrained Behaviour of Quick Clay under Load Tests at Asrum," Geotechnique, Vol. 19, No. 1, pp. 101-115.

Holtz, R. D., and Lindskog, G. (1972), "Soil Movements below a Test Embankment," Proceedings, ASCE Conference on Performance of Earth and Earth-Supported Structures, Purdue University, Lafayette, Indiana, Vol. I, Part I, pp. 273-284.

Lambe, T. W. (1960), "A Mechanistic Picture of Shear Strength in Clay," Proccedings, ASCE Research Conference on Shear Strength of Cohesive Soils, Boulder, Colorado, pp. $555-580$.

Leonards, G. A., and Altschaeff1, A. G. (1964), "Compressibility of Clay," Proceedings, ASCE, Vo1. 90, No. SM5, pp. $133-155$.

Leonards, G. A., and Ramiah, B. K. (1960), "Time Effects in the Consolidation of Clays," ASTM Special Technical Publication No. 254, pp. 116-130.

Martins, J. B. (1965), "Consolidation of a Clay Layer of Non-Uniform Coefficient of Permeability," Proccedings, Sixth International Conference on Soil Mechanics and Foundation Engincering, Montreal, Vol. 1, pp. 308-312.

Moh, Z. C., Brand, E. W., and Nelson, J. D. (1972), "Pore Pressures under a Bund on Soft Fissured Clay," Proceedings, ASCE Conference on Earth and Earth-Supported Structures, Purduc University, Lafayctte, Indiana, Vol. I, Part 1, pp. 243-272.

Moum, J., and Rosenqvist, I. Th. (1957), "On the Weathering of Young Marine Clay," Proceedings, Fourth International Conference on Soil Mechanics and Foundation Engineering, London, Vol. I, pp. 77-79.

Narain, J., Singh, B., Iyer, N. V., and Deoskar, S. R. (1969), "Quasi-Preconsolidation Effects and Pore Pressure Dissipation during Consolidation," Proceedings, Seventh International Conference on Soil Mechanics and Foundation Engineering, Mexico, Vol. 1, pp. 311-315.

0lsen, R. E., and Langfelder, L. J. (1965), "Pore-Water Pressures in Unsaturated Soils," Proceedings, ASCE, Vo1. 91, No. SM4, pp. 127-150. 
Perloff, W. H. (1966), "Study of Long Term Deformation of Compacted Cohosive Soil Embankments," l'lan of Study, Joint llighway Research Project, Project No. C-36-5I', File No. 6-6-6, Purdue University, larfayette, Indiana.

Perloff, W. H. (1969), "Finite Llement Mnalysis of Underground Openings," Strain Distribution around Underground Openings, Technical Report No. 1, Contract No. DACA 73-68C-0002 (P002), Advanced Research Projects Agency, Department of Defense.

Perloff, W. H., and Pombo, L. E. (1969), "Lind Restraint Effects in the Triaxial Test," Proceedings, Seventh International Conference on Soil Nechanics and Foundation Engineering, Mexico, Vol. 1, pp. 327-333.

Poskitt, T. J. (1969), "The Consolidation of Saturated Clay with Variable Permeability and Compressibility," Geotechnique, Vol. 19, No. 2, pp. 234-252.

Radhakrishnan, N. and Reese, L. C. (1970), "A Review of Applications of the Finite Element Method of Analysis to Problems in Soil and Rock Mechanics," The Japanese Society of Soil Mechanics and Foundation Lngincering, Vol. X, No. 3, pp. 95-112.

Ramiah, B. K. (1959), "Time Effects on the Consolidation Propertics of Clays," Ph.D. Thesis, Purdue University, Lafayette, Indiana.

Raymond, G. P. (1966), "Consolidation of Slightly Overconsolidated Soils," Proceedings, ASCE, Vol. 92, No. SM5, pp. $1-20$.

Raymond, G. P. (1969), "Consolidation of Deep Deposits of Homogeneous Clay," Geotechnique, Vol. 19, No. 4, pp. $478-494$.

Rico, A., Moreno, G., and Garcia, G. (1969), "Test Embankments on Texcoco Lake," Procecdings, Seventh International Conference on Soil Mechanics and Foundation Engineering, Mexico, Vol. 2, pp. 669-676.

Roscoe, K. H., and Burland, J. B. (1968), "On the Generalized Stress-Strain Behaviour of 'Wet' Clay," from Engineering plasticity, Cambridge University Press, pp. 535-609.

Schiffman, R. L. (1958), "Consolidation of Soil under TimeDependent Loading and Varying Permeability," Proceedings, Highway Research Board, Washington, Vol. 37, pp. 584617 . 
Schiffman, R. L. (1965), "Soil Properties - Shear Strength and Consolidation," (written contribution), Procecdings, Sixth International Conference on Soil Mechanics and Foundation Engineering, Montreal, Vol. III, pp. 397-399.

Schiffman, R. L. and Gibson, R. E. (1964), "Consolidation of Nonhomogeneous Clay Layers," Proceedings, ASCE, No. SM5, pp. 1-30.

Terzaghi, K. (1923), "Dic Berechnung der Durchlässigkeitsziffer des Tones aus dem Verlauf der Hydrodynamischen Spannungserscheinungen," Mathematisch-NaturwissenSchaftliche Klasse, Part IIa, Vol. 132, No. 3/4, pp. 125-138.

Terzaghi, K. (1940), "Sampling, Testing and Averaging," Proceedings, Purdue Conference on Soil Mechanics and its Applications, pp. 151-160.

Terzaghi, K. (1941), "Undisturbed Clay Samples and Und isturbed Clays," Boston Society of Civil Engineers, Vol. 28, No. 3, pp. 211-231.

Turner, M. J., Clough, R. W., Martin, H. C., and Topp, L. J. (1956), "Stiffness and Deflection Analysis of Complex Structures," Journal of Aerospace Sciences, Vol. 23, pp. 805-823.

Wilson, E. L. (1963), "Finite Element Analysis of Two Dimensional Structures," Dissertation, Doctor in Engineering, University of California, Berkeley, California.

Wilson, E. L. (1965), "Structural Analysis of Axisymmetric Solids," American Institute of Aerospace and Aeronautics, Vo1. 3, No. 12, pp. 1-32. 
APPENDIX A

SAMPLE PREPARATION 


\section{A. SAMPLE PREPARATION}

\section{A.1 Sedimentation Apparatus}

A steel frame designed and constructed at Purdue University by Altschaeffl (1960) was used to sediment the samples. A general view of the eight bay frame is shown in Figure A.1 and a line diagram indicating the arrangement in one bay is shown in Figure $\mathrm{A.2}$. The front tank was filled with petrolatum oil (specific gravity 0.84) such that it balanced exactly the piston and hanger with four $16 \mathrm{~kg}$. counter weights in place. The connecting wire cable was $1 / 8$ inch diameter, $2000 \mathrm{lb}$. test cable passing over balanced twelve-inch diameter ball bearing pulleys.

The lucite tube in which the sample was to be sedimented was 20 inches long and 3-1/2 inches in diameter. A 6 inch diameter by 1 inch thick lucite base with drainage outlet was screwed to the flange on the sedimentation tube. The loading piston was also made of lucite and had a porous stone and alignment spiders attached. A close up of the piston-tube apparatus is shown in Figure A.3.

Loading of the sample was carried out by transferring oil by means of a capillary siphon from the front tank into a second completely independent rear tank. The load on the sample was determined by lowering the rear tank onto a $100 \mathrm{~kg}$ 


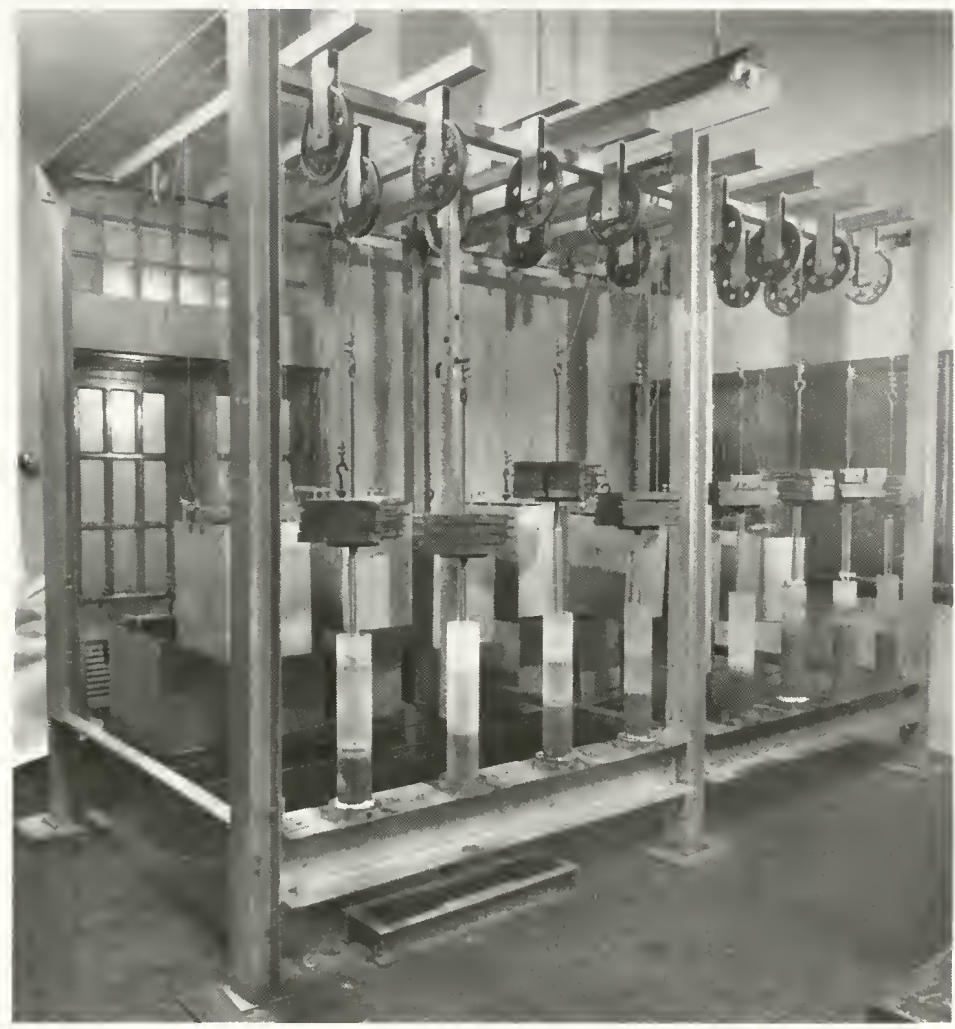

FIGURE A-I THE SEDIMENTATION FRAME . 


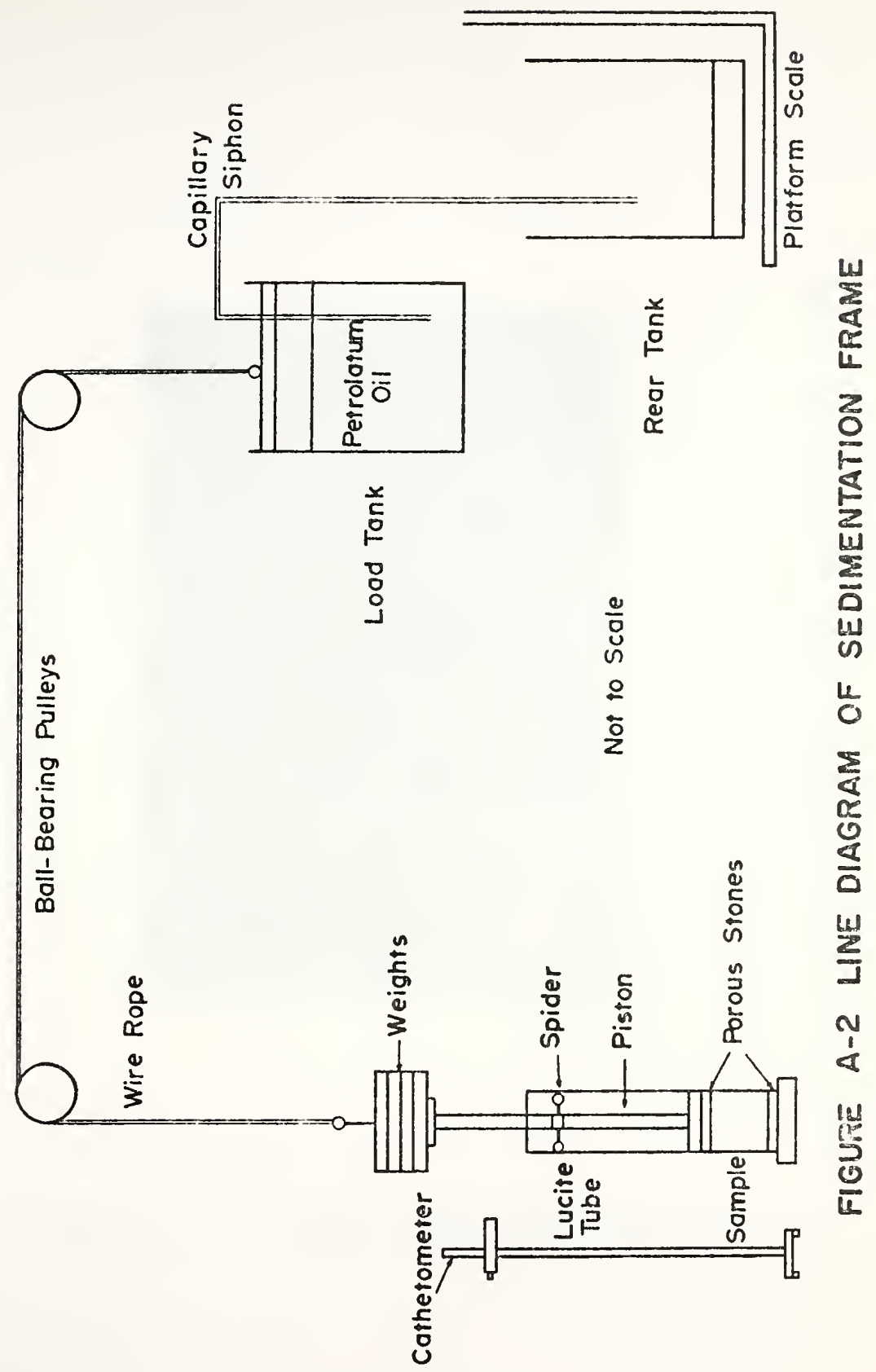




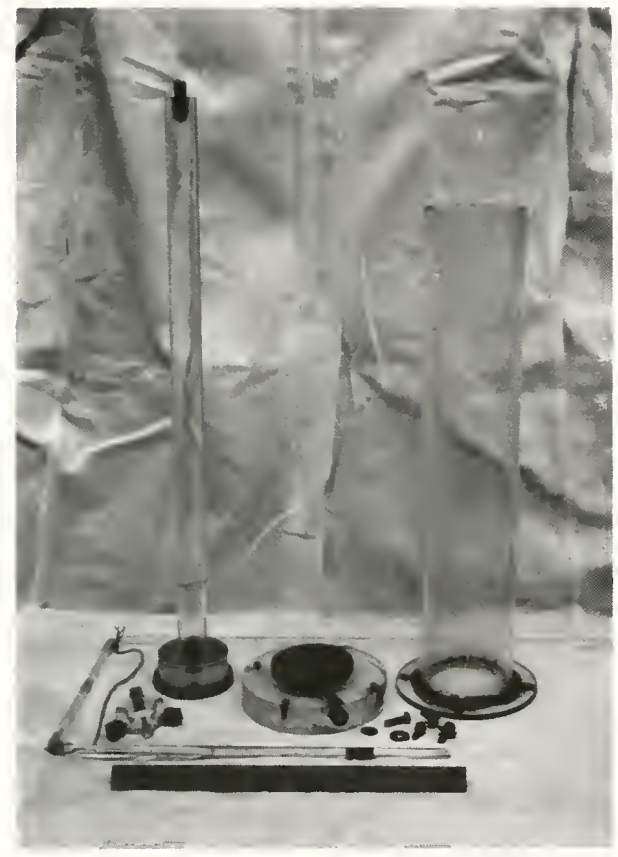

FIGURE A-3 LUCITE TUBE AND PISTON. 
capacity platform scale (sensitivity $10 \mathrm{gms}$. ) and weighing the oil transferred. Capillary siphons were made from glass tubing with bore diameters ranging from 0.75 to $3 \mathrm{mms}$.

Dimensions are shown in Figure 1.4 . All siphons were initially numbered and calibrated with a 12 inch unbalanced head (Table A.1).

\section{A.2 Sedimentation Procedure}

The Grundite was first dry sieved and only that portion which passed through a U. S. Bureau of Standards Number 200 sieve, opening $0.074 \mathrm{~mm}$, used. A Calgon solution, to be used as a clay particle dispersant, was prepared by dissolving 41 gms of commercial Calgon in $1000 \mathrm{ccs}$ of distilled water. Three batches of slurry were made, each consisting of 250 gms of Grundite, 125 ccs of Calgon solution and 375 ces of distilled water. These were mixed in milkshake machines for half an hour. Six drops of $0.1 \mathrm{NHCl}$, a particle flocculant, were added to each batch one minute before mixing terminated. The slurries were then washed into a large glass jar using an additional 500 ccs of distilled water. The preparation apparatus is shown in Figure A.5. The jar was attached to a vacuum and the mixture deaired and stirred for a further half hour. The jar was then inverted and the slurry, consisting of $750 \mathrm{gms}$ of Grundite in 2000 ccs of water, tremied into the lucite sedimentation tube. This procedure was used so as to minimize the possibility of trapping air bubbles in the sample. 


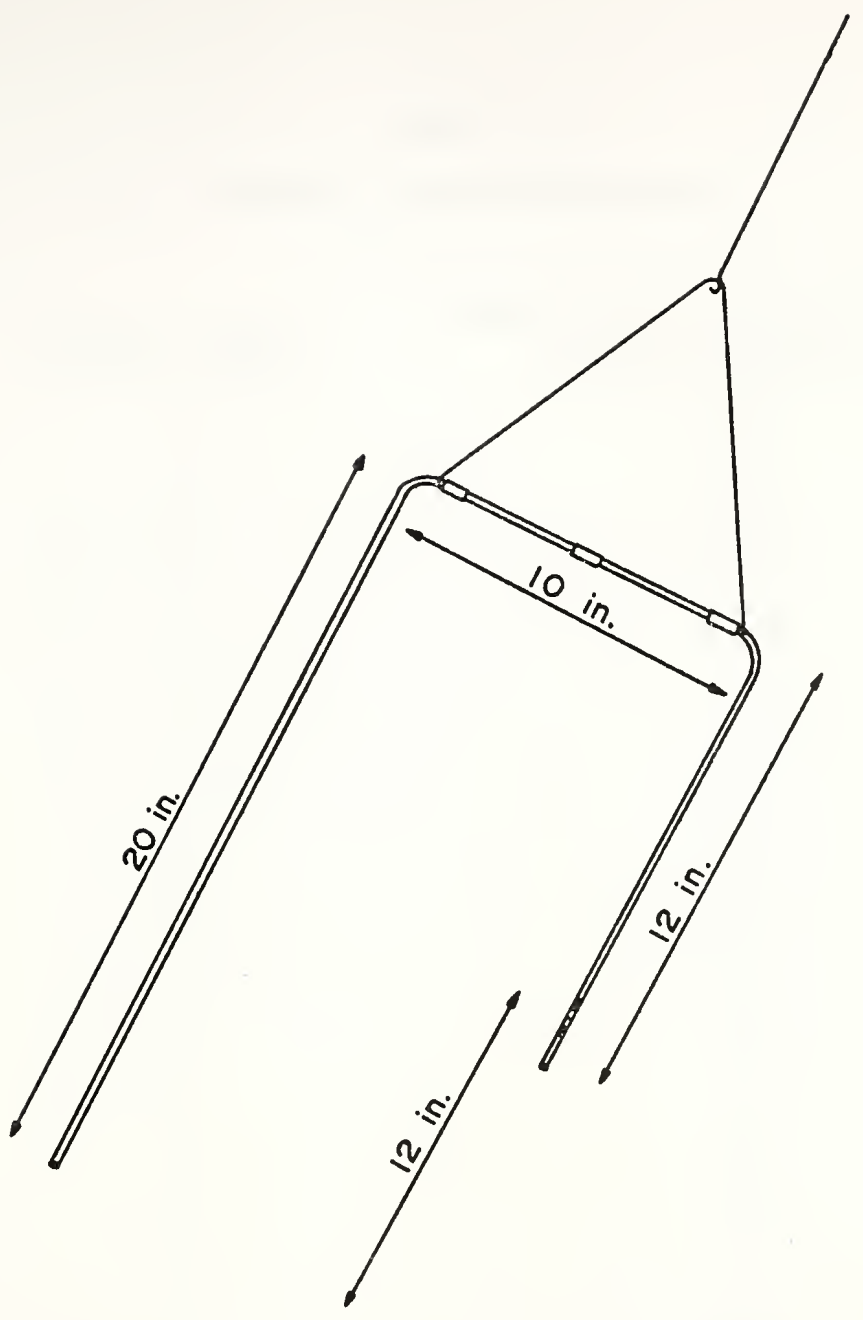

FIGURE A-4 GLASS CAPILLARY SIPHON 
TABLE A.1

\section{G1ass Siphon Calibrations}

Siphon Number

1

2

3

4

5

6

7

8

9

10

11

12

13

14

15

16

17

18

19
Grams of oil transferred/24 hours (12 inch unbalanced head)

$$
\begin{array}{r}
990 \\
1170 \\
1090
\end{array}
$$

980

680

810

400

1050

1000

1150

140

250

260

310

320

4000

2500

2810

2750 


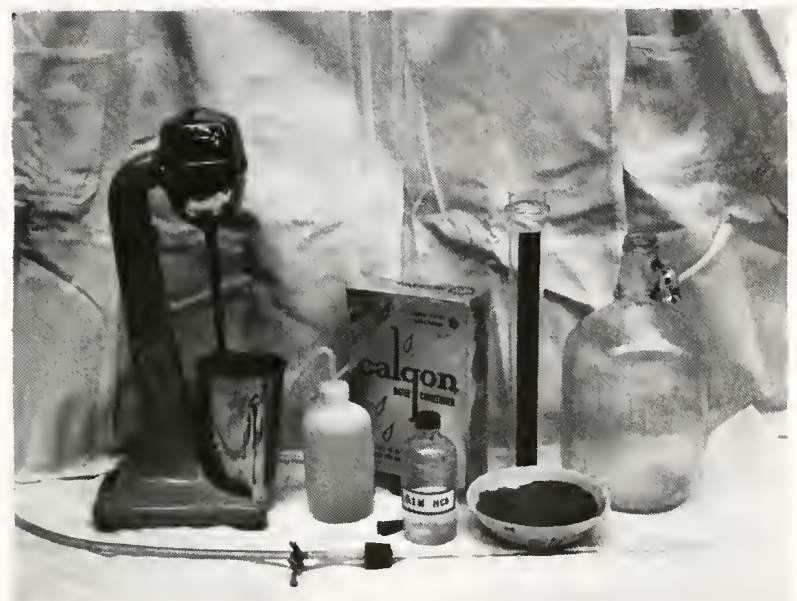

FIGURE A-5 PREPARATION EQUIPMENT FOR SEDIMENTATION SAMPLES. 
The tube had been prepared as follows. First the inside walls were sprayed with a fine coat of Silicone using a Scars silicone spray aerosol. The tube flange and base rim were greased to prevent leakage. The porous stone, carcfully deaired and covered with filter paper, was placed on the base and the tube screwed into place. After the slurry had been tremied into the lucite tube the soil was allowed to settle for 48 hours. The drainage outlet in the basc was kept open to create a small downward flow of water which caused some consolidation of the clay. Figure A.6 shows a freshly prepared sample and one after the 48 hour standing period. In carly samples consolidation was further assisted by applying a vacuum at the drainage outlet. This was discontinued as satisfactory results were obtained during the settling period alone.

The lucite tube was then placed in the sedimentation frame, the piston porous stone deaired and placed in contact with the soil, and the oil tank balanced. A capillary siphon with very slow rate of loading was then introduced and the rear tank weighed every 24 hours. As the soil consolidated and its strength increased it was possible, after a few days, to substitute a larger bore siphon or add an additional siphon. After sufficient strength gain incremental loads of $4 \mathrm{~kg}$. were added to the piston hanger. A typical loading plot is shown in Figure A.7. Samples were all loaded to $50 \mathrm{~kg}$. (11.45 psi) in about three weeks. They 


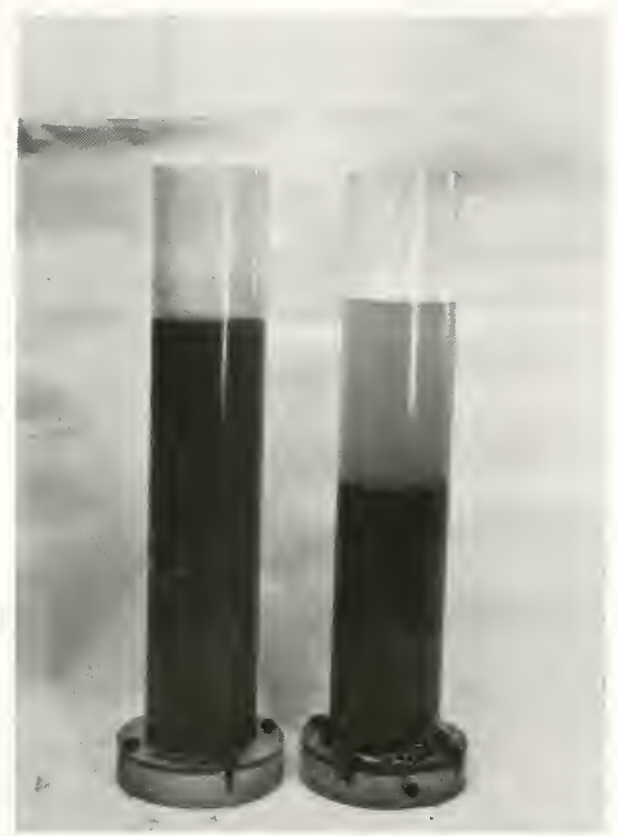

FIGURE A-6 SEDIMENTATION SAMPLES BEFORE AND AFTER STANDING PERIOD . 


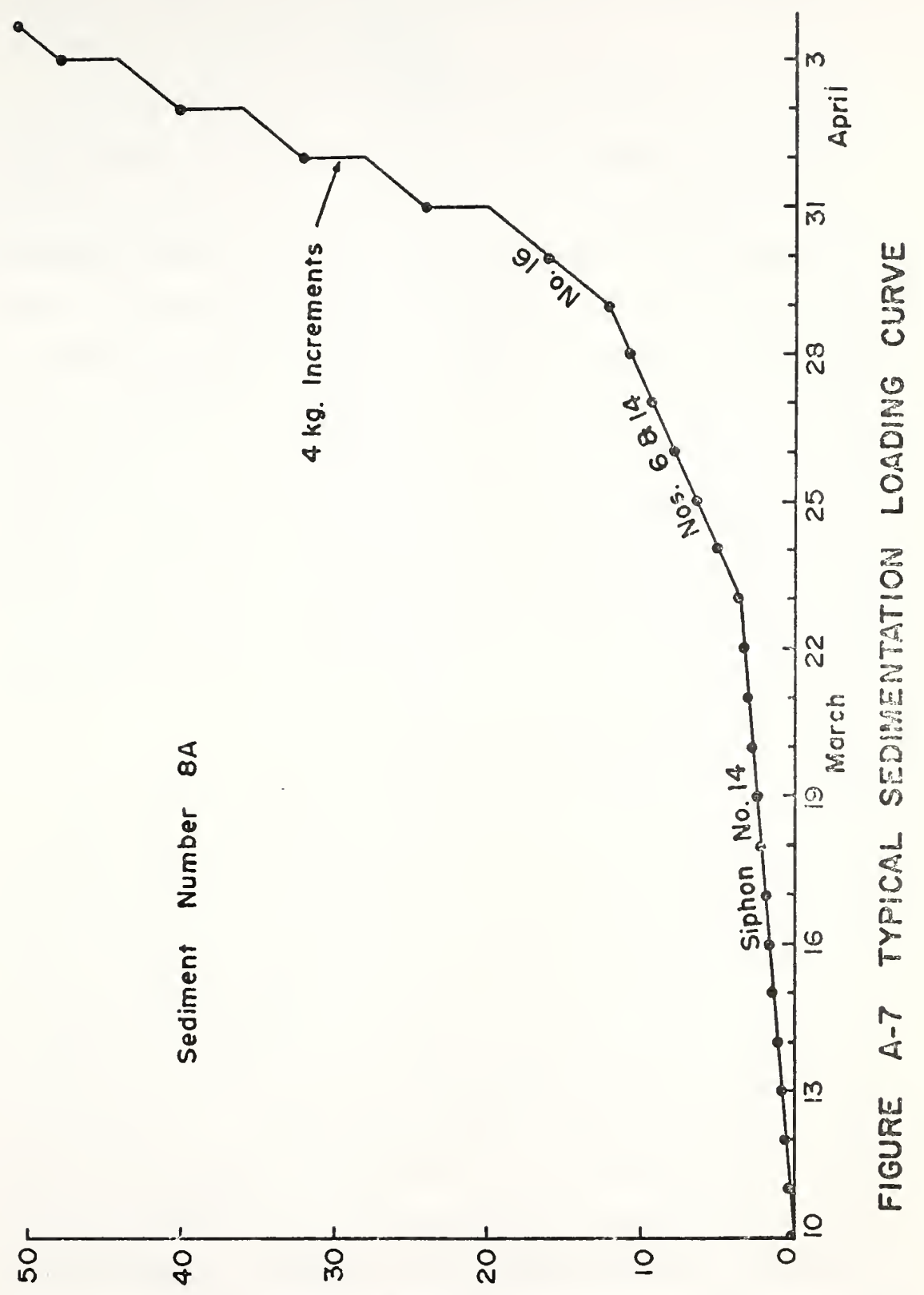


remained under this load for three days bofore being extruded for triaxial sampling.

Homogeneity of each sample was checked in an approximate manner by determining the water content of specimens from the upper, lower and middle third regions of the extruded sample. In no case was the moisture content variation more than $10 \%$. Hydrometer analyses were also performed on three specimens from one sanple and the grain size distribution plots are given in Figure A.8. No significant difference in composition is apparent. Every effort was made to standardize preparation procedures so as to minimize sample variation. Void ratio determinations were made for all samples and a range of values from 1.52 to 1.62 with an average of 1.57 was found.

\section{A.3 Triaxial Apparatus}

A.3.1 The Triaxial Cell Set-up. In order to maintain a constant confining pressure on triaxial samples for a long period of time the following set-up was designed. The system is shown in Figure A.9 and a line diagram showing the essential arrangement is given in Figure A.10. The air pressure was from a Curtis two-stage compressor with a 100 psi capacity. A back-up Nitrogen tank was available via a ball valve should the primary air pressure drop. Three Fairchild Hiller multi stage pressure regulators and dials called SOURCE I, SOURCE II and SOURCE III were connected in parallel with the capability of inserting further portable 


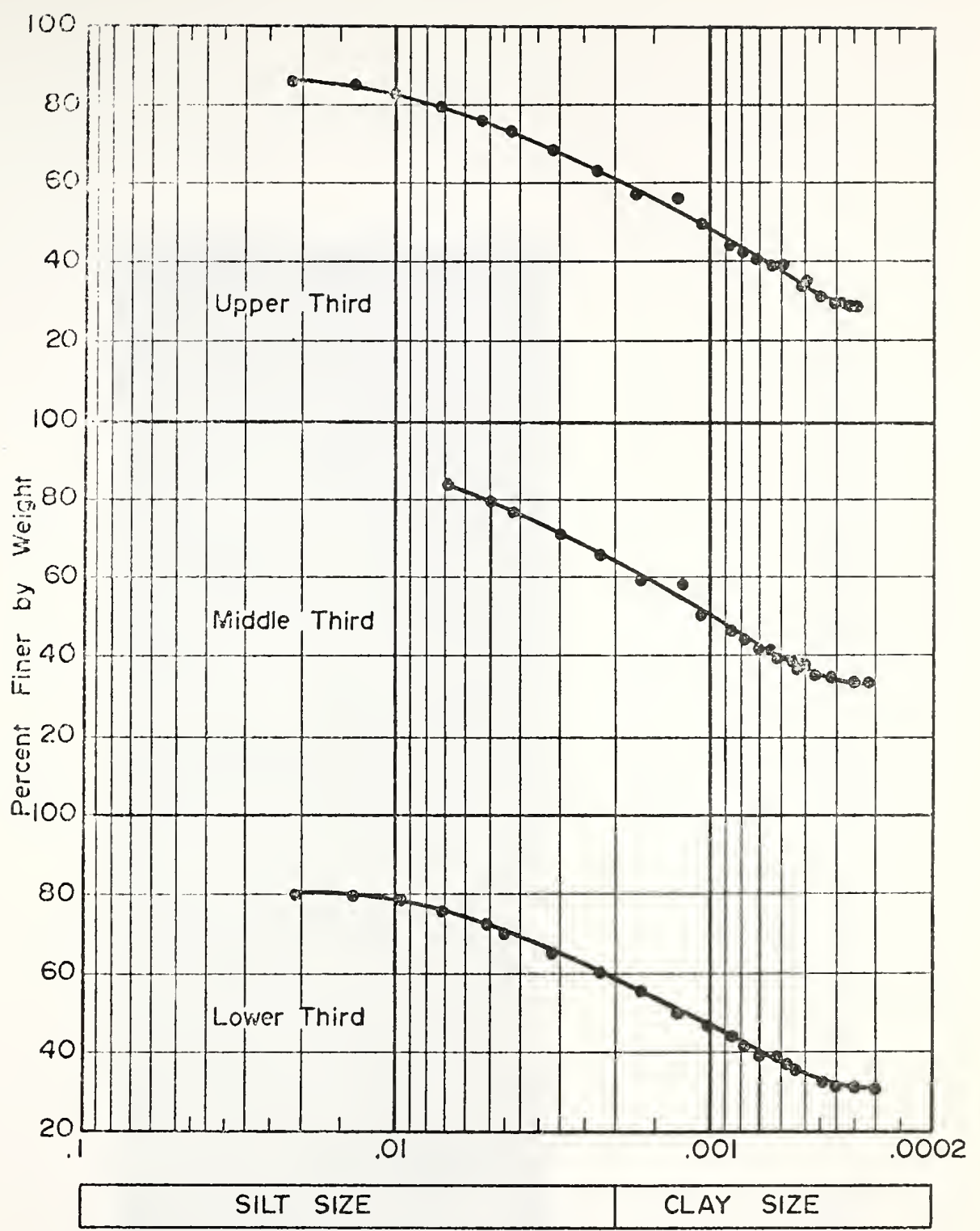

FIGURE A-S GRAIN SIZE DISTRIBUTION FOR SEDIMENTATION SAMPLE. 


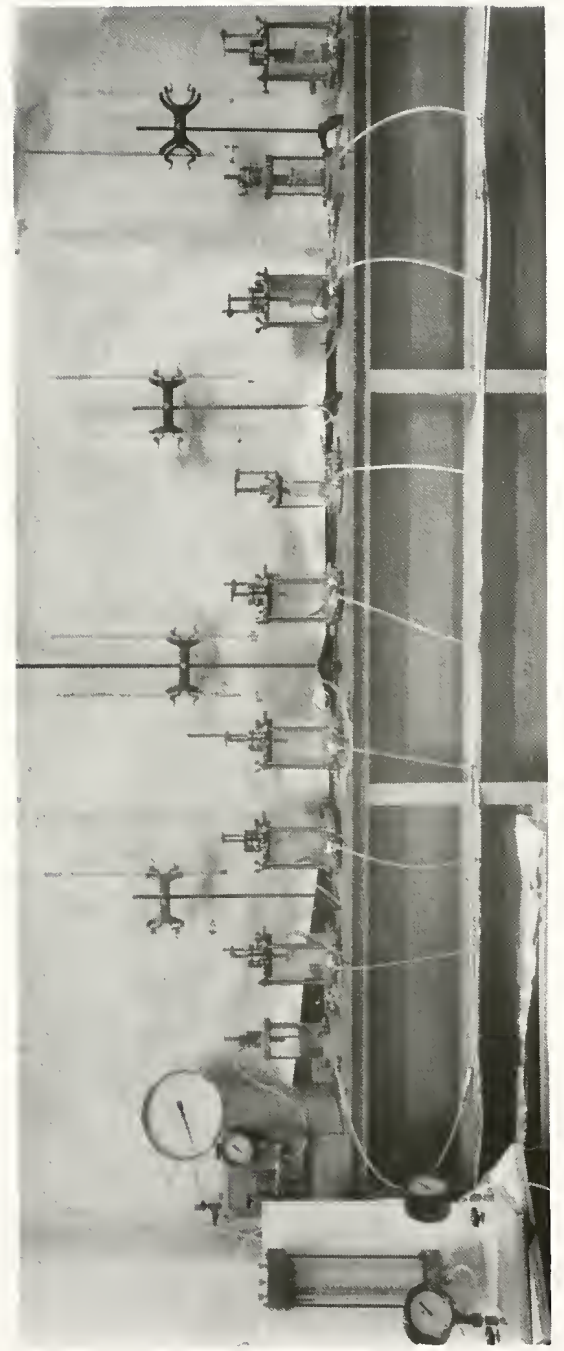

$\frac{0}{0}$

\begin{tabular}{l}
2 \\
0 \\
0 \\
0 \\
\hline 0 \\
0 \\
0 \\
0 \\
0 \\
0
\end{tabular}

뚱

$\frac{a}{5}$

$\frac{\frac{1}{a}}{\frac{a}{x}}$

9
1
$\alpha$

$\frac{w}{\frac{0}{0}}$ 


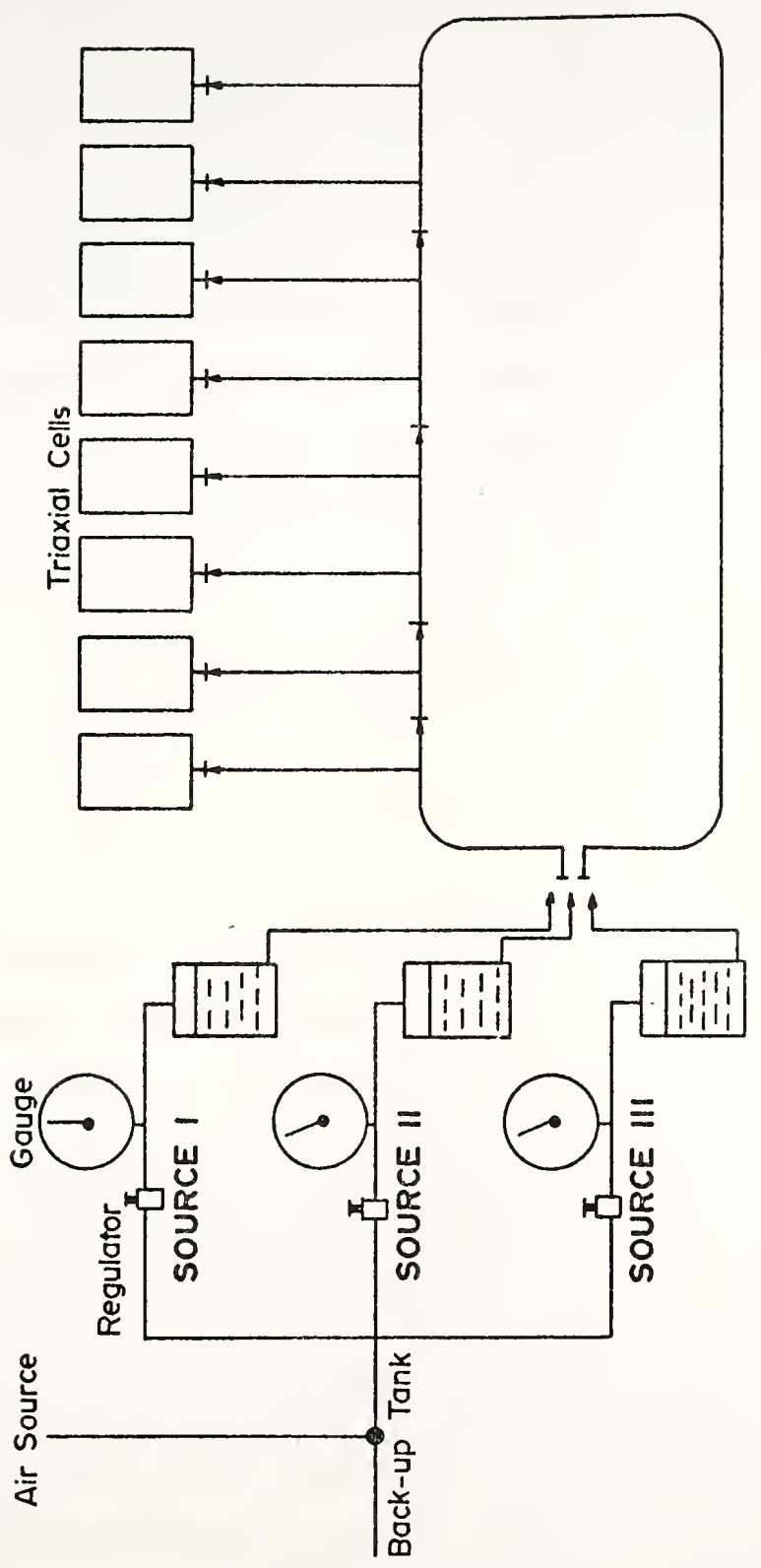

$\frac{a}{5}$

$\frac{\pi}{x}$

u

$\frac{\pi}{0}$

$\underline{w}$

$\frac{0}{1}$

$\frac{u}{2}$ 
sources if required. A loop of $1 / 8$ inch inner diameter plastic tubing had connections into which eight triaxial cells could be attached. The pressure in the loop might be supplied by one source or the loop could have been broken at any one of several quick connectors and different pressures applied to different cells. When a triaxial sample was to be tested a length of tubing with connectors at each end would be inserted and the sample tested in another area of the room while still under the same confining pressure.

A.3.2 The Triaxial Cells. The following makes of triaxial cells were used in the experimentation: -

1. Geonor cell, Norwegian Geotechnical Institute

2. Wykcham cell, Wykeham Farrance Eng. Ltd., Slough, England

3. Test Lab cel1, Test Lab. Corporation, Chicago, I11inois

The Geonor apparatus has been described in detail by Andresen and Simons (1960) and was the cell used primarily in this research. Essentially it consists of two main parts, a base plate with pedestal on which the sample sits and an upper plate with surrounding plexiglass cylinder. These parts are screwed together by three long wing bolts, as shown in Figure A.11. Two outlets in the base pedestal permit drainage from the bottom of the sample to occur or can be used for the measurement of the pore water pressure. Drainage from the top of the sample is possible by connecting a special platen to another outlet in the cell base. 


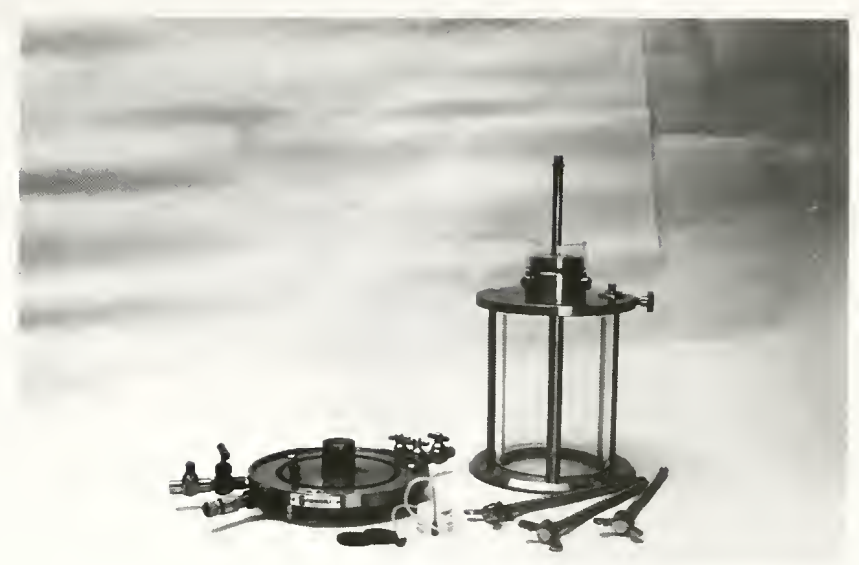

FIGURE A-II THE GENOR TRIAXIAL TEST.

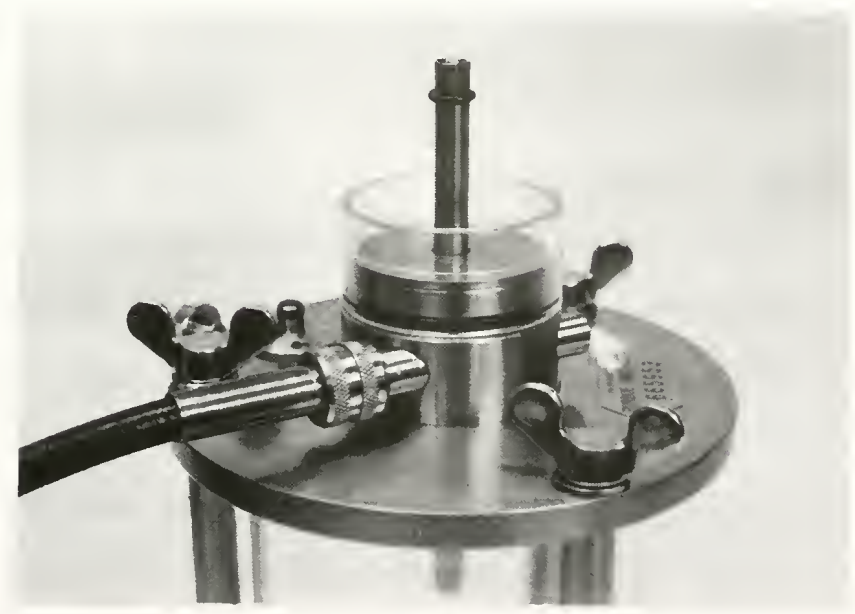

FIGURE A-12 GEONOR CELL, ROTATING BUSHING DETAIL. 
The Geonor cells used were all equipped with rotating bushings to reduce piston friction. Figure A.12 shows the assembly, and Figure A.13 a plot from Andresen and Simons (1960) indicating the considerable advantage of using the rotating bushing. Simple experiments were run "testing" a stiff rubber block and a spring as shown in Figure A.14. Results were not as spectacular as those given by Andresen and Simons but tests run without the rotating bushing did show occasional jagged breaks on the output curve due to piston sticking and releasing.

The Geonor cell was also adapted for use in a scries of isotropic loading tests. In these tests the cell confining pressure was increased incrementally at regular time intervals. It was desired to measure both axial deformation and volumetric change. The latter was easily accomplished by permitting drainage from both ends of the sample and attaching the outlet 1 ines to a calibrated burcte. The axial deformation was measured in the following manner. A linear variable differential transformer (LVDT) core was threaded and screwed into a top platen. The LVDT itself was attached to the piston which was fixed to the cell and not permitted to move. Any axial movement of the top platen produced a corresponding movement of the core within the fixed LVDT and the output was recorded automatically. Figure A.15 shows a photograph of the set-up, in this case with only bottom end drainage permitted. The leads from the LVDT were coated 


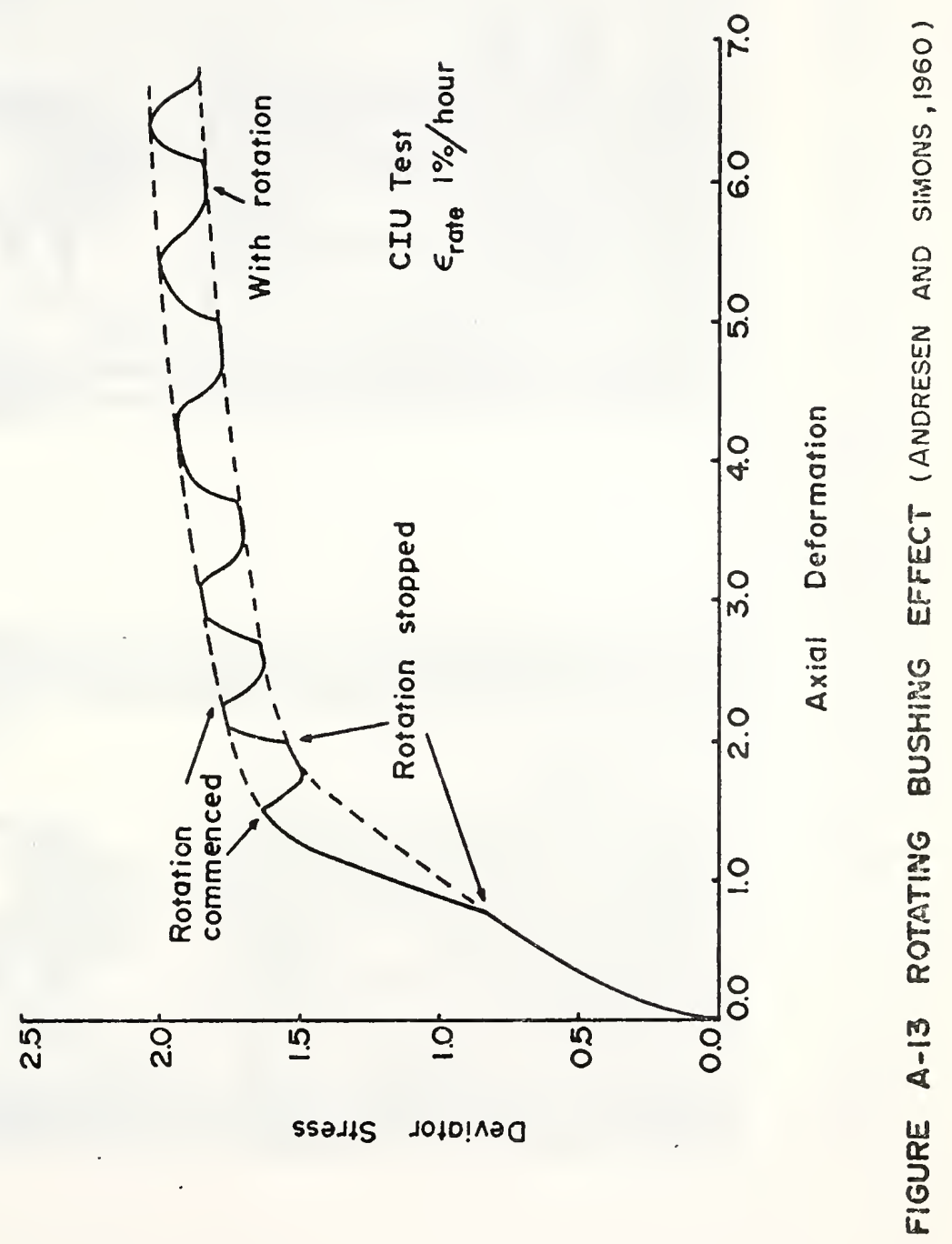



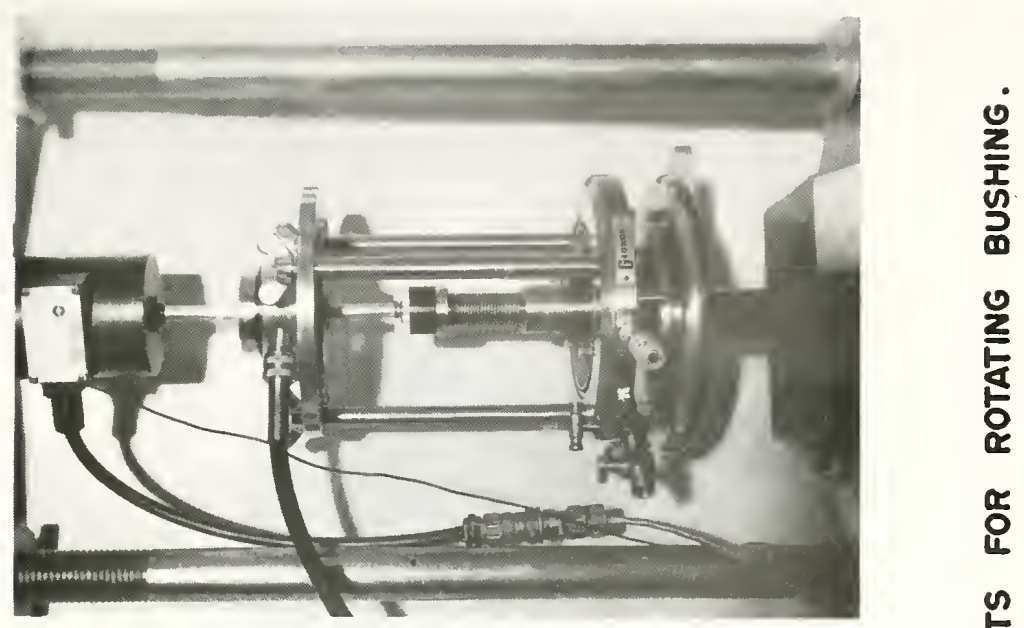

$\frac{0}{2}$

$\frac{0}{0}$

$n$
in
E

$\frac{0}{\frac{2}{n}}$

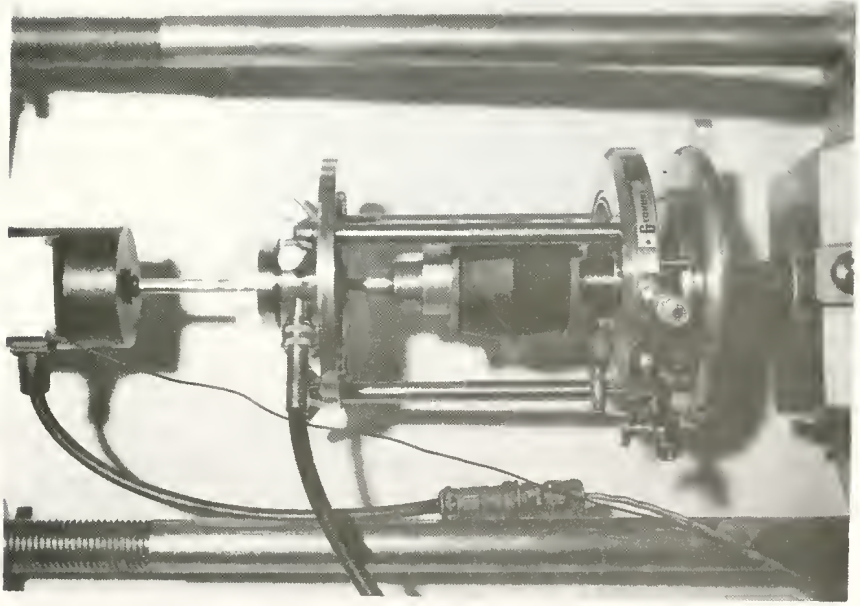

$\frac{0}{2}$

$\alpha$
0
0
0
$a$

$\frac{1}{1}$

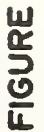




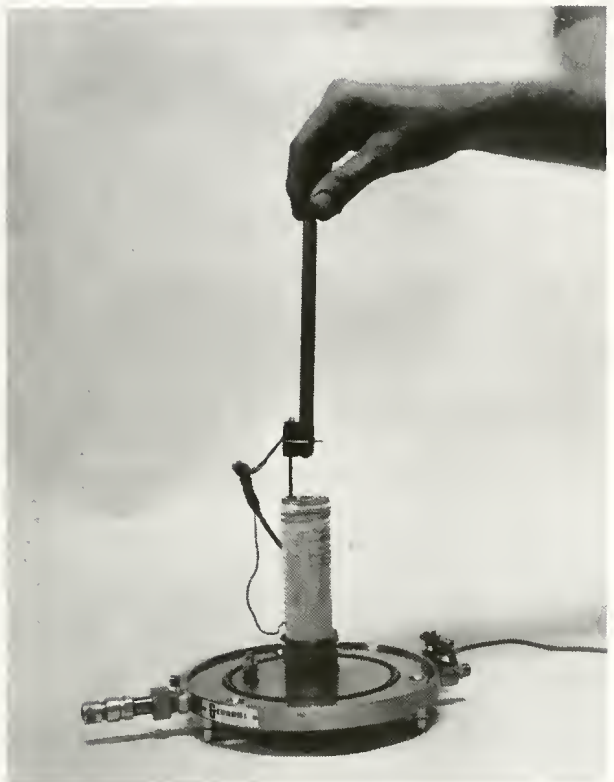

FIGURE A-15 SET-UP FOR ISOTROPIC LOADING TEST. 
with plastic and exited through a carefully sealed hole cut in the cell base. Calibration was accomplished by moving the piston and sighting a point on the LVDT with a cathetometer. These actual measurements were related to the number of divisions transcribed on the recorder output.

The Wykeham-Farrance cell is shown in Figure A.16. This apparatus, like the Geonor, consists of a base plate with pedestal and an upper plate with plexiglass cylinder. Double drainage of the soil sample is also permitted. The main disadvantage of this cell is the absence of a rotating bushing; consequently piston friction is an unknown factor.

A few tests were carried out in a Test Lab triaxial ce11. This apparatus shown in Figure A.17 is very similar to the Wykeham Farrance cell and has the same frictional disadvantages.

A.3.3 Testing Machine and Recorders. The testing machine used for all the constant strain rate tests, and shown in Figure A.18, was manufactured by Engineering Laboratory Equipment Ltd. (ELE) of Rickmansworth, England. The soil sample within the triaxial apparatus was compressed by raising the platform on which the cell sits while the piston bore against a proving ring or load-ce11. In this research a 100 1b. capacity Baldwin-Lima-Hamilton Corporation loadcell was used. The E.L.E. machine allows a wide range of testing rates varying from $1.6 \times 10^{-1}$ to $2.0 \times 10^{-6}$ inches per minute. For a 2.8 inch sample this represents a range 


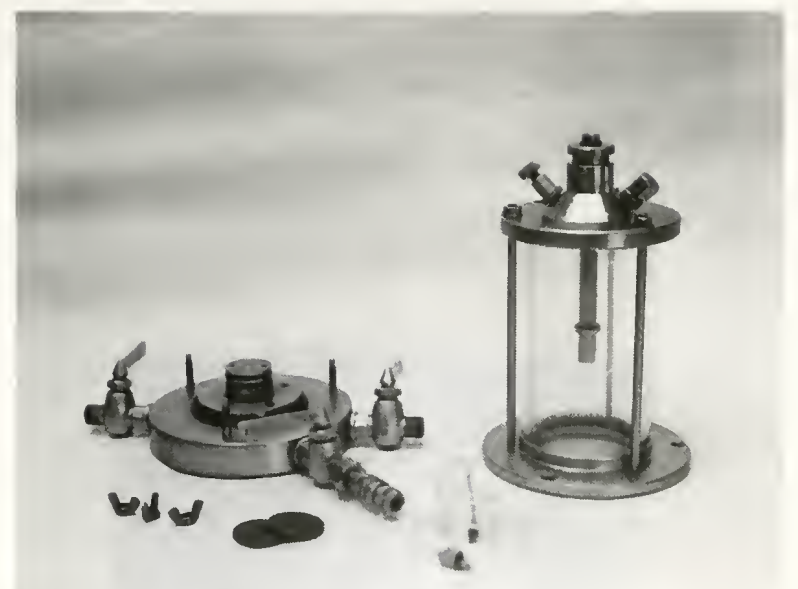

FIGURE A-16 THE WYKEHAM-FARRANCE CELL

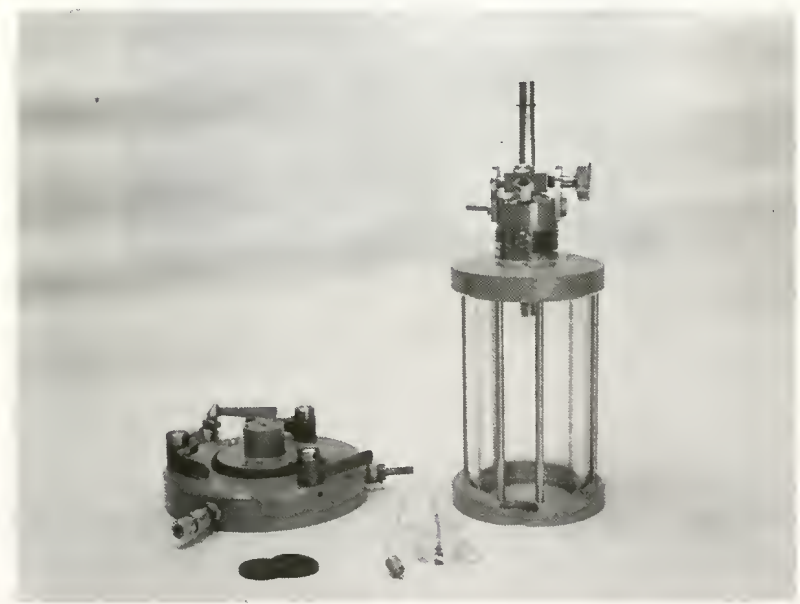

FIGURE A-17 THE TEST LAB CELL 


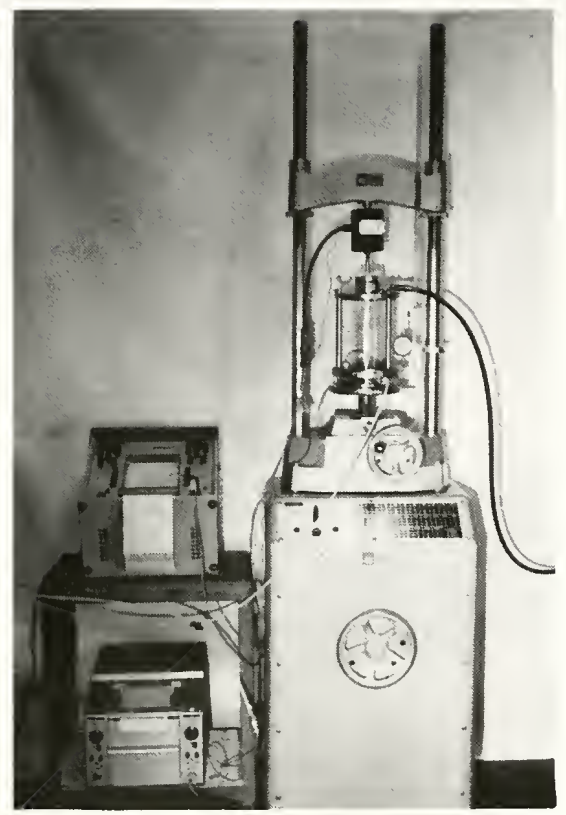

FIGURE A-18 THE TRIAXIAL TESTING MACHINE 
of one percent strain in 10.5 seconds to one percent strain in approximately 10 days.

The recorder used during triaxial testing for both loadcell and volume change output was a Sanborn Carrier Amplifier Recorder, Mode1 321. This is a portable, two-channel recording system using hot-wire writing arms on heat sensitive paper. It is shown in Figure A.19. For the Linear Variable Differential Transformer output in the Isotropic loading tests a single channel ink recorder, Varian Model G-14A-1 was employed (Figure A.20). 
APPENDIX B

LABORATORY TEST RESULTS 


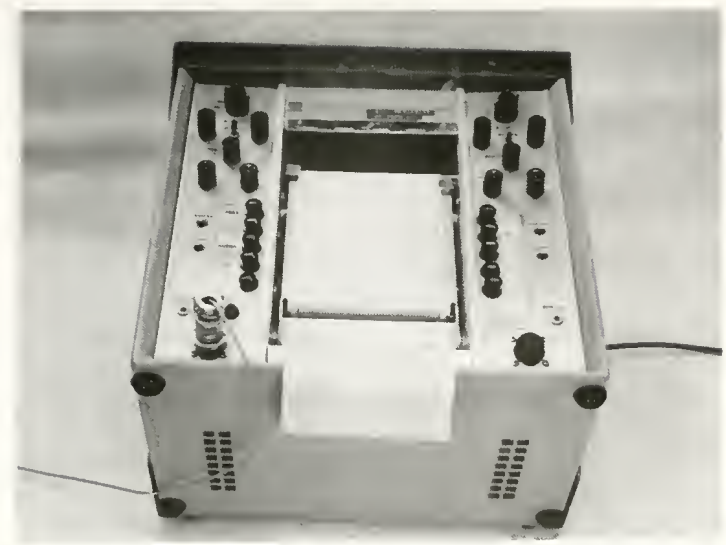

FIGURE A-19 THE SANDBORN 321 RECORDER

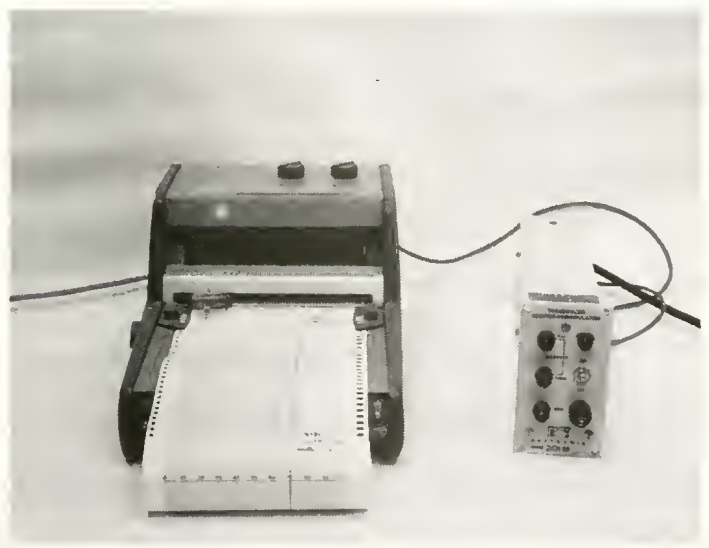

FIGURE A-20 THE VARIAN G-14A-I RECORDER 


\section{B. LABORATORY TEST RESULTS}

\section{B.1 Introduction}

A particular test, Number 23 , is used as an example and is described in detail in the following section. Results from all phases of its preparation and testing are given. Section B. 3 contains detailed results from all twenty-seven tests.

\section{B.2 Triaxia1 Test Number 23}

Scdimentation sample 1D was prepared on June 7, 1972 as described in section A.2 and allowed to consolidate under its own weight with the base drainage outlet open. Fortyeight hours later the lucite tube was placed in the sedimentation frame and the piston and deaired porous stone brought into contact with the soil surface. A reference point was marked on the piston such that cathetometer readings of the sample compression could be measured during loading. Siphon number 11 was inserted and rear tank weight and cathetometer readings taken every 24 hours. After twelve days siphon number 7 with a slightly larger bore was substituted. Still later siphons 9 and 17 were used and finally $4 \mathrm{~kg}$. $10 \mathrm{~d}$ increments were added. The final load of $50 \mathrm{~kg}$. is equivalent to a vertical pressure of 11.4 psi. Figure B.1 shows a 


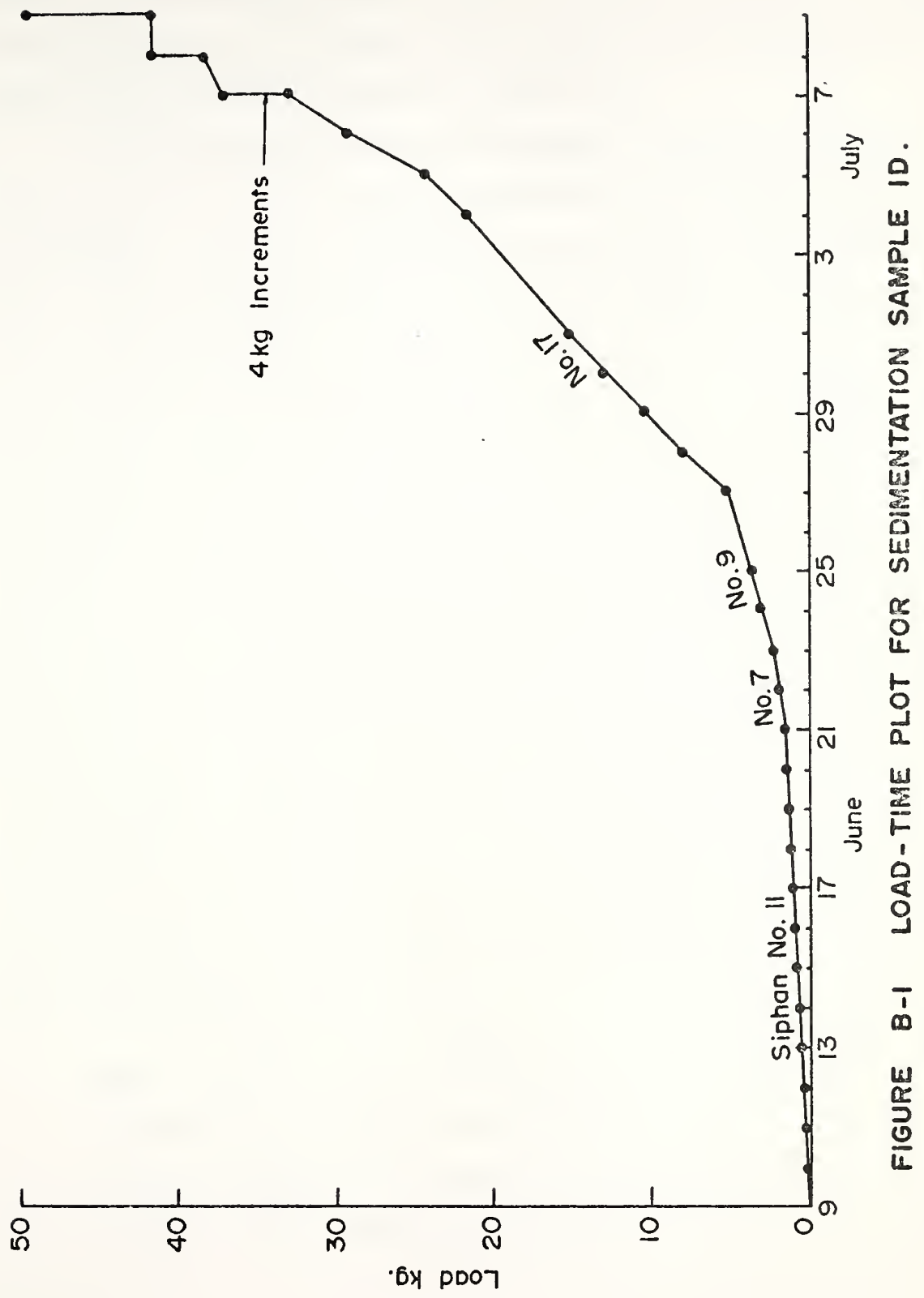


plot of the loading versus time, and Figure B.2 the e - $10 \mathrm{~g} \mathrm{p}$ curve obtained. The final load increment was added on July 10 th and allowed to remain for three days.

On July 13 th the soil was extruded, six water contents of $58,58,59,59,59$, and 60 obtained at different depths within the clay and a specimen cut for Triaxial Test Number 23. The summary sheet for this test is shown in Figure B.3. The triaxial cell was placed in the triaxial set-up in position VII $C$ at a confining pressure of $30 \mathrm{psi}$. The drainage lines were connected to a burette and volume change readings taken at intervals during the q-confining period. These results are shown in Table B.I. From these values, the excess water $(2.10 \mathrm{cc}$.$) contained initially in the filter$ paper which cncircled the specimen, must be subtracted. On August 4, 1972 when the sample was to be tested the total volume change which had occurred during the twenty-two day confining period was $13.00 \mathrm{cc}$. Since there was no discernible visual distortion of the sample, new dimensions were calculated assuming that the sample shape remained a right cylinder with the samc length-diameter ratio.

$$
\begin{aligned}
& \text { Sample volume } \quad \text { VoI }=\frac{\pi D^{2}}{4} \mathrm{~L} \\
& \text { Assumption } \quad r=D / L=\text { constant } \\
& \text { Vol }=\frac{\pi r^{2}}{4} \mathrm{~L}^{3}=0.1830 \mathrm{~L}^{3}
\end{aligned}
$$

Original sample volume $=73.15 \mathrm{ccs}$ 


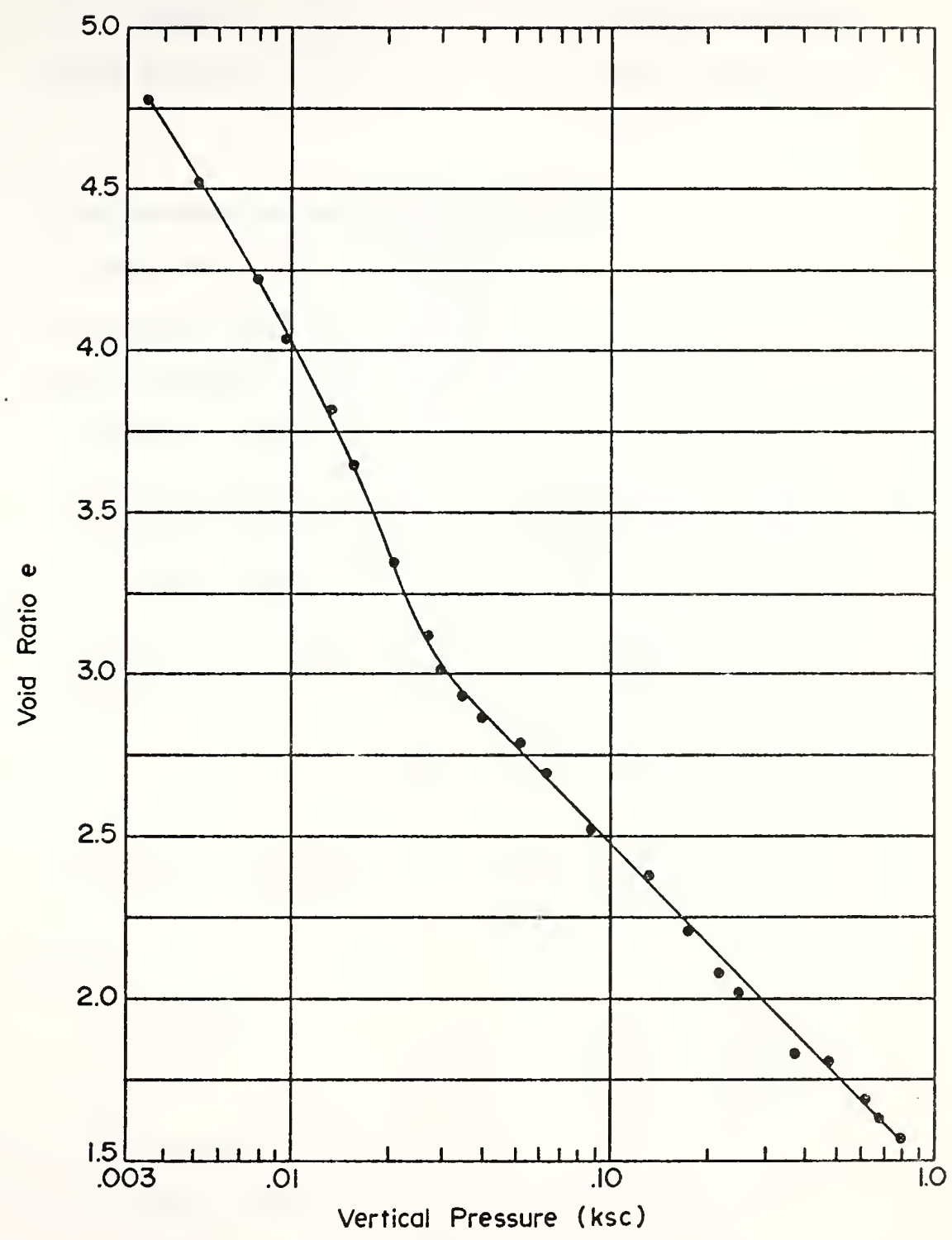

FIGURE B-2 VOID RATIO-PRESSURE CURVE FOR SAMPLE $I D$. 
Test Number ... . 23.......

Quasi Number.....V!! . C.......
John L Davidson

IOIH Grissom Hali

Sedimentation Somple Prepared ...6.7.72

Looding Started ...6.9.7. $72 . . . . .$.

Quosi Sample Set Up ..7.13.72.........

Quasi Pressure Applied ... $7.13,72 \ldots \ldots \ldots .$.

Triaxial Test Started ..... 8.4.72 ........

Initial Void Ratio ... I.57.....

Woter Content

Unit Weight ...108 a...pcf. after Test

Volume Change During Quasi Set-Up ......13.0. _....ccs $\left[\begin{array}{ll}5 & 42.2 \\ 6 & 42.2\end{array}\right.$

Prior to Testing Sample Length....2.72......ins.

Sample Areo...1.3510..... sq.ins.

Cell Type ...WYKENAM ...

Standard Procedures? ..YES...

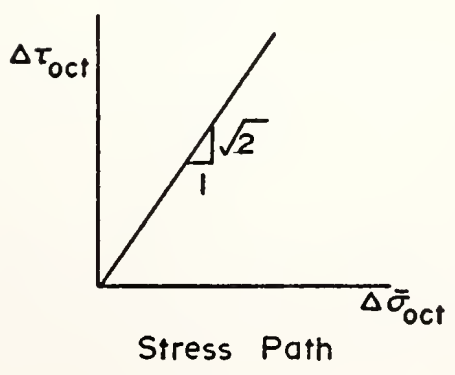

$$
\begin{aligned}
\Delta \vec{\sigma}_{\text {oct }} & =5.92 \ldots \ldots . p s i \\
\Delta \tau_{\text {oct }} & =.8 .36 \ldots \text { psi }
\end{aligned}
$$


TABLE B.1

Volume Change during the q-consolidation period Test Number 23

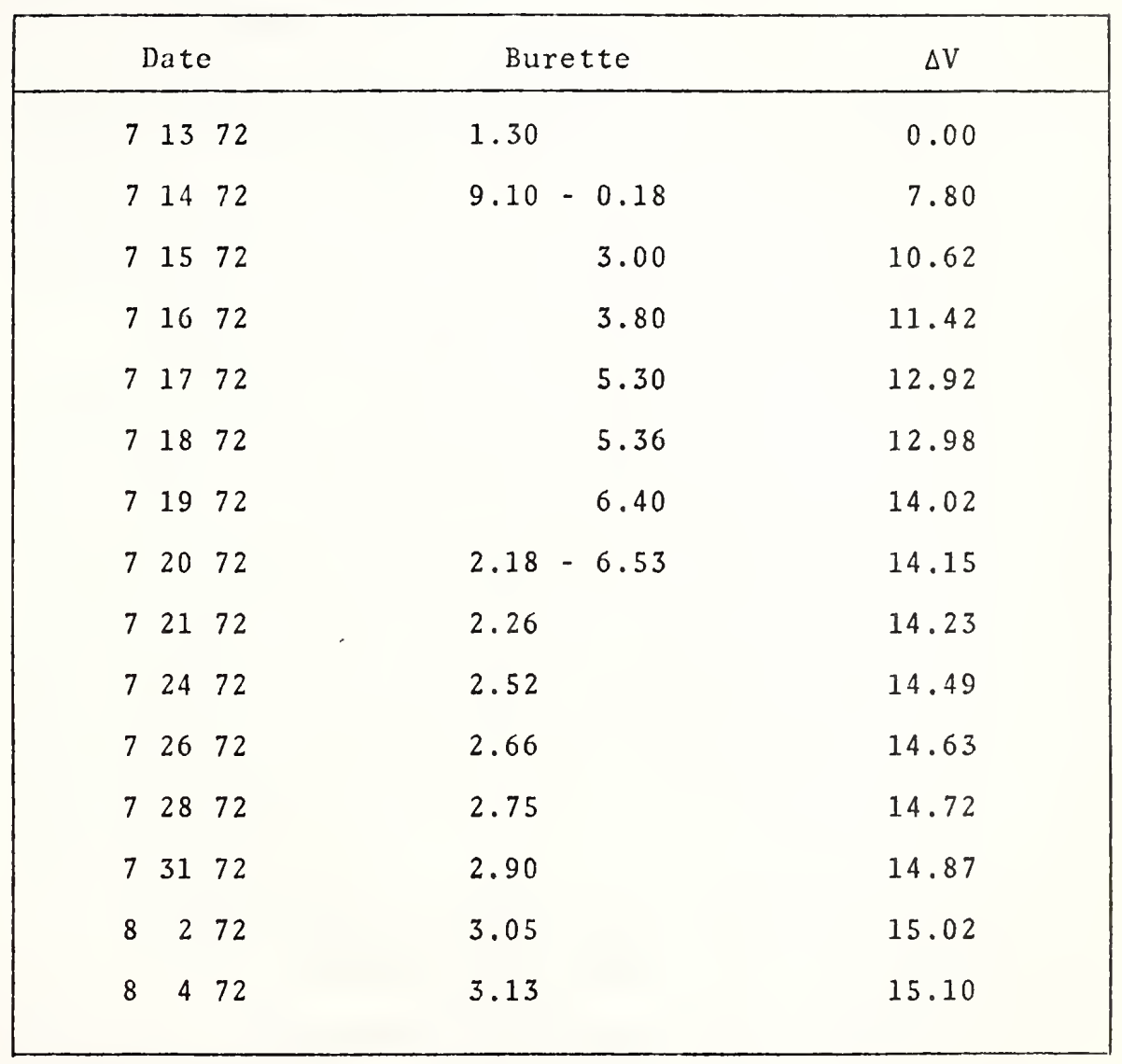




$$
\begin{aligned}
\text { New sample volume } & =73.15-13.00=60.15 \mathrm{ccs} \\
& =0.1830 \mathrm{~L}_{\text {new }}^{3} \\
\mathrm{~L}_{\text {new }} & =6.90 \mathrm{cms} \\
& =2.72 \text { inches } \\
\mathrm{D}_{\text {new }} & =1.31 \text { inches } \\
\text { Area } & =1.3510 \mathrm{sq} \text { ins }
\end{aligned}
$$

These calculations were carried out only in Triaxial Test Number 23. Consequently, in all other tests there is an underprediction in axial strain, axial stress and volumetric strain due to use of larger than actual sample dimensions.

Triaxial Test Number 23 was a Type 1 test with a constant chamber pressure of 30 psi, equal to the q-consolidation pressure. An extension plastic tube with quick connectors at each end was inserted so that the sample could be placed in the loading frame and still be attached to position VII $C$ at the q-consolidation pressure. The burette was removed and the drainage lines connected to the special burette with transducer attachment described in Section 3.6. The initial test parameters were:

Triaxial machine loading rate: $4 \times 10^{-5}$ inches/minute Sandborn chart speed: $\quad 1.2$ divisions/minute Load cell calibration: 0.4 1b./division Volume change burette calibration: $0.05 \mathrm{cc} /$ division It was found to be more convenient to calibrate the burette accurately during the test. Burette levels were read 
visually at different times throughout the test and recorded directly on the Sandborn chart. After the test these readings were compared with the transducer output and the best calibration constant derived. For Test 23 this was 0.0464 cc./division. During the test the Sandborn attenuator was altered to reduce the output scale, changing the load cell calibration to $0.8 \mathrm{lb}$./division. The test was continued at constant strain rate until approximately 15 percent axial strain had been achieved. Finally the triaxial sample was removed and water content determinatjons made.

Test data consisted of the Sandborn chart with plots of load ccll output and volume change burette output. A computer program was written to facilitate the reduction of the test data. After reading in the initial test parameters described above, it was only necessary to punch cards containing three variables. These were the number of divisions along the chart, number of load cell divisions and number of burette divisions. Computer output consisted of listings of axial strain, axial stress, volumetric strain, deviatoric strain, octahedral normal and shear stresses, axial load, axial deformation and corrected sample areas. The Calcomp Plotter was then used to plot the desired stress-strain relationships. A program description, listing, flow chart and example problem are given in Appendix C. Figures (B.4), (B.5) and (B.6) show respectively the $\Delta \tau_{\text {oct }}$ vs $\varepsilon, \Delta \tau_{\text {oct }}$ vs $\varepsilon_{\text {axial }}$, and $v$ vs $\Delta \bar{\sigma}_{\text {oct }}$ plots for Test Number 23 . These figures were traced from the Calcomp plots to provide visual uniformity. 


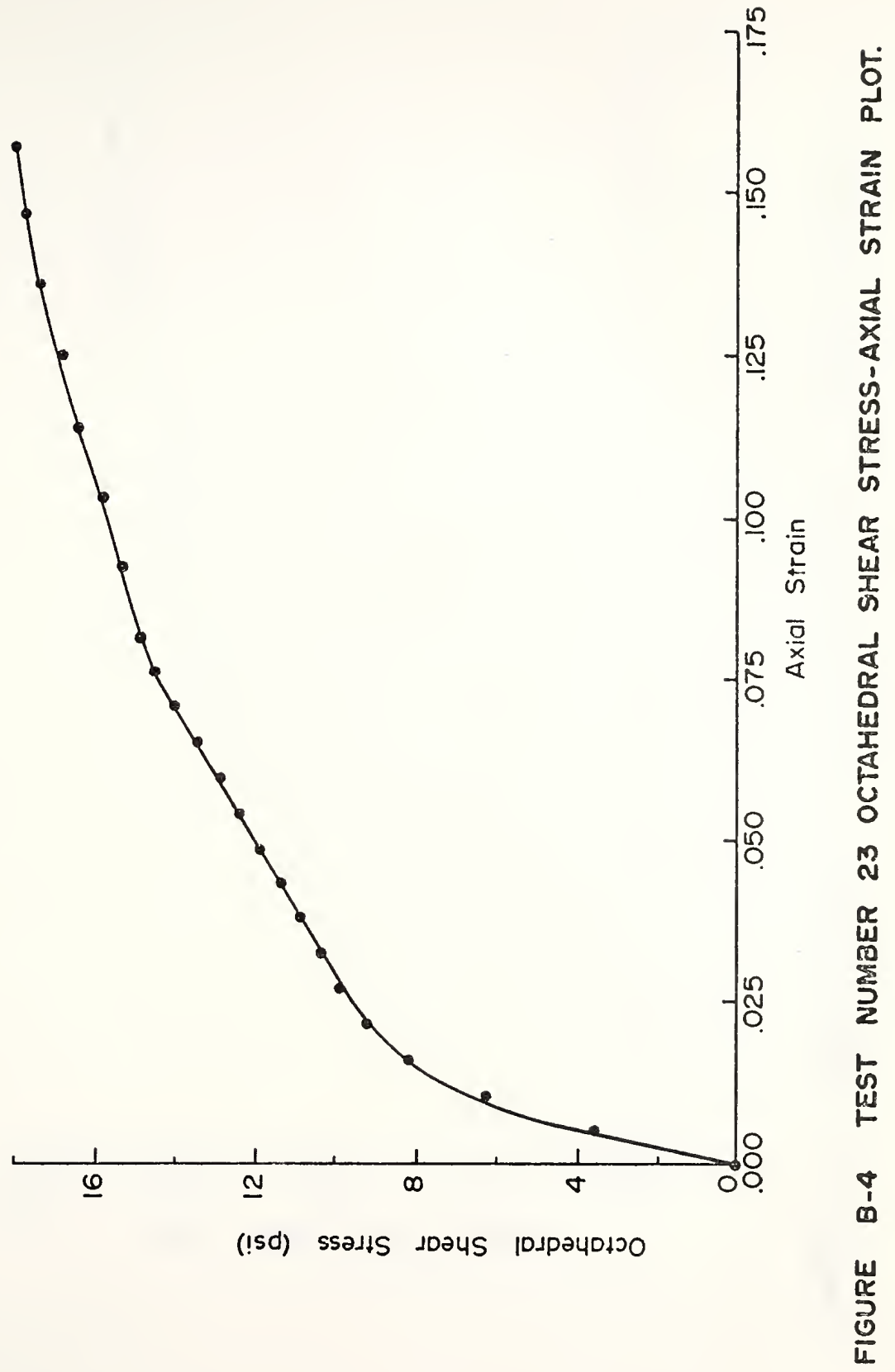




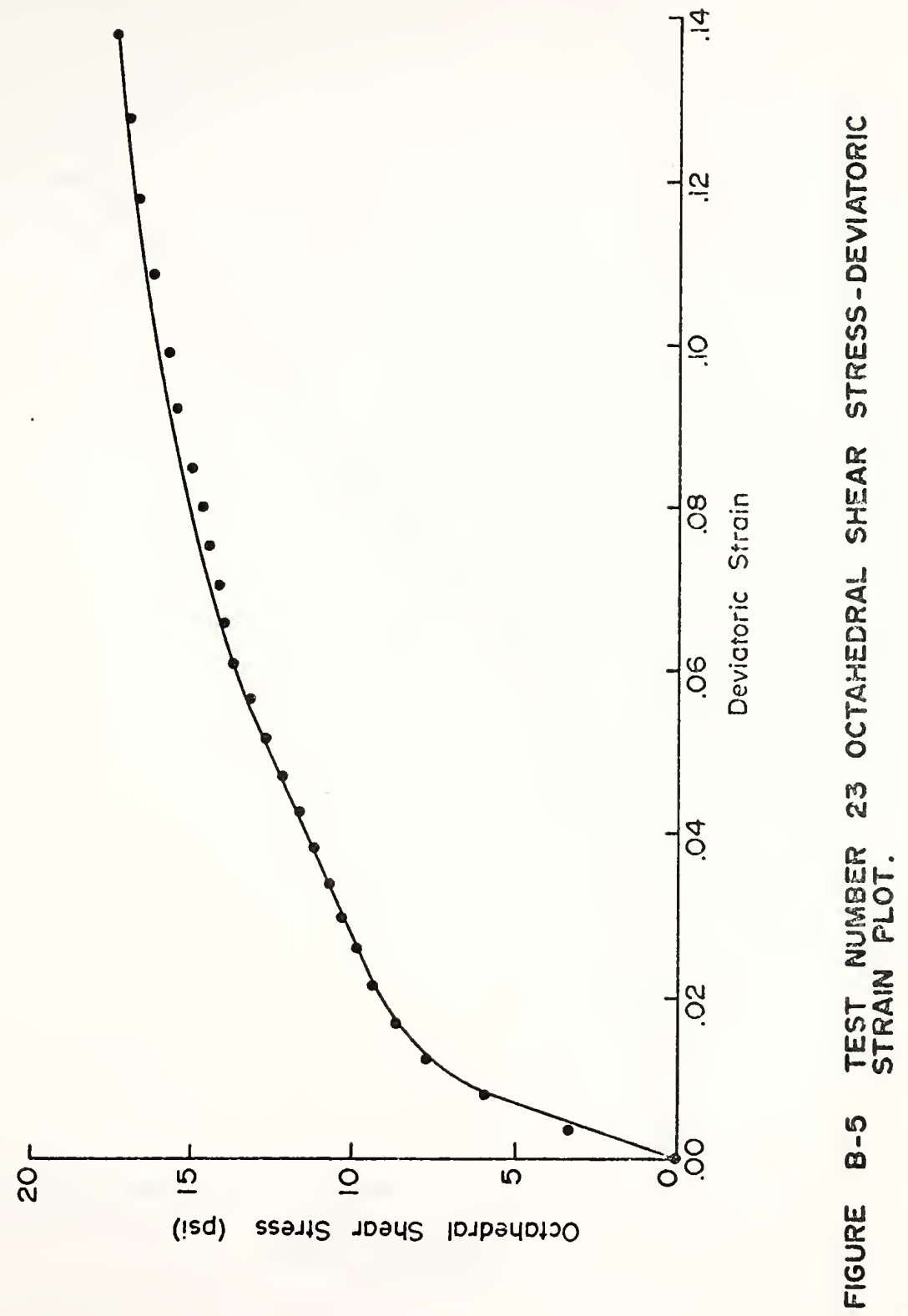




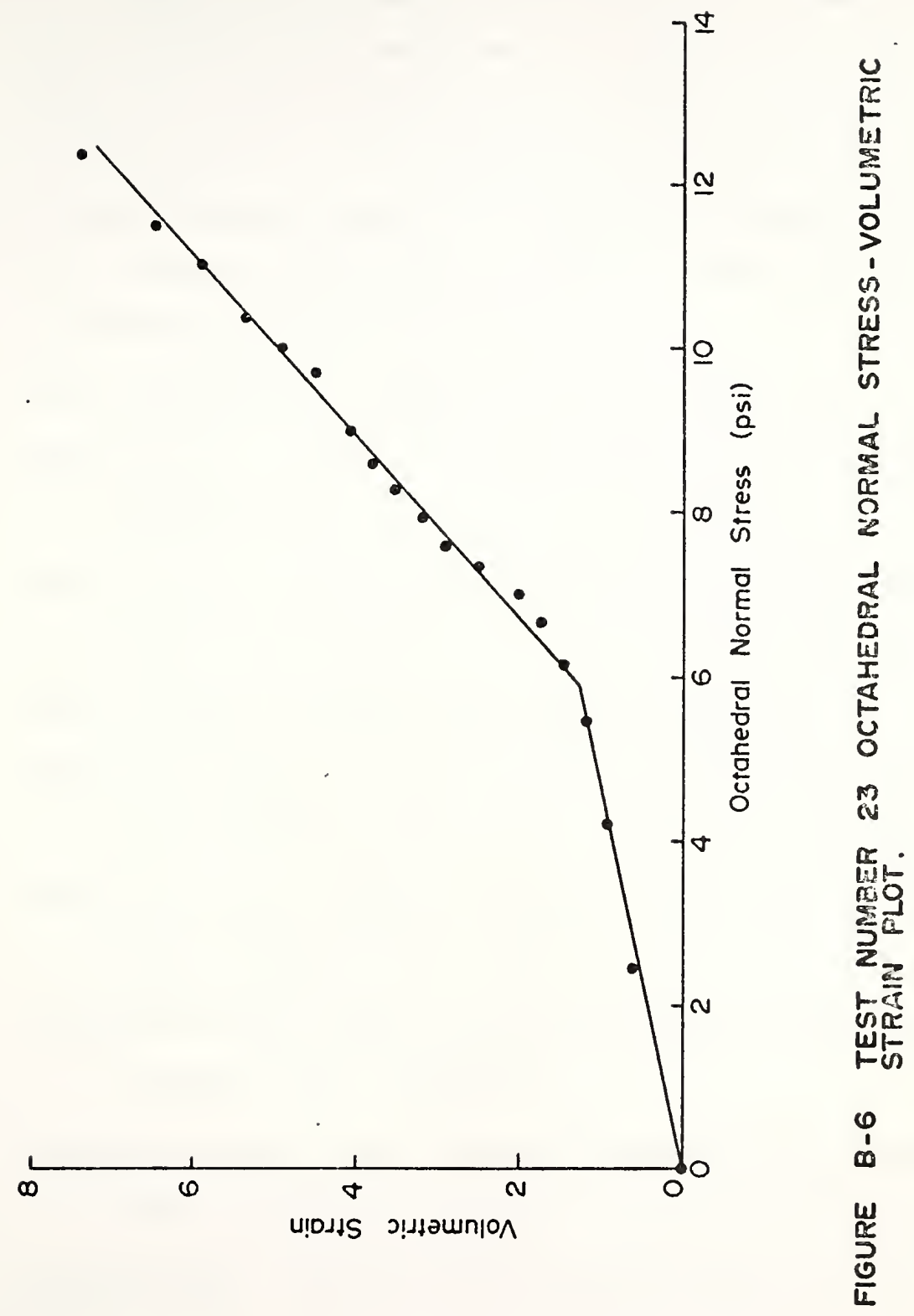




\section{B.3 Triaxial Test plots}

ligures $B .4$ through $B .41$ givo results from the twontyscven triaxial tests performed in the laboratory study. Stress and strain parameters were defined in Section 3.5. A brief summary of the parameters used as axes descriptors in the following figures is now given. Note that all stresses are increments from the $\mathrm{q}_{\mathrm{c}_{i}}$ (octahedral normal stress prior to shearing) values given in Table 4.2 .

Axial deformation - change in specimen length [ $\Delta \mathrm{L}]$

Axial strain - change in specimen length divided by original length $[\Delta \mathrm{L} / \mathrm{L}]$

Axial stress - axial load divided by specimen cross sectional area $\left[\mathrm{P} / \mathrm{A}_{\mathrm{S}}\right]$

Cell pressure - triaxial cell fluid pressurc [ $\left.\bar{\sigma}_{C}\right]$ Deviatoric strain - major principal strain minus one-third the volumetric strain [ $\Delta \varepsilon_{1}-\delta v / 3$ ]

Deviator stress - difference between major and minor principal stresses $\left[\Delta \bar{\sigma}_{1}-\Delta \bar{\sigma}_{3}\right]$

Octahedral normal stress - mean of principal effective stresses $\left[\left(\Delta \bar{\sigma}_{1}+2 \Delta \bar{\sigma}_{3}\right) / 3\right]$

Octahedral shear stress - factor times principal effective stress differences $\left[\sqrt{2}\left(\Delta \bar{\sigma}_{1}-\Delta \bar{\sigma}_{3}\right) / 3\right]$

Volume change - specimen volume change [ $\Delta \mathrm{V}$ ] 
Volumetric strain - volume change divided by original volume $[\Delta V / V]$ 


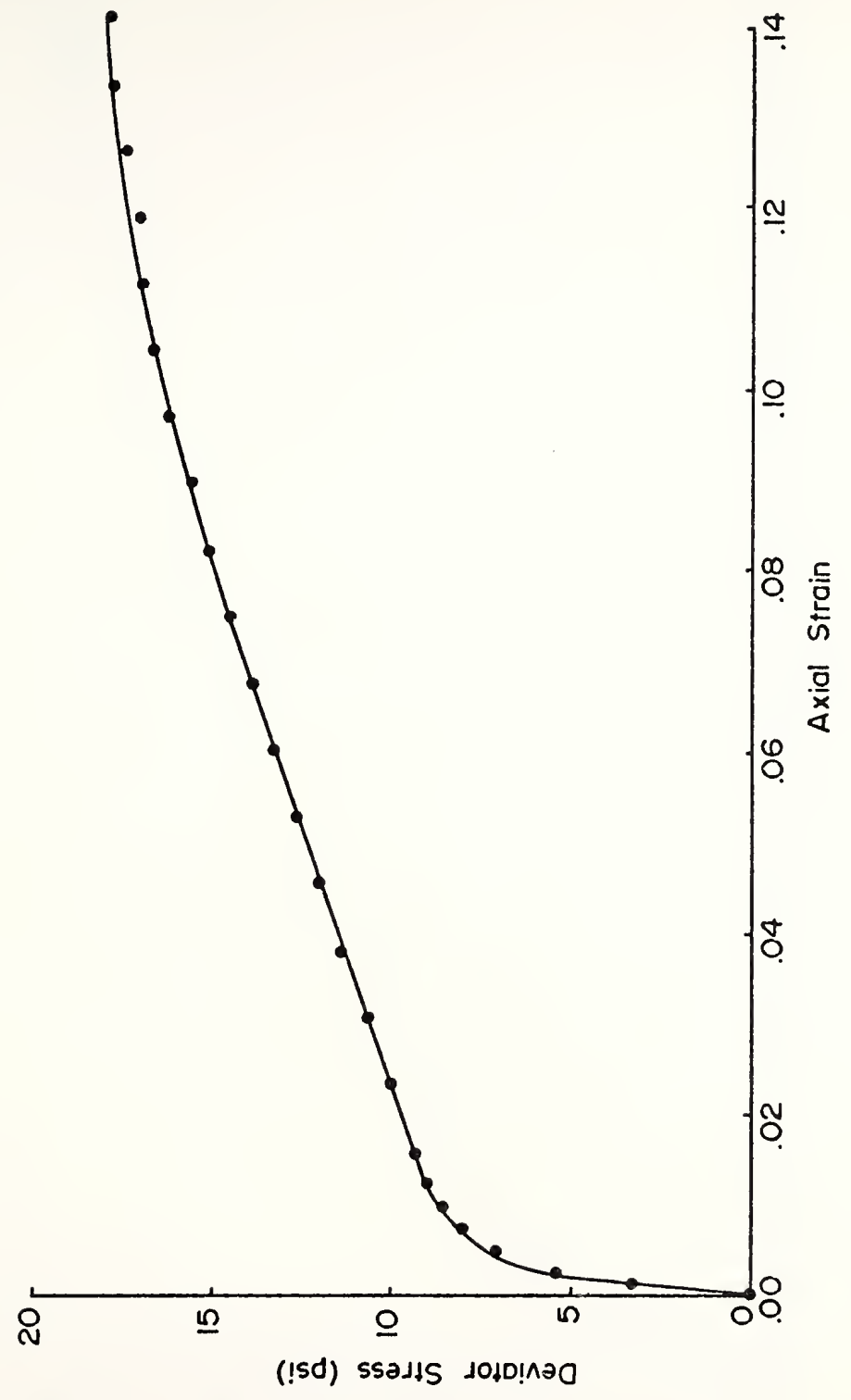

$\frac{5}{0}$
$\frac{a}{a}$
$\frac{a}{a}$
$\frac{5}{6}$

京

㭊

占

ก

1

$\frac{w}{\frac{w}{0}}$ 


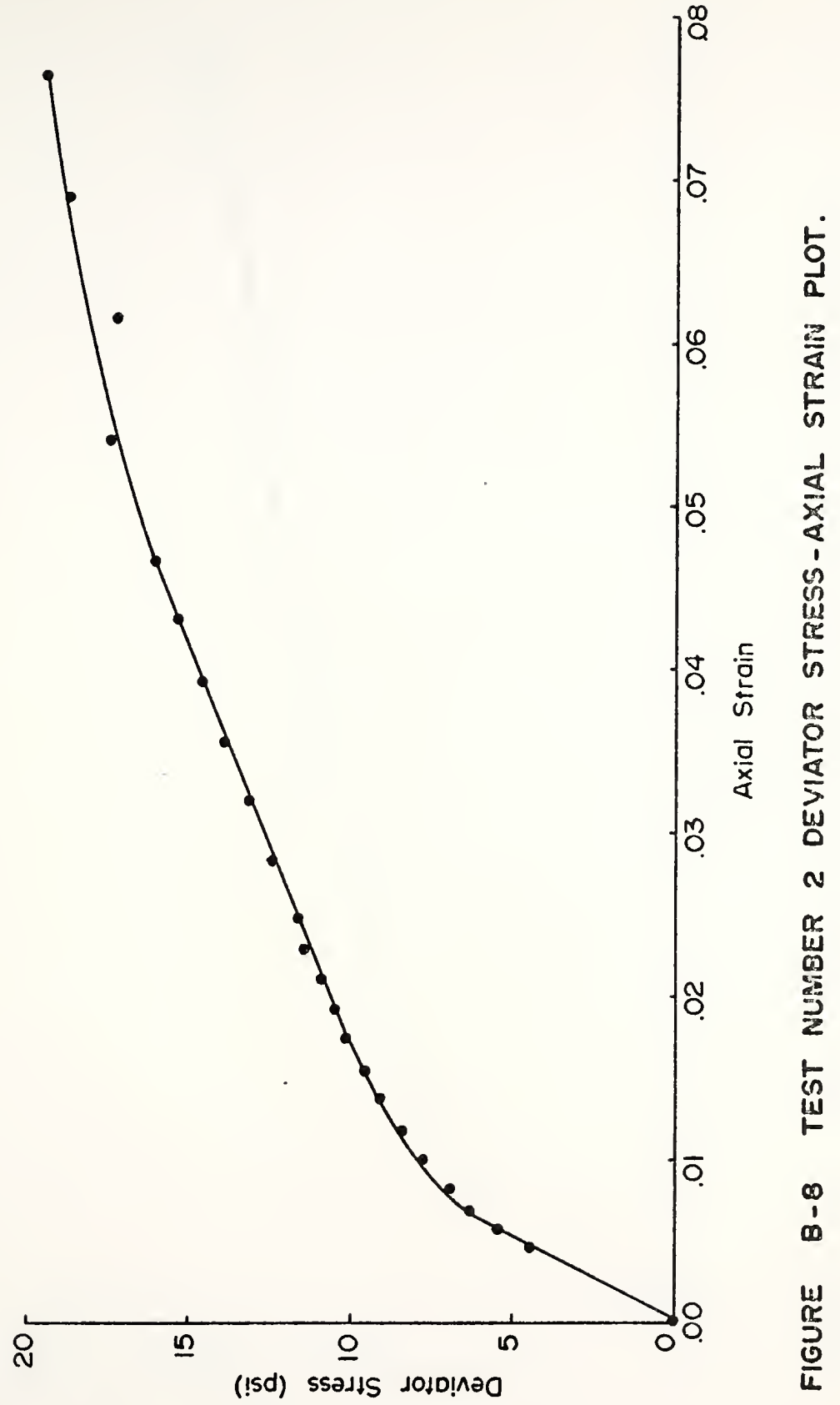




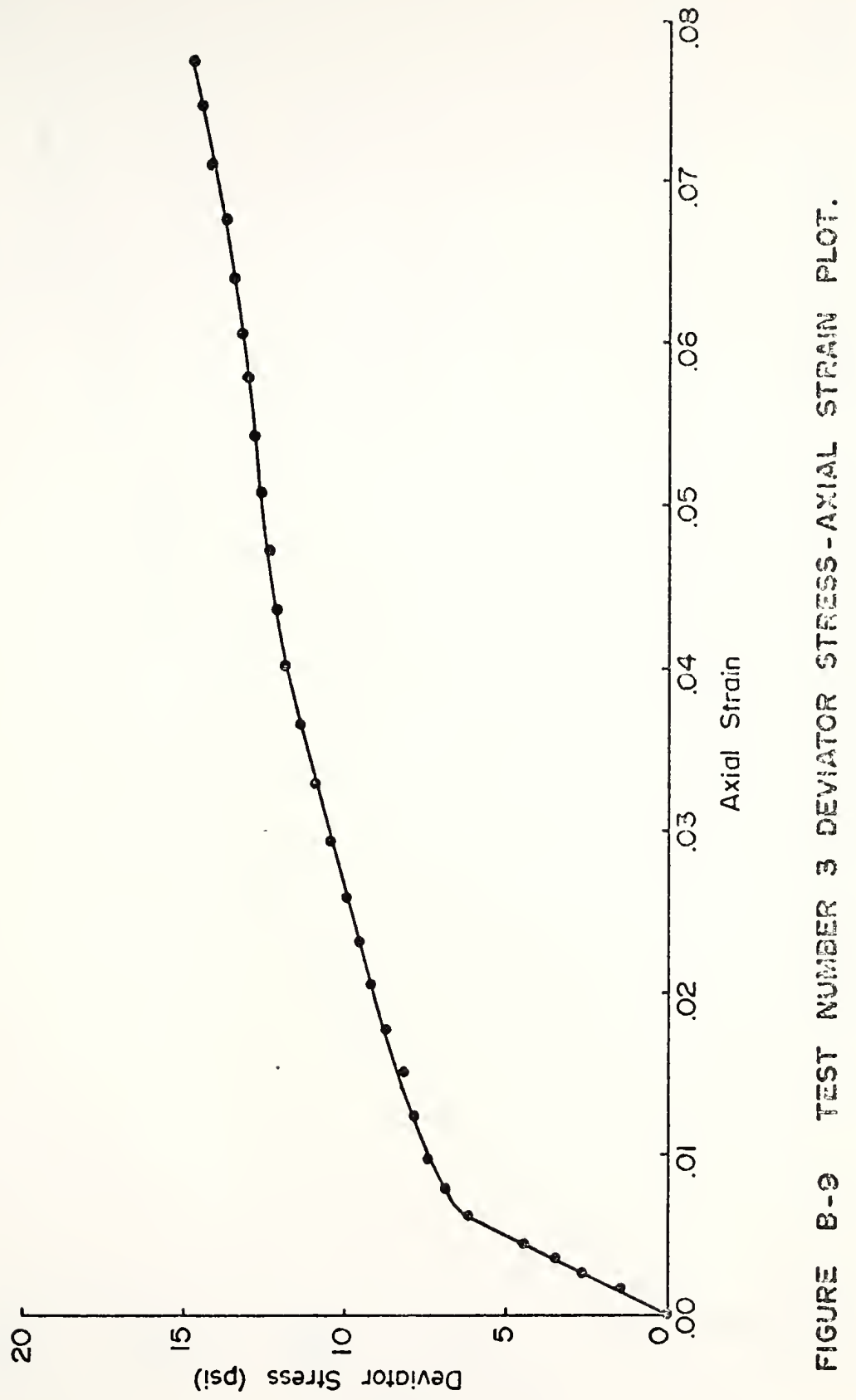




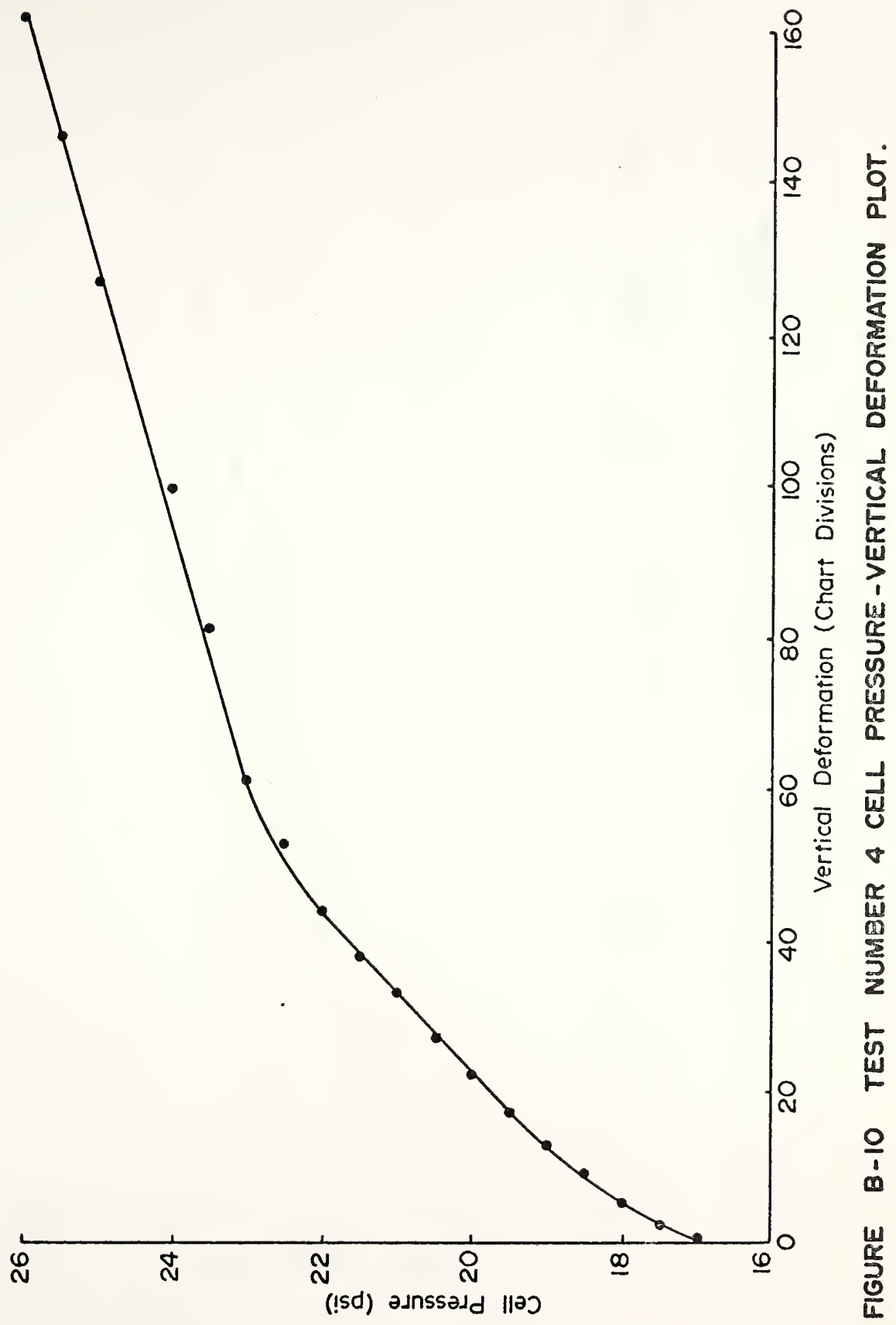




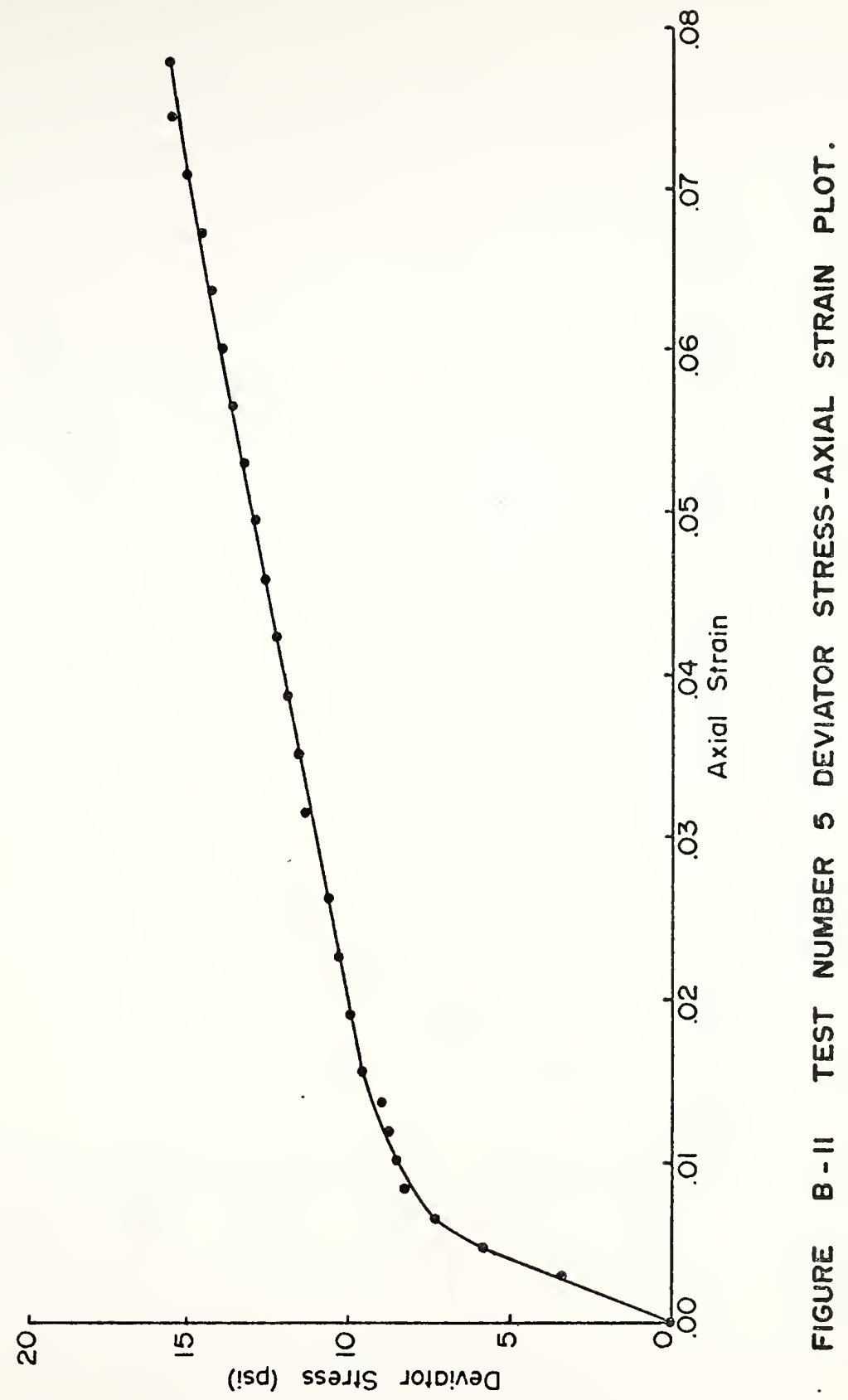




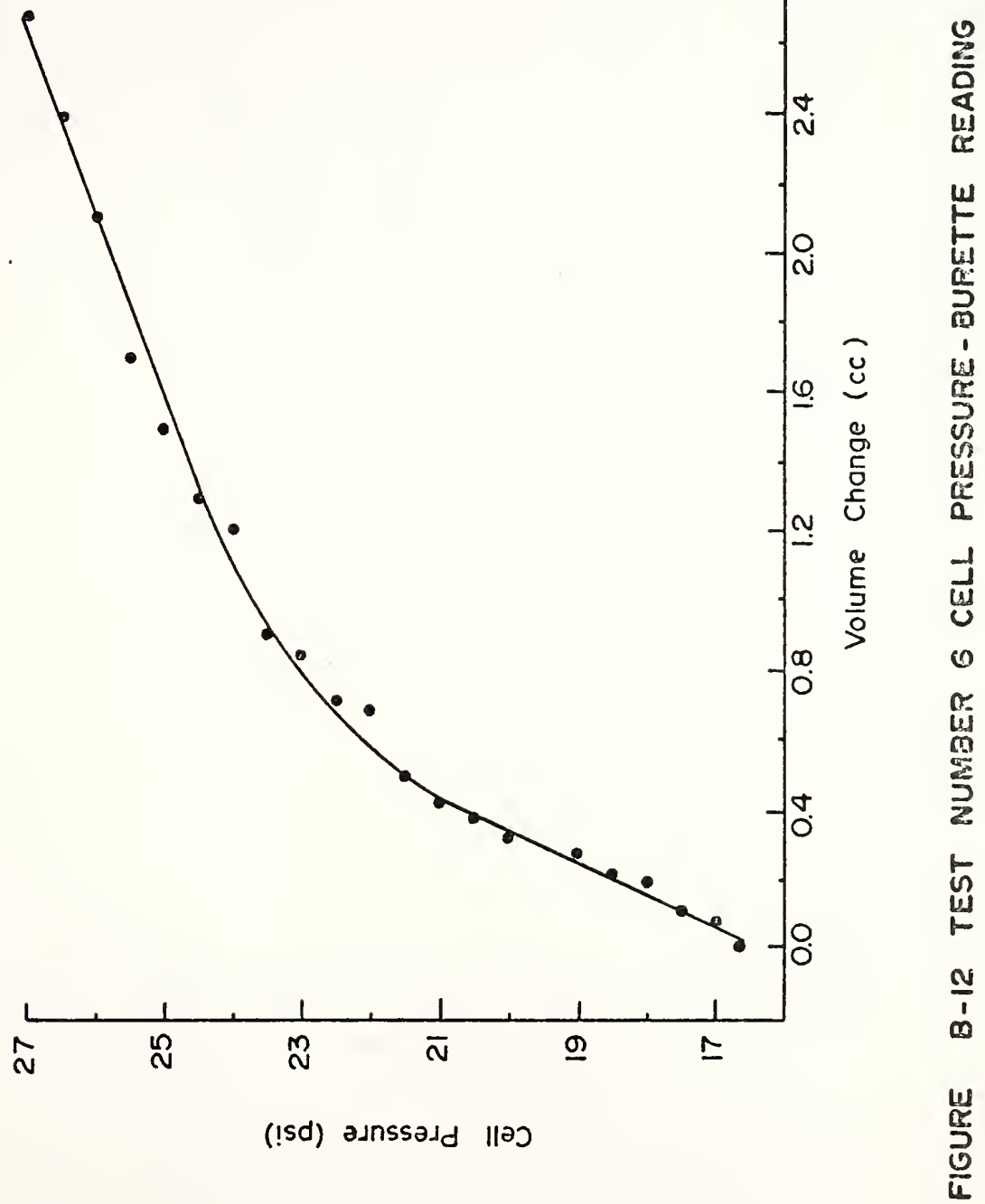




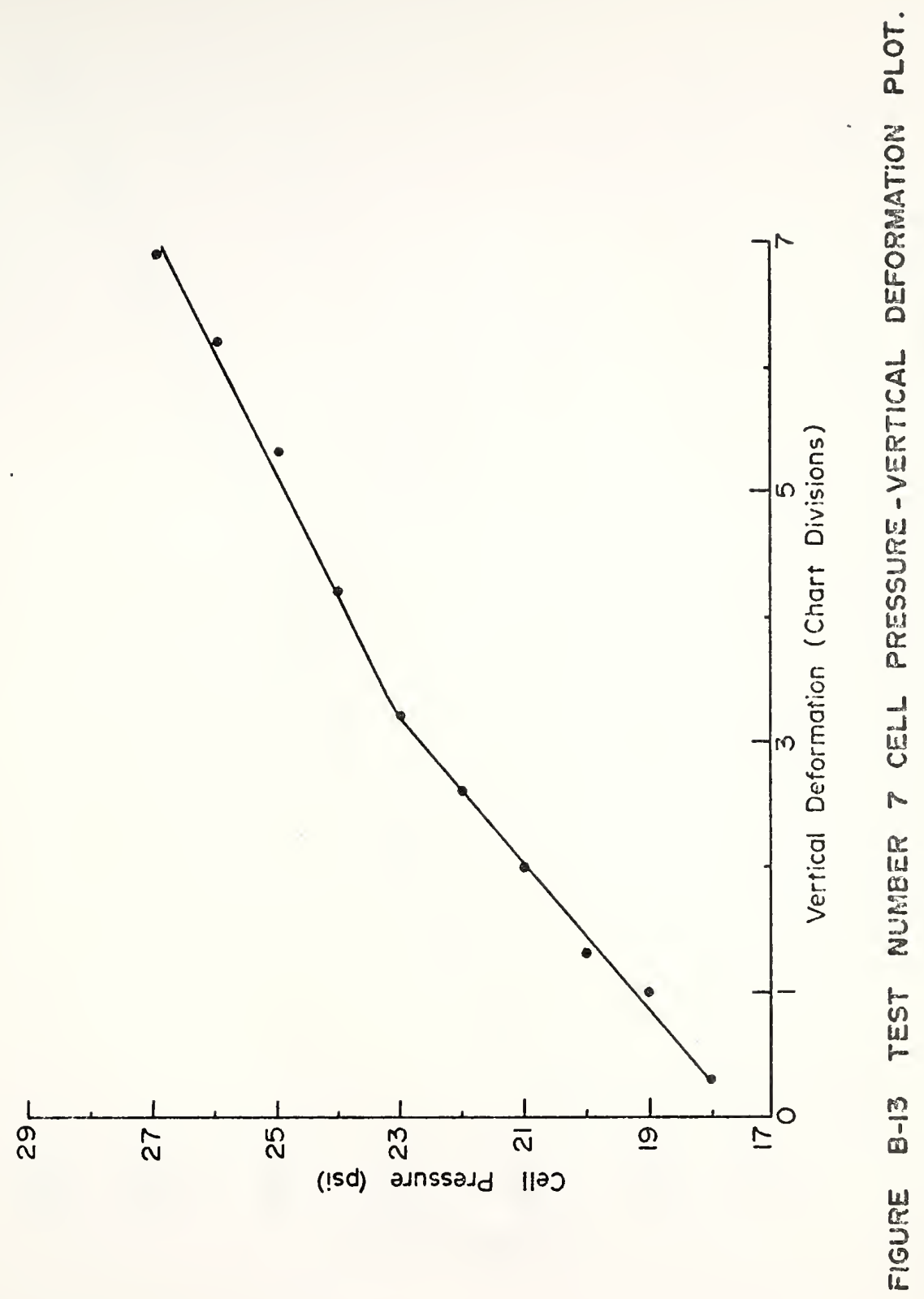




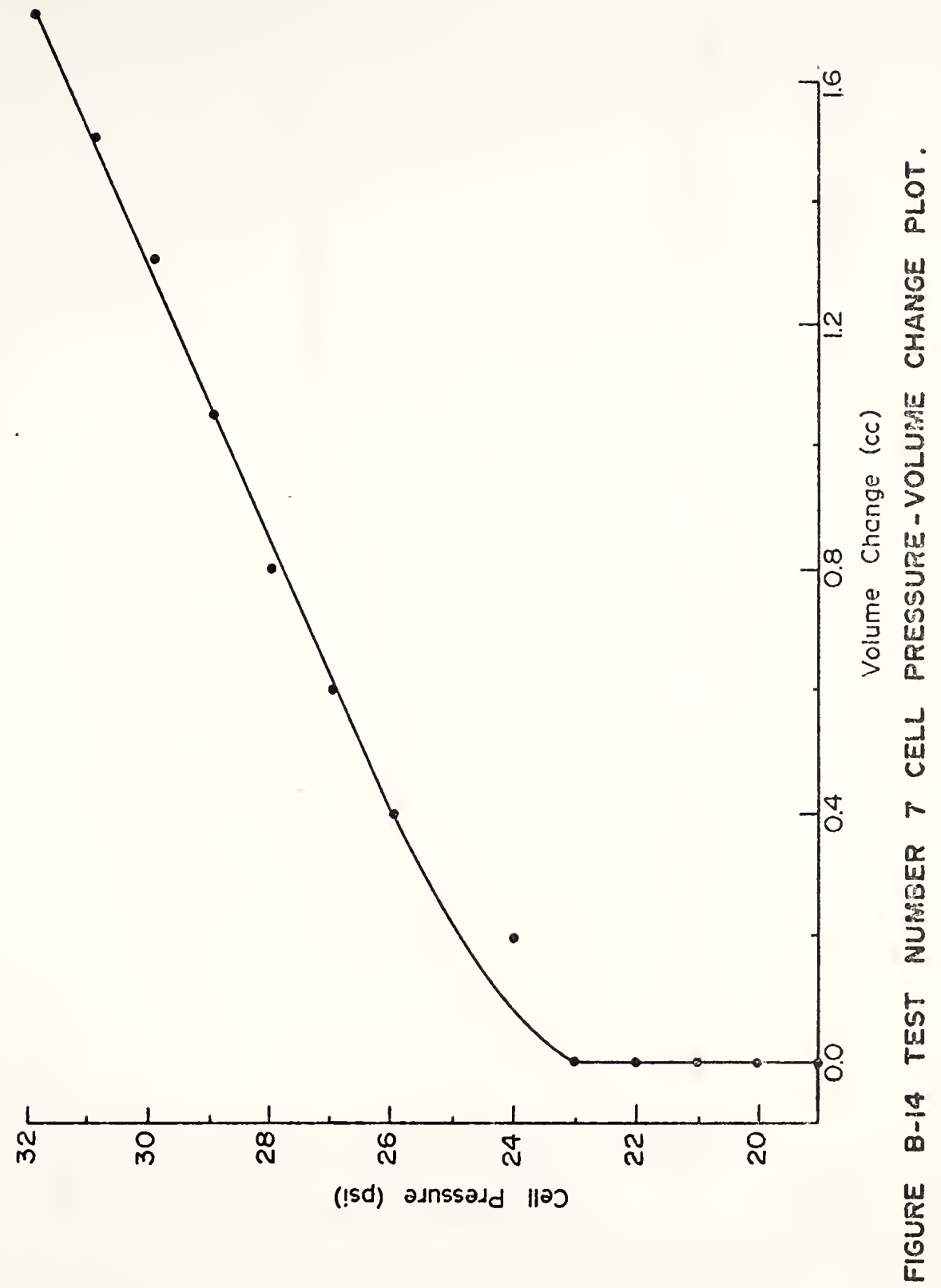




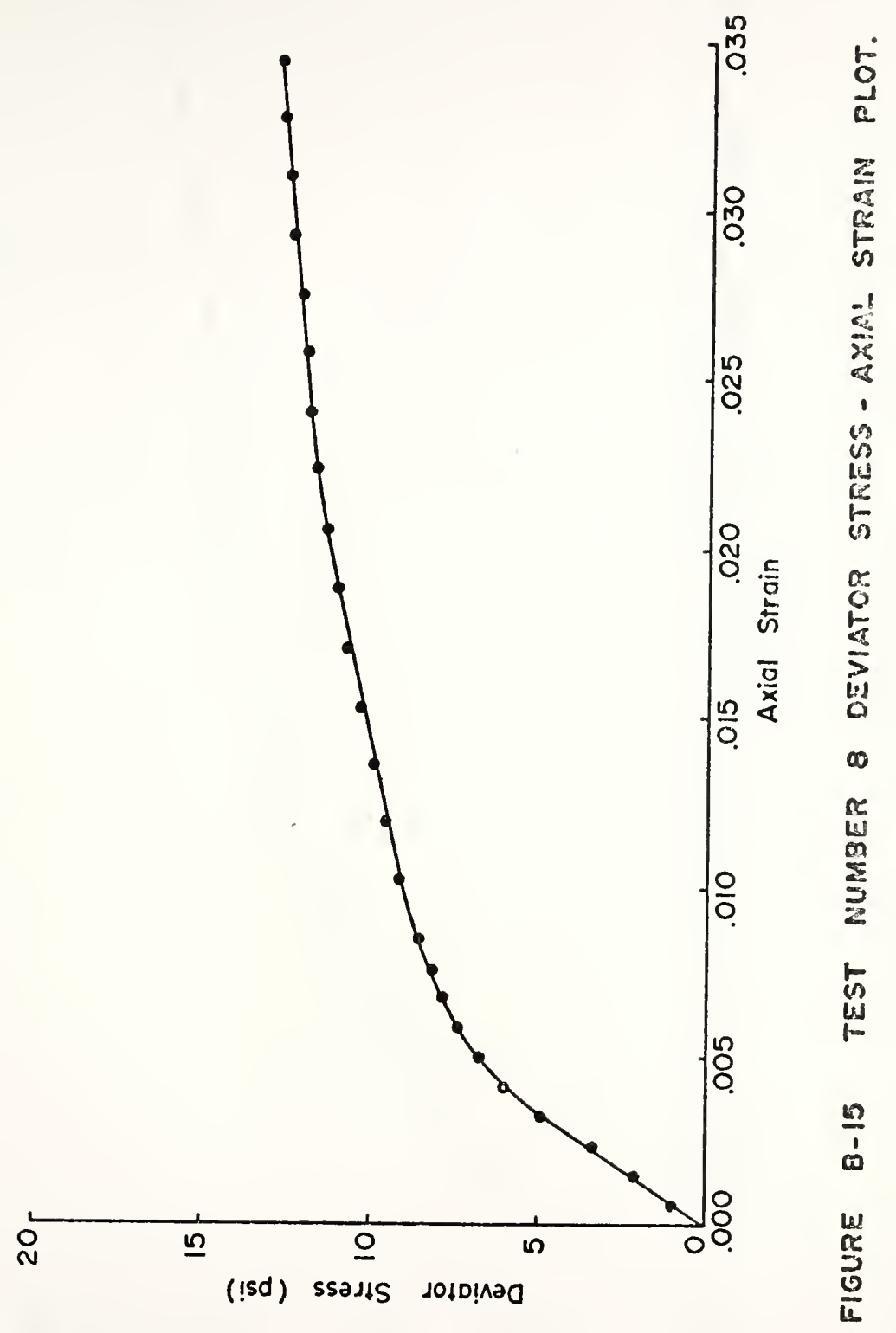




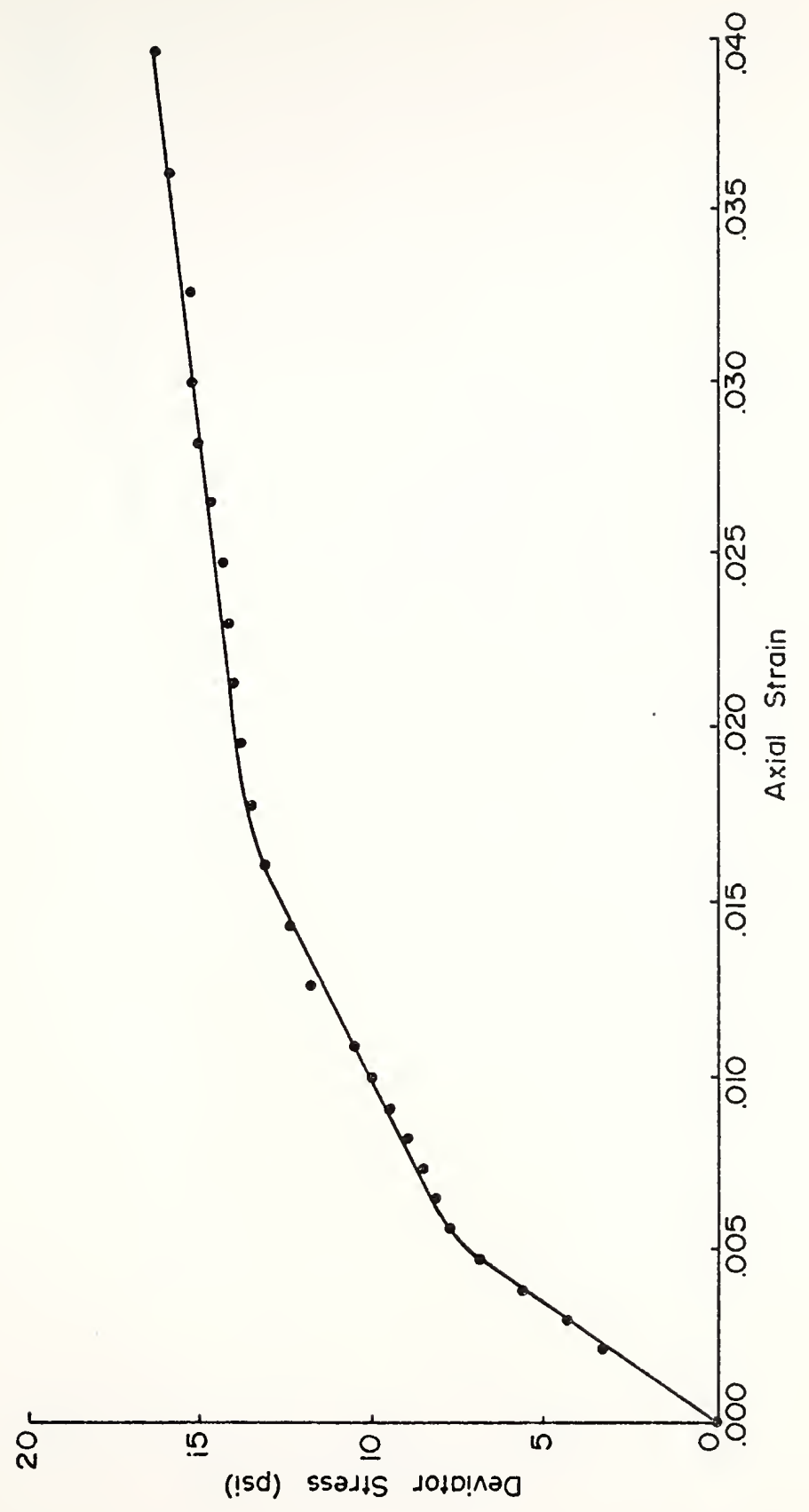

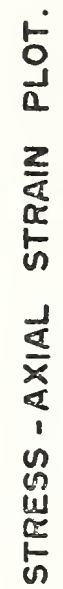

0
0
$\frac{1}{0}$
0
0

o)

$\frac{\pi}{\frac{\pi}{\infty}}$

ज

L

$\frac{0}{1}$

$\infty$

$\frac{w}{0}$ 

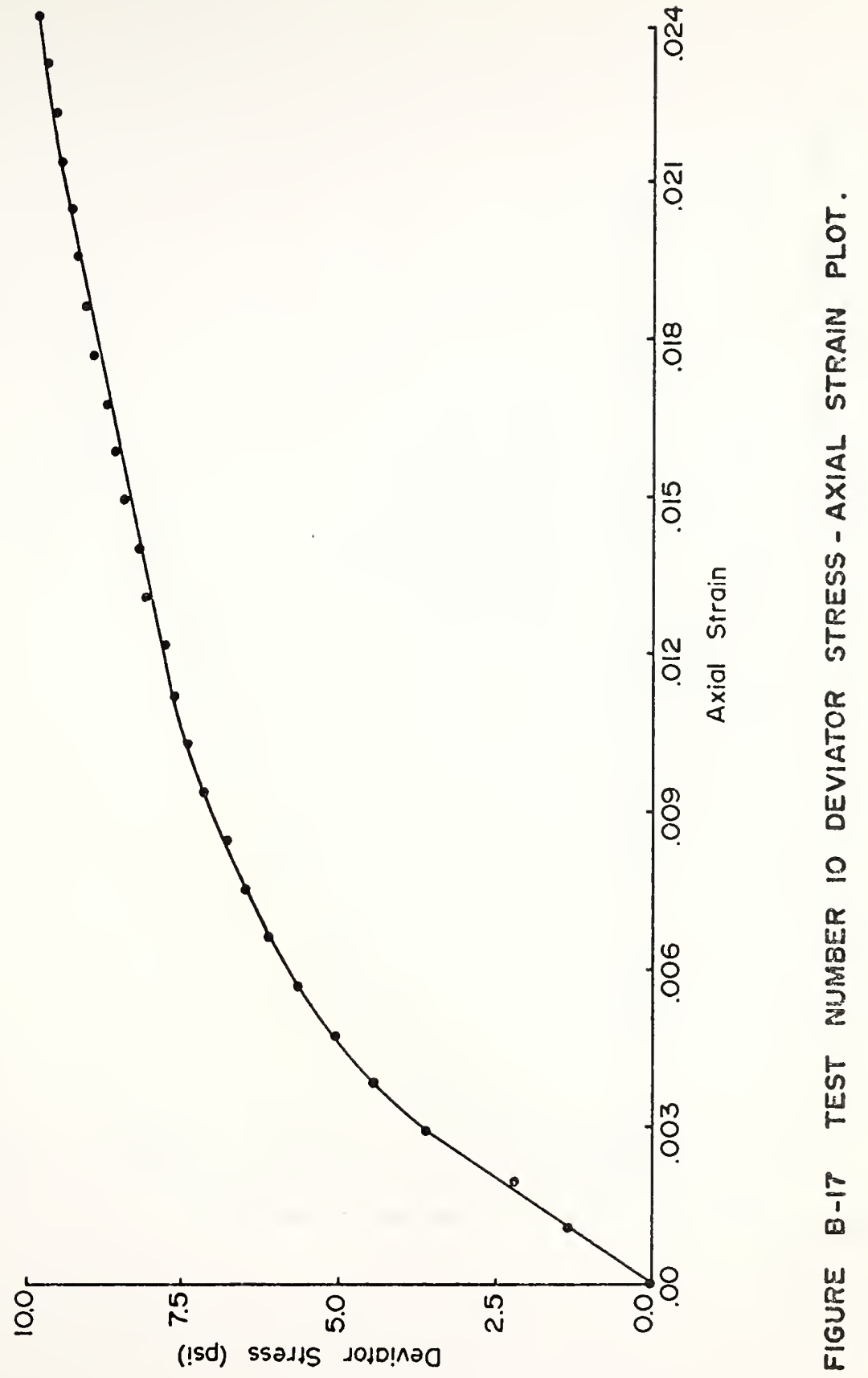


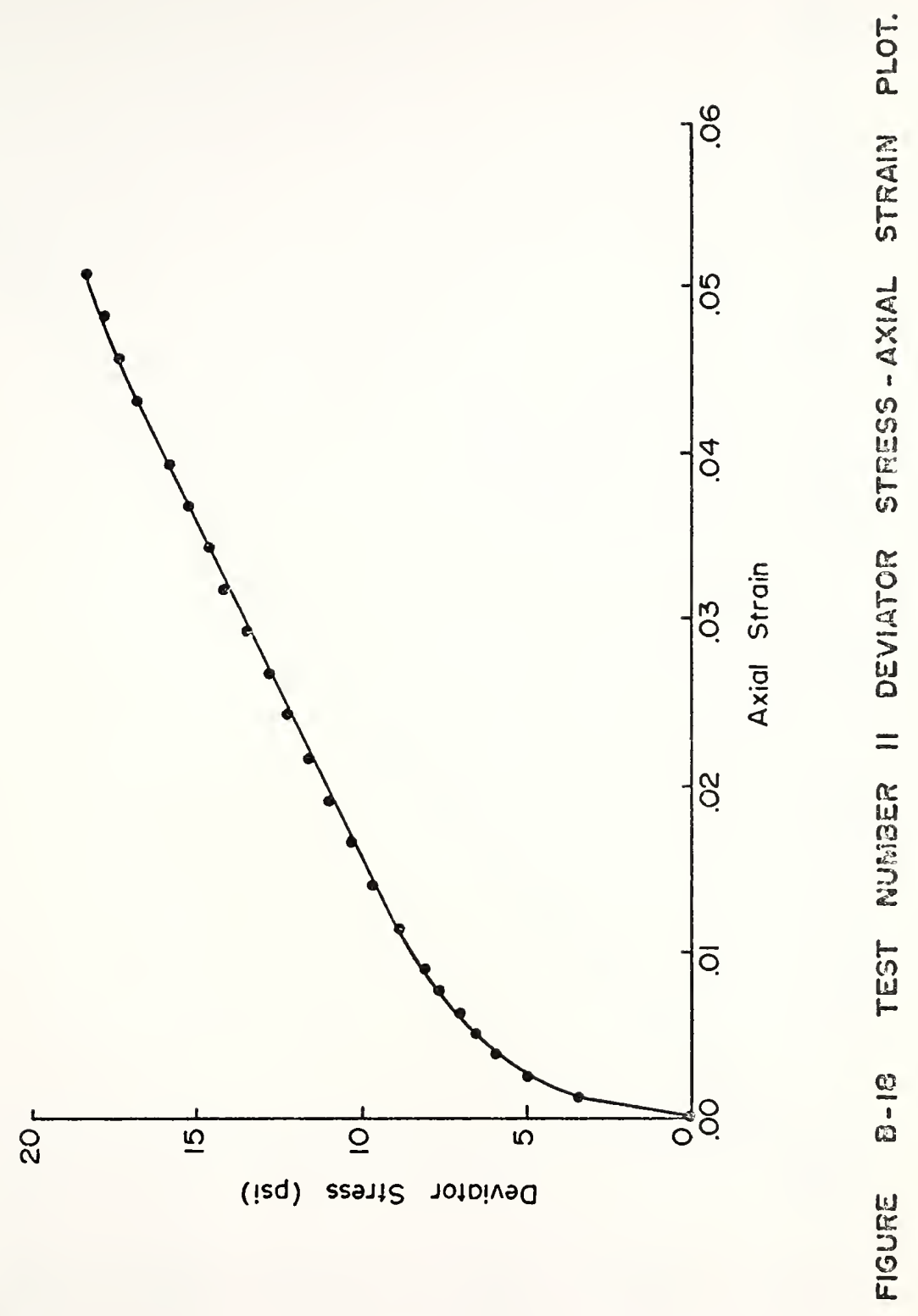




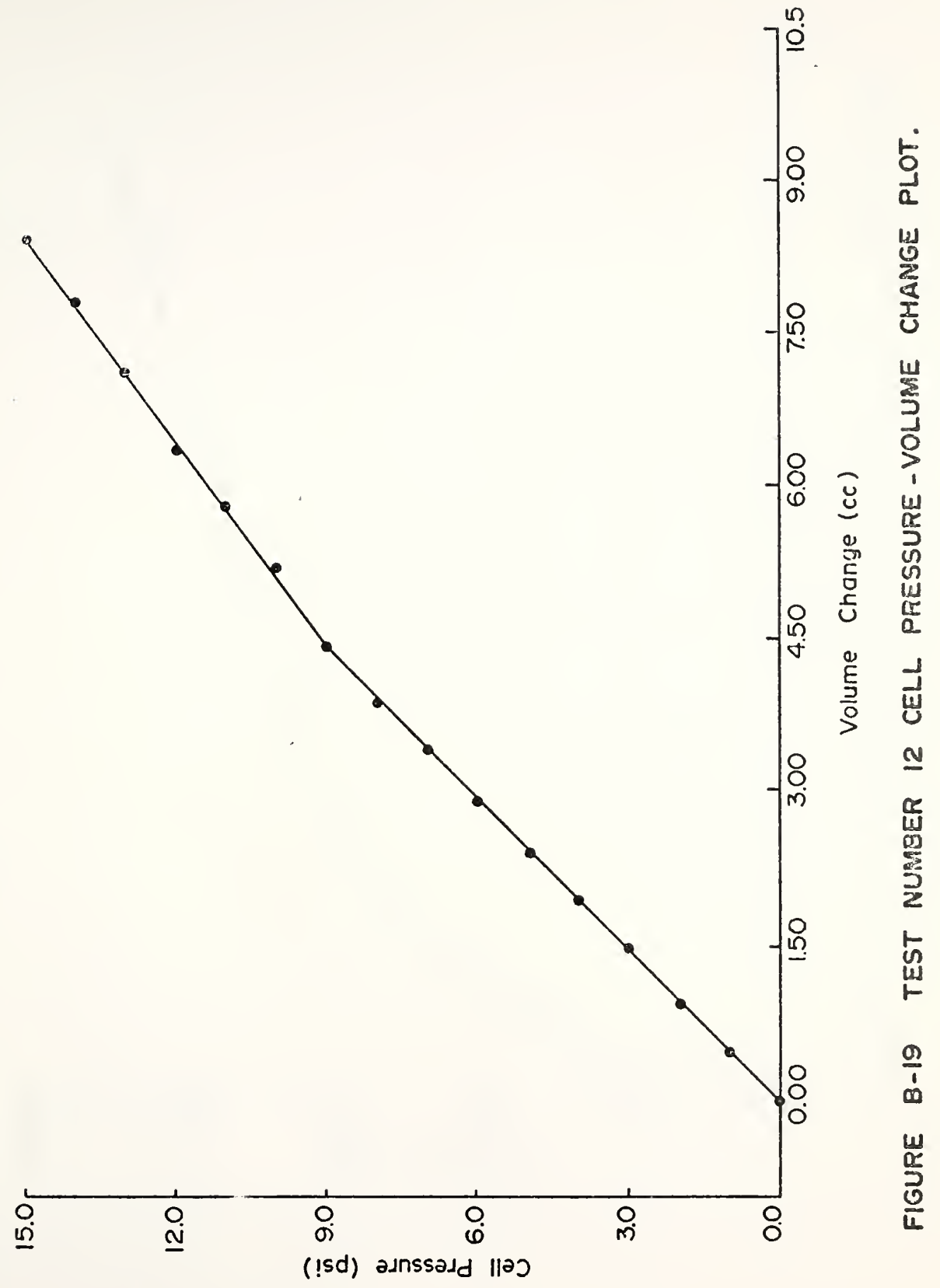




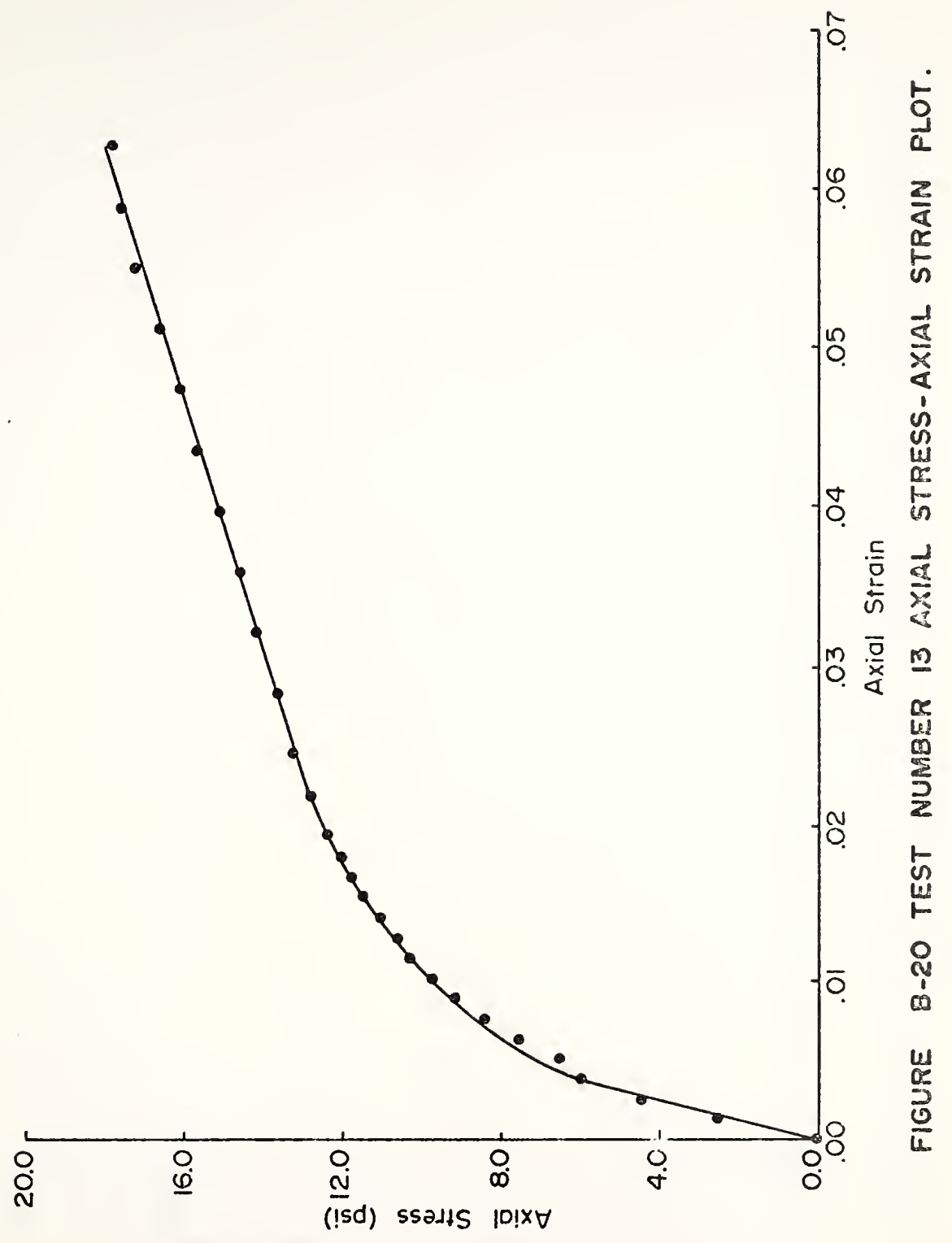




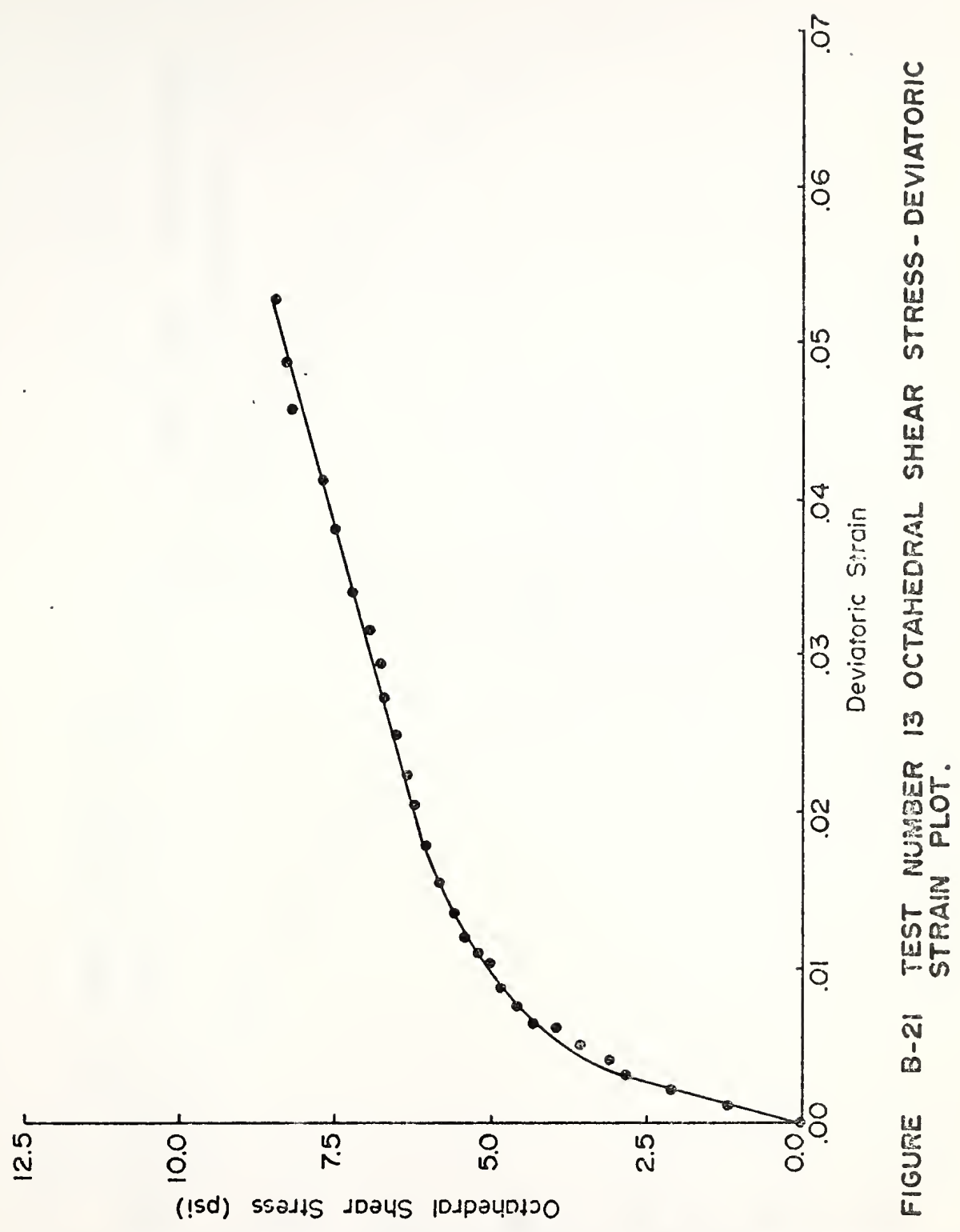




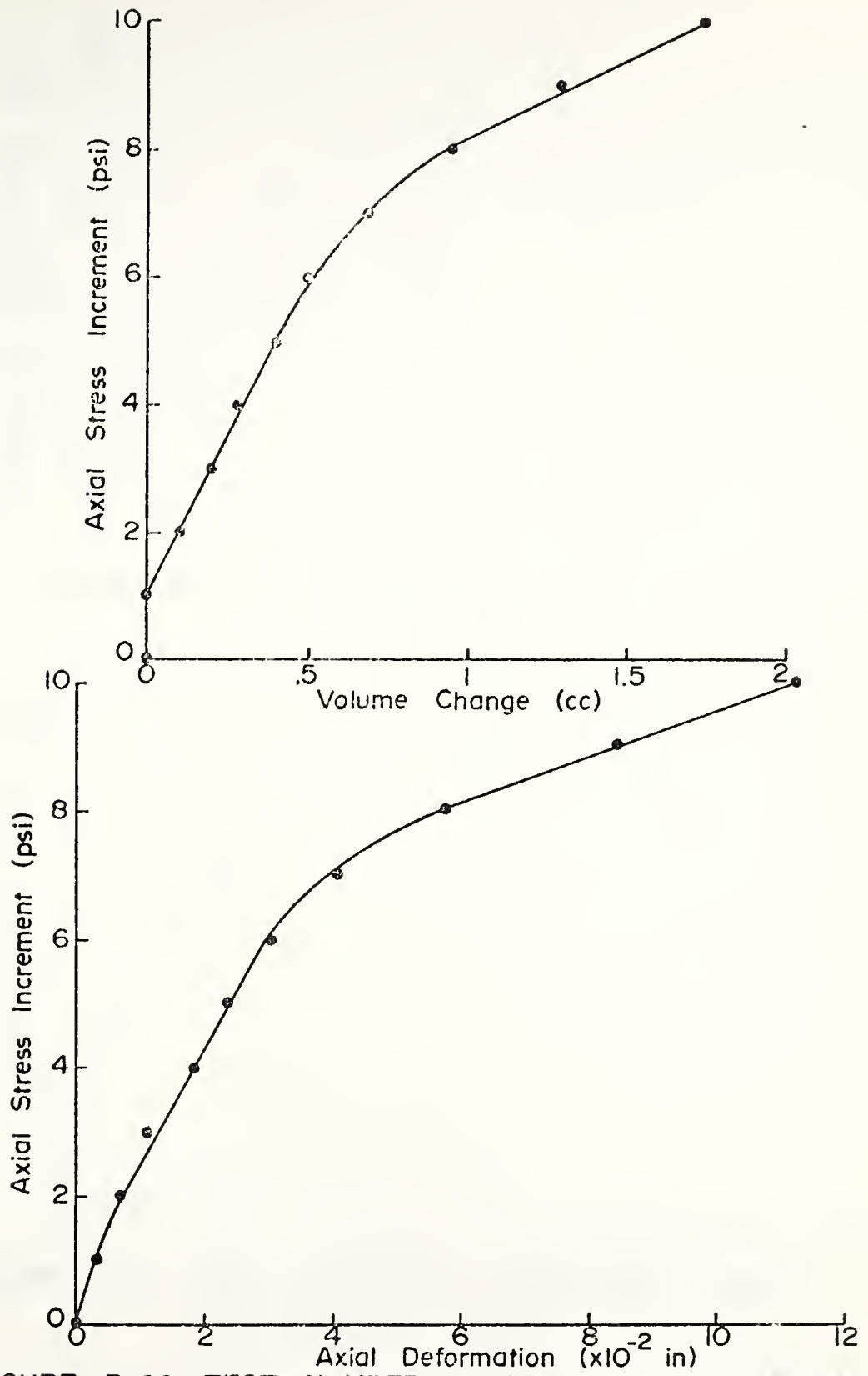

FIGURE B-22 TEST HUMBER 14 AXIAL STRESS INCREMENTVOLUINE CHAHGE AND AXIAL DEFORMATION. 

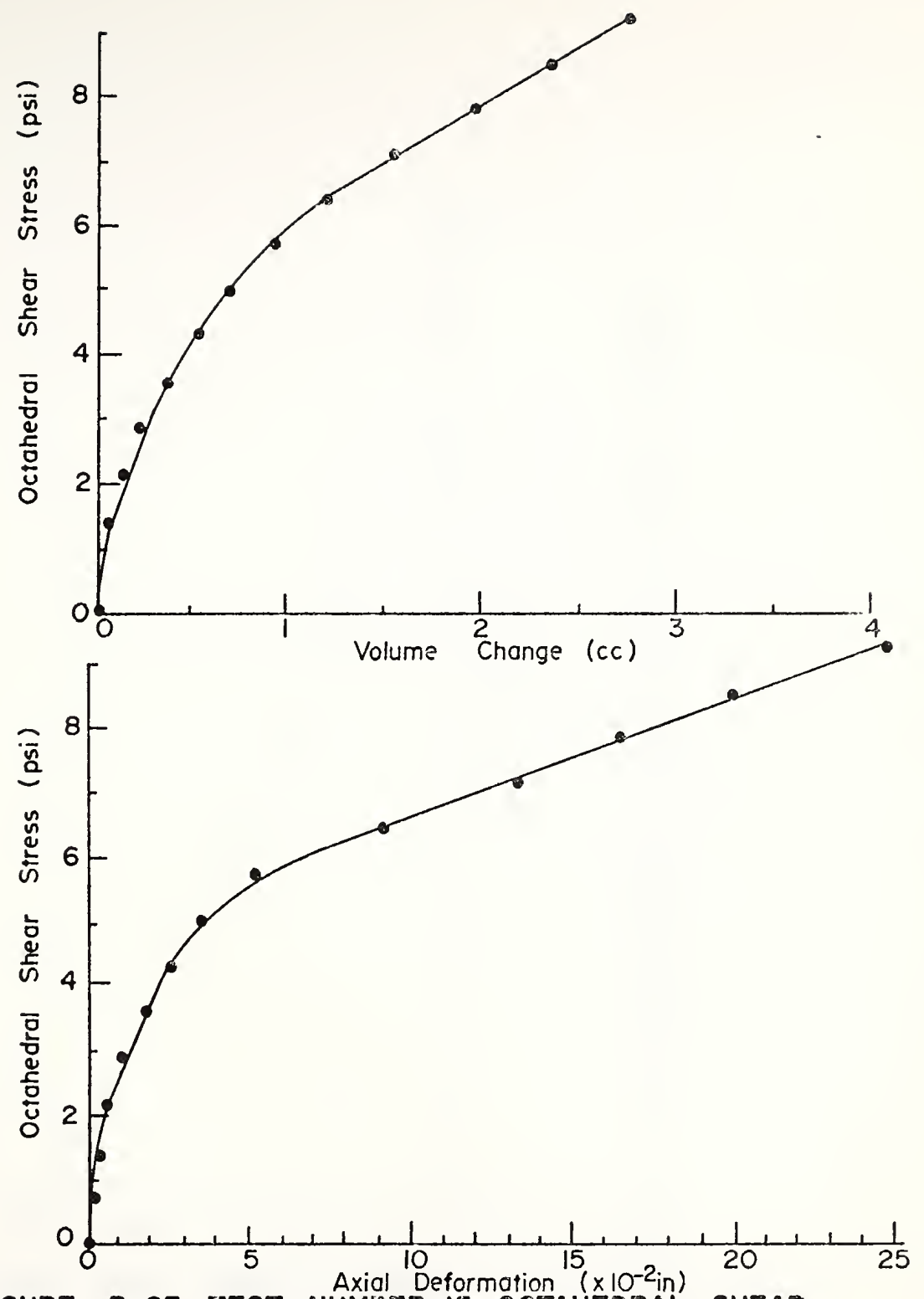

FIGURE B-23 TEST NUAAPSR I5 OCTAHEDRAL SHEAR STRESS - VOLUME CHANGE AND AXIAL DEFORMATIOISS PLOTS. 


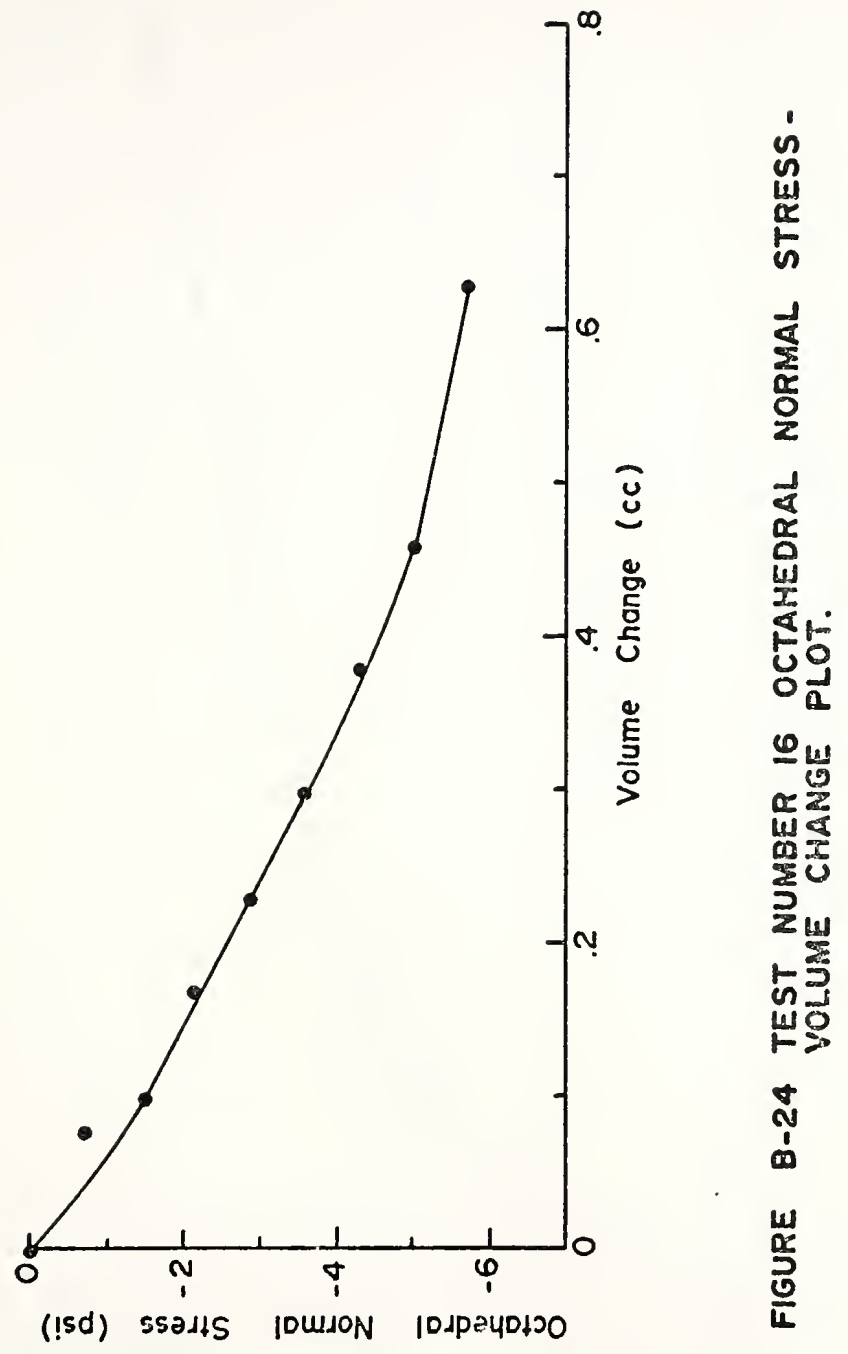




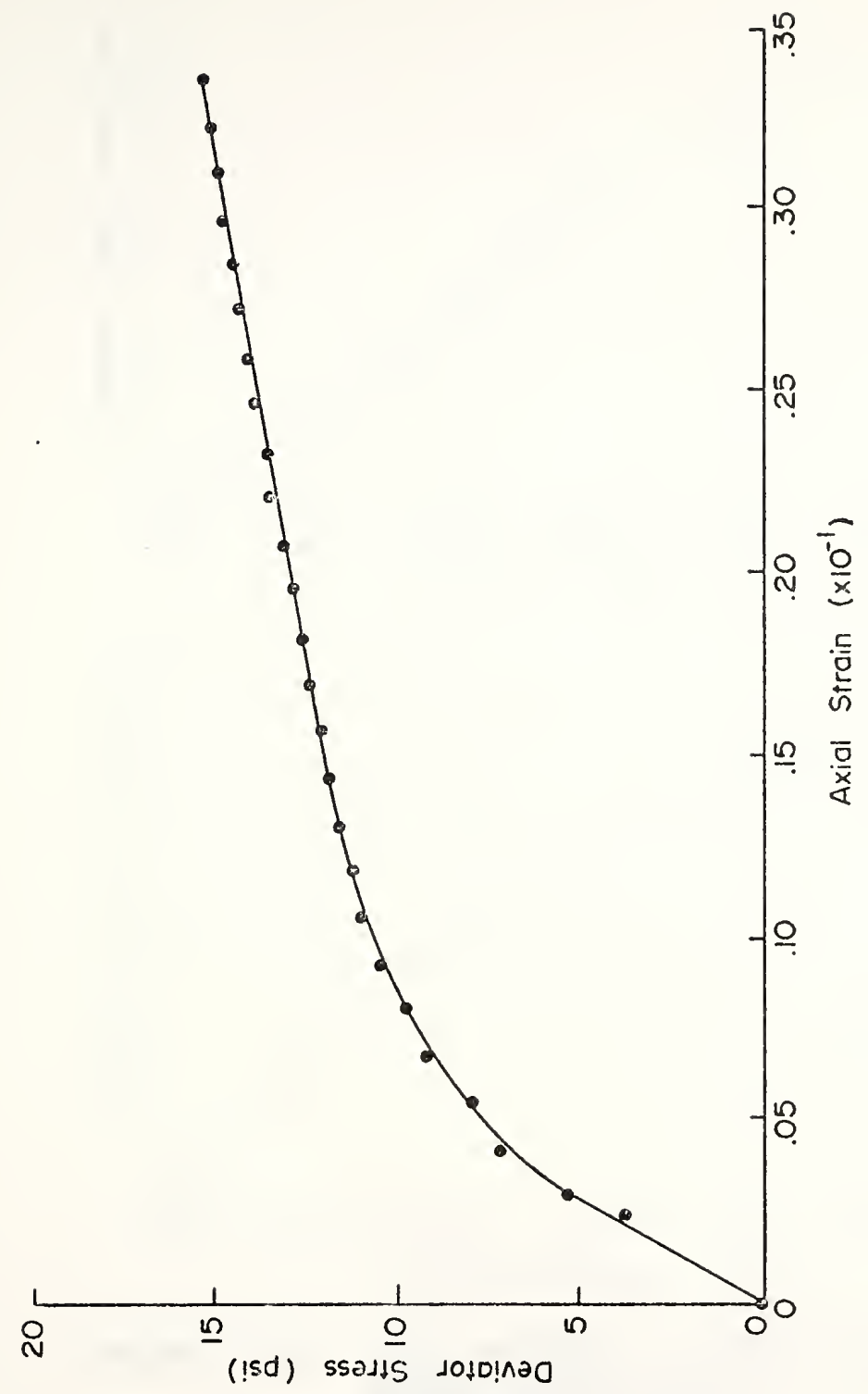

5
$\frac{5}{0}$
$\frac{2}{4}$
$\frac{2}{6}$

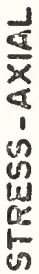

告

0

I

8

焉

点

N

m

$\frac{\omega}{0}$ 

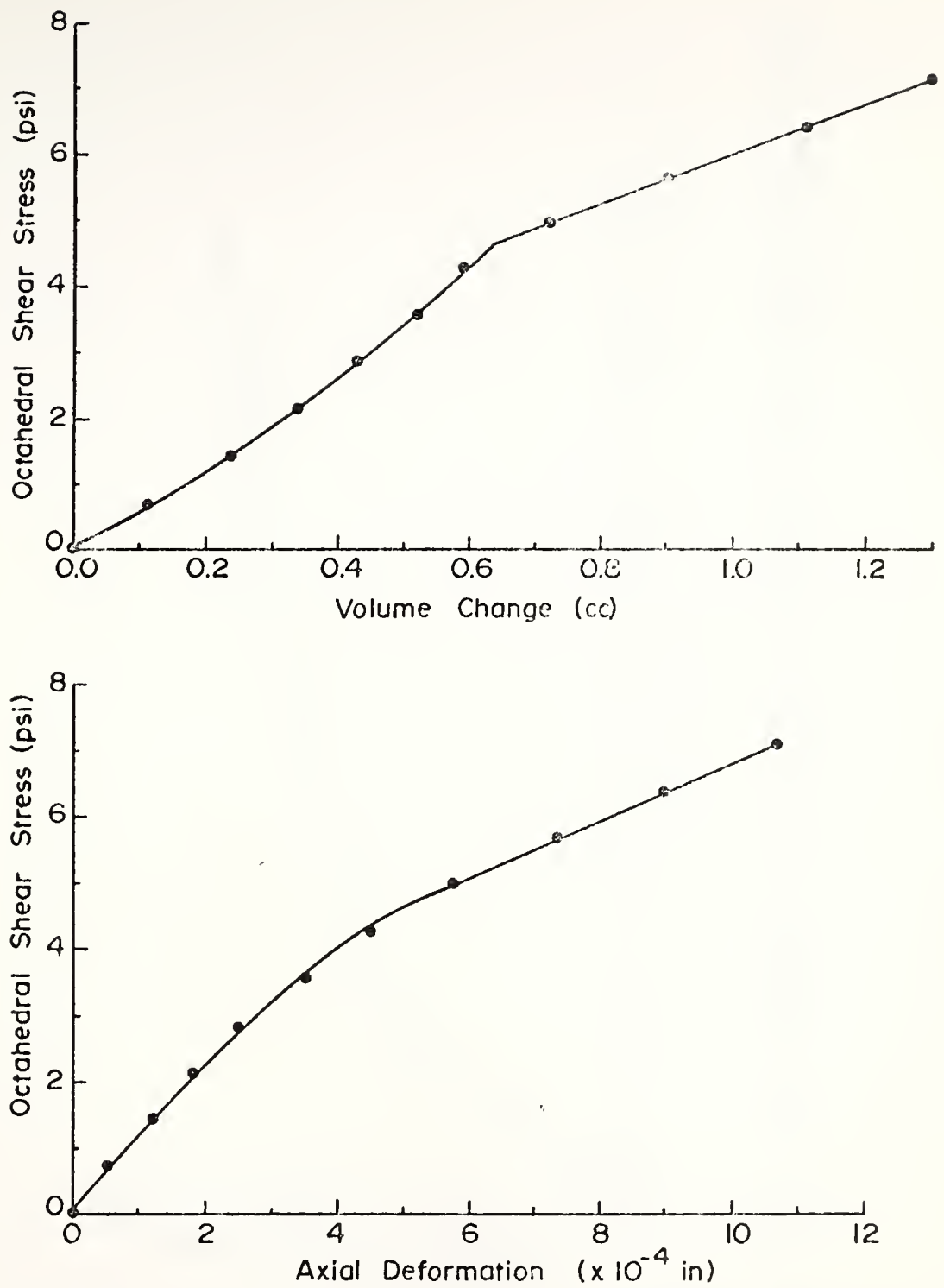

FIGURE B-26 TEST NURIBER 18 OCTAYEDRAL GHEAR STRESS-VOLURE CHAAVGE ARD AXIAL DEFORMATION PLOTS. 


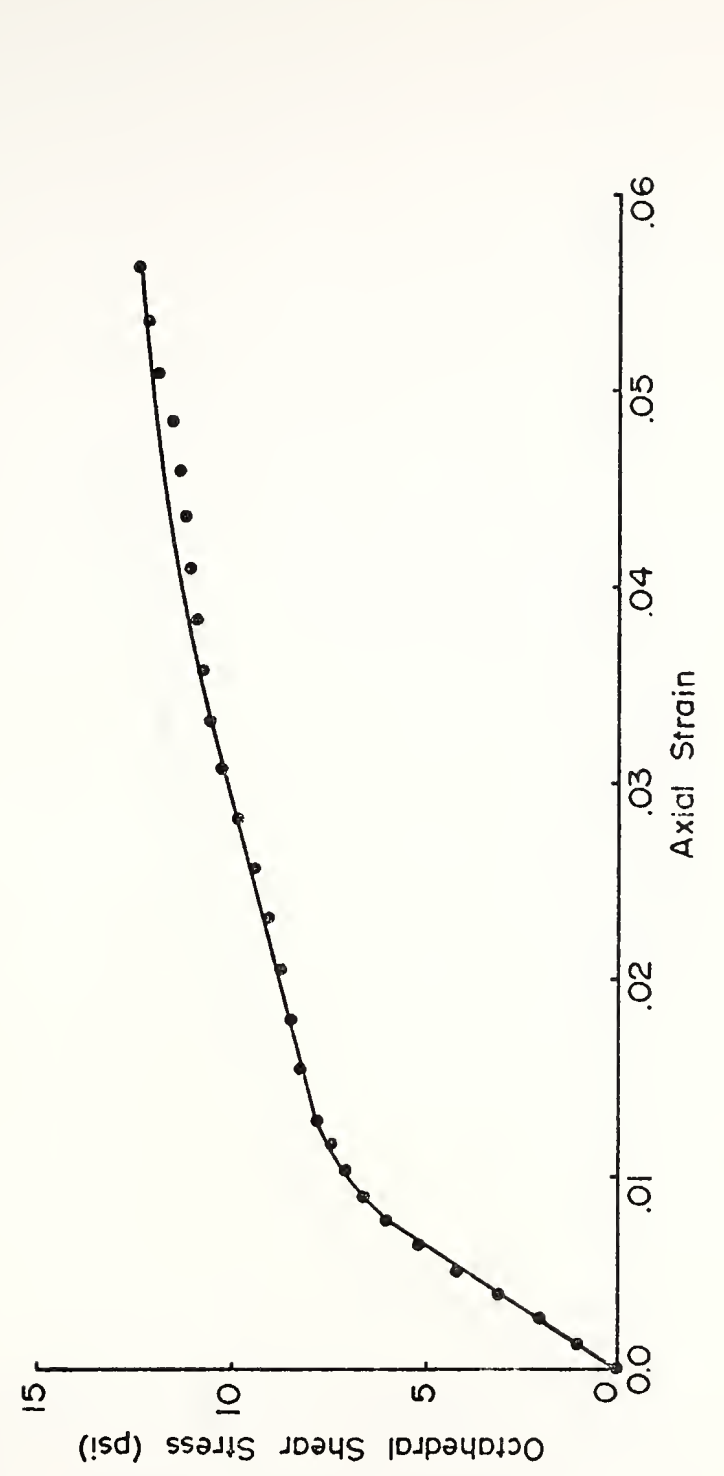

$\frac{5}{a}$

$\frac{a}{a}$

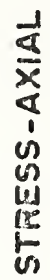

$n$

$<$

$\pi$

$\frac{1}{8}$

III

$\frac{x}{\alpha}$

$1-$

0

ㅇ

c

U.

$\infty$

$\frac{5}{2}$

as

N

$\infty$

$\frac{4}{\frac{1}{6}}$ 


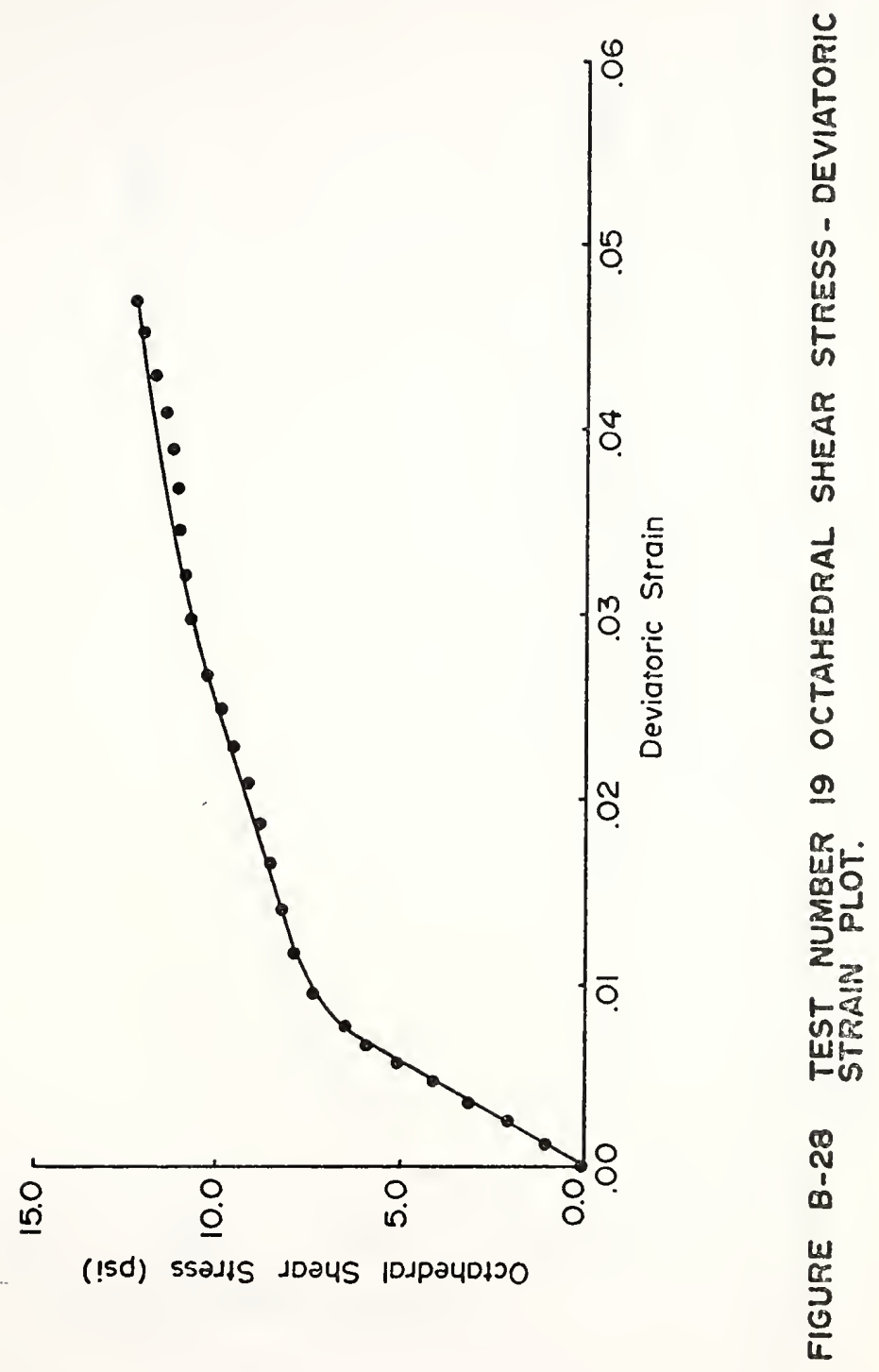




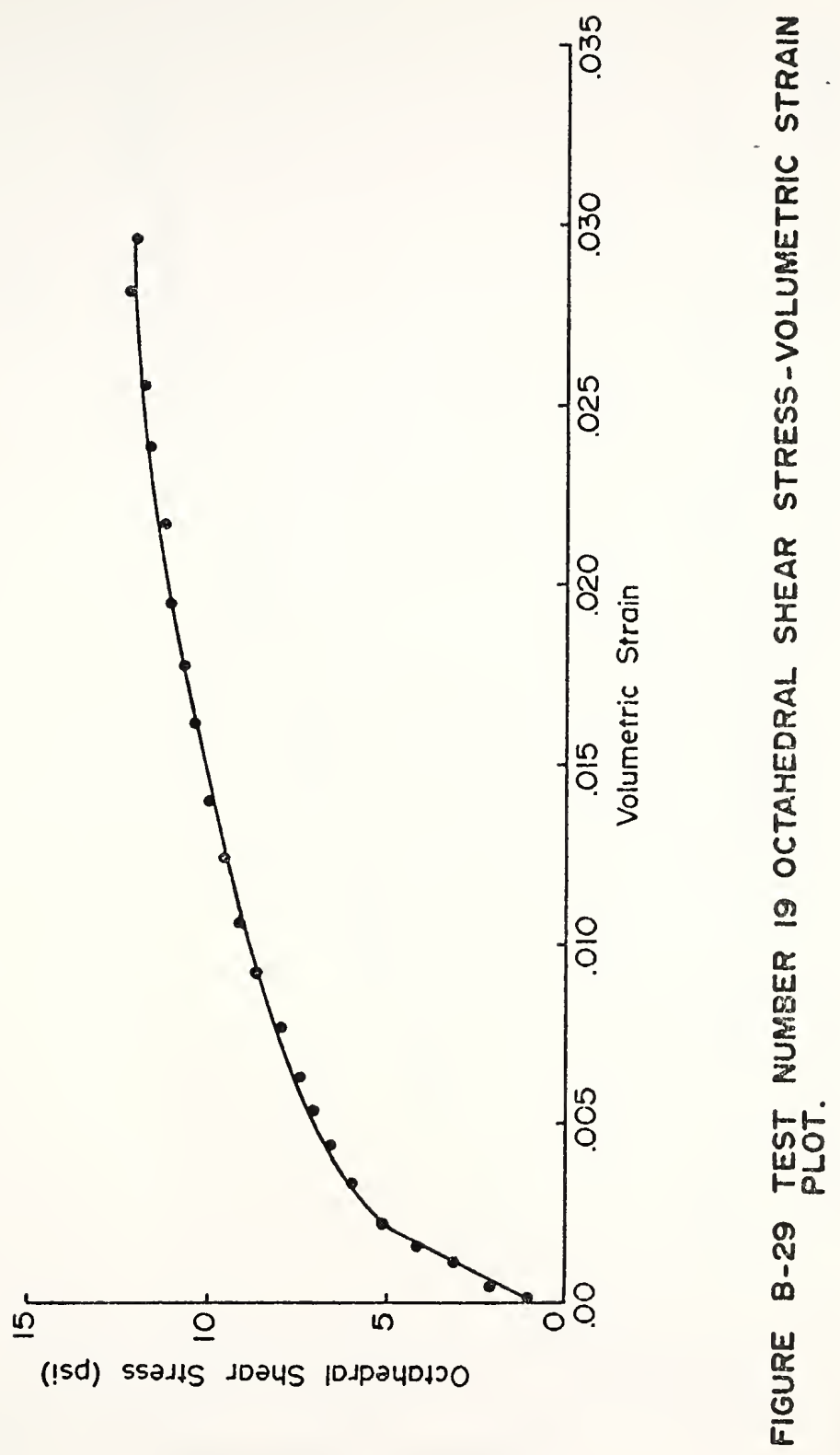




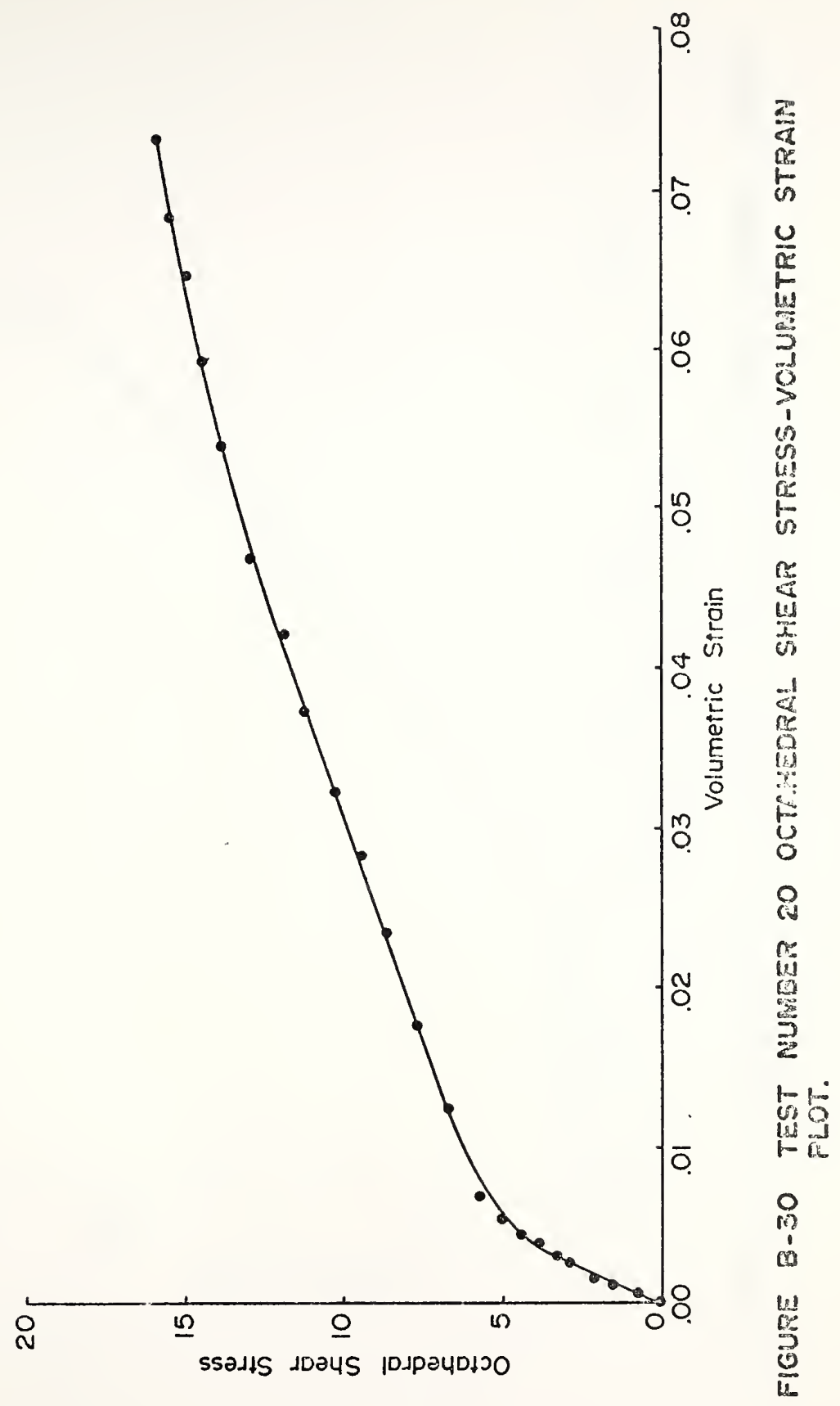




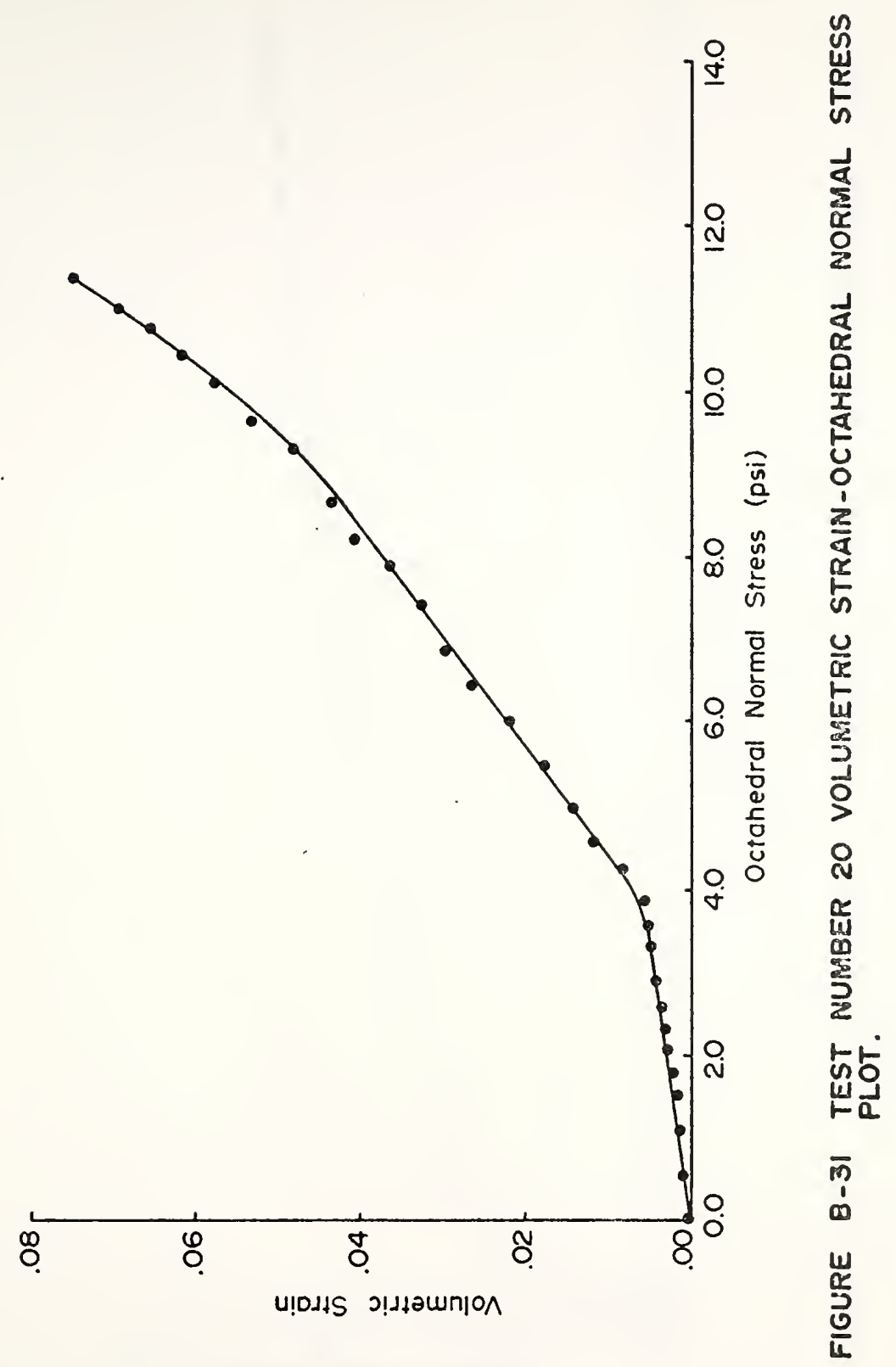



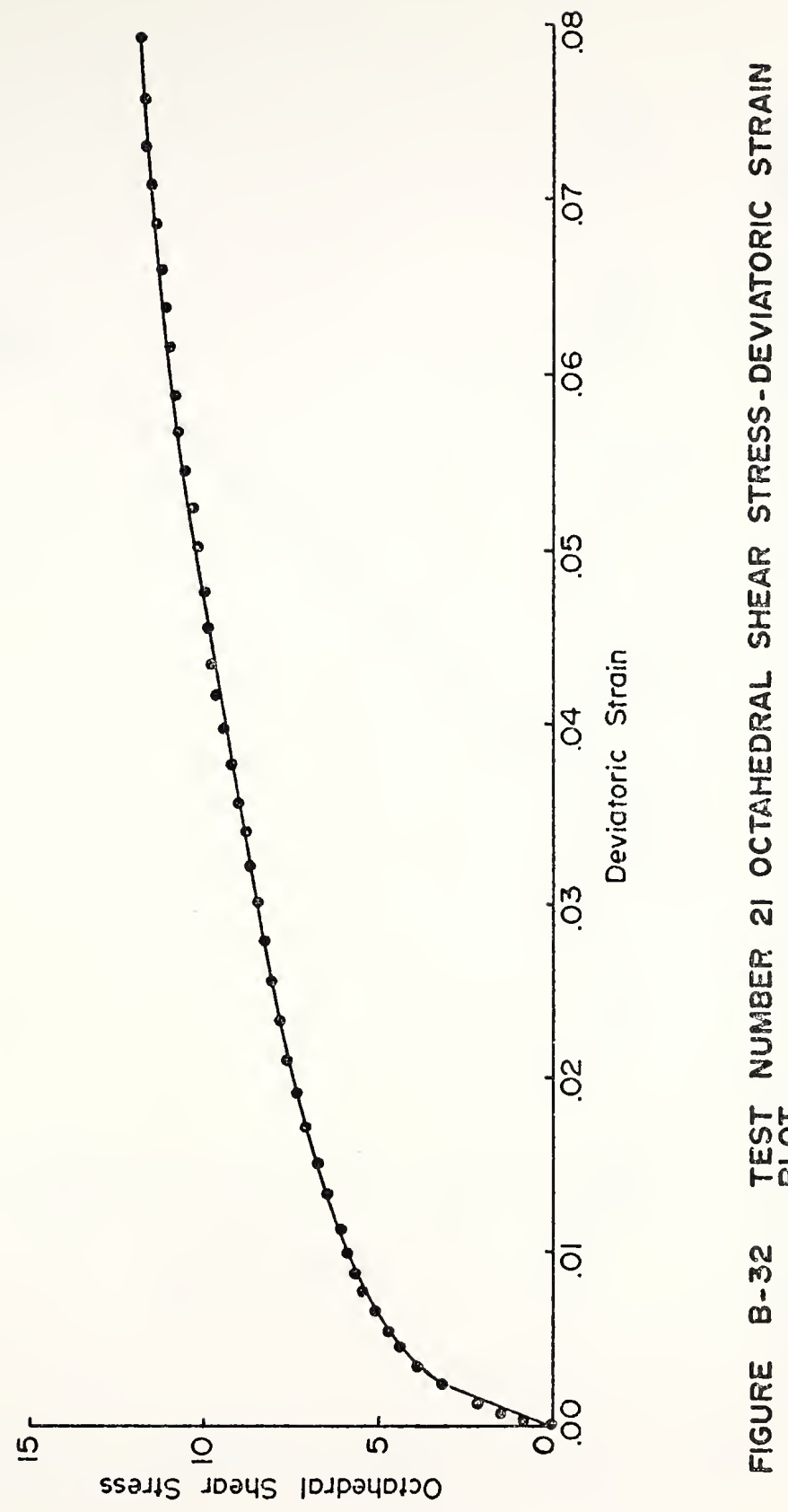

否

ल

竞

남

m

$\frac{w}{c_{0}^{2}}$ 


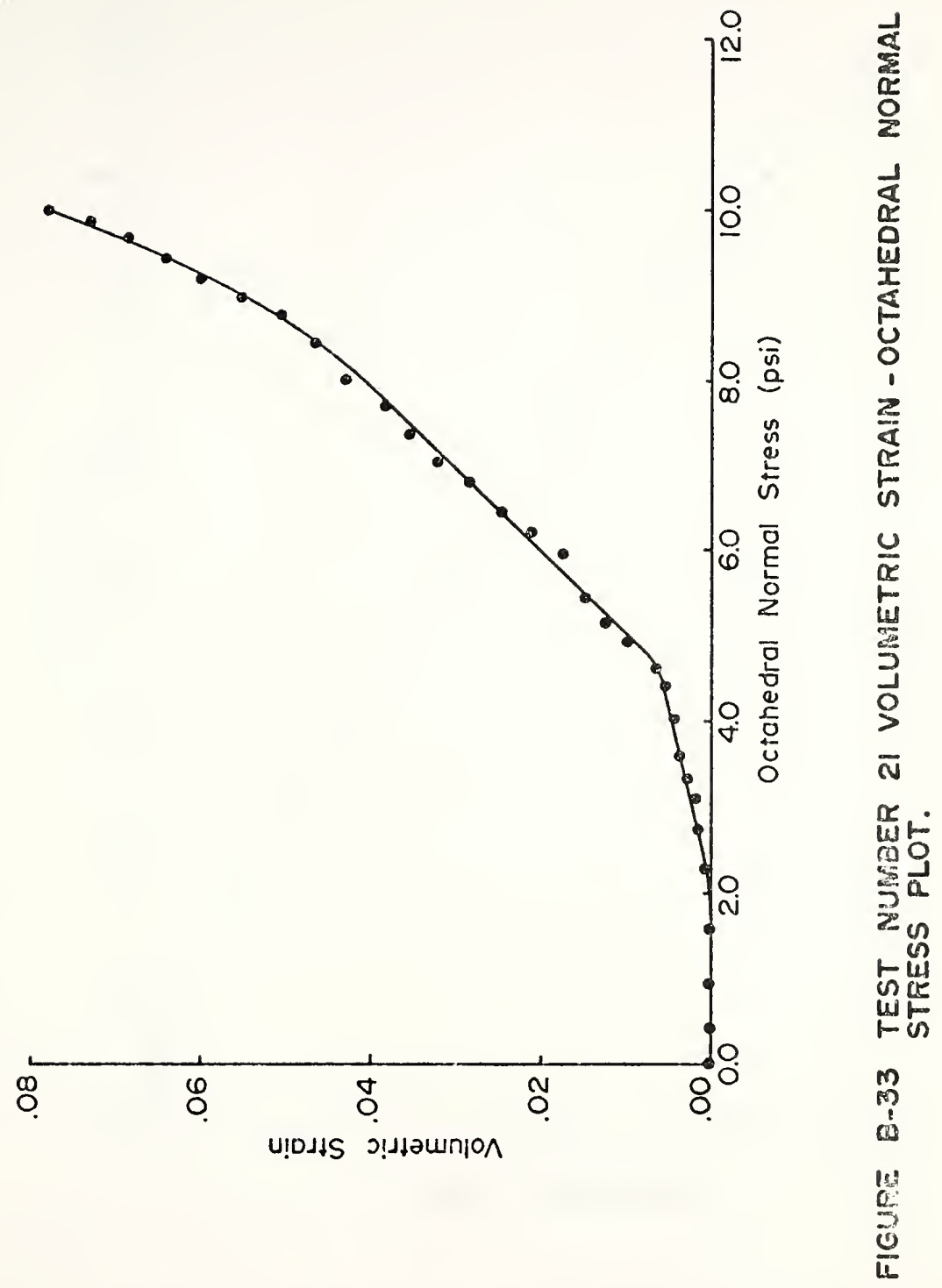




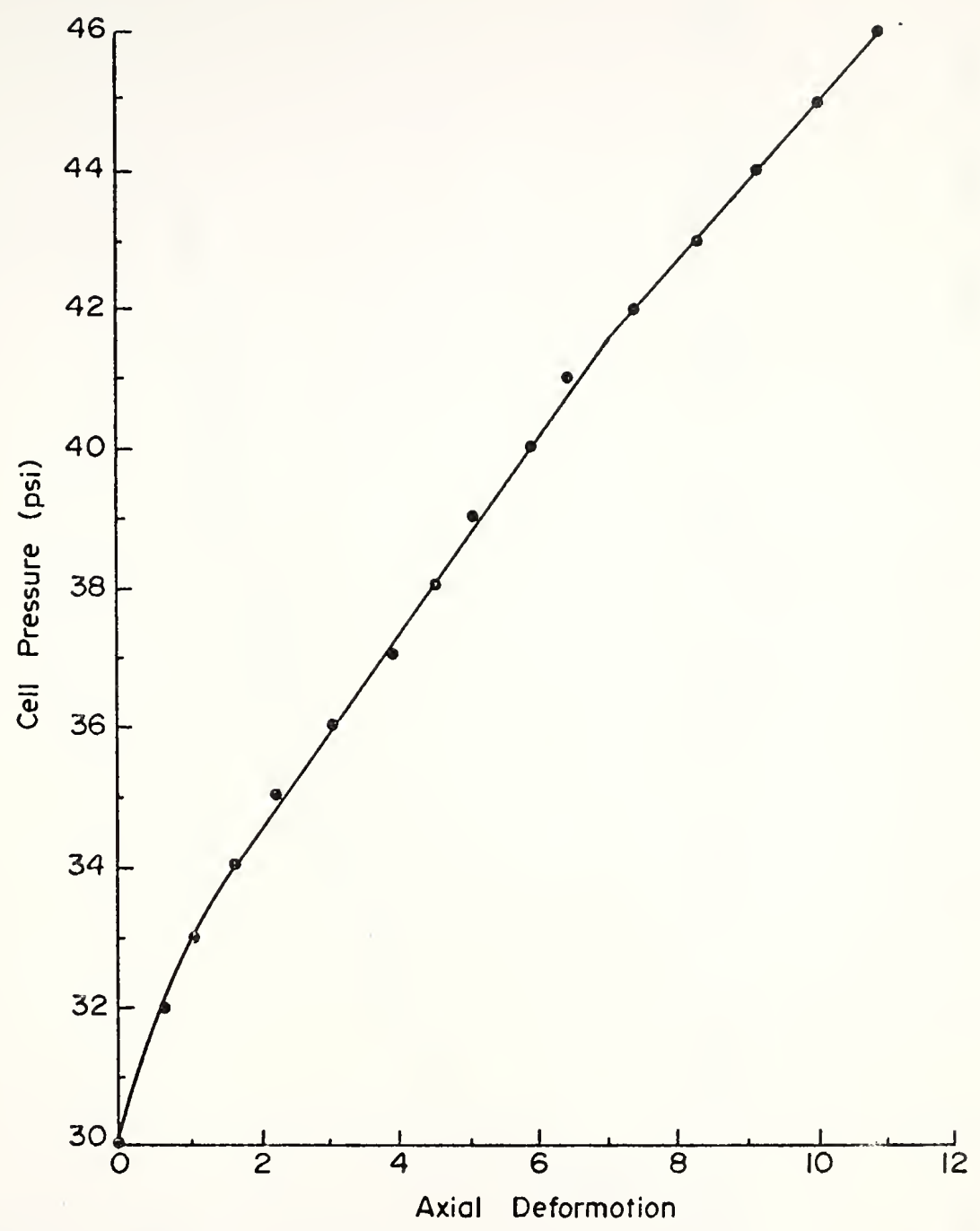

FIGURE 8-34 TEST NUPABER 22 CELL PRESSUREAXIAL DEFORMATION FLOT. 


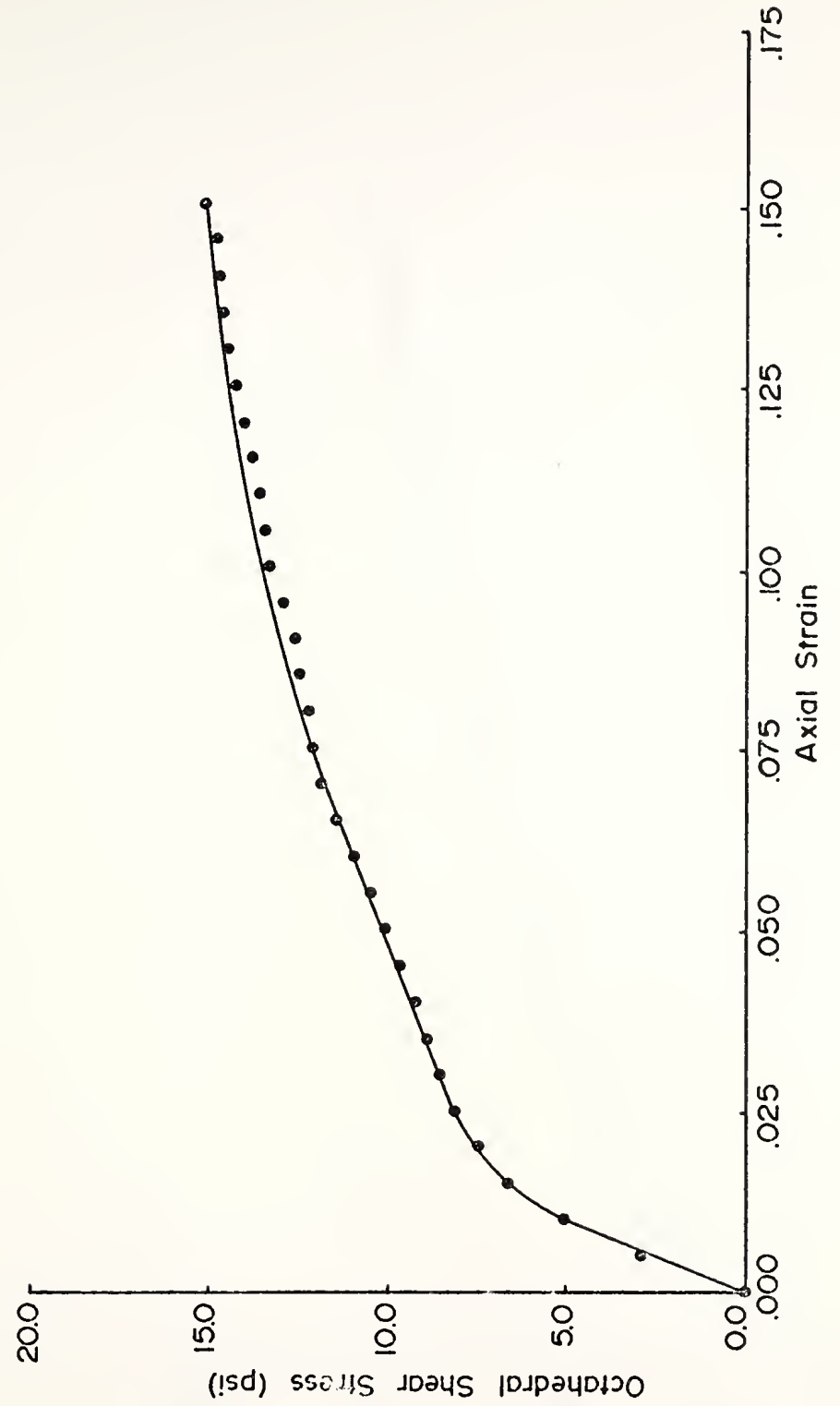

$\frac{1}{0}$

$\frac{z}{a}$

$\frac{1}{x}$

ज

w

$\frac{6}{6}$

$\frac{0}{x}$

告

m

N

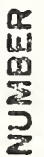

占

10

(6)

$\frac{w}{\frac{6}{5}}$ 


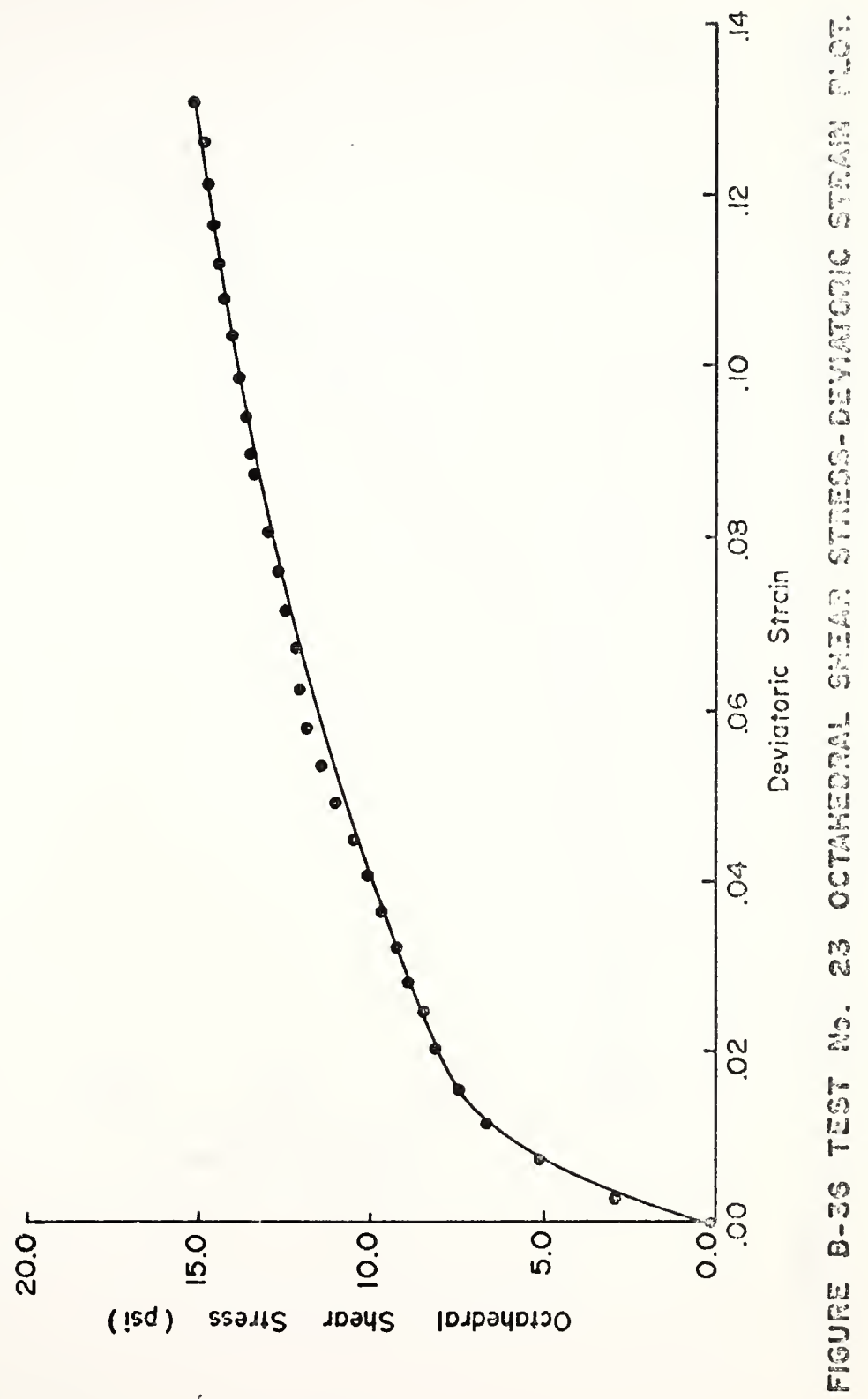




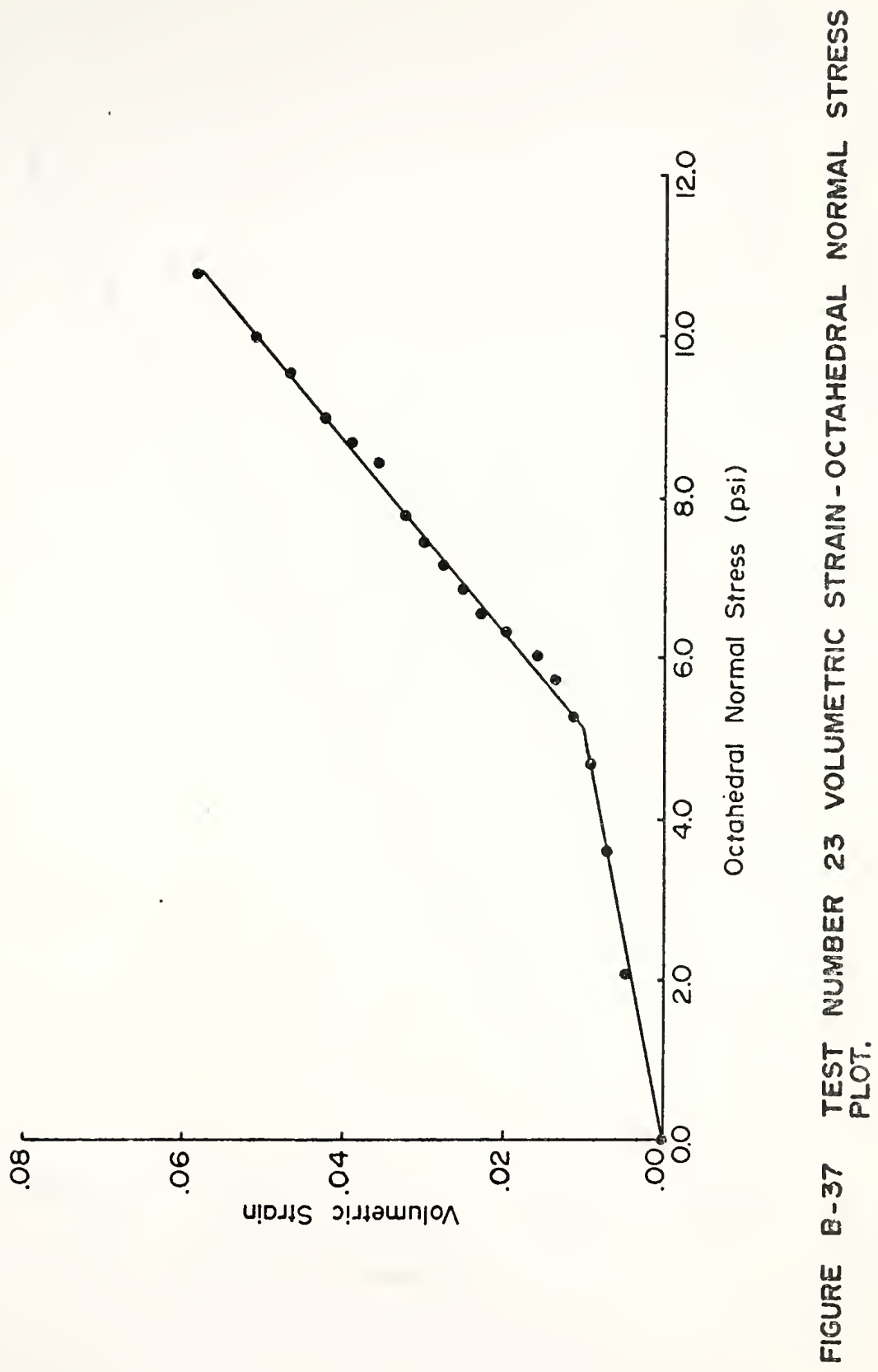




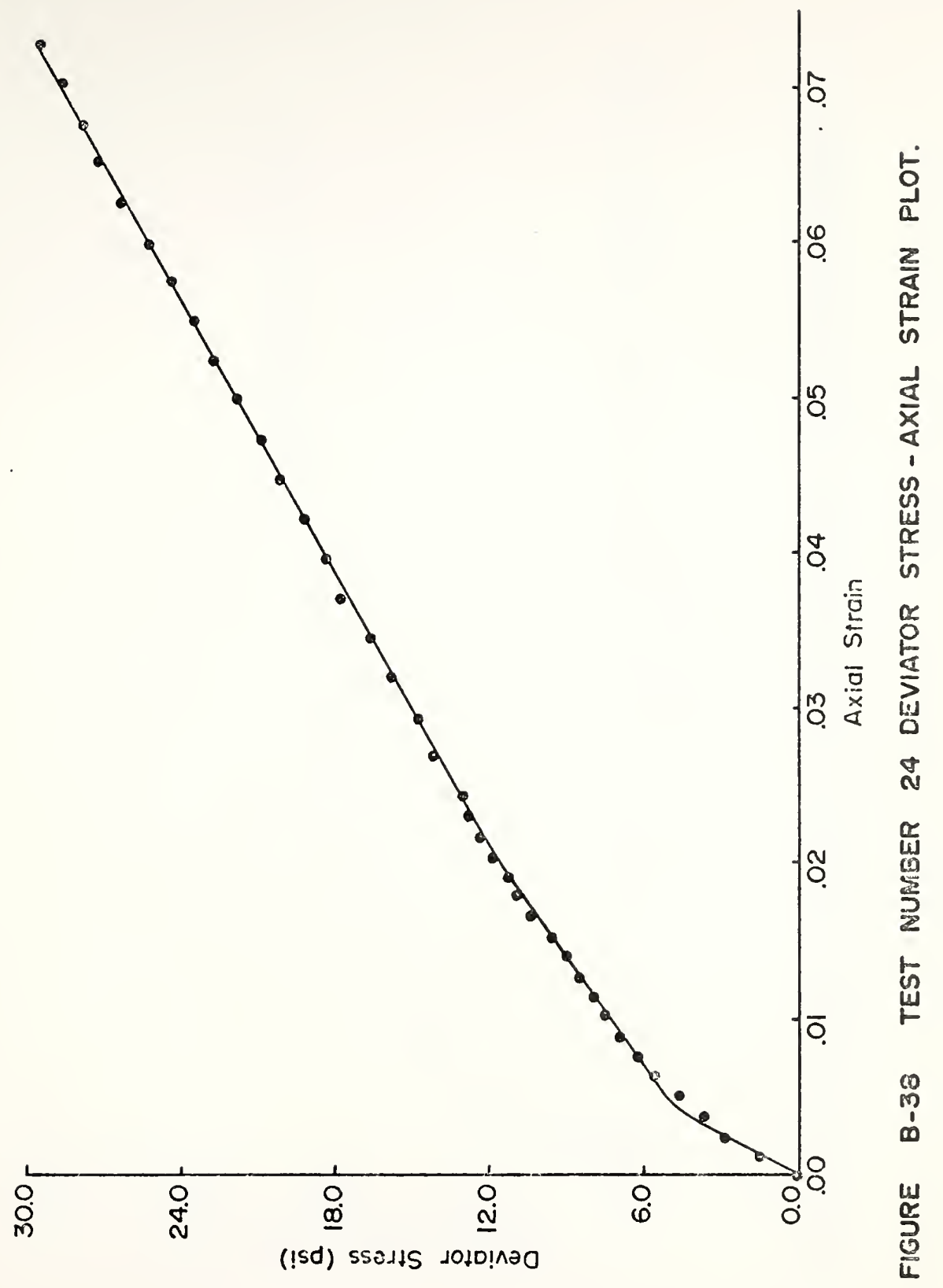




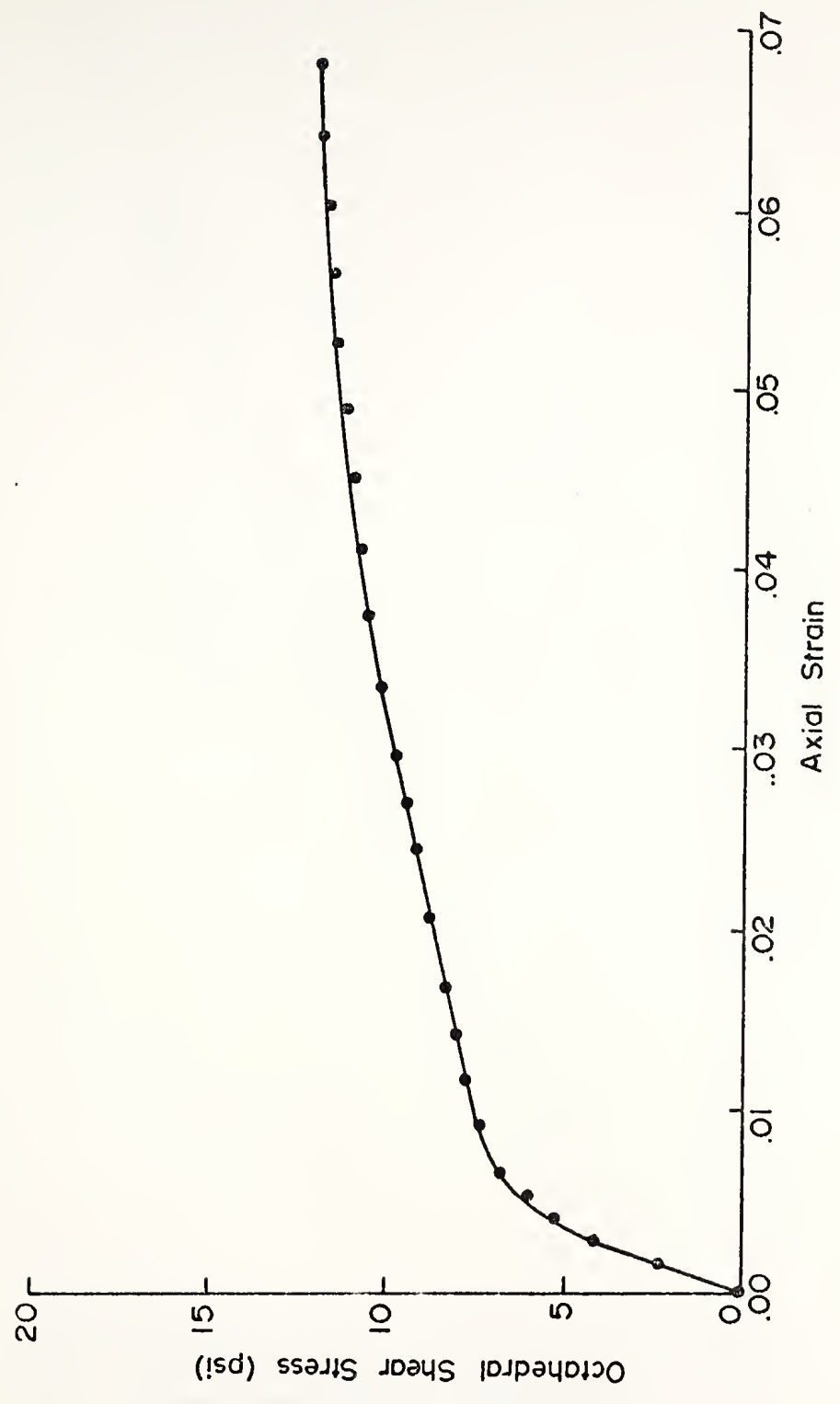

$\frac{2}{\frac{2}{a}}$

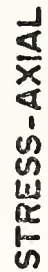

$\frac{c}{10}$

宸

th

N

点

50
wa
wa

m

$\omega$

$\frac{\pi}{\frac{5}{5}}$ 


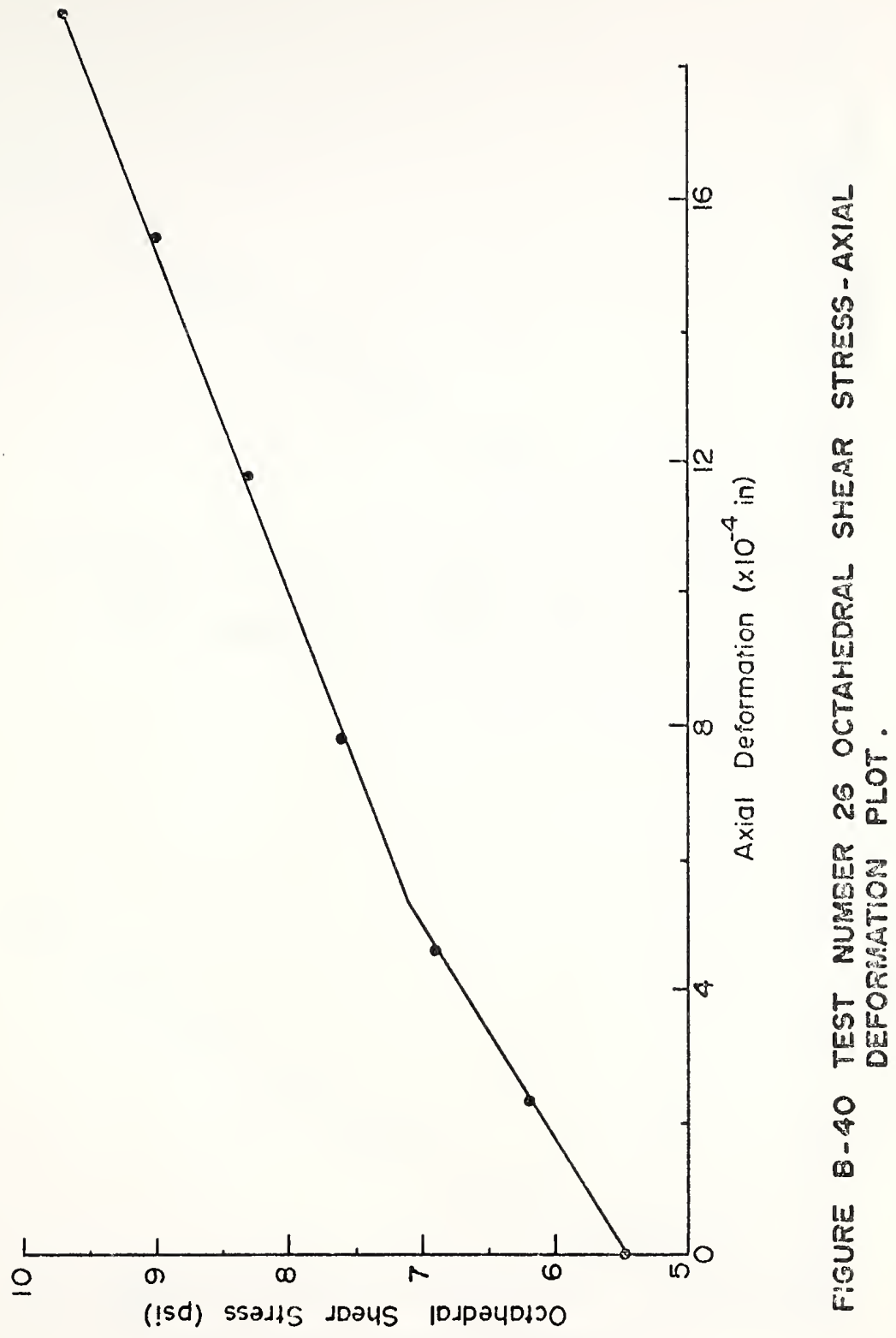




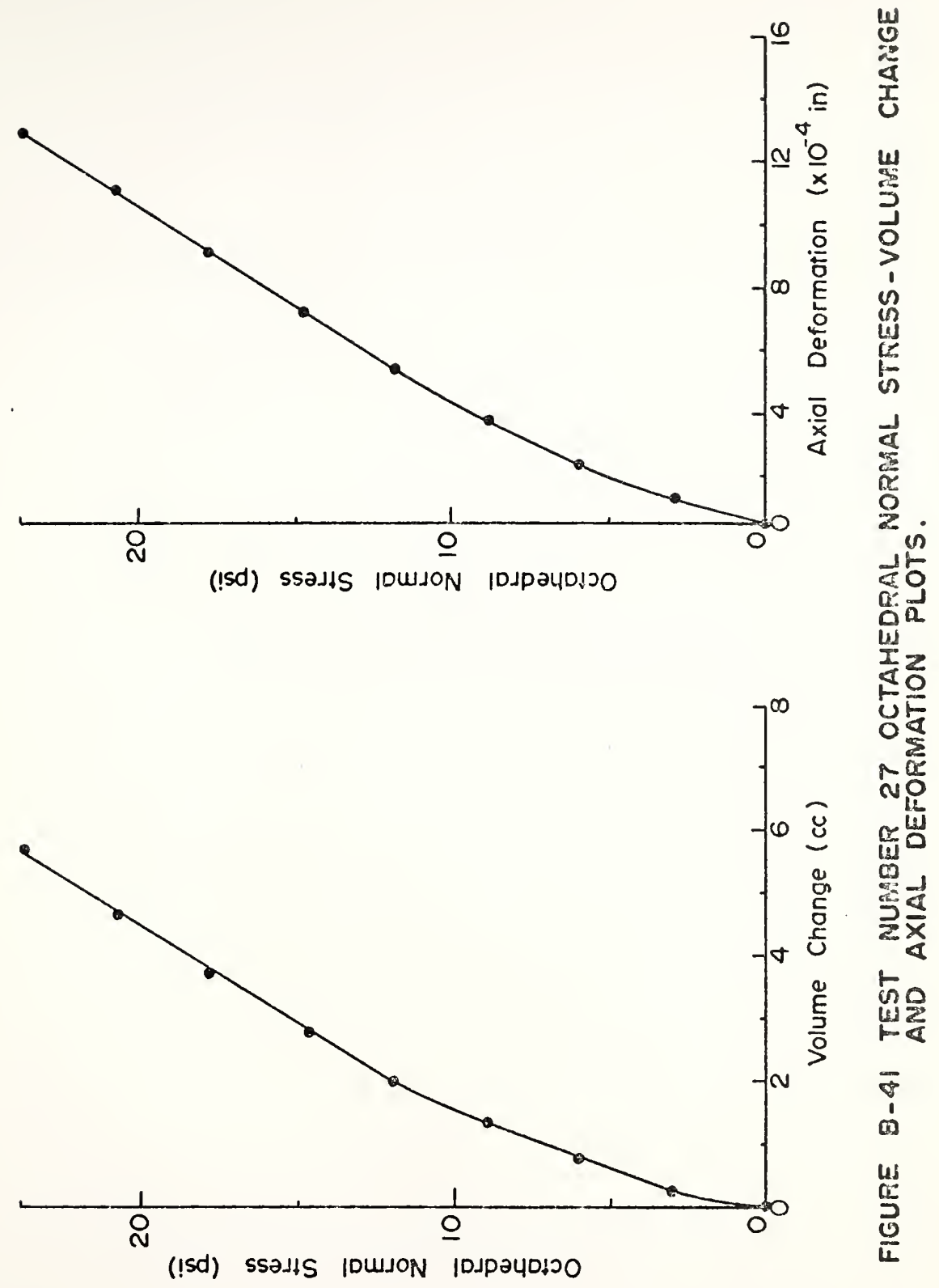


APPENDIX C

THE TRIAXIAL TEST REDUCTION PROGRAM 


\section{THE TRIAXIAL TEST REIJUCTION PROGRAM}

\section{C.1 Introduction}

Load cell and sample volume data from drained triaxial tests are recorded as continuous curves on a single roll of output paper by the Sandborn recorder. This computer program has been written to facilitate the meaningful interpretation of the output by calculating relevant stresses and strains and listing these in tabular form and if desired in CALCOMP plots.

A flow chart for the program is given in Figure C.1. Section C. 2 contains the program input format and computer word definitions. Section C. 3 shows a simple example consisting of only thirteen points. Input, output and plots are shown. A listing of the program is given in section C.4. Comment cards have been used to explain the step by step manipulations. 


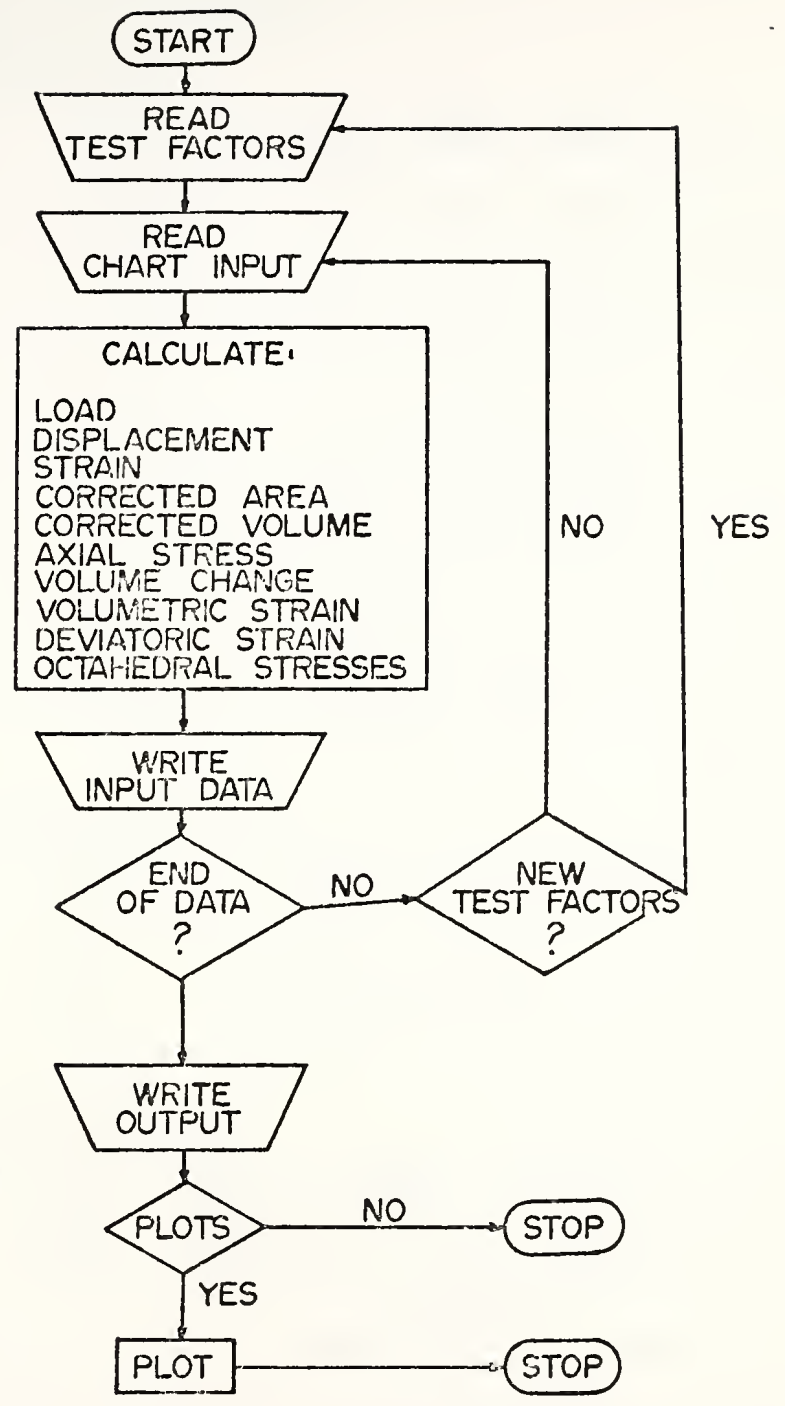

FIGURE C-I FLON CHART FOR TRIAXIAL TEST REUUCTION PROGRAAH. 


\section{C.2 Jnput Format for Triaxial Program}

i. IDENTIFICATION CARD (3A10)

Columns 1-30 TITLE (3)

ii. PLOT CARD (I8)
Column 1 IPLOT $=0$ if no plot required
$=1$ Oct. Shear Stress - Oct. Nornal
Column 2 IPLOT $=0$ if no plot required
$=2$ Oct. Shear Stress - Deviatoric
Column 3 IPLOT $=0$ if no plot required
$=3$ Oct. Shear Stress - Volumetric
Strain
Column 4 IPLOT $=0$ if no plot required
Oct. Shear Stress - Axial. Strain
Column 5 IPLOT $=0$ if no plot required
$=5$ Oct. Normal Stress - Axial strain
Column 6 IPLOT $=0$ if no plot required
$=6$ Volumetric Strain - Oct. Norlial
Stress
Column 7 IPLOT $=0$ if no plot required
$=7$ Deviator Stress - Axial Strain
Column 8 IPLOT $=0$ if no plot required
$=8$ Volumetric Strain - Deviatoric
Strain

iii. TEST IACTORS $(4 F 10.0)$
Columns $\begin{array}{r}1-10 \\ 11-20\end{array}$
$\mathrm{FC}-$
Sandborn chart speed
divs/minute
$21-30 \quad$ FT $=$ Triaxial machine loading rate
31-40 FB - Burette calibration
factor
lbs/divisjon
ins/minute
ccs/division

iv. CHART INPUT ( $3 F 10)$
Columns $1-10$
$11-20$
DIVST
- Number of divisions along chart
$21-30$
DIVLD - Number of load-cel1 divisions
$31-40$
DIVBU - Number of burette divisions
$I C O D E=0$ test factors do not change
$=1$ after this point new test factors
$=999$ last data point

There will be a type iv. card for each data point. If $1 \mathrm{CODE}=1$ the next data must be type iii, the new test factors. 


\section{C.3 lixample Problem for Iriaxial Test program}

$\Lambda$ Cictitious triaxial test, Number 99 , has been run and Iable C.1 Jists the output obtained from the Sandborn Recorder.

The test parameters were

Triaxial machine loading rate $4.0 \times 10^{-5} \mathrm{ins} / \mathrm{min}$. Sandborn chart speed $\quad 6.9 \times 10^{-3} \mathrm{divs} / \mathrm{min}$. Load-crl] calibration $\quad 0.8$ and 2.0 1bs/div. Burette calibration $0.1 \quad$ ccs/div and it was desired to have results printed out in both tabular form and on all eight possible plots. Table C.2 gives a listing of the sixteen data input cards. Note that auring the test it was necessary to alter the load output scale by switching the aitenuator to a higher value. It was therefore nocessary to input a new test parameter card, the ninth card in the listing. The resulting stresses and strains are listeci in Table C.3 in tabular form while ligures C.2 and C. 3 show the CALCOMP plots for this test. 
TABLE C.I

Sandborn Data for Example Triaxial Test Reduction Program

$\begin{array}{ccc}\begin{array}{c}\text { Number of divisions } \\ \text { along chart }\end{array} & \begin{array}{l}\text { Number of load- } \\ \text { celi divisions }\end{array} & \begin{array}{l}\text { Number of volume } \\ \text { burette divisions }\end{array} \\ 10 & 0.0 & 0 \\ 20 & 19.6 & 6 \\ 30 & 30.1 & 10 \\ 40 & 36.8 & 14 \\ 50 & 41.8 & 17.5 \\ 60 & 46.0 & 20.5 \\ 70 & 19.9 & 23 \\ 80 & 21.3 & 25 \\ 90 & 22.2 & 27 \\ 100 & 23.2 & 28 \\ 110 & 24.3 & 29 \\ 120 & 25.4 & 29.6\end{array}$


TABLE C. 2

Input llata Cards for Example Triaxial Test Reduction Program

Card No.

Card Columns

1234567890123456789012345678901234567890

1

2

3

4

5

6

7

8

9

10

11

12

13

14

15

16
TRIAXIAL TEST NUMBER 99

12345678

0.0069

0.8

0.00004

0.1

10.0

19.6

6.0

0

20.0

30.1

10.0

0

30.0

36.8

14.0

0

40.0

41.8

17.5

0

50.0

46.0

20.5

1

0.0069

2.0

0.00004

0.1

19.9

23.0

0

21.3

25.0

0

22.2

27.0

0

23.2

28.0

0

24.3

29.0

0

110.0

25.4

29.6

0

120.0

26.0

30.0

999 
TABLE C. 3

Output from Example Triaxial Test Reduction Program

Triaxial test number 99

Initial cross section area $=1.53918$

Initial sample volume $\quad=73.146$

Initial sample length $\quad=2.90$

Chart speed factor (no. divs/minute) $=.007$

Load factor (no. pounds/division) $=.8$

Strain rate (no. inclies/minute) $\quad=.00004000$

Volumetric strain factor (ccs/division) $=.10000$

\begin{tabular}{|c|c|c|c|c|c|c|c|}
\hline $\begin{array}{l}\text { Strain } \\
\text { Divs }\end{array}$ & $\begin{array}{l}\text { Load } \\
\text { Divs }\end{array}$ & $\begin{array}{l}\text { Buret } \\
\text { Divs }\end{array}$ & $\begin{array}{l}\text { Time } \\
\mathrm{Hr}\end{array}$ & $\begin{array}{l}\text { Load } \\
\text { Lbs }\end{array}$ & $\begin{array}{l}\text { Disp. } \\
\text { Ins }\end{array}$ & $\begin{array}{l}\text { Area } \\
\text { Correct }\end{array}$ & $\begin{array}{c}\text { Del Vol } \\
\text { Ccs }\end{array}$ \\
\hline $\begin{array}{l}10.0 \\
20.0 \\
30.0 \\
40.0 \\
50.0\end{array}$ & $\begin{array}{l}19.6 \\
30.1 \\
36.8 \\
41.8 \\
46.0\end{array}$ & $\begin{array}{r}6.0 \\
10.0 \\
14.0 \\
17.5 \\
20.5\end{array}$ & $\begin{array}{r}24.15 \\
48.31 \\
72.46 \\
96.62 \\
120.77\end{array}$ & $\begin{array}{l}15.680 \\
24.080 \\
29.440 \\
33.440 \\
36.800\end{array}$ & $\begin{array}{l}.05797 \\
.11594 \\
.17391 \\
.23188 \\
.28986\end{array}$ & $\begin{array}{l}1.57058 \\
1.60328 \\
1.63737 \\
1.67295 \\
1.71011\end{array}$ & $\begin{array}{r}.6000 \\
1.0000 \\
1.4000 \\
1.7500 \\
2.0500\end{array}$ \\
\hline
\end{tabular}

Chart speed factor (no. divs/minute) $=.007$ Load factor (no. pounds/division) $=2.0$

Strain rate (no. inches/minute) $=.00004000$

Volumetric strain factor (ccs/division) $=.10000$

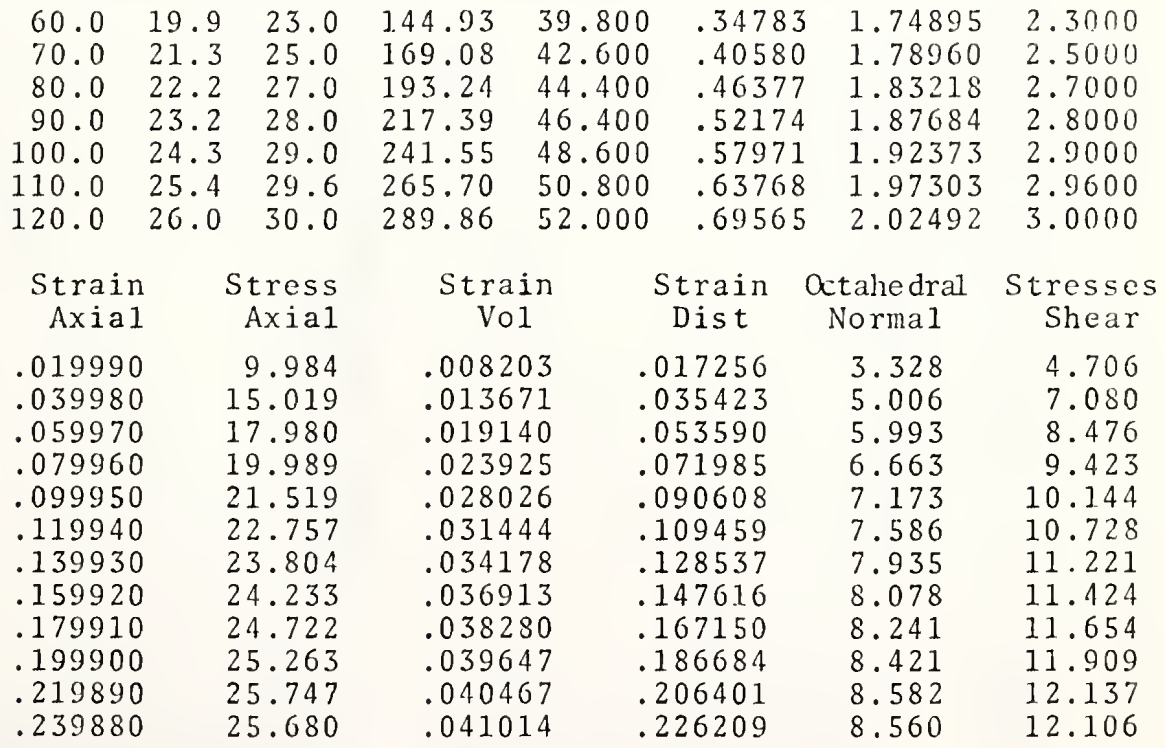



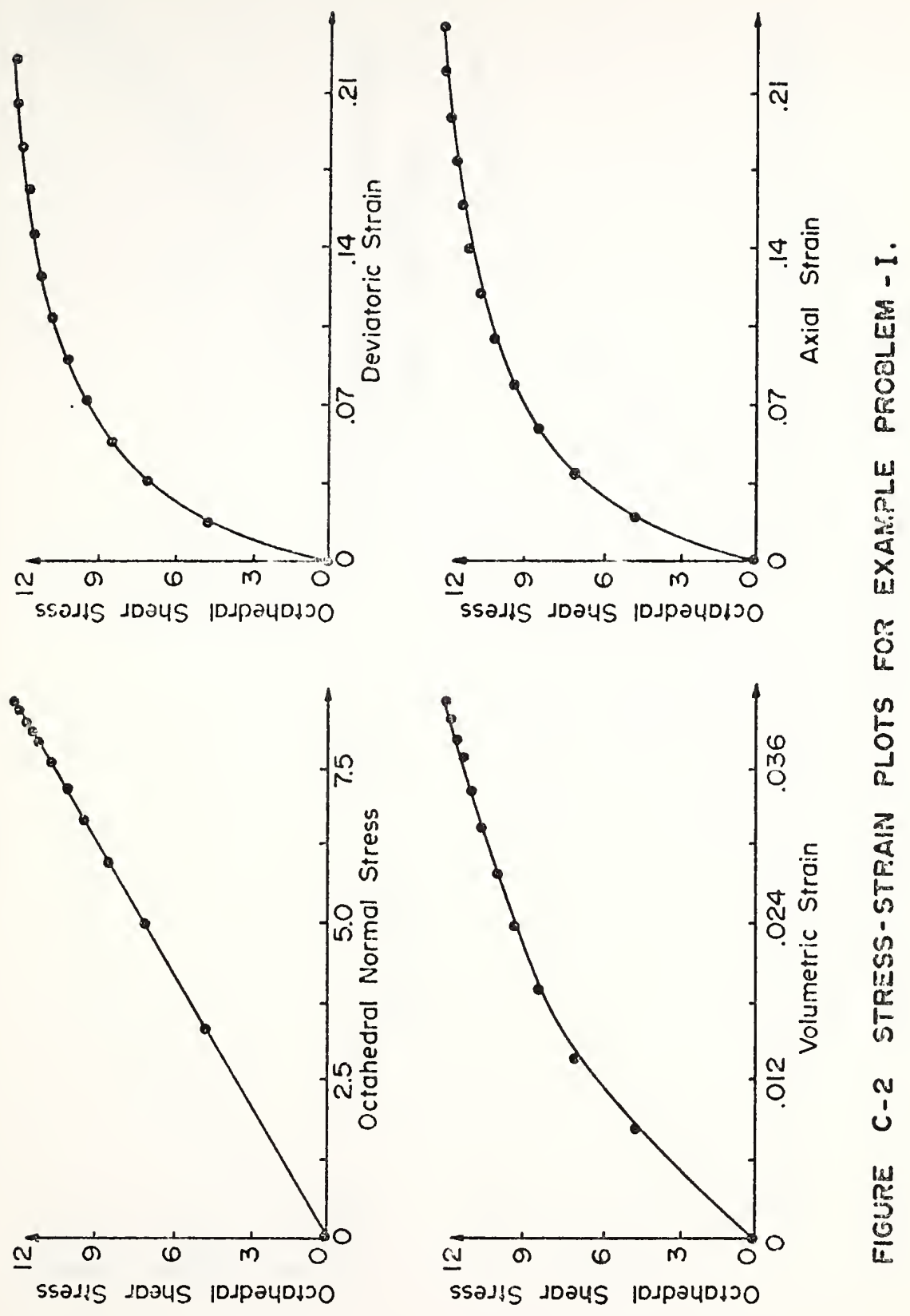

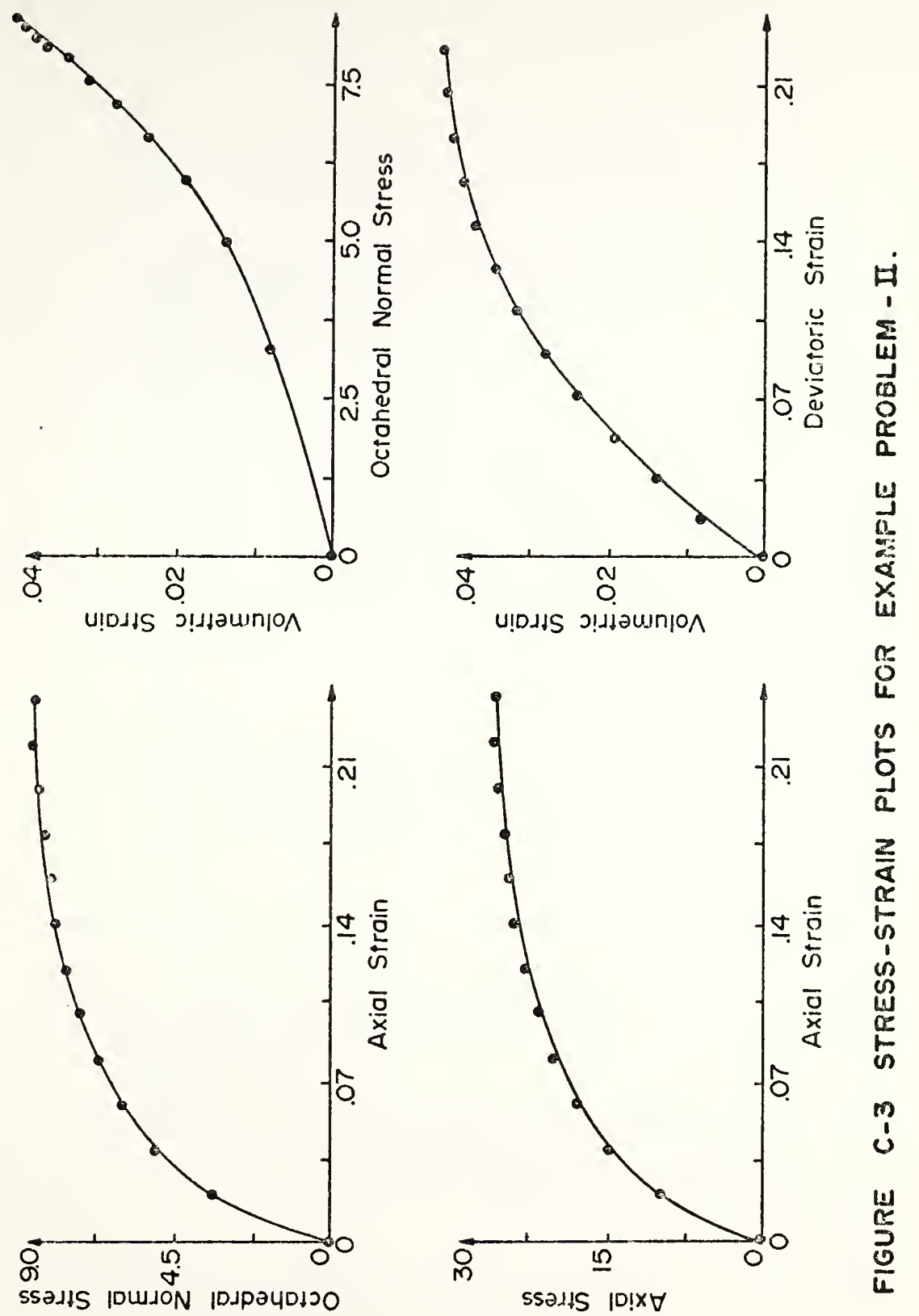
239

C.4 LISTIIRG UF PEugiraia

REAL LUAD, LTNUIH

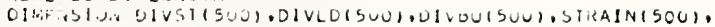

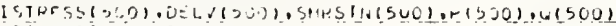
OITAFNSION XISUZ). Y UIMFNSIOH TITLE(3) CAI.L PLOTS PLALIS.11 TIILC

J $\quad$ (SPNATI 3010$)$ NPP!HI $=0$

- C ENOICF Uf PLOTS

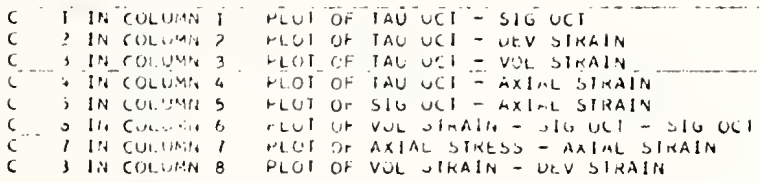




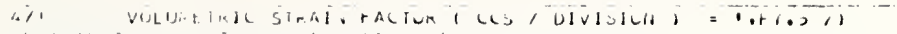

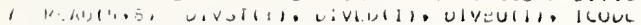

F Pif

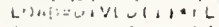

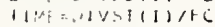

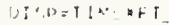

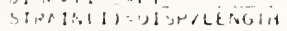

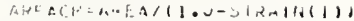

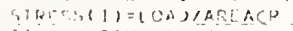

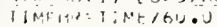

DELIAV-UIVIDOCI:FV

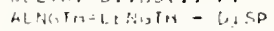

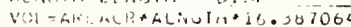

$L=\mid \vee(i)=i, t .1$ li V $/ V C L$.

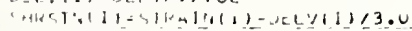

$H(1)=31,2501,1 / 3.0$

$50=5+1+11<\cdot 1)$

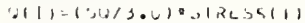

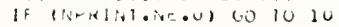

vilution

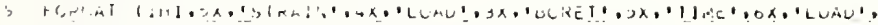

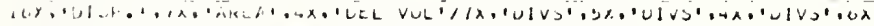

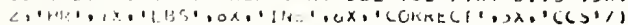

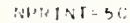

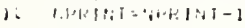

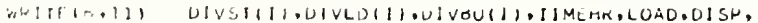

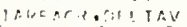

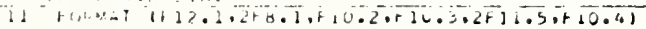

11 I ICU!) . IRt $9991 \quad 60104$

$\operatorname{linint-1}$

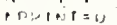

(u) $1>1=1, x ! m e t$

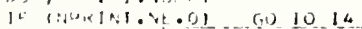

Q

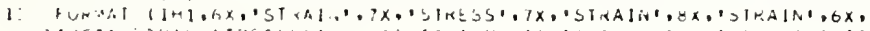

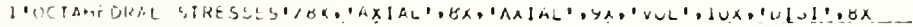

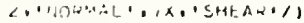

1.

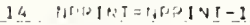

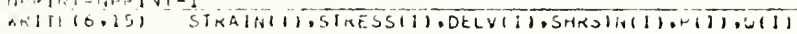

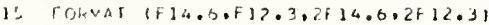

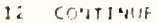

itrilleto.ci 60 10 99

$M=N U M+T$

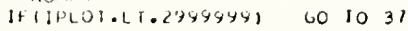

C PIOT OF IAU OC̈T - SIG OCT

- OO $1 \mathrm{~F}, \quad \mathrm{I}=1$,

$x(1)=3 i)$

$Y(1)=011)$

$y(M+1)=0.0$

$x(M+2)=1 \cdot 5$

$Y(M+1)=0.0$

$Y(N+2)=3 \cdot 0$

$x M T=X T M+1)$

$0 X=X(1 A+2)$

$Y: 1 N=Y(1.9+1)$ 
DY $=Y(M+\overline{2})$

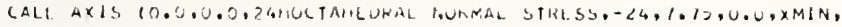
$10 x, 1) 1$

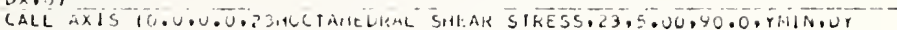
1.01

GALL SY!ABSL $11.0 .5 .0 .0 .10,111 L ! \cdot 0.0 .30\}$

CALT LINL $(x, \because, \cdots, 2,-1,3)$

(AL: PLUICII,U.J.0.-3)

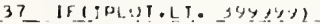

CQ_IO_36.

C PLUT OH IAU OCT - DEV SIRAIN

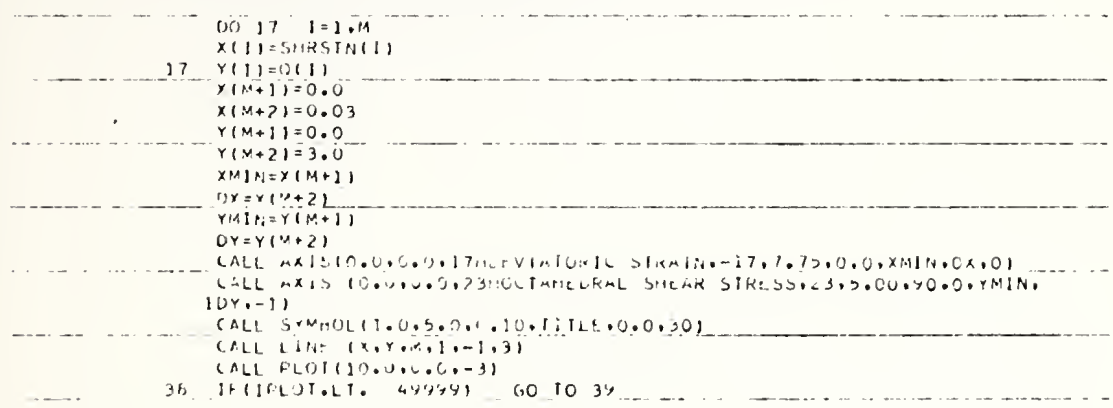

6 JOT OF IAU OCI - VOL SIRAIM

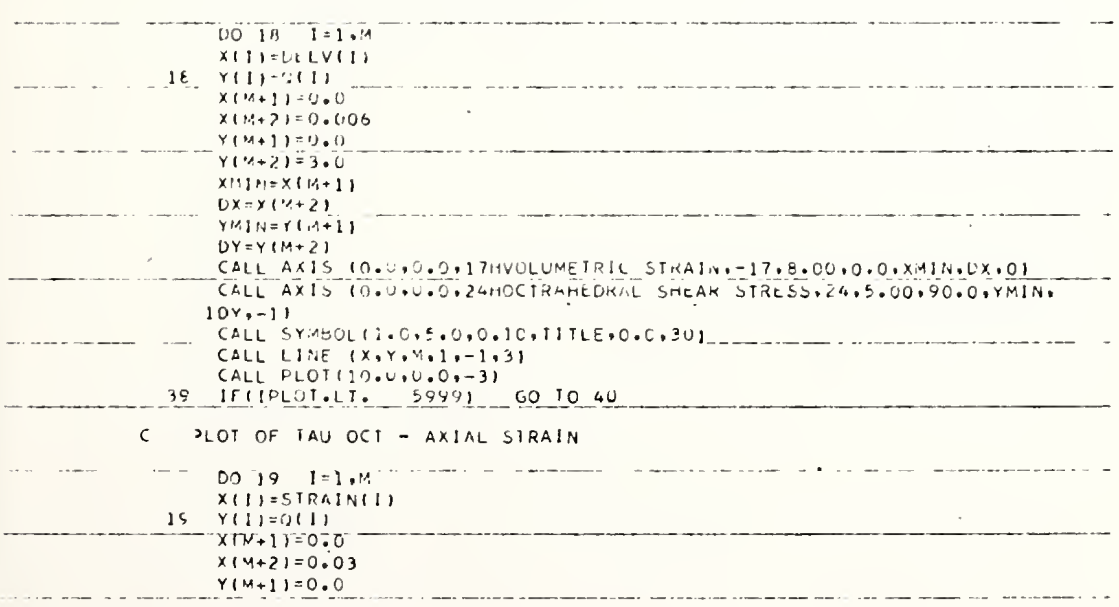




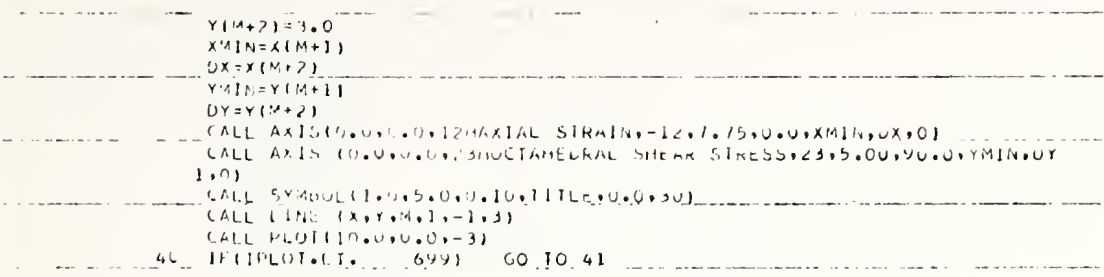

C Lor of 516 OLI - AxIML SIRAIN

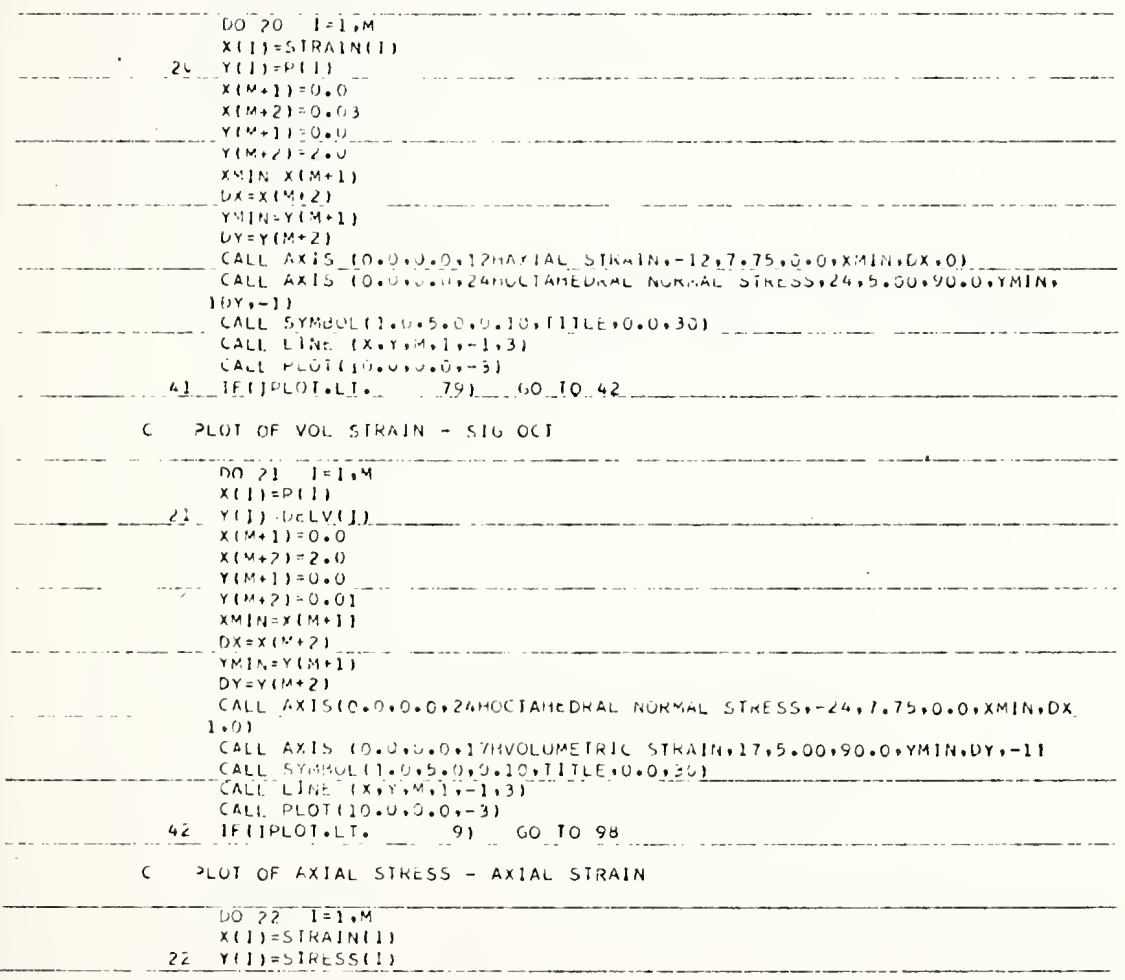




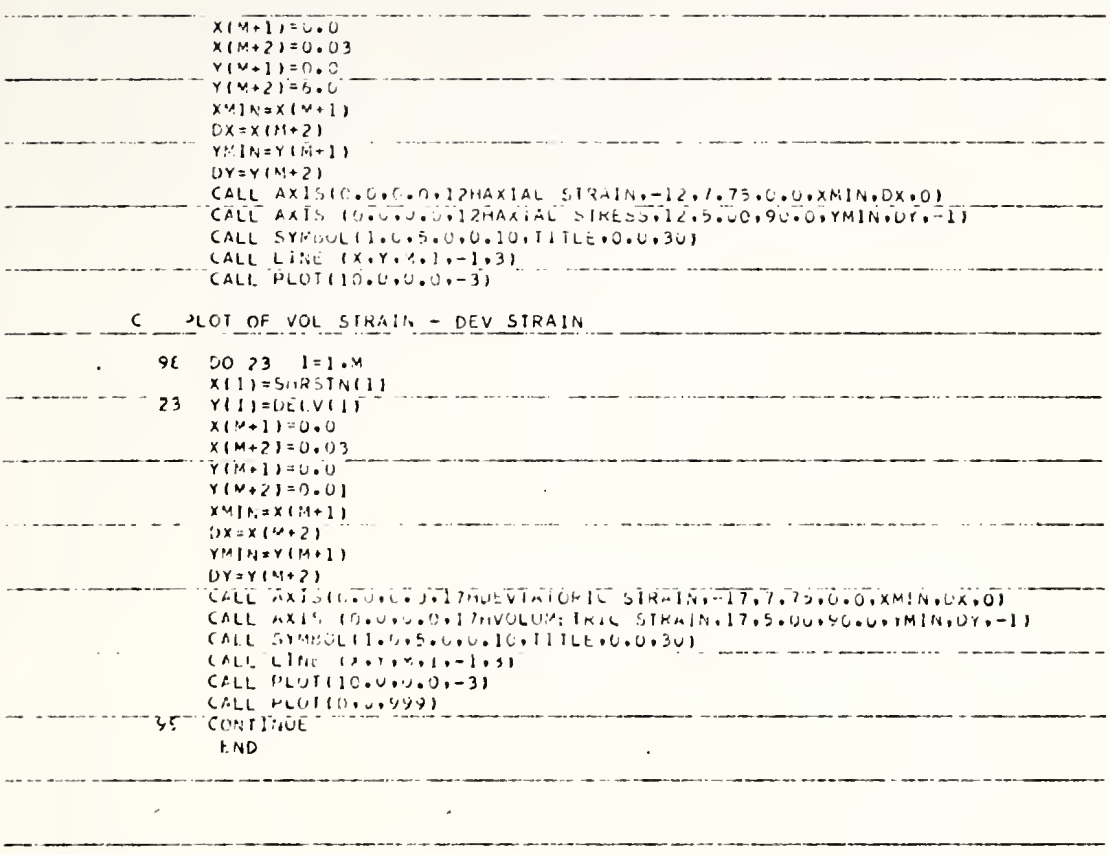


APPENDIX D

THE FINITE ELEMENT CONSOLIDATJON PROGRAM 


\section{THI FINILE ELEMINT CONSOLIDATION I'ROGRAM}

\section{D.1 Input Format for Consolidation Program}

\section{i. IDENTIFICATION CARD (18A4)}

Columns $1-72$ HED (18)

ii. CONTROL CARD (8I5, F10.0, 2I5, F10.0)

Columns 1-5 NUMNP - Number of nodal points

6-10 NUMEL - Number of elements

11-15 NUMAT - Number of different materials

16-20 NUMPC - Number of boundary loading cards

21-25 NUMSP - Number of elements with specified pore pressures

26-30 NUMBC - Number of flow boundary cards

31-35 NDEGR - Code for degree of consolidation calculations

36-40 NFPERC - Percentage desired

41-50 F'TIME - Final consolidation time

51-55 NLOADC - Code for time-dependent loading

56-60 NPLT - Code for plotting

61-70 DTIME - Initial consolidation time increment 
iii. MATERIAL PROPERTY CARDS (I5, 5X, 4F10.0)

Columns 1-5 MTYSE - Matcrial number

$$
\begin{array}{rr}
\text { 6-10 } & \text { Blank } \\
11-20 & \text { E - Modulus of elasticity } \\
21-30 & \text { GNU - Poisson's ratio } \\
31-40 \text { COND, } 1 & - \text { Horizontal permeability/unit } \\
& \text { weight of water } \\
41-50 \text { COND, } 2 \text { - Vertical permeability/unit } & \\
& \text { weight of water }
\end{array}
$$

There will be a type iii card for each material type.

iv. NODAL POINT CARDS (2I5, 4F10.0)

Column $1-5 \quad \mathrm{~N}$ - Nodal point number

6-10 CODE - Code for specified forces or displacements

11-20 X-X-coordinate

21-30 Y-Y-coordinatc

31-40 UX - Force or displacement in X-direction

41-50 UY - Force or displacement in Y-direction

There will be one card for each nodal point

v. ELIMENT CARISS (6I5)

Column $\quad 1-5 \quad M$ - Element number

6-10 IX,1 - Nodal point I

11-15 IX,2 - Nodal point $J$

16-20 IX, 3 - Nodal point $K$

21-25 IX,4 - Nodal point $\mathrm{L}$

26-30 IX,5 - Material type 
vi. BOUNDARY LOAD CARDS (2I5, F10.0)

Columns $1-5$ IBC - Nodal point I

$$
\text { 6-10 JBC - Nodal point } \mathrm{J}
$$

11-20 PR - Normal pressure

There will be NUMPC cards of type vi.

vii. ELIMINT PORE PRESSURE CARDS (2I5, F10.0)

Columns $1-5$

L - Flement number

$6-10$

$$
\begin{gathered}
\text { NL - +ve - pressures initially only } \\
\text {-ve - pressures apply throughout } \\
\text { consolidation }
\end{gathered}
$$

11-20 PRESS - Specified pressure

There will be NUMSP cards of type vii

viii. FLOW BOUNDARY CARDS (4I5, F10.0)

$$
\begin{aligned}
& \text { Columns 1-5 I - First boundary node } \\
& \text { 6-10 J-Second boundary node } \\
& \text { 11-15 K - Element number inside boundary } \\
& \text { 16-20 KODE - Code - flow or no flow } \\
& \text { 21-30 BPR - Pressure outside boundary }
\end{aligned}
$$

There will be NUMBC cards of type viii.

ix. DEGREE CARDS

$x$. TIME DEPENDENT LOADING CARDS

xi. PLOT CARDS 


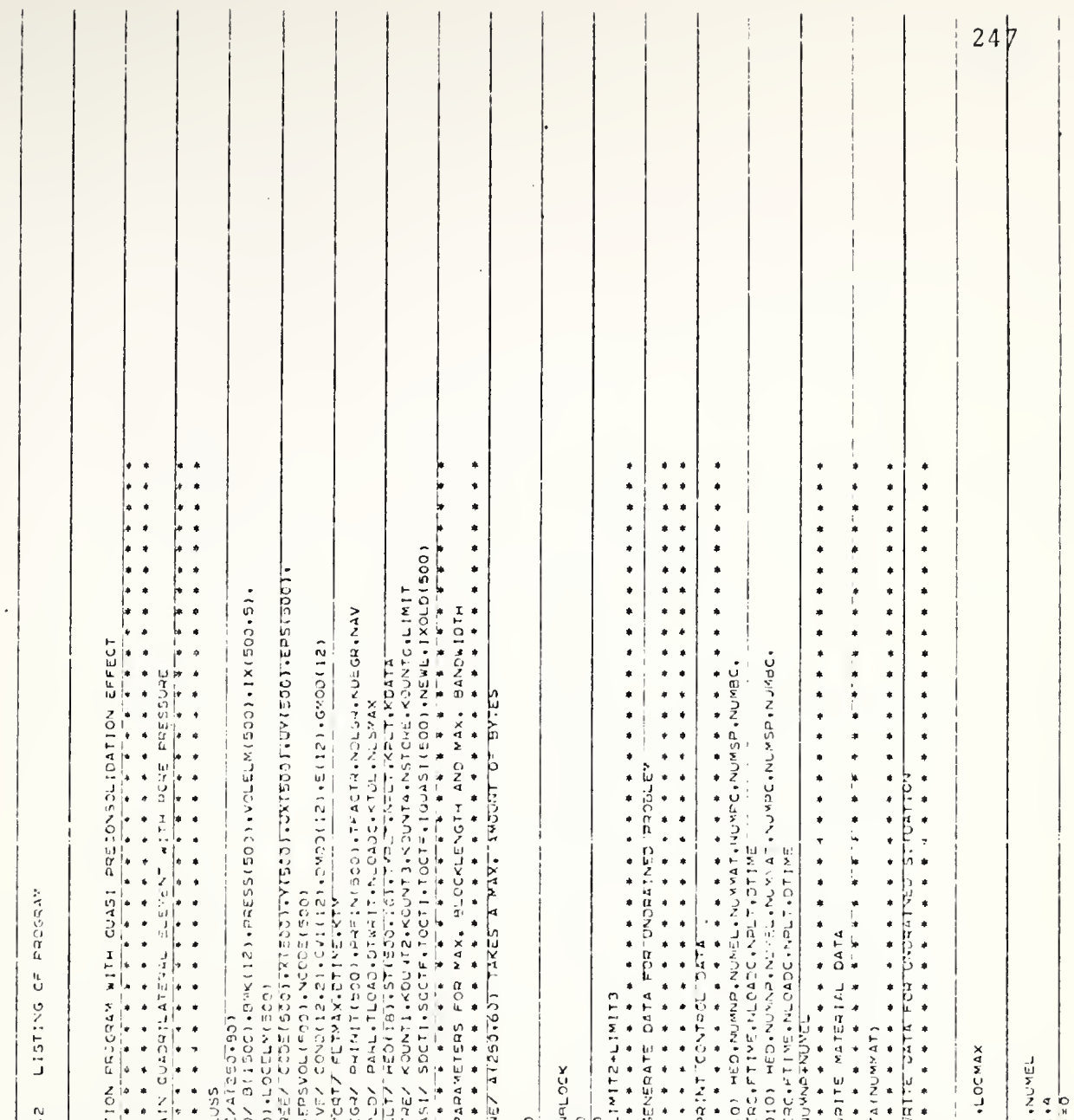

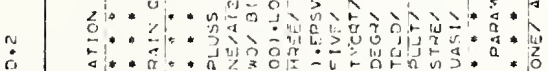

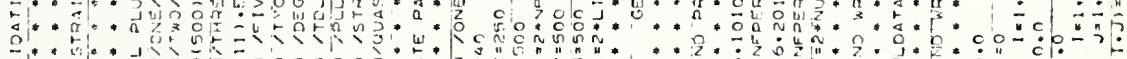

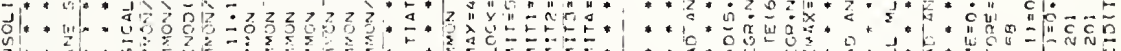

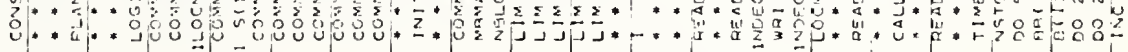

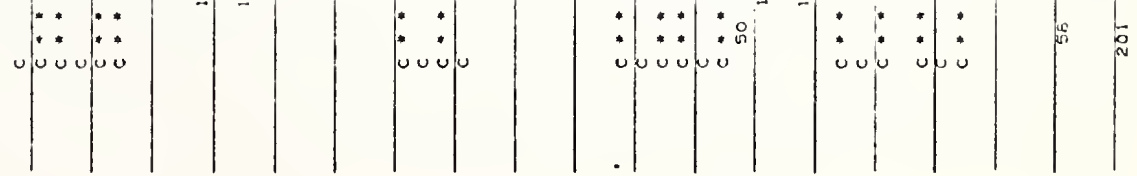




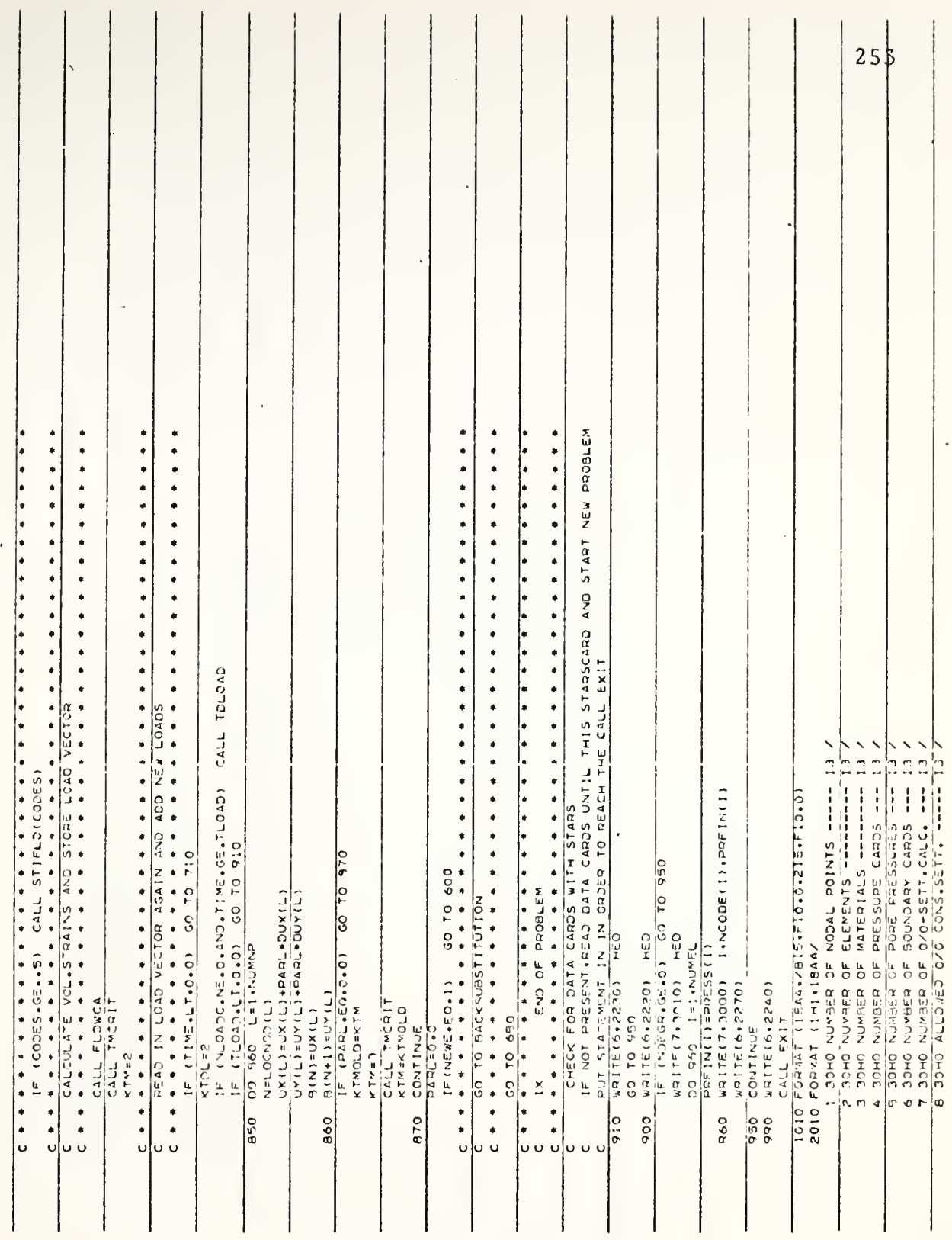




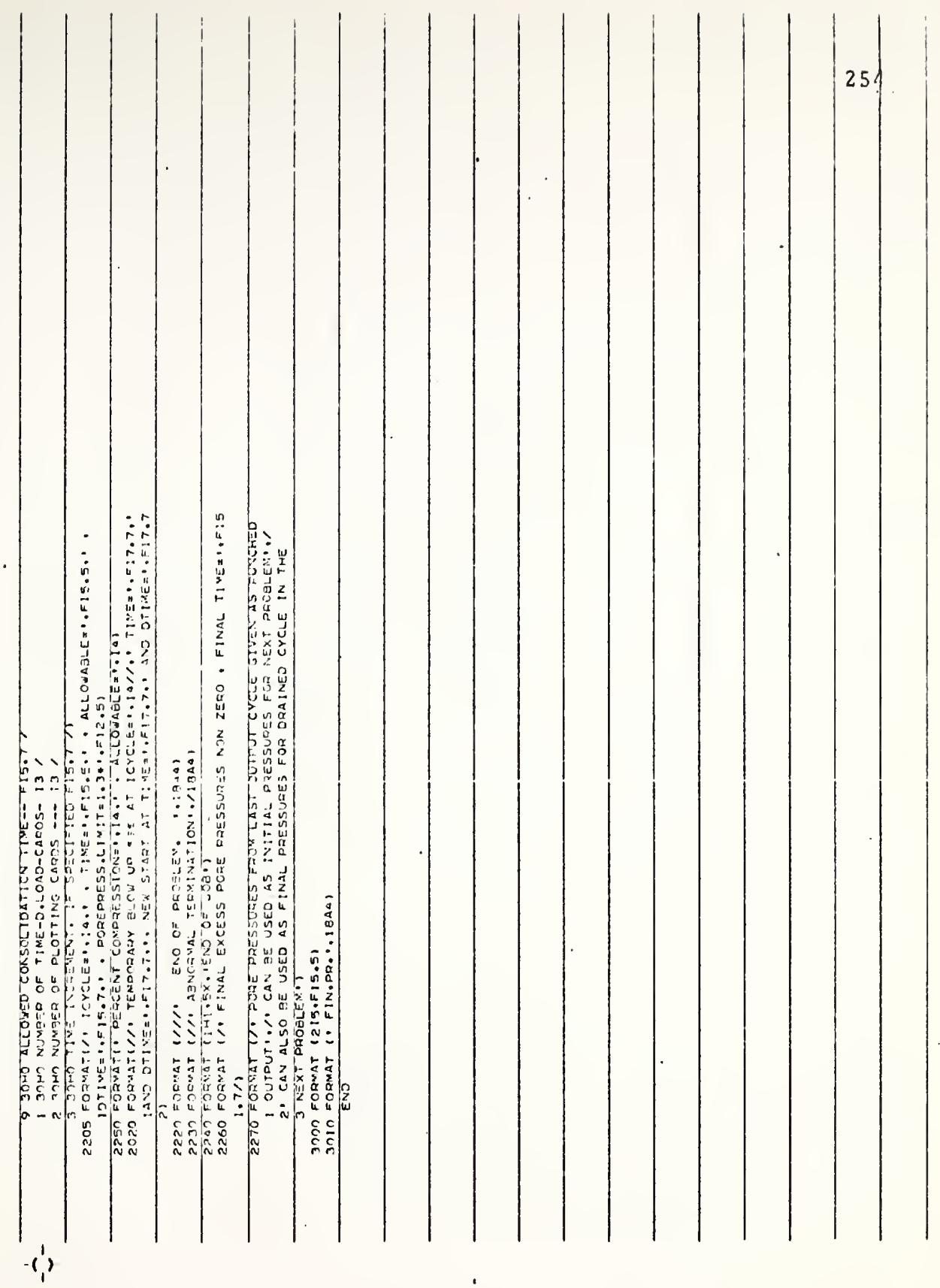




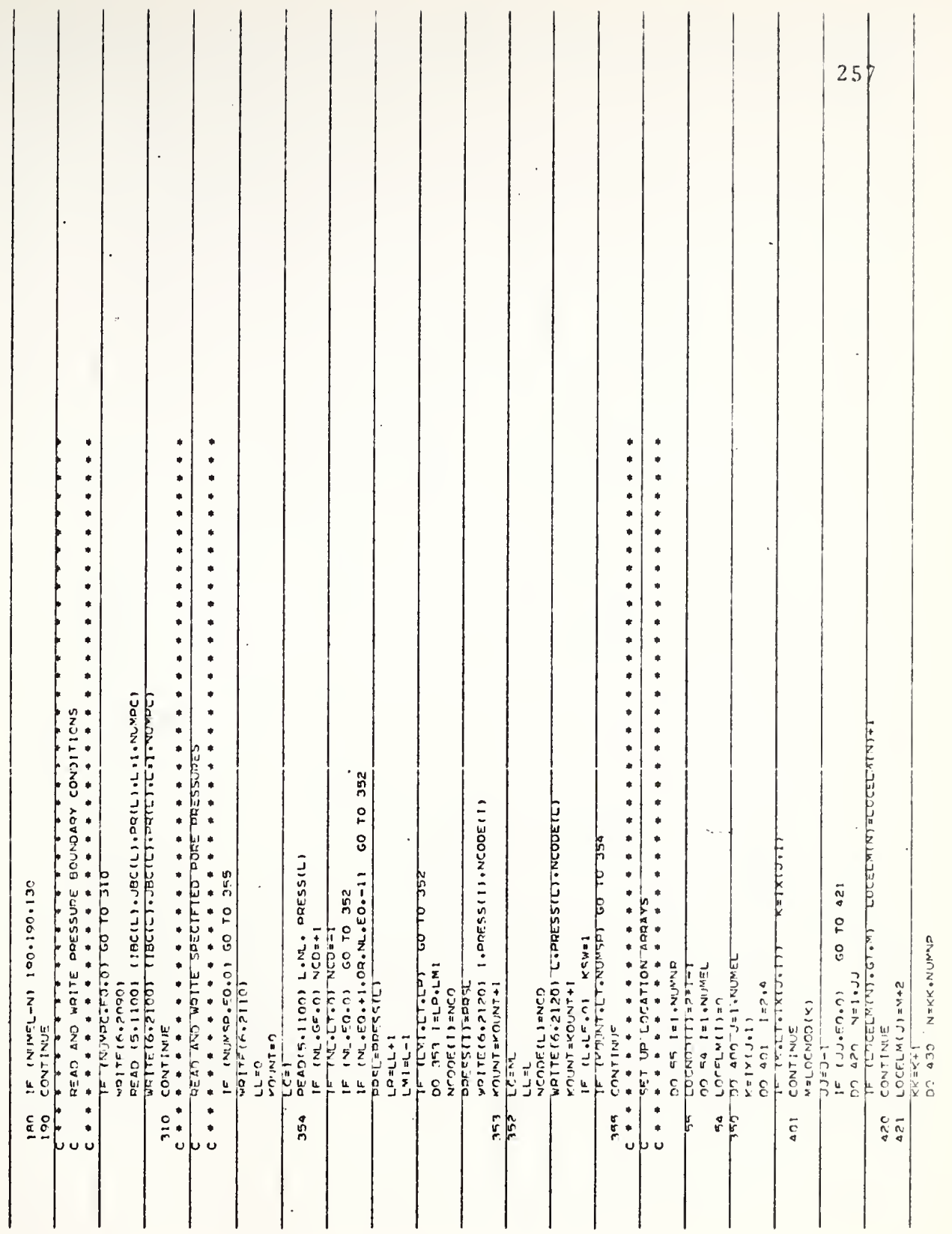




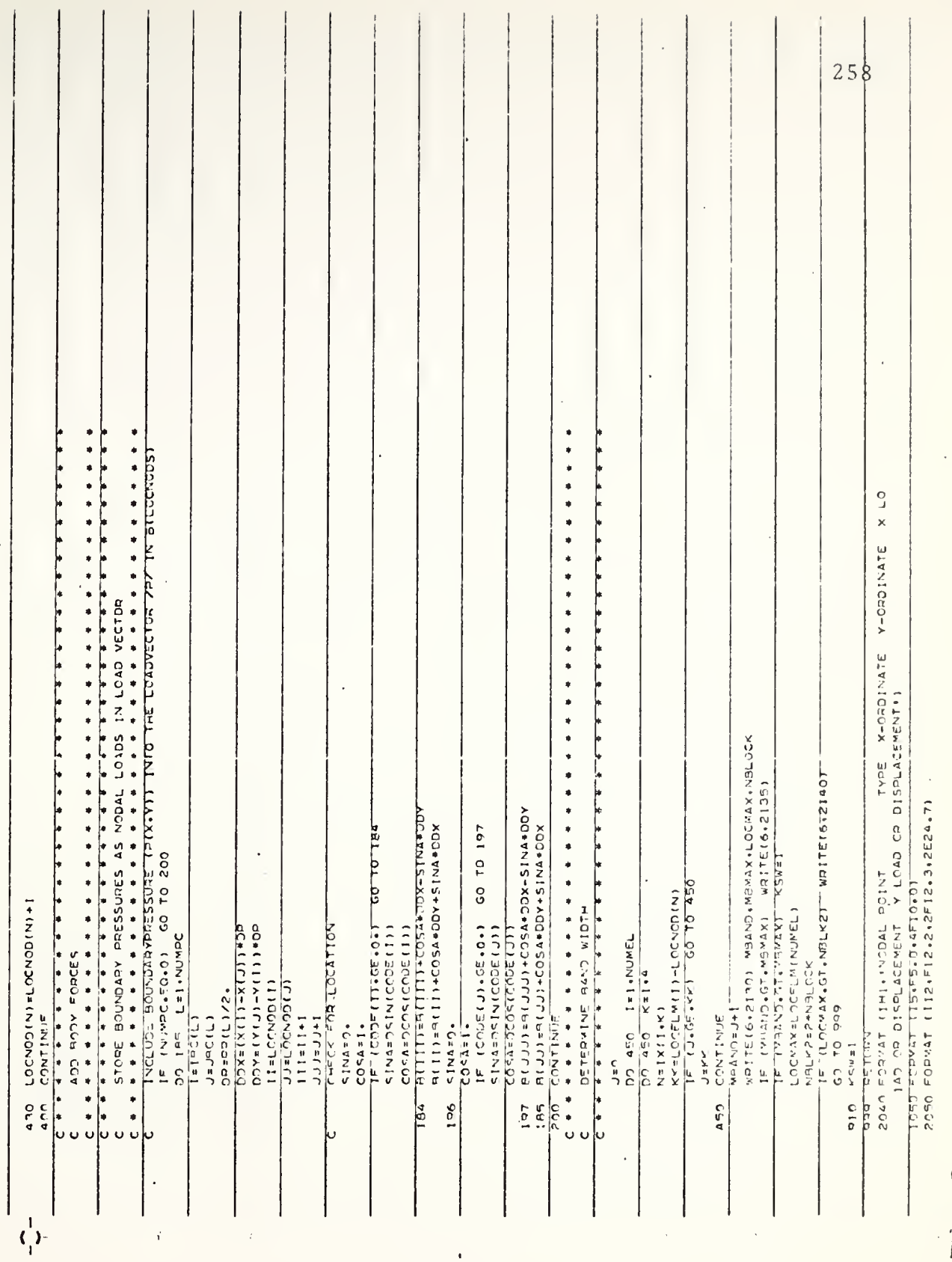




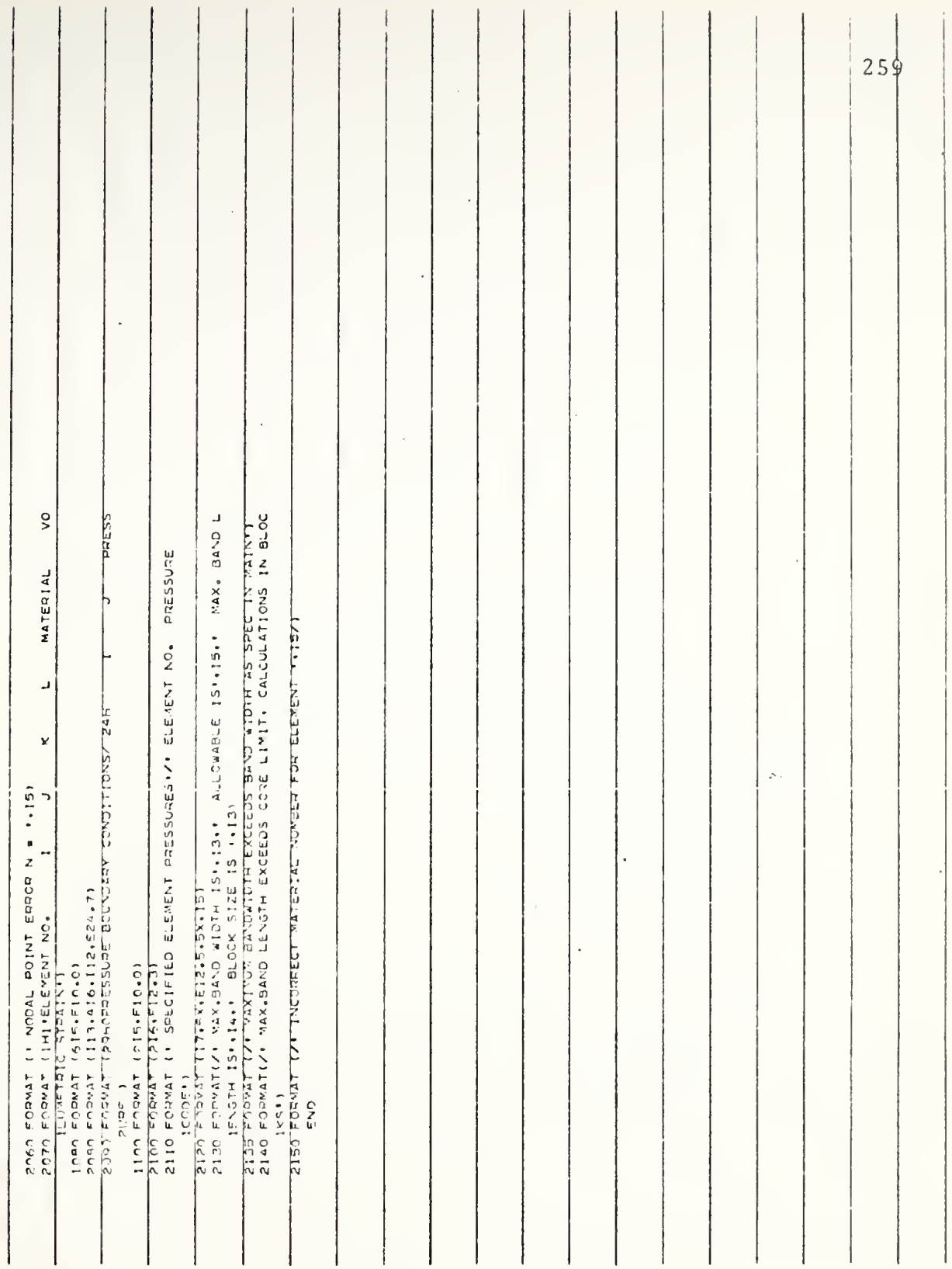



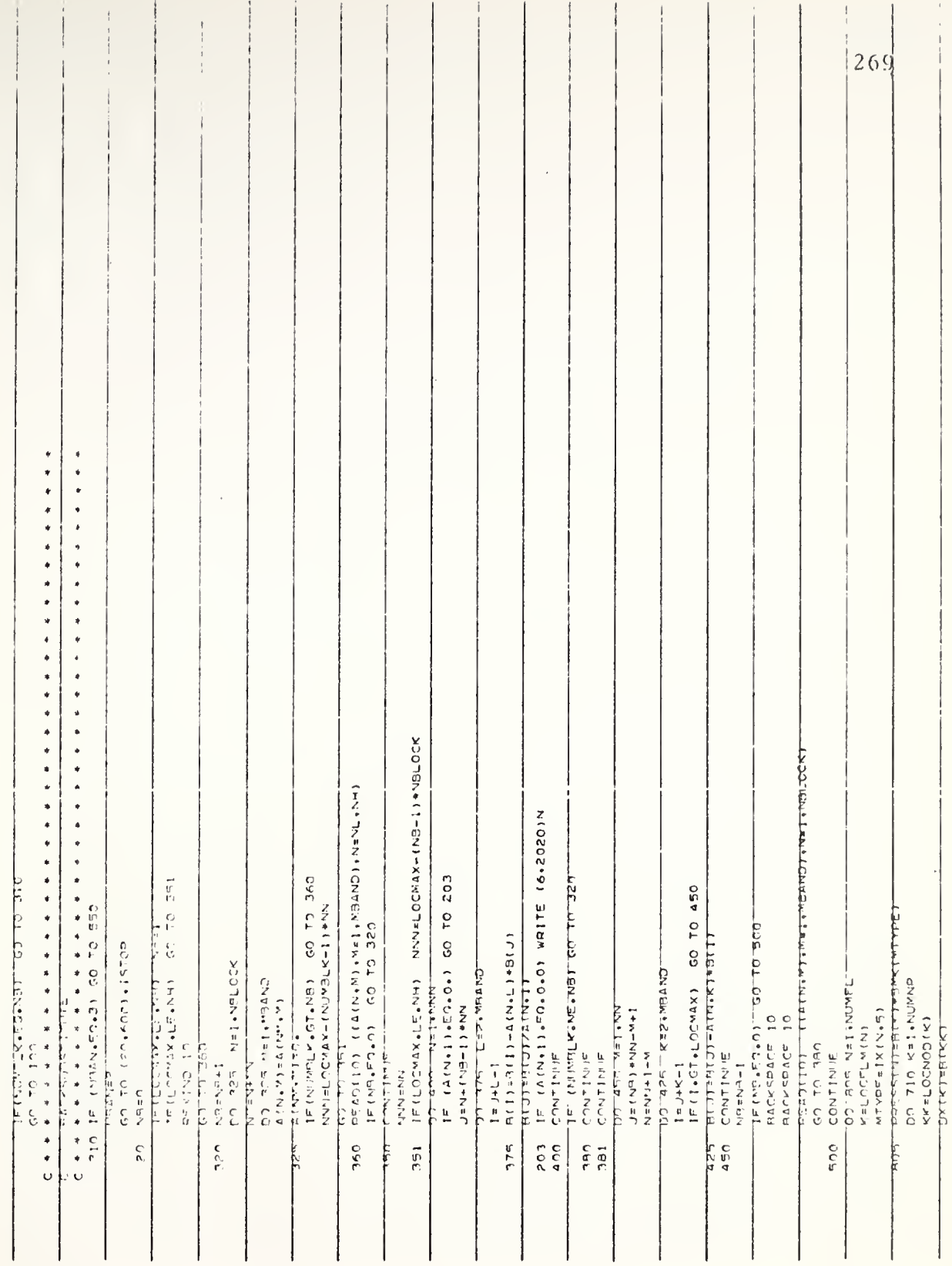


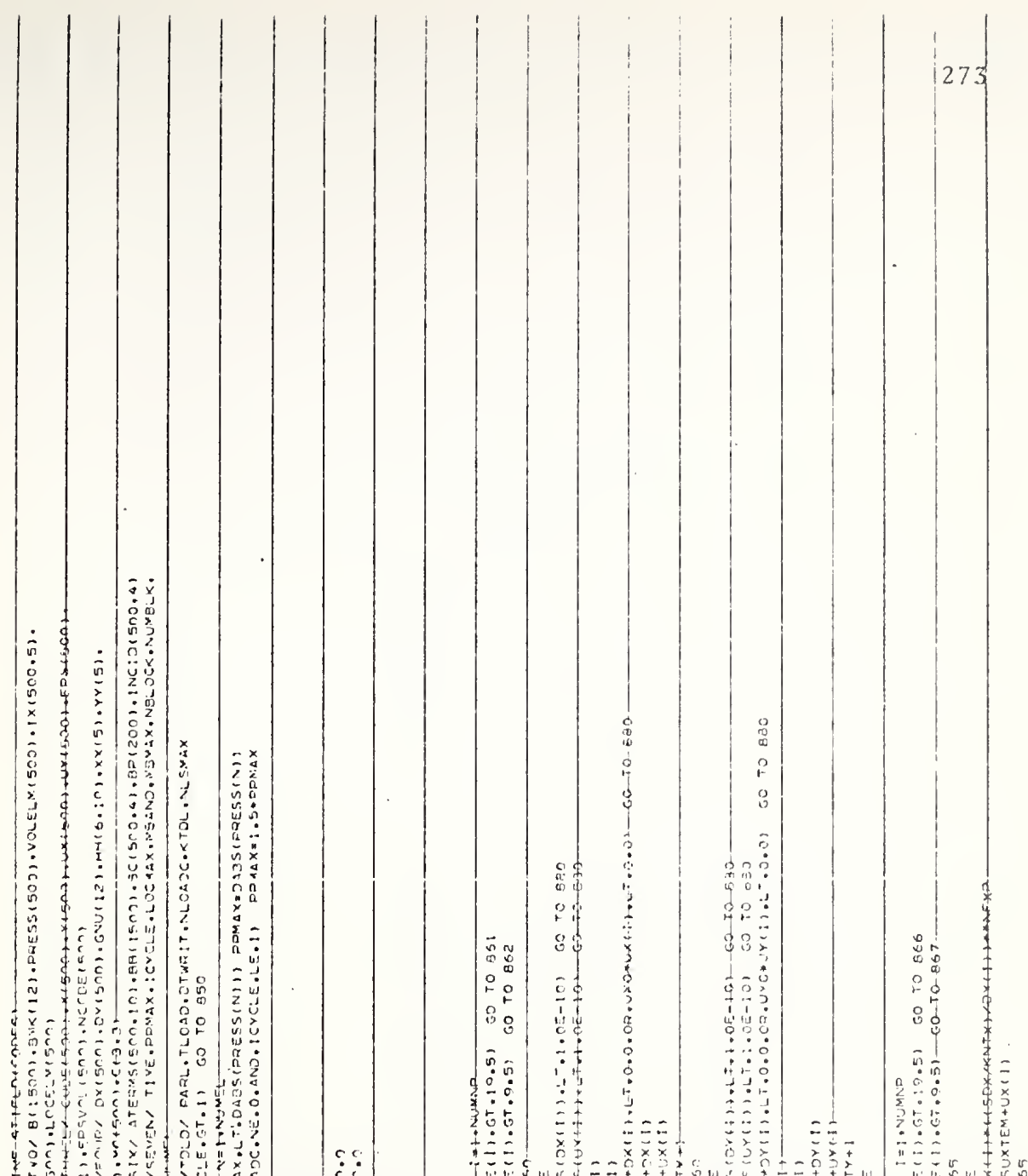

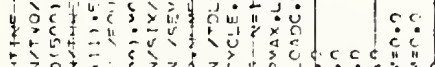

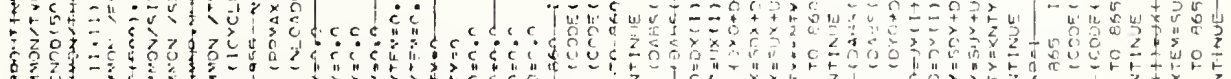

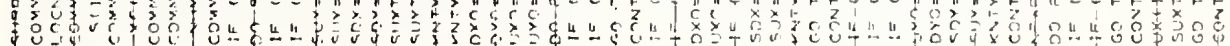

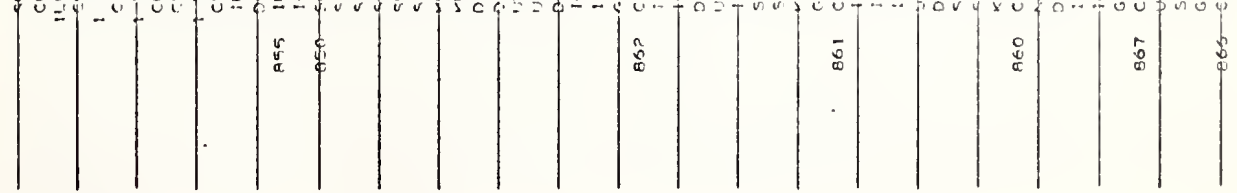




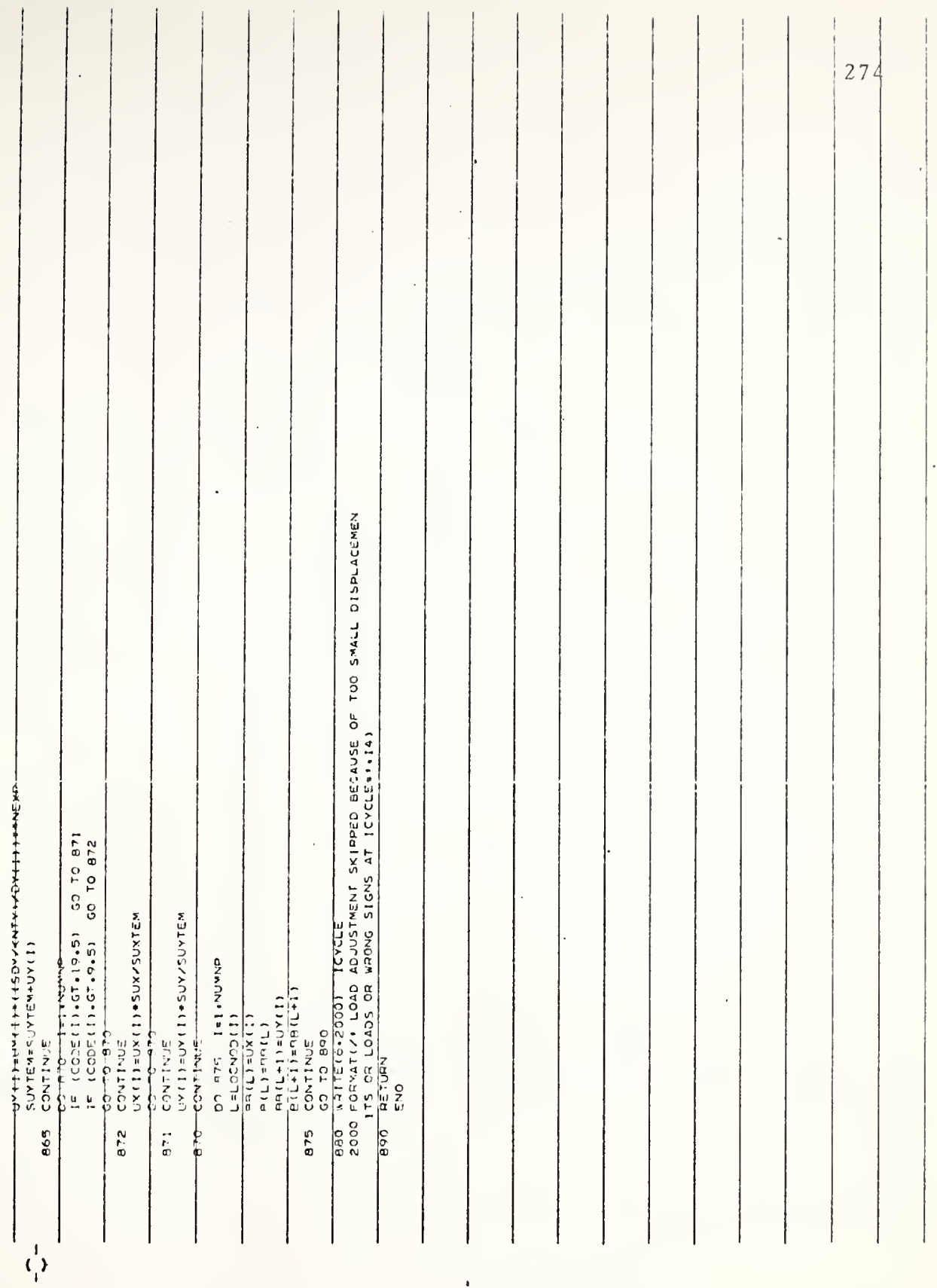




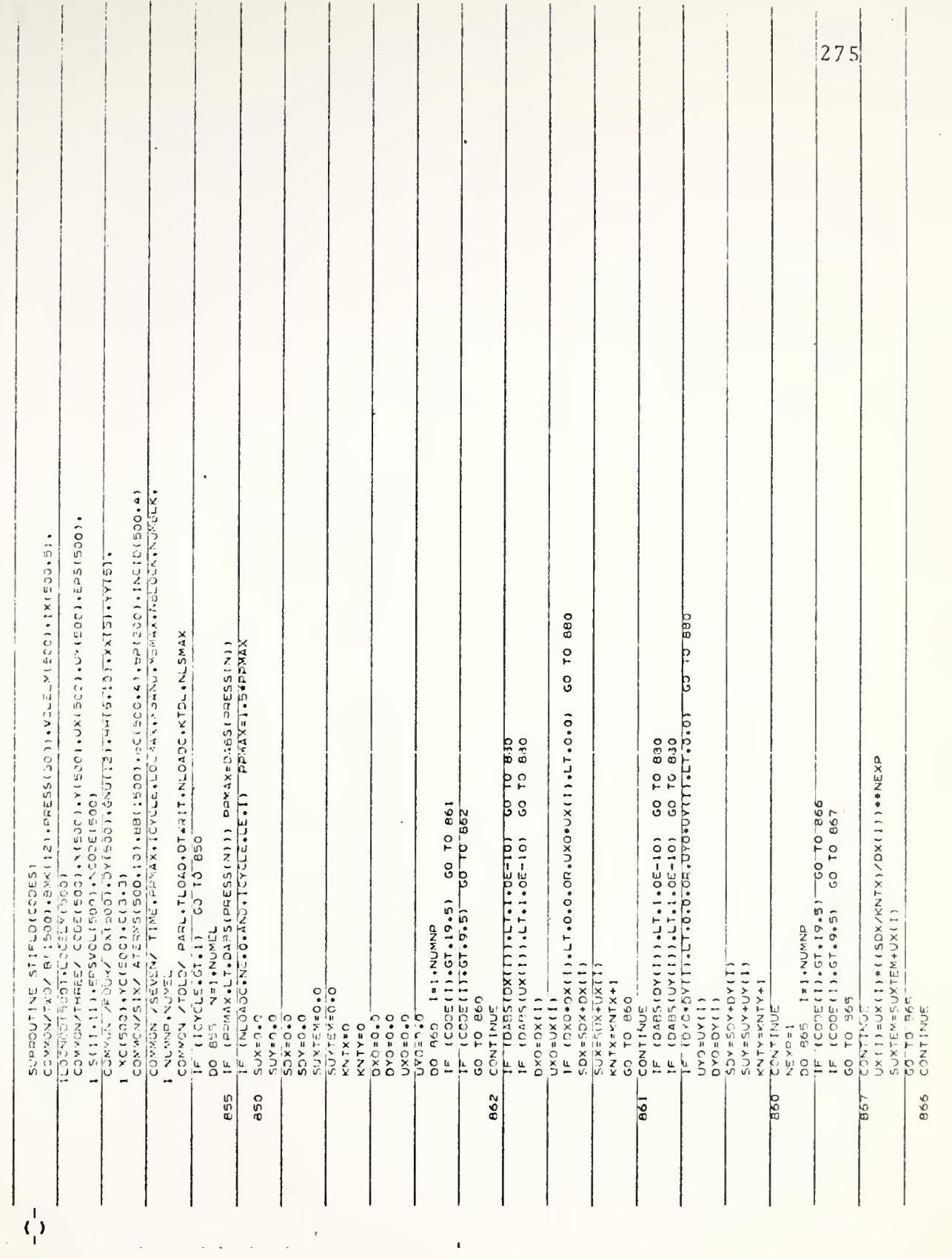




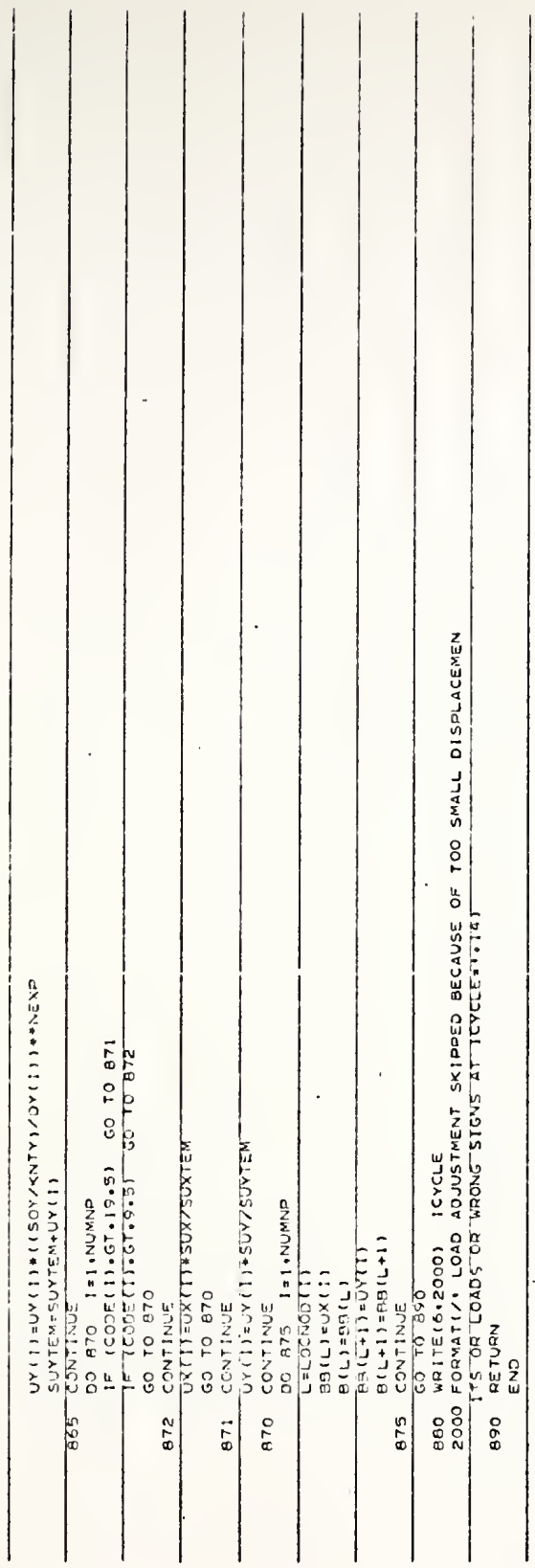




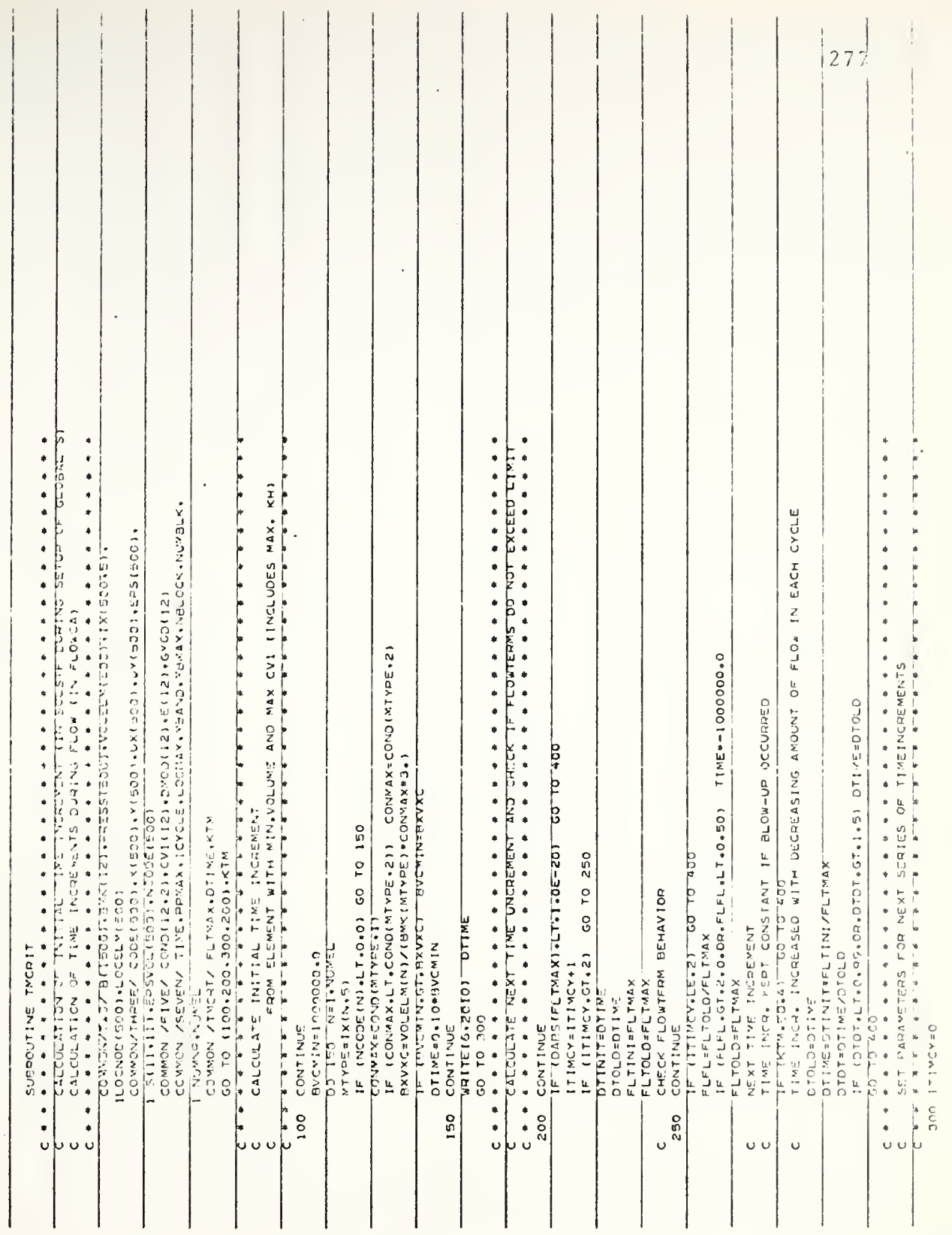





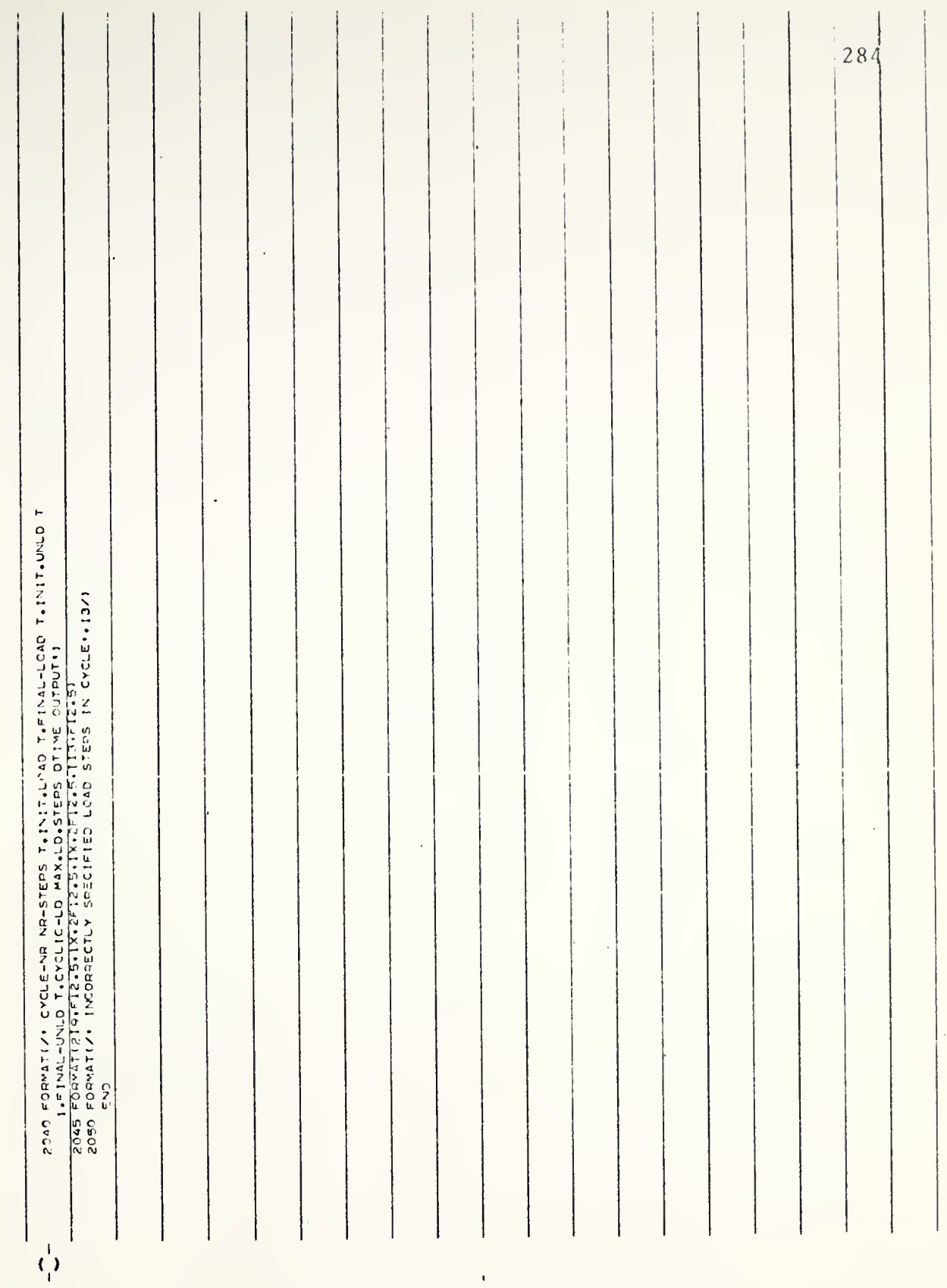




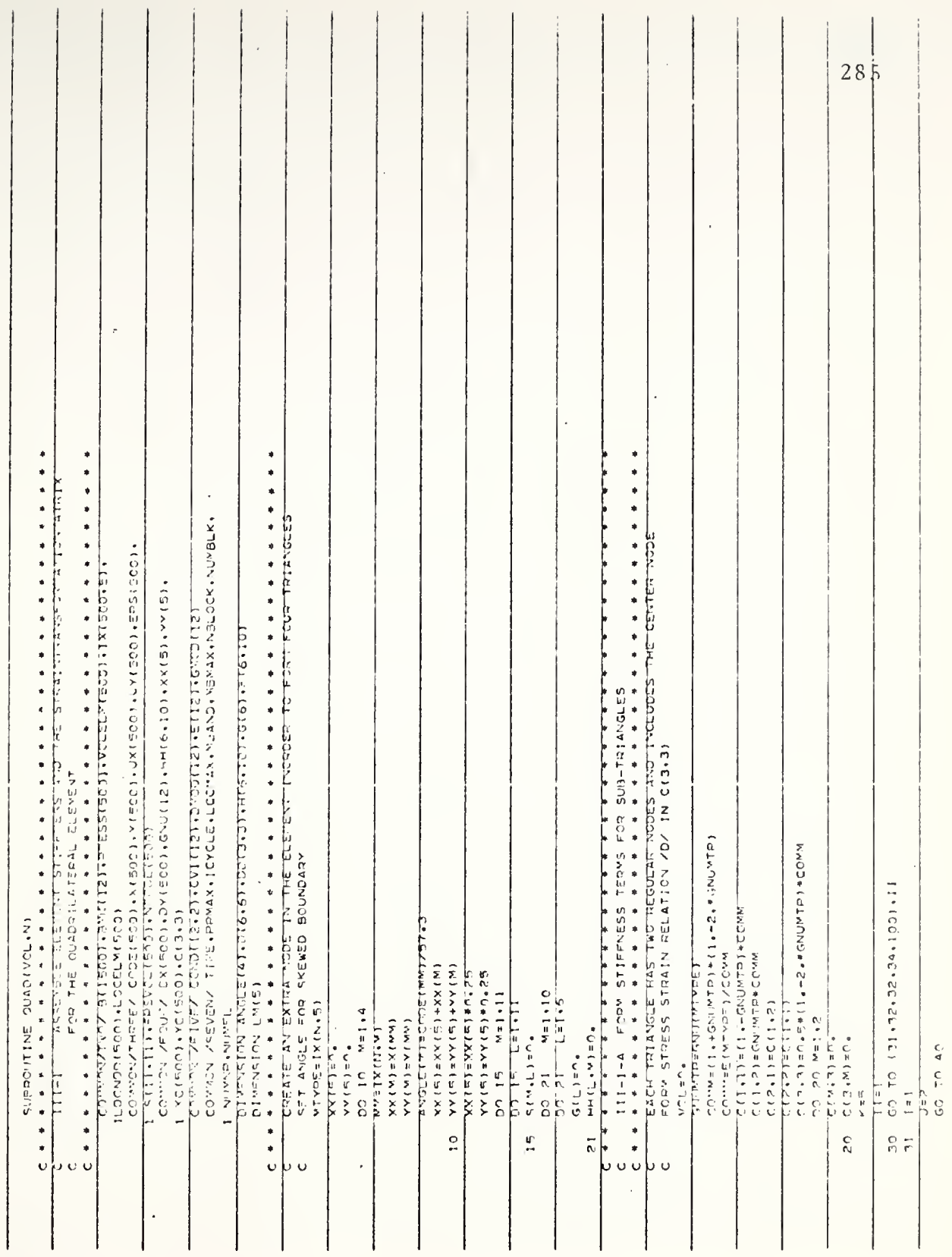




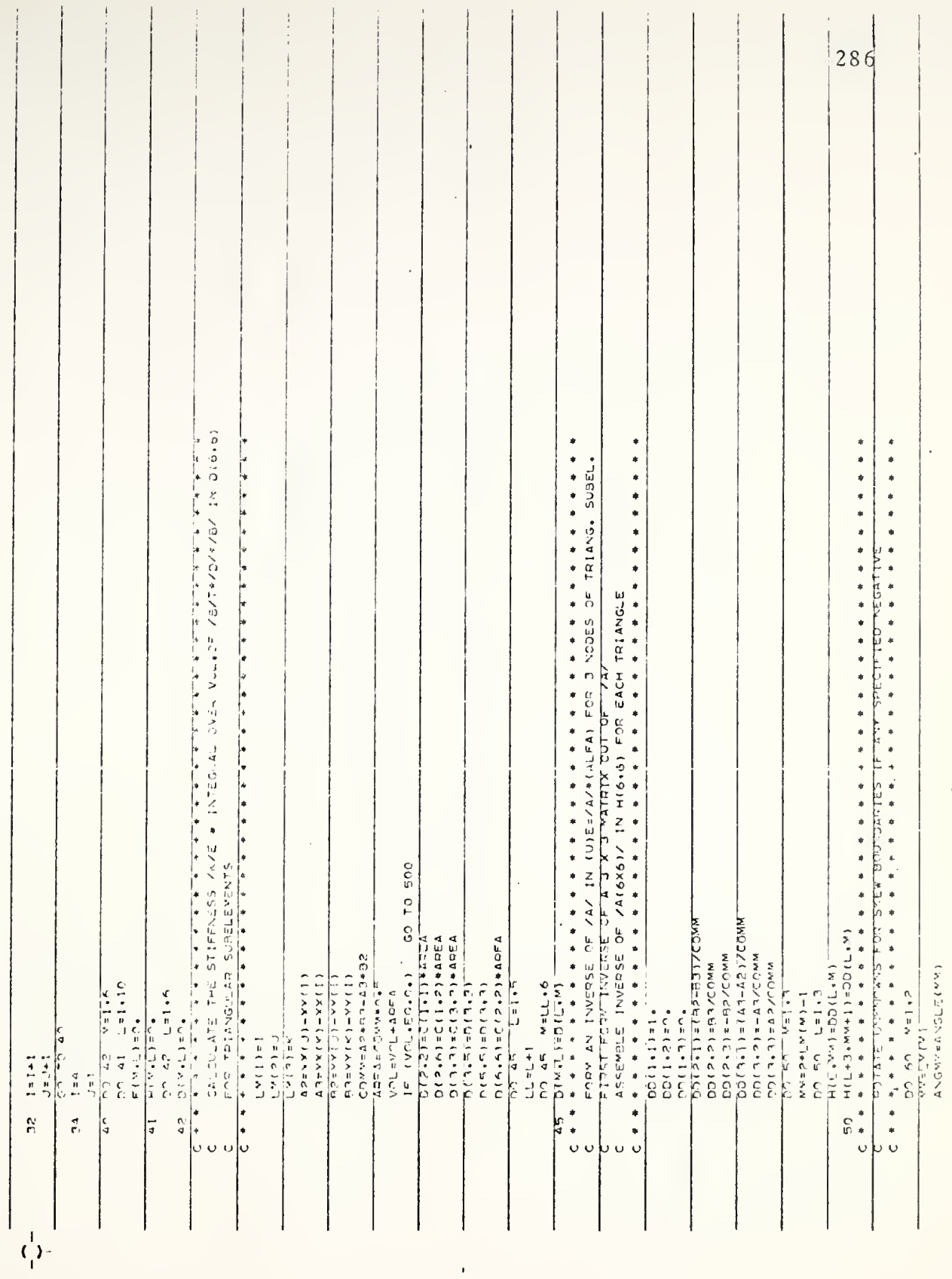




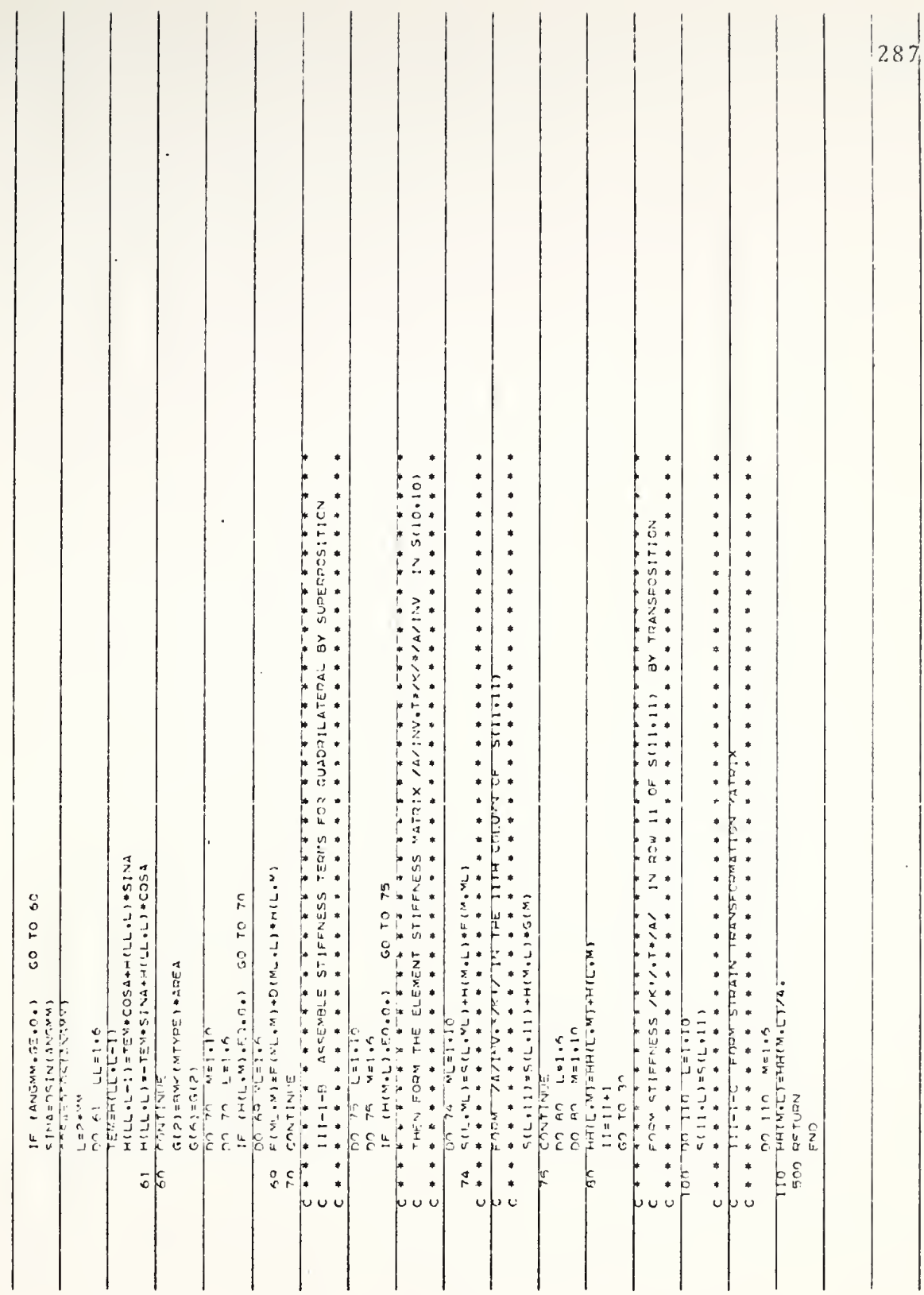




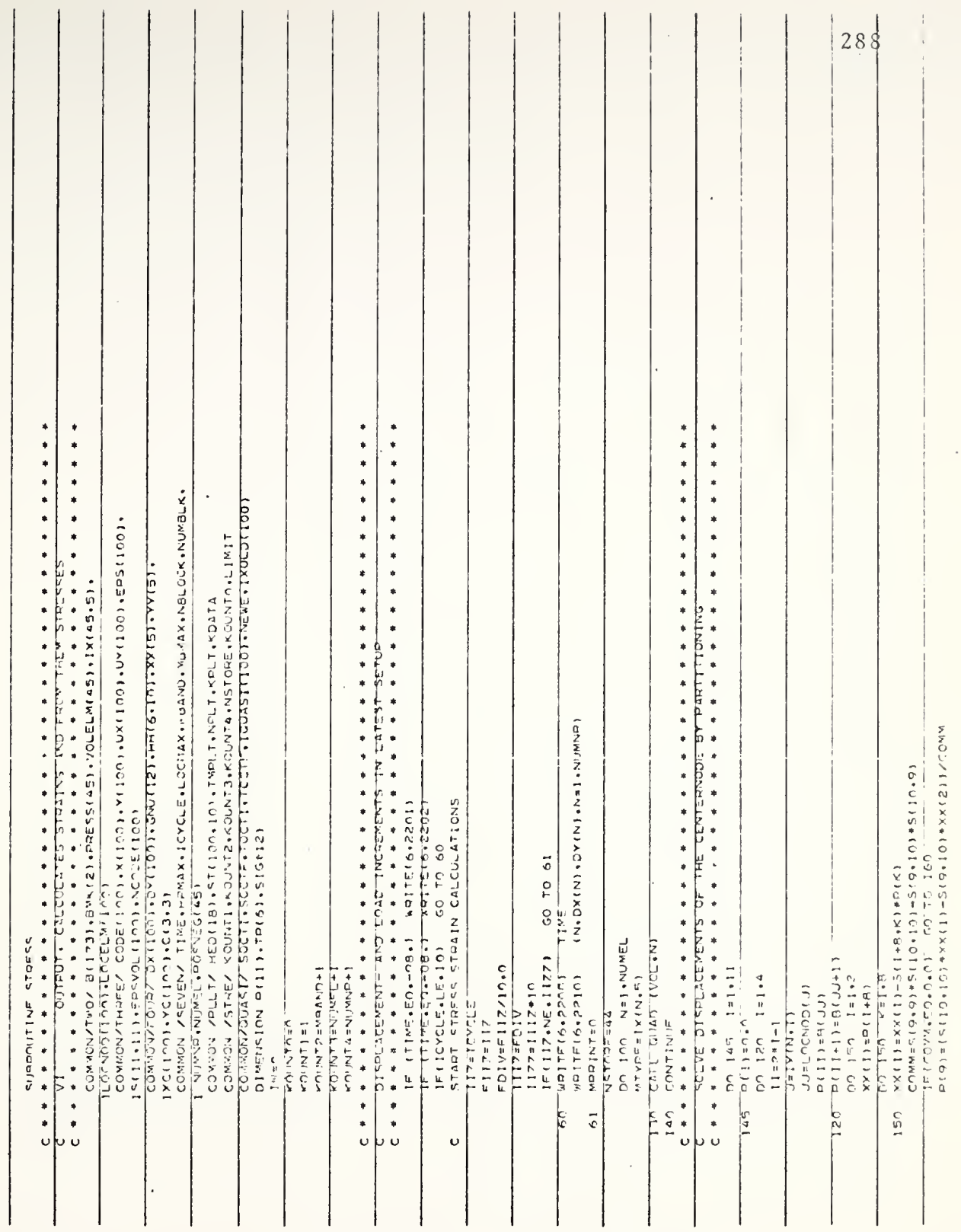



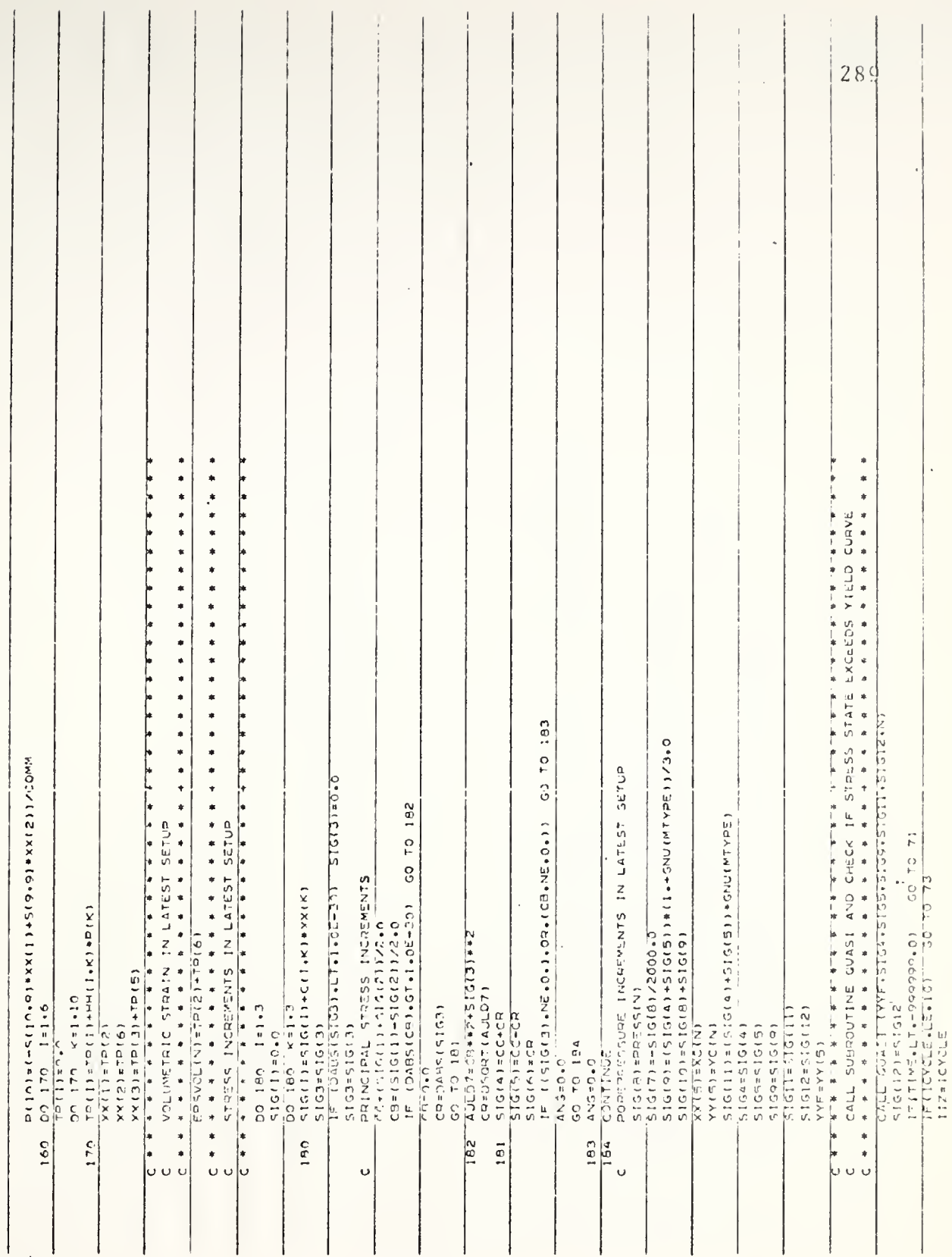

- is 


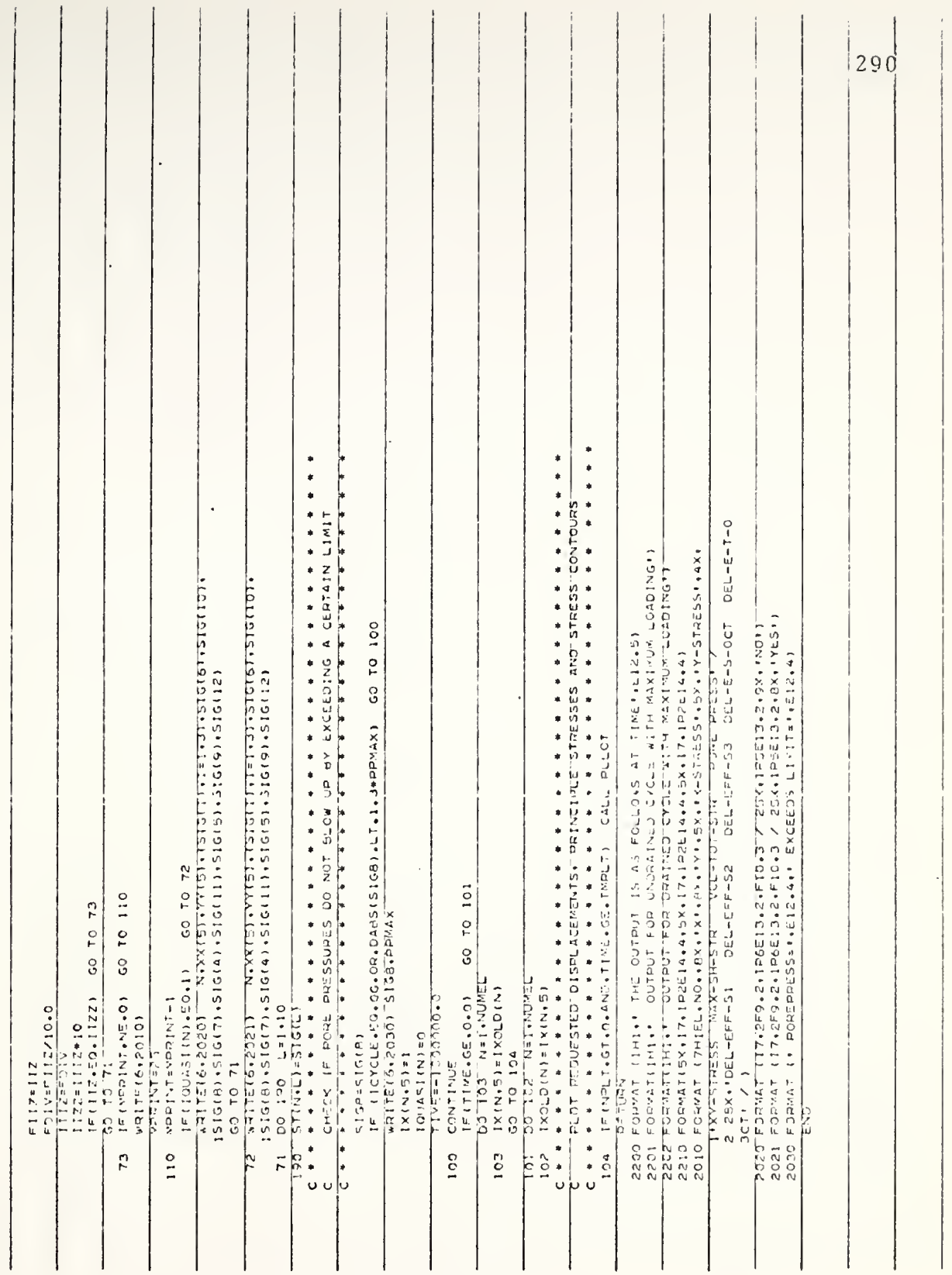


VIIA 
VITA

John Leitch Davidson was born in Londonderry, Northcrn Ireland on January 28, 1943. He recejved his high school education at Bangor Grammar School and won a scholarsh to attend the Queens University, Belfast, where he was awould his Bachelor of Science degrec in Civil Engincering in 1964. Mr. Davidson then emigrated to Toronto, Canada, where ho joined the firm of H. Q. Golder and Associates Lta., worling as a soils engineer in Canada, Kuwait and Ethiopia.

He entered Purdue University and received his Mastor of Science degree in Civil Engineering in 1967. While at Purdue, Mr. Davidson held both teaching and rescarcli instructorships in the Soil Mechanics Department.

Mr. Davidson is an Associate Member of the American Society of Civil Engineers, a supporting menber of the Highway Research Board, and a member of the Nmerican Socjety for Engineering Education.

He is married and a British citizen.

Mr. Davidson currently holds the position of Assistant Professor in the Civil and Coastal Engineering Department at the University of Florida. 

